\title{
ORM-5133
}

(Third Revision of ORNL-3794)

\section{OR TEP-II: \\ A FORTRAN Thermal-Ellipsoid Plot Program for Crystal Structure Illustrations}

Carroli K. Johnson

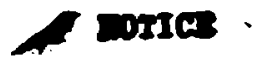

Mencs of THIS RLPORT ARE ILLEGTPLE. IL has been regrodiced irou the best arailable copy to pestit tho broadest posatble evall abustr. 


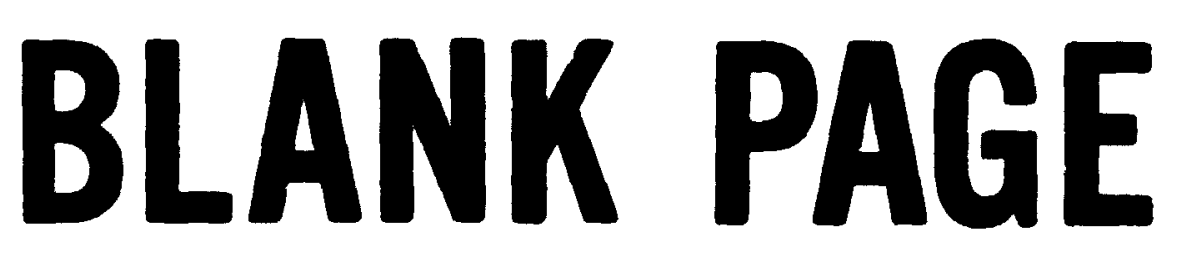




\begin{tabular}{|c|}
\hline 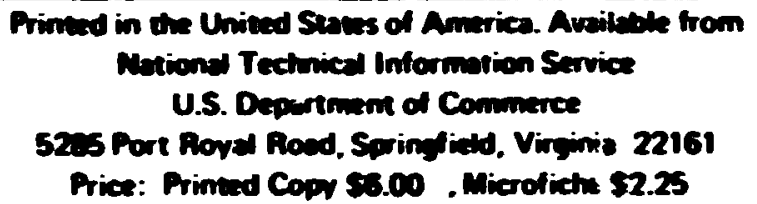 \\
\hline
\end{tabular}

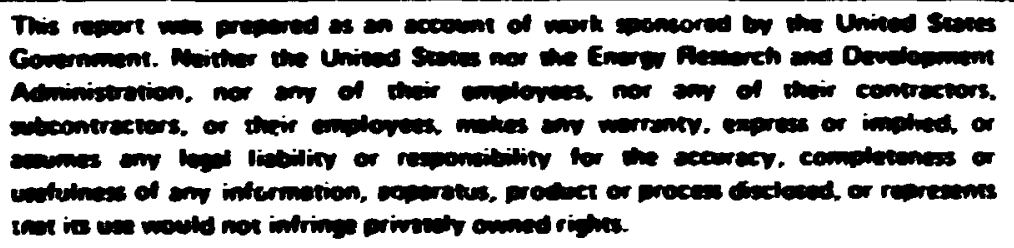




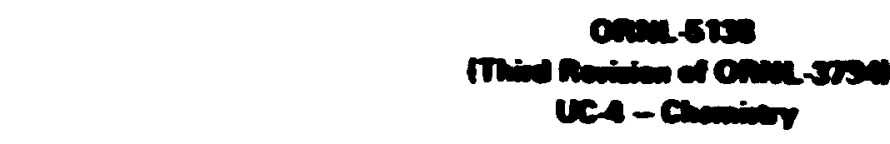

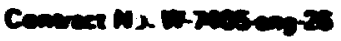

CHEMISTRY Division

OA TEPH:

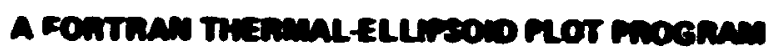

Fon Carstal stauctune ulusthations

Cartall K. Johrison

Revind Forwery 1978

MARCH 1976

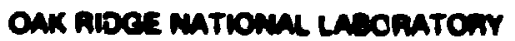

On Alde. Tenomene 3720

connine by

UNION CARABOE CORPOAATION

for the

ENEAOY RESSARCH ANO OLVELOPMENT AOMWHSTMATION

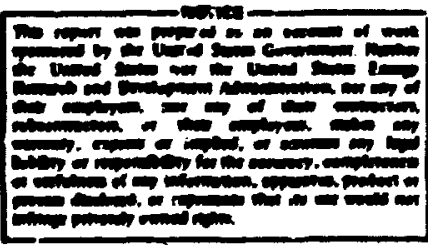

WhisT 


\section{contants}

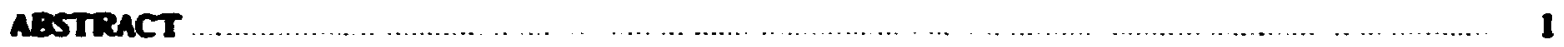

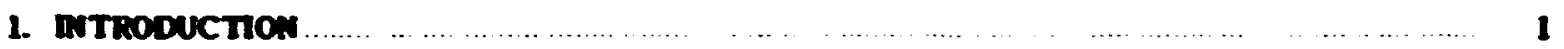

2. GENERAL PDANCPLES AND PROCEDURES … . . .

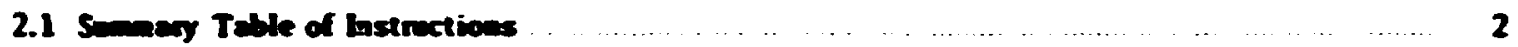

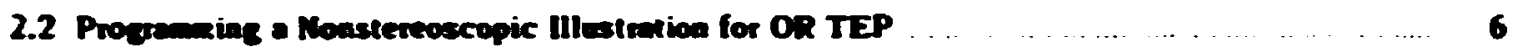

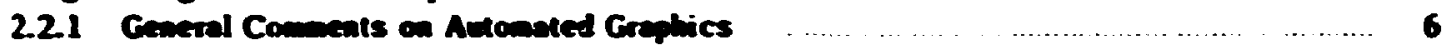

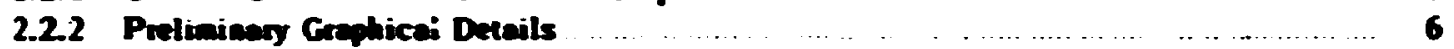

2.2.3 Composing the Illastration . . . .

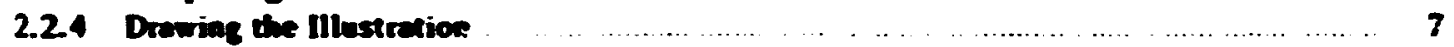

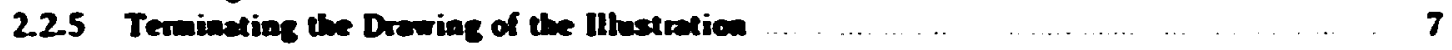

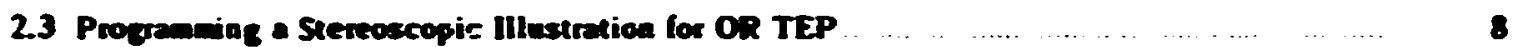

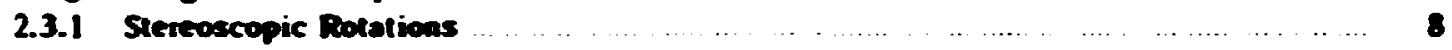

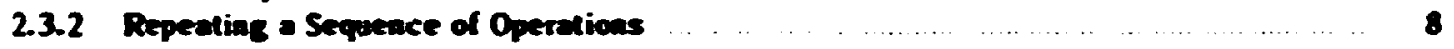

2.4 Drowias the Cubane Structure: An Example $\quad \ldots$

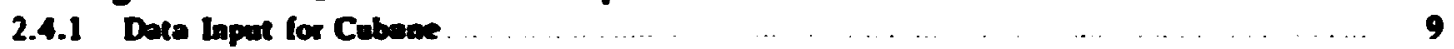

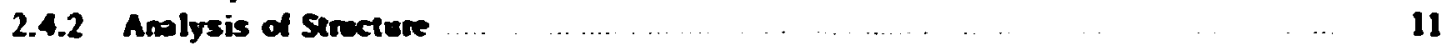

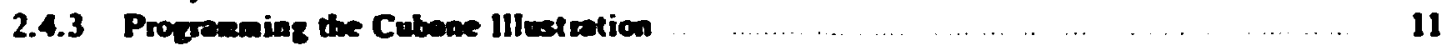

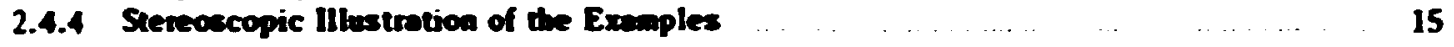

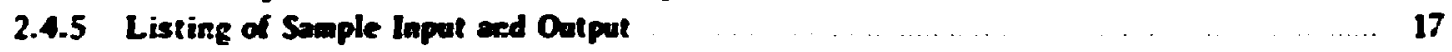

3. DETAILED OPERATWG INSTRUCTIONS $\ldots \ldots$

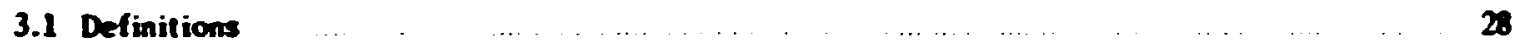

3.1.1 Atom Designator Code (ADC) and Addressable Poiat $\ldots \ldots . . .24$

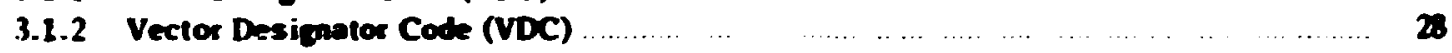

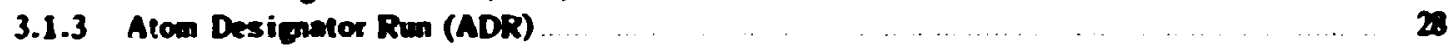

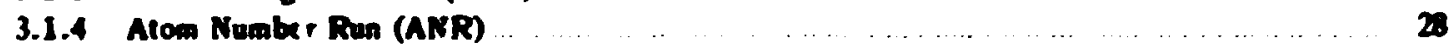

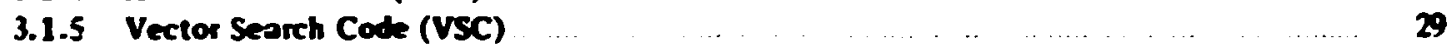

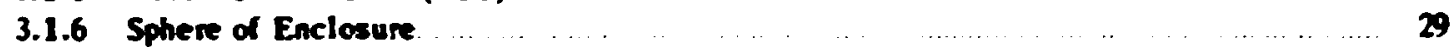

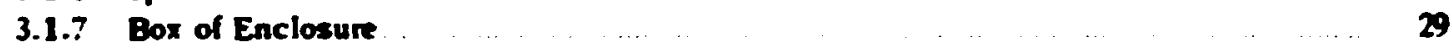

3.1.8 Refrrence, Working, and Stendard Cartesien Coondinote Systems . . . . . .... 29

3.1.9 Prime Parameters and Prime. Constants $\ldots \ldots \ldots \ldots \ldots \ldots \ldots$

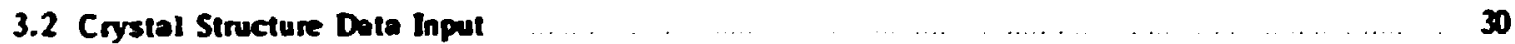

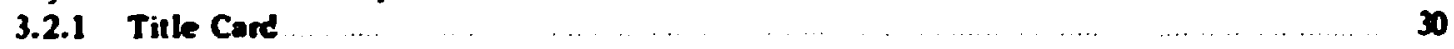

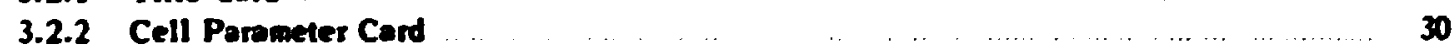

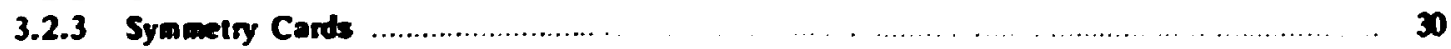

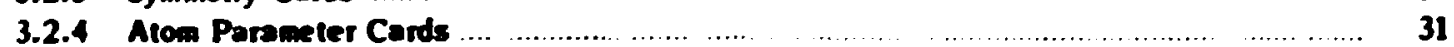

3.3 Instruction Input $\quad \ldots \ldots \ldots$

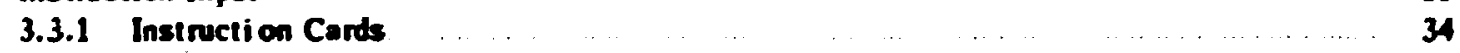

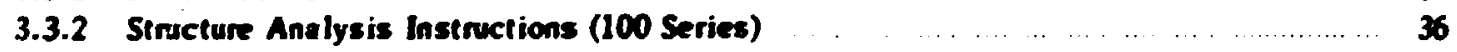

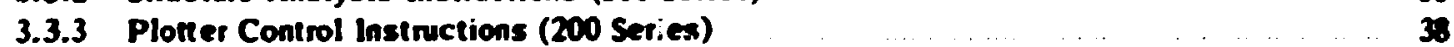

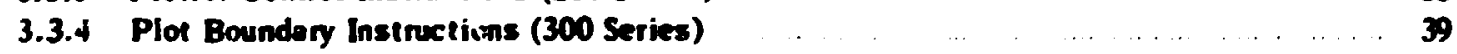

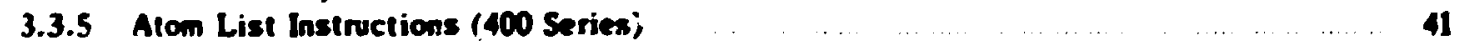

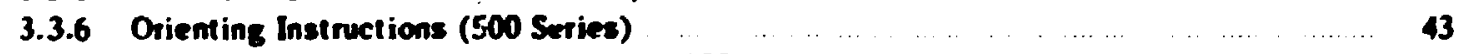

3.3.7 Positioning and Scaliag Instructions (600 Series) $\ldots \ldots \ldots \ldots \ldots \ldots$

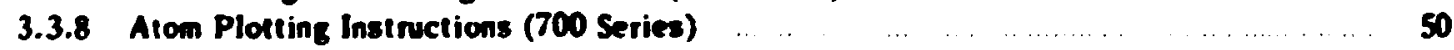

3.3.9 Bond Plotting Instructions (800 Series) $\ldots \ldots \ldots \ldots . .54$

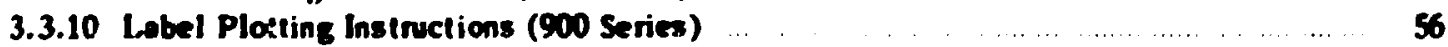




\section{BLANK PAGE}

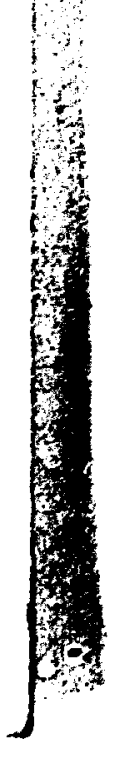




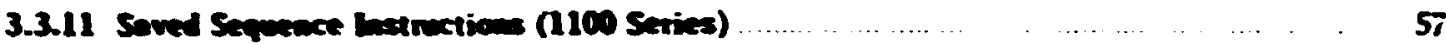

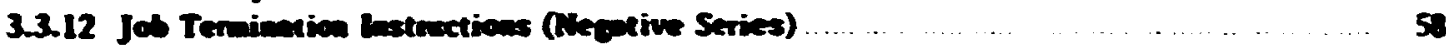

3.3 .13 Snplenentary lestuctions (1200 Seties) ............................................................. 5.

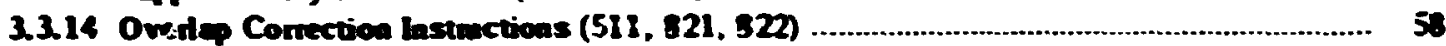

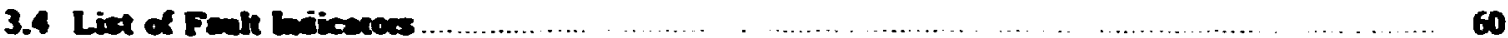

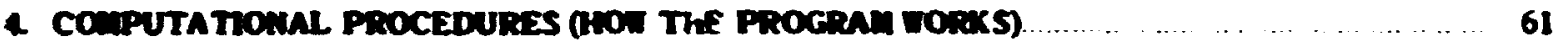

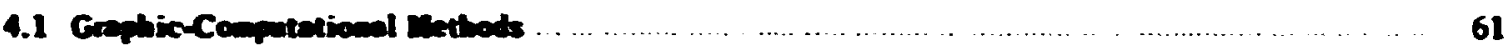

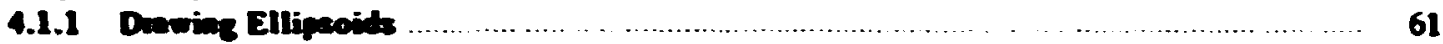

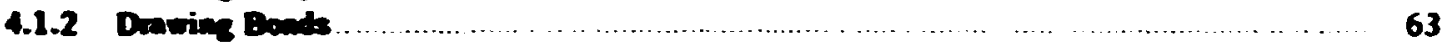

4.2 OR TEP Swhom

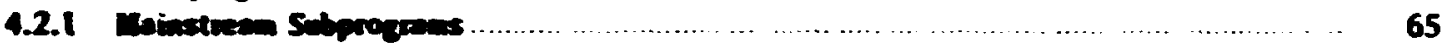

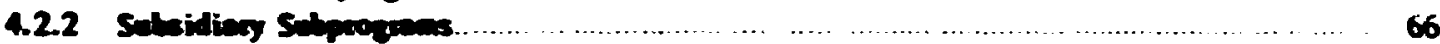

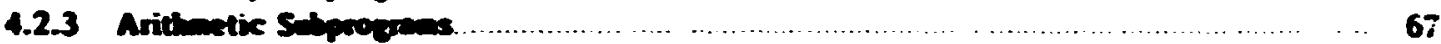

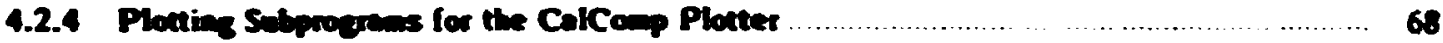

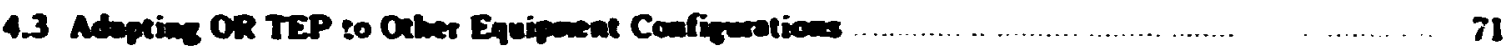

4.3.1 OR TEP Source Dect Differences for the IEI 360 and the

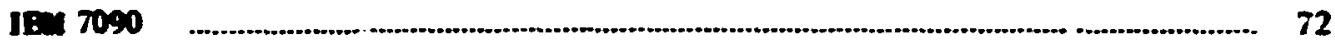

4.3.2 Extemal Device Logical Nubet Assi guments ........................................... 72

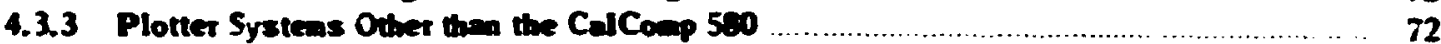

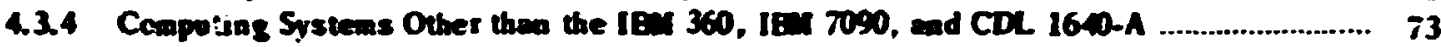

4.3.5 Spuce Requinments with Overlap Fenture ....................................................................... 73

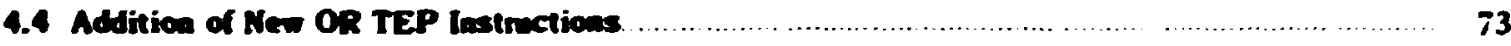

4.5 Gloseany of Symbols in OR TEP Common, with Arrey Dibeasions .............................. 74

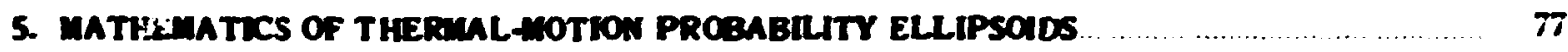

5.1 Prob bility Density Function (pd) of \& Triveriate Nonal Distribetion ........................ T7

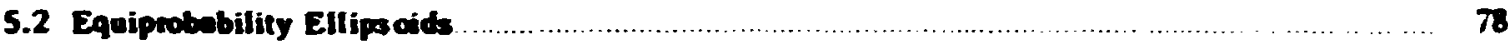

5.3 Charecteristic Function (c.f.) of a Triveriate Nomel Drstribetion ................................... 73

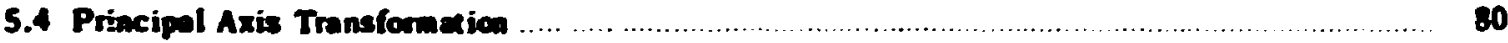

6. EXAYPLES OF ILLUSTRA TIOAS THAT HAVE BEDV PRODUCED WITH OR TEP................ 82

6.1 Nosstentoscopic Drawises Show in Then motion ..................................................... 82

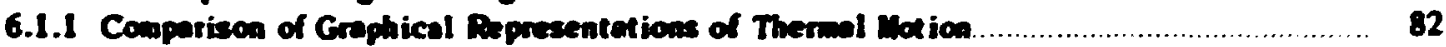

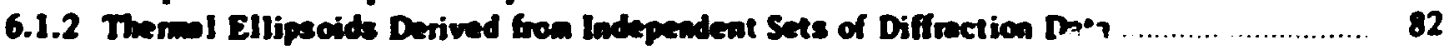

6.1.3 Therial Motion in Molecules Not Retexed by Cystallogrophic Sya netry...................... 32

6.2 Stencescopic Dewiap of Cystel Strncter ................................................................... 83

6.2.1 Thernal Ellipreid Derived from Nevteon Studies ..................................................... 83

6.2 .2 Thend Ellipaids Durived from X-Poy Stodies........................................................ 83

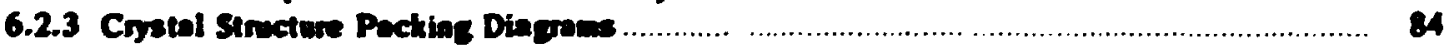

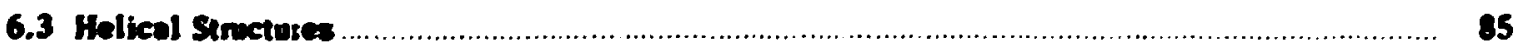

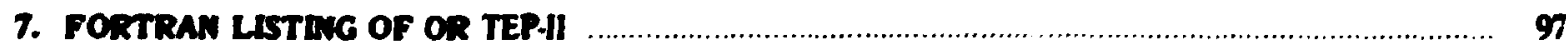




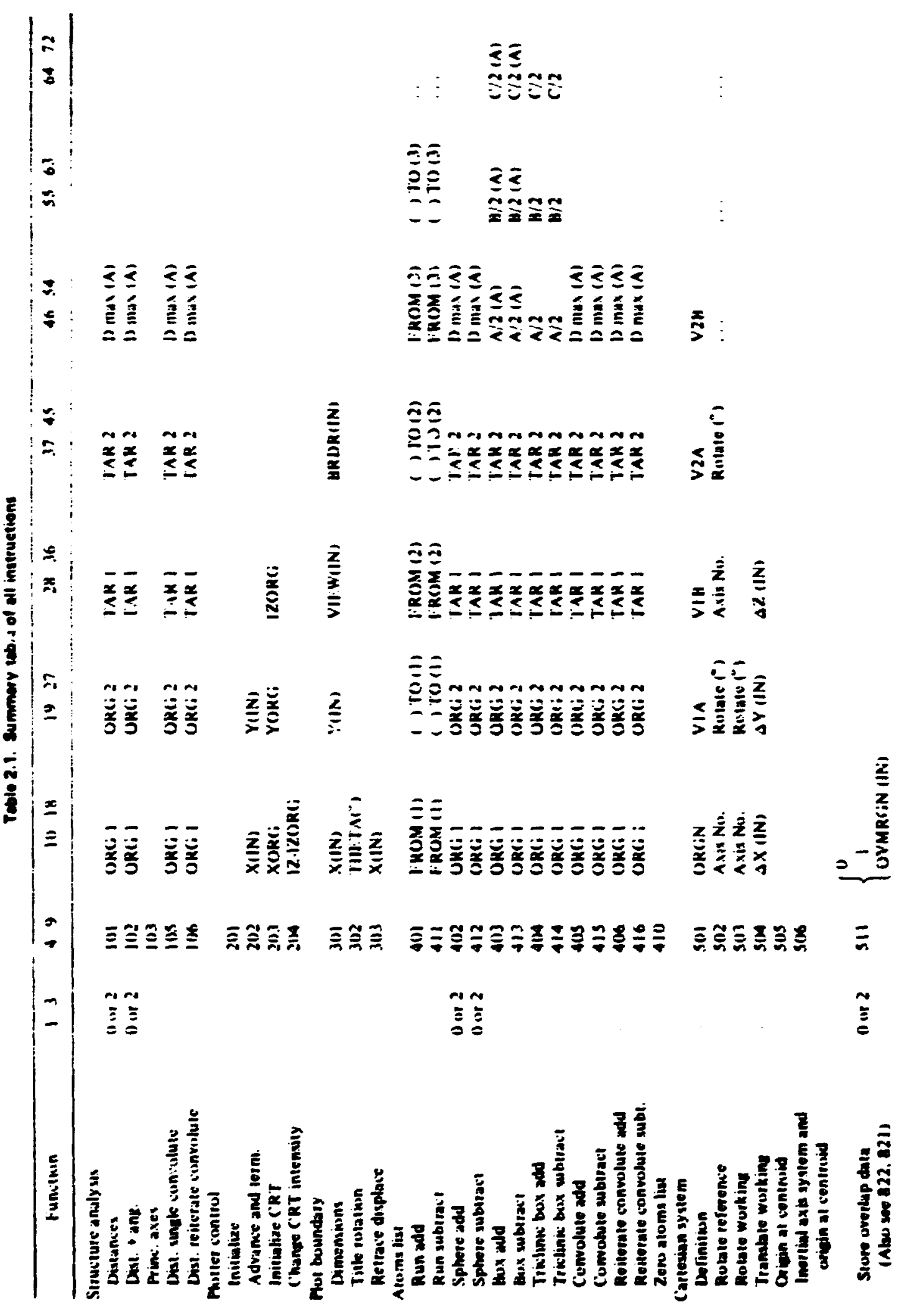


Table 2.1 leontinued)

\begin{tabular}{|c|c|c|c|c|c|c|c|c|c|}
\hline Funcinun & 13 & +9 & $111 \cdot 18$ & 1427 & $2 n \quad 16$ & 3745 & 4634 & 3503 & 6472 \\
\hline \multicolumn{10}{|l|}{ Crenier and wale } \\
\hline $\begin{array}{l}\text { Sixplinill } \\
\text { Siake undy }\end{array}$ & & 6(1)! & $\begin{array}{l}X O(N) \\
X O(N)\end{array}$ & $Y(O(I N)$ & S'Al.I & $\begin{array}{l}\text { STAl.2 } \\
\text { SCAl.2 }\end{array}$ & & & \\
\hline Center unly & & 6113 & & & MAl.I & SCAl.2 & - & & \\
\hline Center and wiak & & 604 & & & & SCAI.2 & & & \\
\hline I.P. and 1.S." & & 611 & $2 X O(I N)$ & $د Y(D I N)$ & دSCAI.! & SCAl.2 & & & \\
\hline I.P. and withe & & 612 & $2 X()(I N)$ & $د Y(D I N)$ & & SCA1.2 & & & \\
\hline I.S. and center & & 61.3 & & & AST'NII & X'Al.2 & & & \\
\hline Lillopmouls: & & & & & & & & & \\
\hline $\begin{array}{l}\text { Shuded livurball } \\
\text { Iformal No. I Ifathe curd) }\end{array}$ & 0 ar 1 & 701 & & & & & SYM llial & PAK.ISIP" & PI:R.(J). \\
\hline finolball & O uII I & 702 & 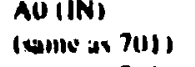 & $A \mid(\mid N)$ & ANR II & ANR (2) & & & \\
\hline Open mudsi & Uur I & 711.3 & (xunus as $7(1)$ ) & & & & & & \\
\hline Buundary unby & Uw I I & 314 & (4) dow $70 \mid$ ) & & & & & & \\
\hline 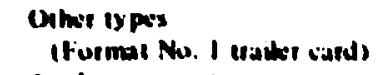 & Dur I & ins & $\begin{array}{l}\text { NPL. ANI: } \\
\text { AU (IN) }\end{array}$ & $\begin{array}{l}\text { NIXU) } \\
A(\text { (IN) }\end{array}$ & $\begin{array}{l}\text { NLINI: } \\
\text { AN' } 11 \text { I }\end{array}$ & $\begin{array}{l}\text { NIDASII } \\
\text { ANR (2) }\end{array}$ & SYM III:I & MAK.(D) I & PI: $R+1) \cdot{ }^{\circ}$ \\
\hline As abuve excest in & D) I I & 31 & (wank as 71$) 1$ ) & & & & & & \\
\hline 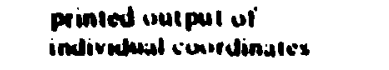 & $\begin{array}{l}\text { Dof I } \\
\text { bor I I }\end{array}$ & 713 & 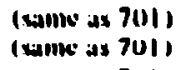 & & & & & & \\
\hline & Nor 1 & 714 & $(w 110$ is 71$)(1)$ & & & & & & \\
\hline & 0,1 & 715 & (sime ins 711S) & & & & & & \\
\hline \multicolumn{10}{|l|}{ Ahinds } \\
\hline $\begin{array}{l}\text { Explinil } \\
\text { (cunt.) }\end{array}$ & 1 ur 2 & no1 & HOM II) & 10111 & I R(SM) $1 \geq 1$ & 10121 & $\mid \cdot K C) \mid(3)$ & $\mid(1)(3)$ & $\cdots$ \\
\hline $\begin{array}{l}\text { Implinil fiamy } \\
\text { (furmal Nu. } 2 \text { traibe card) }\end{array}$ & 2 & no2 & & & & & & & \\
\hline $\begin{array}{l}\text { Implicil lime } \\
\text { Ifurmal No. I (raiker card) }\end{array}$ & 2 & 811.3 & & & & & & & \\
\hline As sburs except & & xi1 & 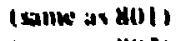 & & & & & & \\
\hline nu prinled unipul & & $\begin{array}{l}812 \\
813\end{array}$ & $\begin{array}{l}\text { (wink ax 80) } \\
(\text { sillike as } 80.3)\end{array}$ & & & & & & \\
\hline $\begin{array}{l}\text { M.nd uverlap } \\
\text { inplinil }\end{array}$ & 102 & X:1 & IRUM (I) & 10(1) & IR(OM 13) & $1(1) 121$ & JiR(JM (.3) & $\mid(1), 3)$ & . \\
\hline $\begin{array}{l}\text { And ureetisp } \\
\text { implixit }\end{array}$ & 2 & $\mathbf{8}: 2$ & & & & & & & \\
\hline \multicolumn{10}{|l|}{ Lisbets } \\
\hline $\begin{array}{l}\text { Chem. Symb. } \\
\text { Rez. rilles. } \\
\text { furmal No. I litke sard }\end{array}$ & 3 & $\begin{array}{l}901 \\
902\end{array}$ & $\begin{array}{l}\text { ATOM-I } \\
\text { ATOM-I }\end{array}$ & $\begin{array}{l}\text { (ATOM-2) } \\
\text { (AIOM.?) }\end{array}$ & $\begin{array}{l}\text { X l:dpe Rewel } \\
\text { X l:dpe Kew }\end{array}$ & $\begin{array}{l}\text { Y lidwe Kowl } \\
\text { Y lidxe Krwil }\end{array}$ & 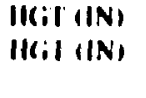 & $\begin{array}{l}\text { PAR (I)I. } \\
\text { PAR-1III }\end{array}$ & $\begin{array}{l}\text { PI. R+(I) I } \\
\text { PIR.(II) }\end{array}$ \\
\hline 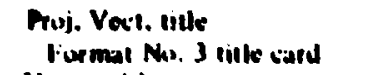 & 3 & 803 & ATOM.I & ATOM.2 & X liane Rinel & Y I:dke Krw'I & $\|(\because \mid \| N)$ & PAR-(I)I & PI. R.()I. \\
\hline $\begin{array}{l}\text { Vectur lithe } \\
\text { Furmis No. } 3 \text { lithe carci }\end{array}$ & 3 & 91.3 & 91911 & AION.2 & & & $\|(C)$ IN) & PANール! & $\boldsymbol{H}: \mathbf{R} \cdot(\boldsymbol{I}) \mathbf{I}$ \\
\hline
\end{tabular}


Tolb 2.1 coominumed

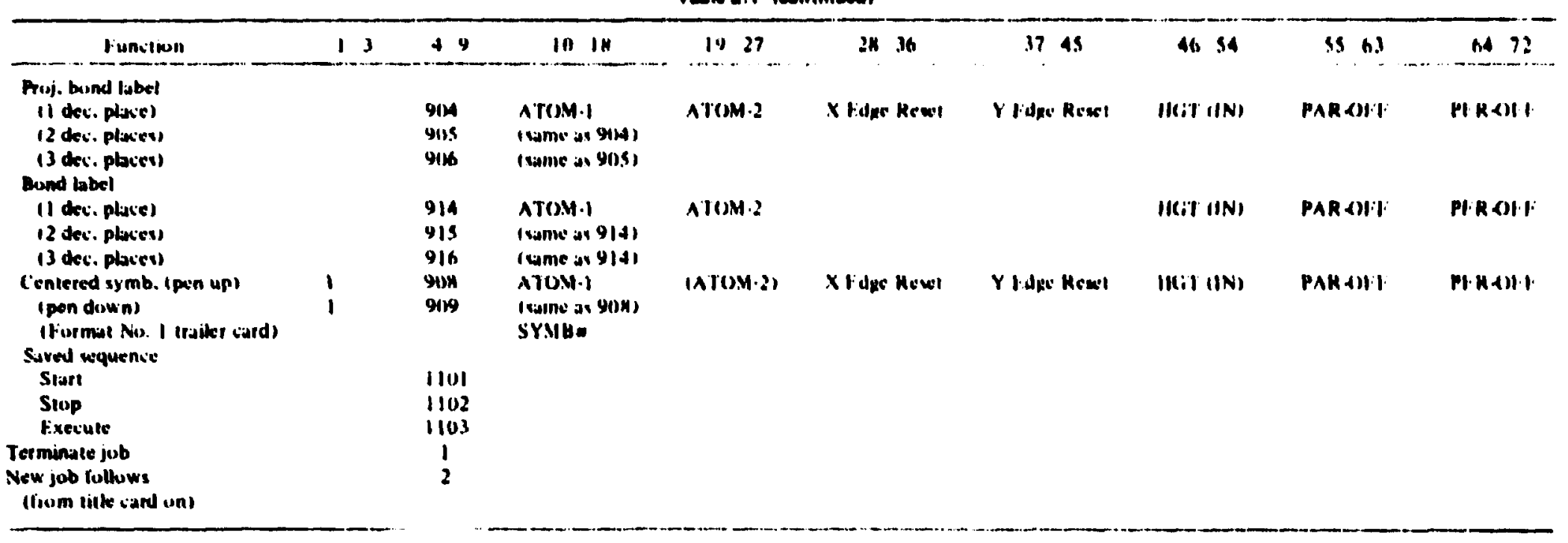

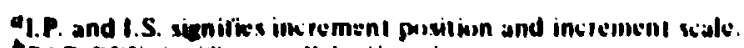

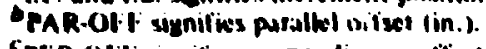

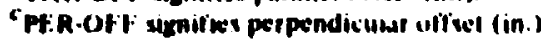




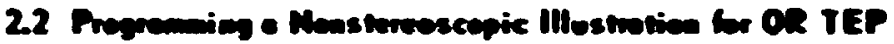

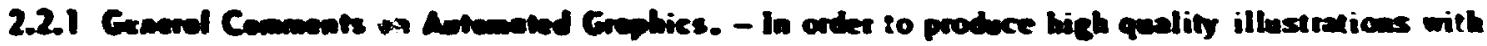

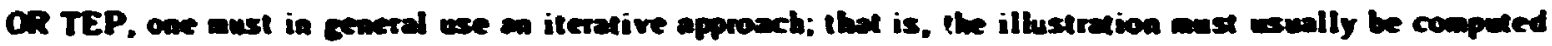
and plated several times before an optianl figare is proheed with each trial, as many iuctors as possi.

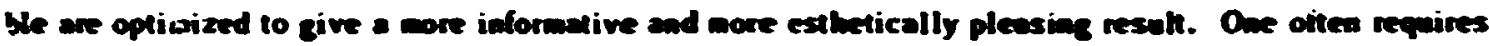

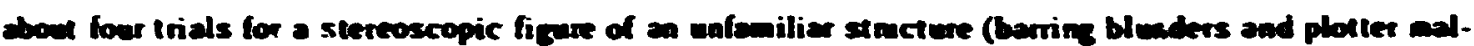
(tenctions).

Overtop is sece of the major pooblems, panticularly for chemical syabols and bond distance labels. If the wer is not drawing stereoscopic figures, it is often better to do the letterime with a LePloy letterine template instead of the computer. The template letteriog is neater then the compotet letterian. and it can be positioned much mone easily. Howevet, lor stcreoscopic lefteriog the mamal procedure appears to be cosanisfactory because of the necessity for exact relative placenent of the lettering on the two views to miatsin eod stereopsis.

The major porti ins of the hidden line sezuments of atoms and boads that are partially or lotally behind other atoms and boads may be onitted by usil.g the overlop-elimination fealures of OR TEP-II. However, there are often areas where additional manual louch-up is needed. This can be accomplistwed Hy erasing of "whiting oul" the remaining unwan:ed line segments. Even with stereo views, the features are more effective if overlap is taken care of , especially when "opaque" ellipsoids are used.

In order to maintain generality in OR TEP, the concept of progamaing is applied to the problem of dran sag illustrations with a plotter. This concept allows access to a series of basic buildine block operations which an fut together by the user to "program" an illustration. The instructions used in grogramaing OR TEP are divided inte the following calegories: (1) irstructions used to specify preliminary eraphical details, (2) instruction, used co compose an illus:tration. (3) instructions used to draw the illustration, (4) instructions used to repea: a sequence of other instructions, and (5) rermination instructions. Each instruction stans on a separate punched card and contains an identifyiaz nimber and what. ever parameters are needed fos the particular instruction. The general role of these instructions is explained in the renaining parts of Sect. 2. and the individual instructions are described in detail in Sect. 3.3 . The simplest way to construct the program is, first, to scan through the list of instructions in numerical ordet and pick out the relevant ones to construct the iramework of the program. Then certain other instructions are giaced into the framework program to furnish the remaining "bookkeeping" details.

Let us assume that the structural dato cards (described in 3.2) have heen prepared for a crystal structure and that we want to prepare a program to draw a single nonstereogrephic figure of the contents it one unit cell. We describe next the general stepwise procedure one would follow lo program such an illustration.

2.2.2 Preliminery Groptical Davils. - The first instruction card should be the plotes control instruction 201 (see 3.3.3.1) which will initialize the plotting package.

Next, the plot boundary insiruction 301 (see 3.3.4.1) is needed to set the following porameters: (1) $x$ dimension in inches for the plol boundary, (2) $Y$ dimension in inches for the plot boundary, (3) viewine 
distance in ixches for perspective pajection (zero as a sigaal for pabllel projection), and (4) border (or margia) dimerision inside the bowadary.

No ofber $\mathbf{2 0 0}$ or 300 series instanctions are required for this paticalon hypothetical figuse.

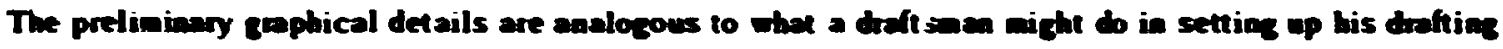
boud in prepertion for a dravine.

2.2 .3 Conpesing the Ithestrefien. - This step involves specifying: (1) which deos are to be used as the figare subject, (2) the rcational orientetion of the subject, and (3) the scaling and positisaing of the subject relative to the drawiag area. These three componeats of composition are inplewented by the bo, 500, and 600 series instructions respectively.

For our hypothetical exmaple, suppose we want to place the b crystal axis aloan the plotter $x$ axis and the $c$ axis of the cystal in the ploter ay piase as aedy es possible paralled to the plotter $y$ axis. This setting can be eccomplished with 501 instrection (see 3.3.6.1) alone, bet if adfitional reorientation were mecssary, a 502 instraction (ste 3.3.6.2) would also be used.

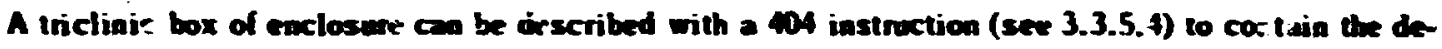
sined atous for the subject drfinition. The scoliag and positionias of the subject to fill the deawiag area ary be accomplish:d automatically with a 604 instruction (see 3 3.7.1).

2.2.4 Drowieg the Illoswetien. - Cystal structure illustrations of the ball-aad-stick type are made up of three components: balls (zoms), stichs (bonds), and labels. The three componems ars drown with the 200. 800, and 900 instruction seriex respectively; the first two instruction series can also perform certain topes of labeiink.

A new instruction 511 in the OR TEP-II versiven of the program was added to store information needed for the oterlap correction. This unstruction is used before the 700 and 800 series instructions.

The atom represent ation can be either a general ellipsoid or a boundary ellipse. In some cases these become a sphere and a circle. Chemical symbols may be plotted simultaneously with ihe atoms.

For our example we might simply draw circles and pot the chemical symbols within the circles by using instruction 704 (sce 3.3.8.1). This instruction will draw all the atorns of the subject and their chemical symbols.

The bonds zre not alwa's necessary in a drawing, but for struclures witl molecules or with distinctive groupings they are usually quile helpful. The most convenient method for describing and drawing bonds is instruction 812 (sse 3.3.9.2). This instiuction uses vector search codes (see 3.1.5) which refleat the user's knowledge of the suructura' chmmistry and the interatomic distance ranges for the compound being drawn. Covalent bonds or any other oesired type are found and drawn aufomatically from the list of atoms which make up the subject. If dexired, the interatomic distance label can a!so be drawn with each bond (see 3.3.9).

Various types of labeling can be dose with the $9 M$ series instuction. The one which will most often be included is a caption for the figure, using instruction $9: 2$ (see 3.3.10.2).

2.2.5 Terminating the Drewing of the Illustretien. - The plotter control instuction 202 (see 3.3.3.2) allows the uscr to renove the finisiced drawing from the plotting area and to place a fresh area of plot paper in position for any additional plots which may be drawn. 
To termiante the compater job, a (--1) instnction (see 3.3.12) is used as the last instruction of the papran.

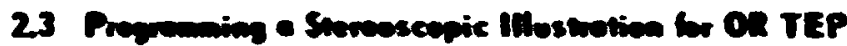

A steverscope pair of figures is sinply two perspective views of the subject as seen tom two difiet-

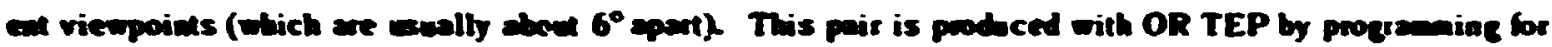

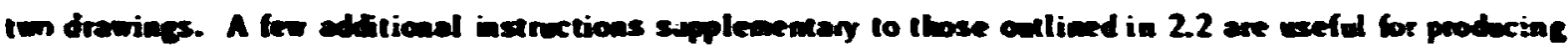
sterco figures. These iastructions axe the sterwscopic rotation instenction 503 and the 1100 series of isstections, which facilitate the ripetition of a series of instractions.

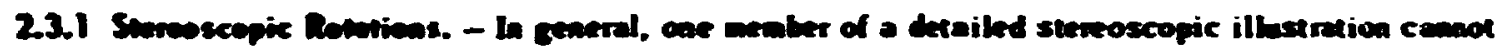

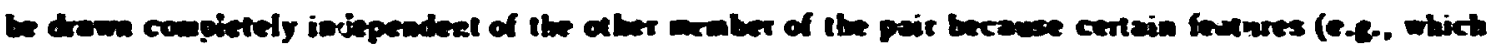

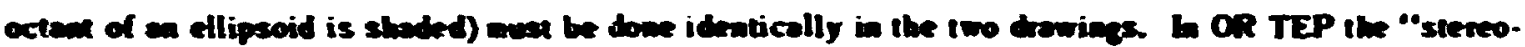

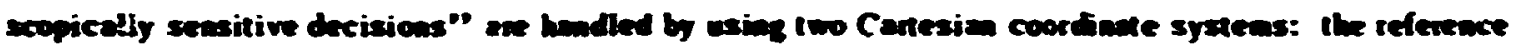

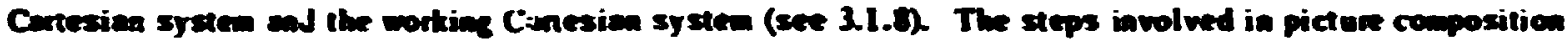

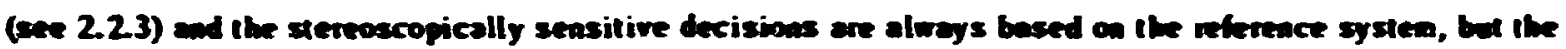

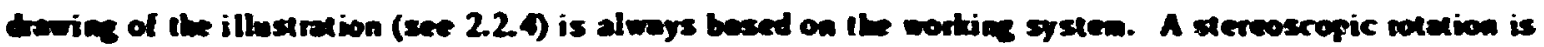

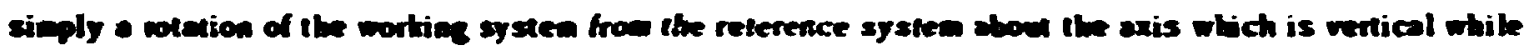

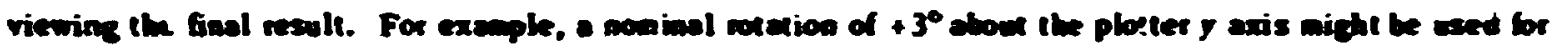

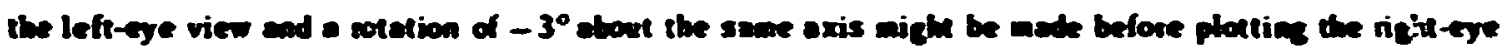
view, thes peodecies a rotal iaterocular sade of $6^{\circ}$.

A pooren to drew a sterno pait would incolve the bllowing steps:

1. preliniasery eroptical detals,

2. cuposition of sebject.

3. lete-gye sterco nototion,

4. dren the sebject.

5 cobrace the plotter.

6. righteye stereo wotion,

7. drow the subject,

2 edvance the ploter,

9. teminate the job.

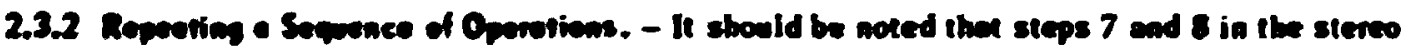

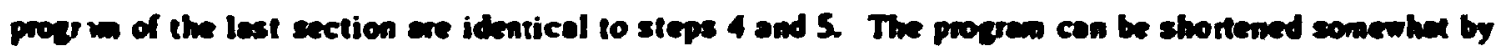
wies the "saved sequence" instructions (se 3.3.11). A 1101 instruction (stent saved sequence) would be placed between 3 and 4, and 1102 instruction (end seved seguence) betwen 5 and 6 . Then steps 7 and 8 can be repleced by 01103 inctruction (execule saved sequence).

Any sequence of instructions con be soved in this manmet ead repeated es meny tines as desined with 1103 inseructions. For exemple, the soved senguence featore cea be und to prodece a complete series of views of a structure at (sey) $15^{\circ}$ intervals wout en ads. Hote thet the instractions between the stort end stop instructions are both executed end seved the first tine throofh. 


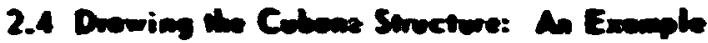

The novel compound cubone " $\left(\mathrm{C}_{4} \mathrm{H}_{4}\right)$ bas been crystallized and the structure deternimed" The cabon-carbon bouds lie aloag the ecizes of a cabe within experimental enor. The cuapound crystallixes

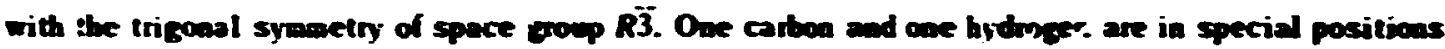
along the $\overline{3}$ axis. and the remainiag carbon and hydropen ore in tearm! positions. Aaisolmopic tempercture

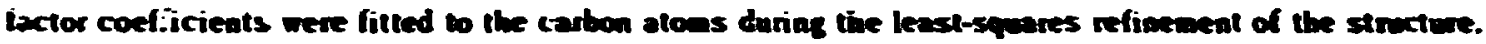
and isotropic tempersture factors were used for the hydwoger. stow.

The cell paraneters ais

$$
\begin{aligned}
& a-b-c-5.34 A \\
& \therefore-A-I=7226
\end{aligned}
$$

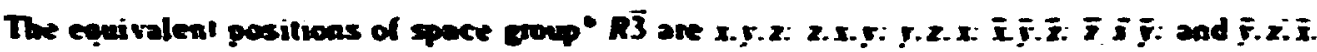

The positisnal paraneters for C1. C2. H1, and H2 are given as -0.1871 1. 0.19519. 0.10706; 0.11540 . 0.11546, 0.11546; -0.3246, 0.3465. 0.1840; ad 0.2100, 0.2100, 0.2100, respectively. The acisotropic temperaiure factors given for the carboa atoms are of the type called zero in this neport (see 3.2.4.2). The coefficients $b_{11} \cdot b_{22} b_{13} b_{: z^{2}} b_{13}: b_{23}$ for $C 1$ and $C 2$ are $0.0410,0.0425$. 0.0450, -0.0042 . -0.0142 . -0.0051 ; and 0.0468. 0.0468. 0.0468. -C.0143. $-0.0143,-0.0143$.

\subsubsection{Dowe laper for Cobans}

2.1.1.1 Tille Card (see 3.2.1). - FORaAT (12A6)

Cord No.

CUBANE (E. B. FLEISCHER (1964) J. A.C.5. 86, 3909)

2.4.t.2 Cell Pieranciter Card (see 3.2.2). - Foratat (6r9.6)

$$
\begin{array}{llllll}
5.34 & 5.34 & 5.34 & 72.26 & 72.26 & 72.26
\end{array}
$$

2.4.1..) Symuerry Cards (see 3.2.3)

FORWAT (11, F14.10, 3F3.0, 2(F15, 0, 3F3.0) )

(3)

(4)
0. 100
0. 00 0 1

0. 0 I 10

0. 1000
0. 00 i

0. 010

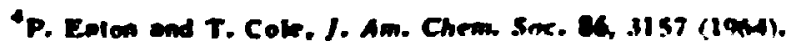

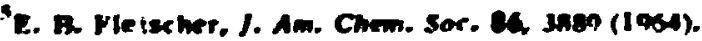

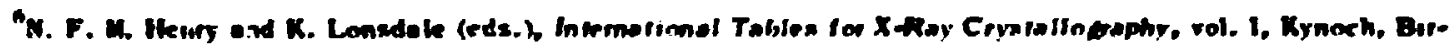
minghem. I962

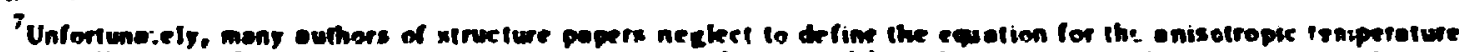

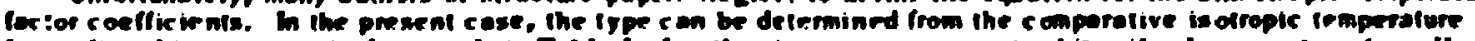

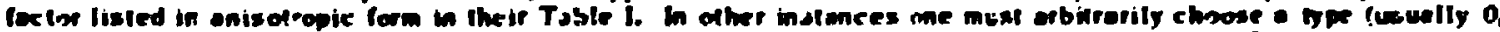

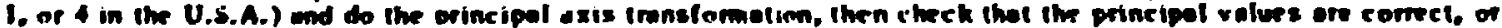

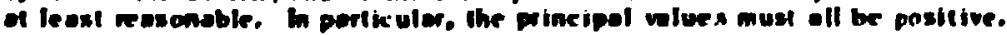


Cord no.
(5) 0
a 010
a 0 ) 1
1. 100
(6)
a -100
a $0-10$
a $00-1$
(7)
a $00-1$
a -100
a. $0-10$
()
a $0-10$
$200-1$
a -100

24l.t Alanic Paraner Conds -

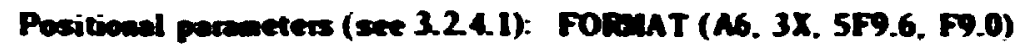

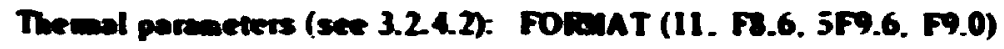

Alems 1 and 2 are enternd with pesitional parancters igne 0 and anisotmpic temperature bectors tyre a

Cord the

(9)

\begin{tabular}{|c|c|c|c|c|c|c|}
\hline \multicolumn{4}{|c|}{ Cl } & -.18711 & .15519 & .10705 \\
\hline 0 & .04100 & .01250 & .04500 & -.0020 & -.01420 & -.00510 \\
\hline & & & & .11546 & .11546 & .11546 \\
\hline 0 & . owed & .04600 & $.0 \times 620$ & -.01430 & -.01430 & -.01430 \\
\hline
\end{tabular}

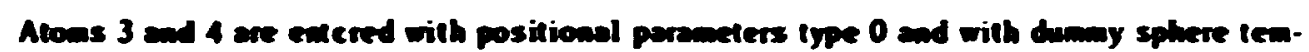
perture fectors (type 7 O.I $A$ in radiex

$\begin{array}{rrrrrrr} & \text { III } & & -.32460 & .3400 & .18400 & 0 \\ 0 & 112 & .1 & .21000 & .21000 & .21000 & 7 \\ 0 & & .1 & & & 7\end{array}$

Alom 5 is a danny otom of the cell origin with a bask cond dwangy sphere (see next to lest porngreph of 3.2.4.2). This could also be entered with type 7 as were atomx 3 and 4 .

In the card deck for this scople progrem, extensive use of Fonnt No. 3 toilet cords (see 3.3.1.4) is made as a method of incleding a comment with en instuction. This convention is not

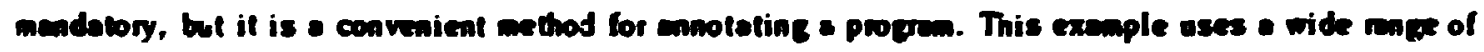
instructions in order to demonstrote them. As in the case with eay progranaing system, there one meny woys of doing any diven problem. The Formats are deecribed in Sect. 3.3. 


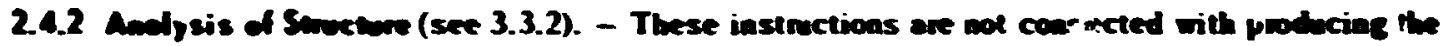

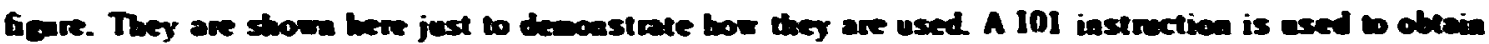

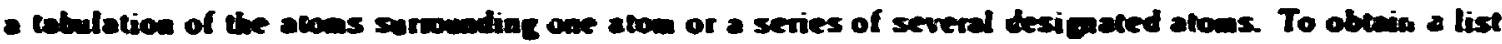

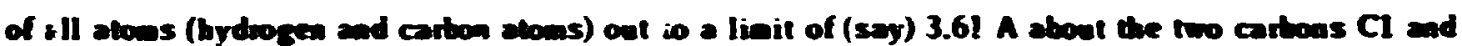
C. ane would ese the followiag iustanction. (The soterion is explained in Sect. 3.3.2)

Cord Mo.

$101 \lcm{155501 \quad 2,}$

Atoms 1 throuph 2 of Atoms 1 through 4 of all syametry $\quad D$ max
syonetry operation 1 and translation ope. ations

A $10 \mathrm{~h}$ instmuction gives both interztomic distances and intratomic andes. In order to find all covelem bonds and bood angles about the two catbons we aigh we the follcwing instruction.

102155501

1

4

1.8

In this case a swaller D max was used so that only the distances and angles of immediate interest would be computed.

2.4.3 Prengremaing the Cobane Illostrotion. - First we must initialize the ploter packags.

201

The two plat boundisty dimensions can be equal for the present illustration siace the cubane wolecule is a cube. Suppose we use an 11- by 11-ia. boundary and pecify a 1.5in margin to give a total wotkias area of 9 by 9 in. A 30 -in. view distance mitht be reasonable to use in viewing a model of this size.

$3 n 1 \quad 11 \quad$ I1 $\quad$ ji $\quad 1.5$

In general we would we retracing to malse the lettering, and certain ofher details, stand out wore prominemly. However, for the test example we will eliminate the re. trecing so thet the ilbstration will plot as fast as possible.

3030

The subject of the illustration is a single cubane molecule, which we will now de. fine. One way of dexigaating this subject is to specify a sphere of enclosure, centered on the dunmy atom 555501, which is at the center of a cubone molecule. A radius of 3.2 A showld be adequare to isolate a single molecule. 
Com then

(20)

402,55500

(a)

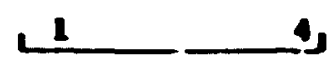

(b)
3.2

(c)

whene the severel pens besigante:

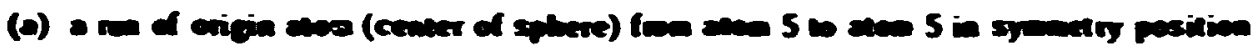

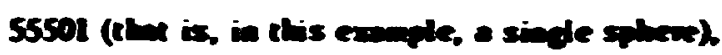

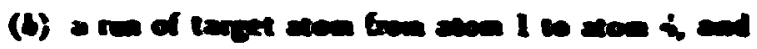

(c) o splecte raties of $3.2 \Omega$

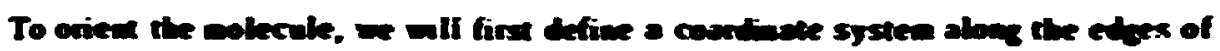

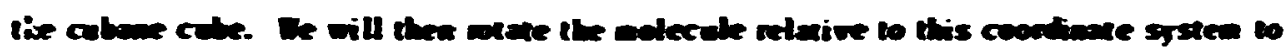
minimixe overtap

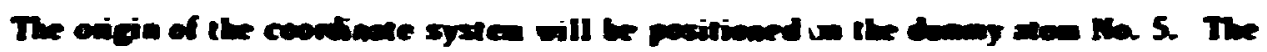

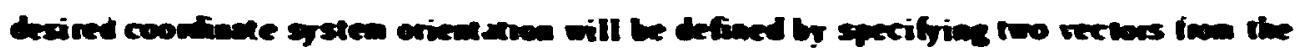

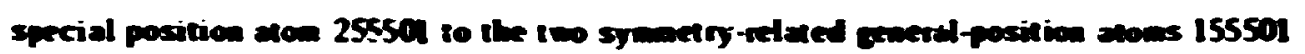
and 155502.

(25)

$\begin{array}{llllllll}501 & 555501 & 25550 & 155501 & 255501 & 155502 & 0 & 0\end{array}$

A rotation of 25" about the $Y$ axis (axis 2) bolbond by a rotarion of 28 about the $X$ aris (a.s 1) will produce a suisfactory view of ite molecale.

(26)

$\begin{array}{lllll}502 & 2 & 25 & 1 & 25\end{array}$

To scale and position the sabject for projection onto the hrowiat boond and to utilize all avilable sace. we will ate the 604 instruction. Which will ambatically set 20 . Y0. and SCAL1. However. the ellipsoid scale foctor ratio SCAL2 mst be specified iadependeally. If we wat thereal ellipsoids corvespondiag to 50\% probatiing. tiven we will eater I.54 for SCAL2. 604 o n n 1.54

This completes the composition of the illestrotion.

The stereoscopic wotion bor the left cye can be done at this point. We will use a rototion of 2.7 obout the $Y$ axis (axis 2 ) bor the left-eye view. Loner in the progran. we will make a -2.5 motation aboat the sane axis for the right-eye vien to give a lotal iaterocular ande of 5.4 .

$5032 . ;$

Since the anxictere will be drown trice, once for each eye, the "soved sequence"

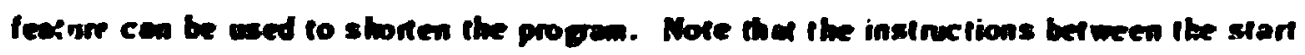


Cord No.

and stop insinctions are both erezered and sancl the first time through. They can then be re-exeruled as aang tibes as desired by using the "enocule saved sequence" instantion 1103.

The 1101 instruction sants the saved sequeace.

(30) 25

1

\section{0}

I

4

4

0.9

1.6

.04

The ATOuS list currently contains all the atom desipnators for one cubere nolecale.

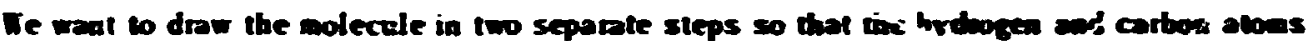
can be given differeat graphical representations. To drow the carbon ans (RNR = 1.2). we will construct a special code thot $(a)$ dens the thre priacipal-plane formend troces and the boundory-plape troce (MPLAVE : $П$ ). (b) onits the reverse sides of the priacipal

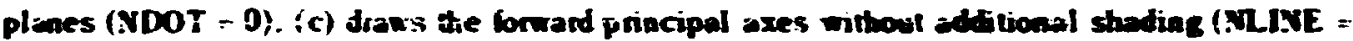
1). and (d) omits the reverse prnacipal ases (XDASH - Vi. In adition we weat the cheraical symbols to be drom with letters 0.2-in. high (before projection) and displaced from the aloaic centes by $0.6 \mathrm{in}$. in the horizontal direction and 0.7 .2. in the venical derection.

0

4

0

I

$\mathbf{0}$

$.2 \quad .6$

The 715 instruction is used. rother thon 705. to shorten the onout listing of the example. Nomally we would use the 705 to obtain a listing of all coondian.es.

Since the hydrogen alows $(A M R=3$. 4$)$ are to be drown with a standand wodet. the constacetion details will be taken coue of atometically. We want cheaical syblols 0.2 in. hifh and oftect 0.35 in. horizontally and 0.4 is vertically.
712

0
0

0
0

0

The most convenient procedure for drowing bonds is to we the inplicit bond insterc. tion 812. All othet intormetion can be entened with a single fomet Wo. 2 irailet card (vector seerch code cand) 
Cord no.

(3) $2 \quad \mathbf{2 2}$

(37)

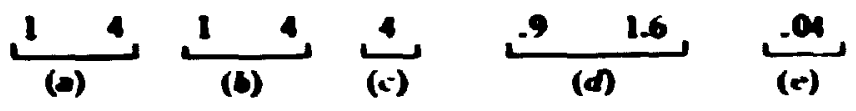

Itwere

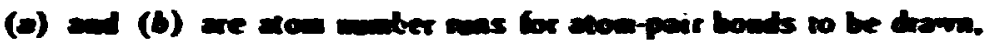

(c) denotes boud type 4.

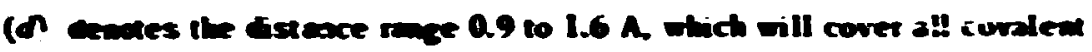
boul hisances, and

(e) the bond radies, is $0.04 \mathrm{~A}$

The remariag fields in ite card can be blank sioce a complete set of boud distance labels is not desined.

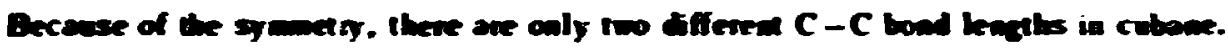
These are $\mathrm{Cl}-\mathrm{Cl}$ and $\mathrm{CI}-\mathrm{C2}$. We shall Latel ane example of each of ilvese boads. For

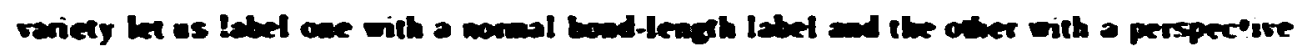

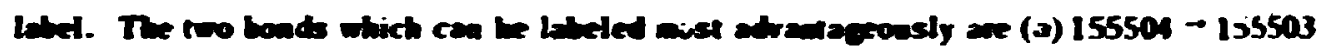
and (b) 255504 - 155505. The lahels will te 0.15 in. in leight and dispbced vertically frow the rood cemer by $-a, 4$ in.

$\begin{array}{llllllll}906 & 155504 & 155503 & 0 & 0 & .15 & 0 & -.4 \\ 916 & 255504 & 155505 & 0 & 0 & .15 & 0 & -.4\end{array}$

The fial feoture to be drovg is a coption (CUBAare) for the illustration. Thus can

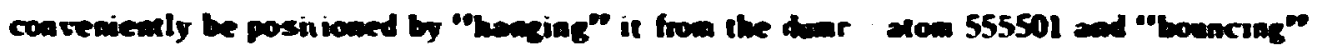
it I in. off the lowet s boundony.

(4) $3 \quad 902 \quad 555501$

n 0

I. $\quad 250$ o

The sored sequence can wow be lerminated. 1102

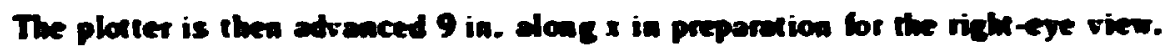
202 9

The stereo rotation of -2.7 about axis 2 is now perforaed in properotion for the rifht-eye view. (Note thot this rototion sterts with the refenence orientation. wot the previous wotking orientation.)

(4) $503 \quad 2 \quad-2.7$ 
Cord mo.

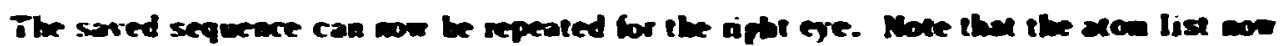

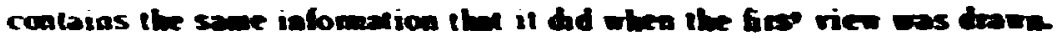
1103

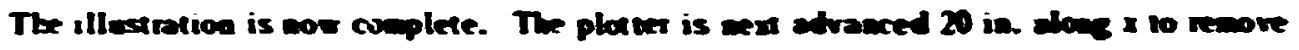
Itus figure trom the vodiac area.

(4) 202 20

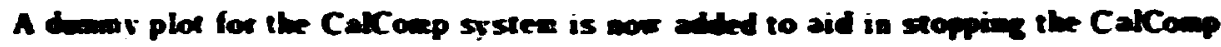
plone: 202 0

Findly we revainate the job and exit fou the progan. $-1$

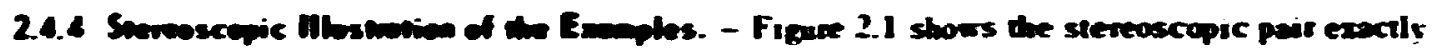

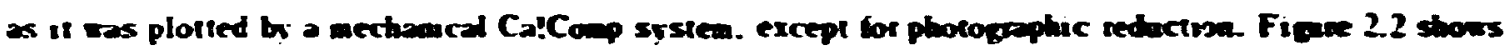

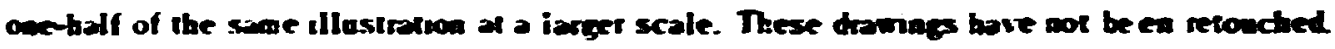

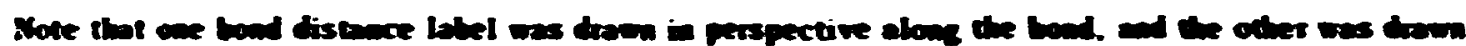

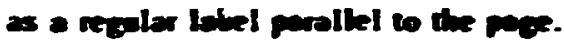

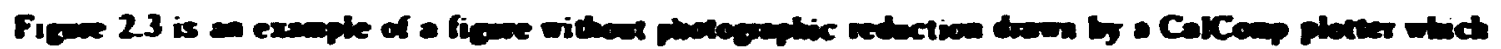

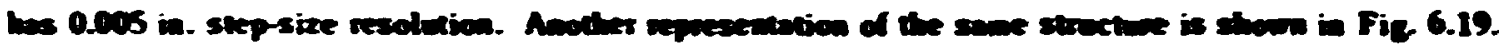

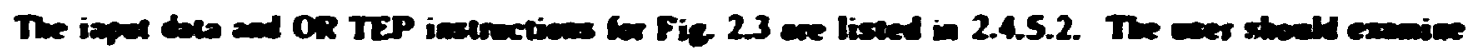

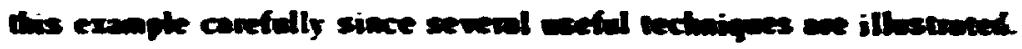




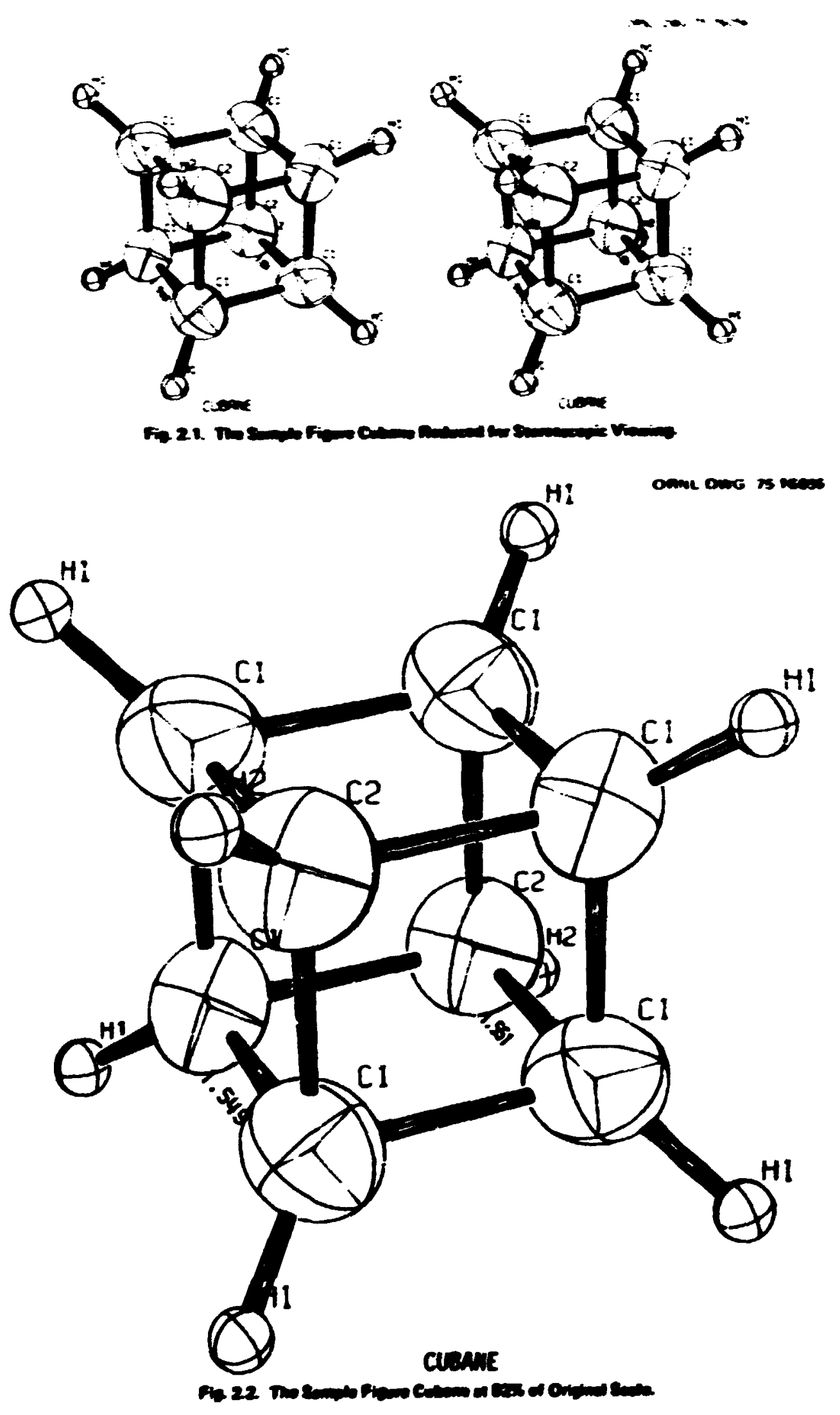




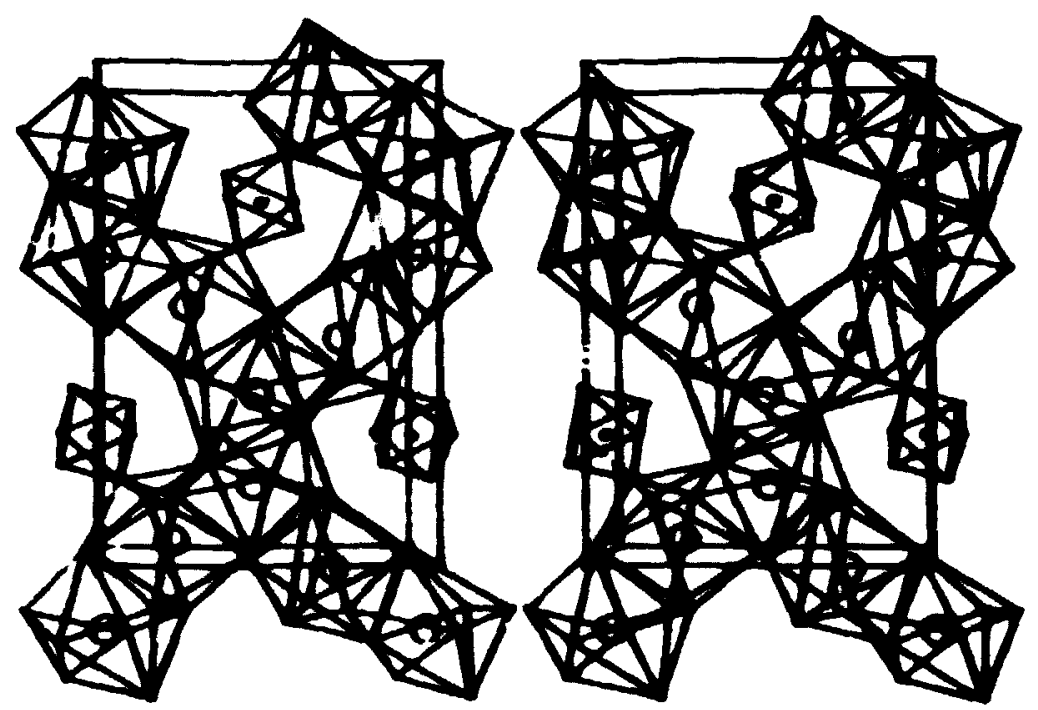

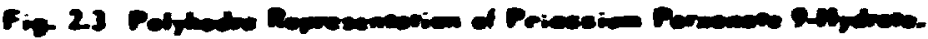

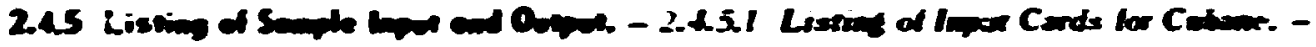

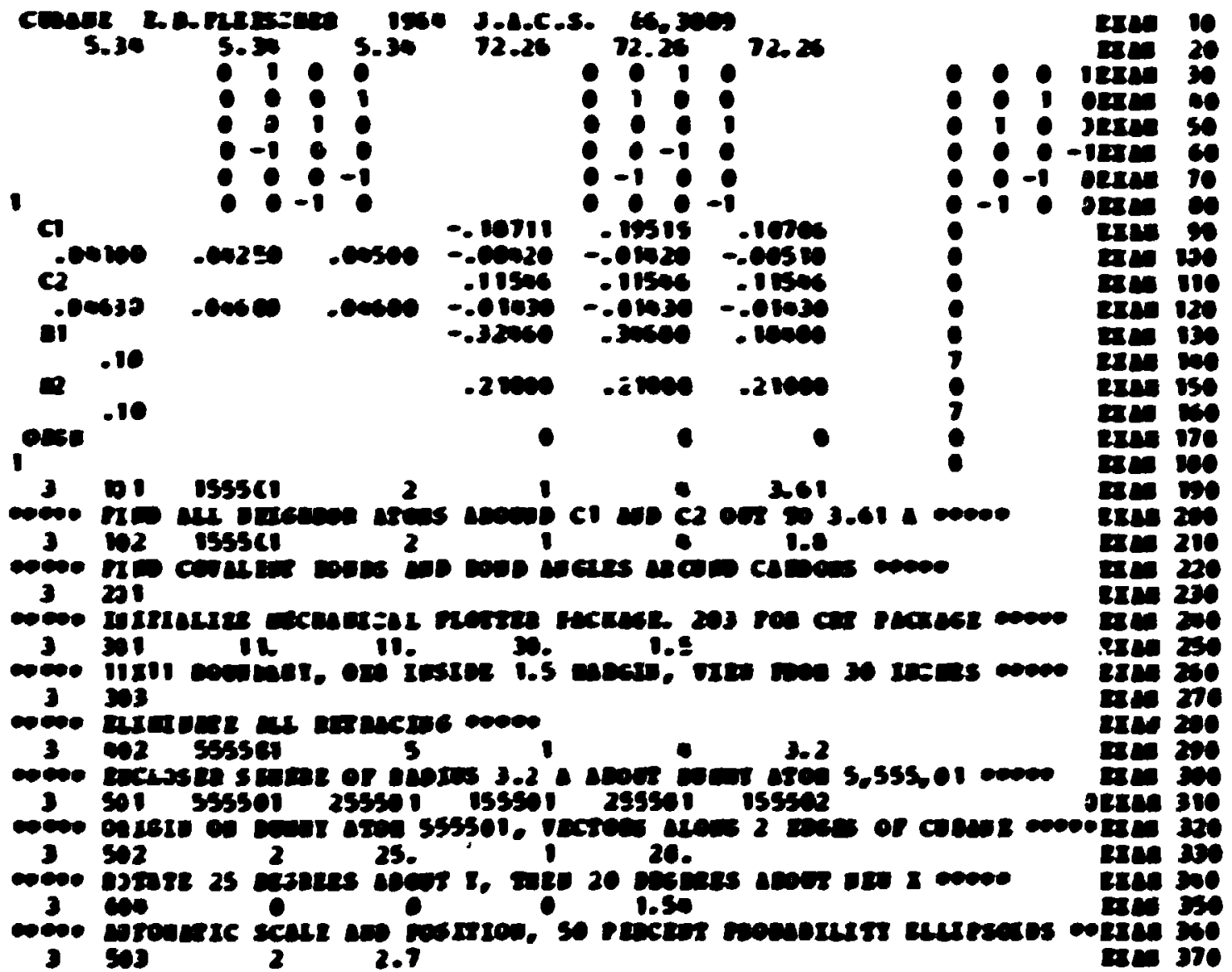




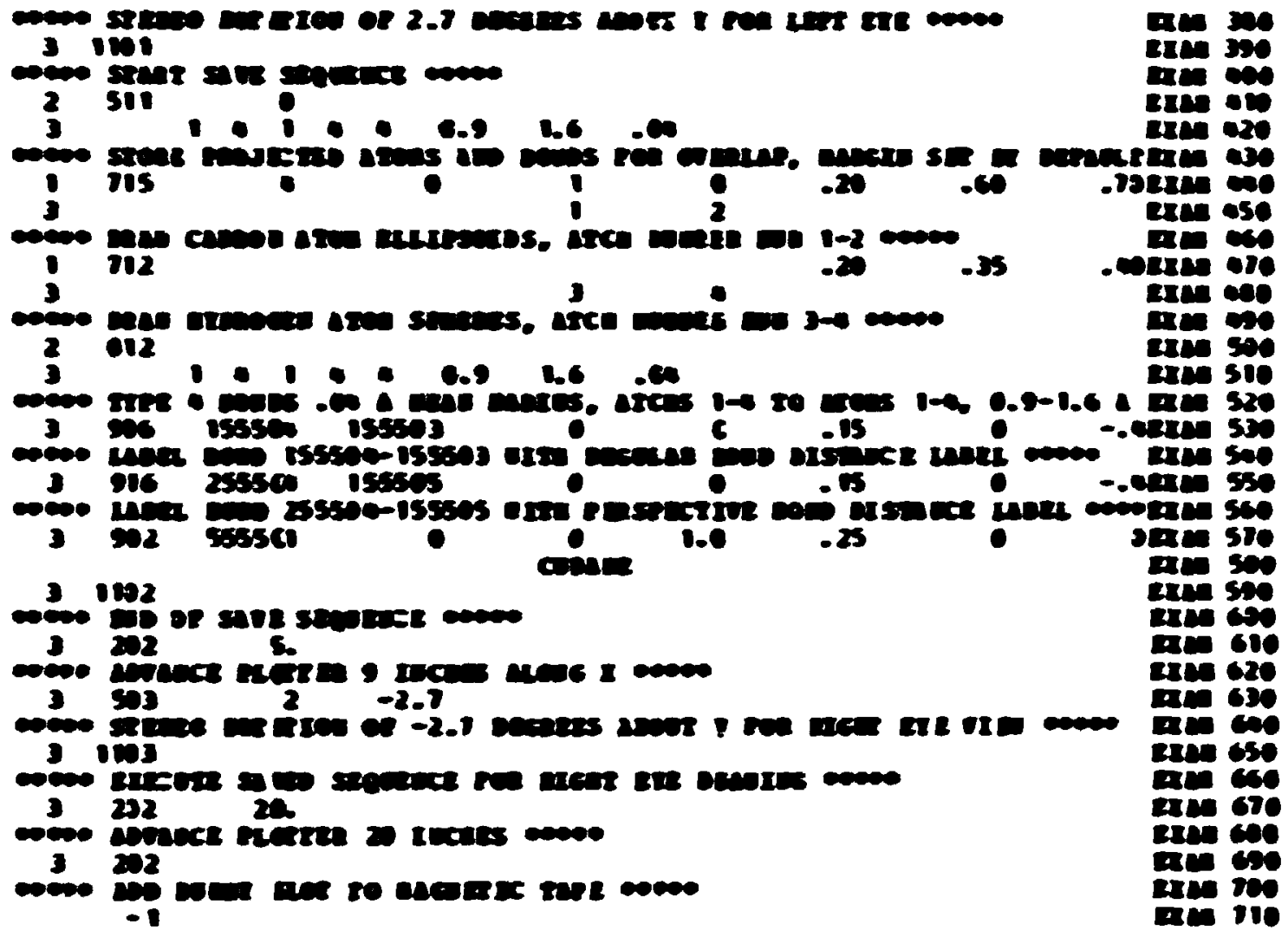

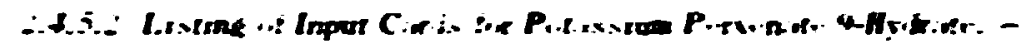

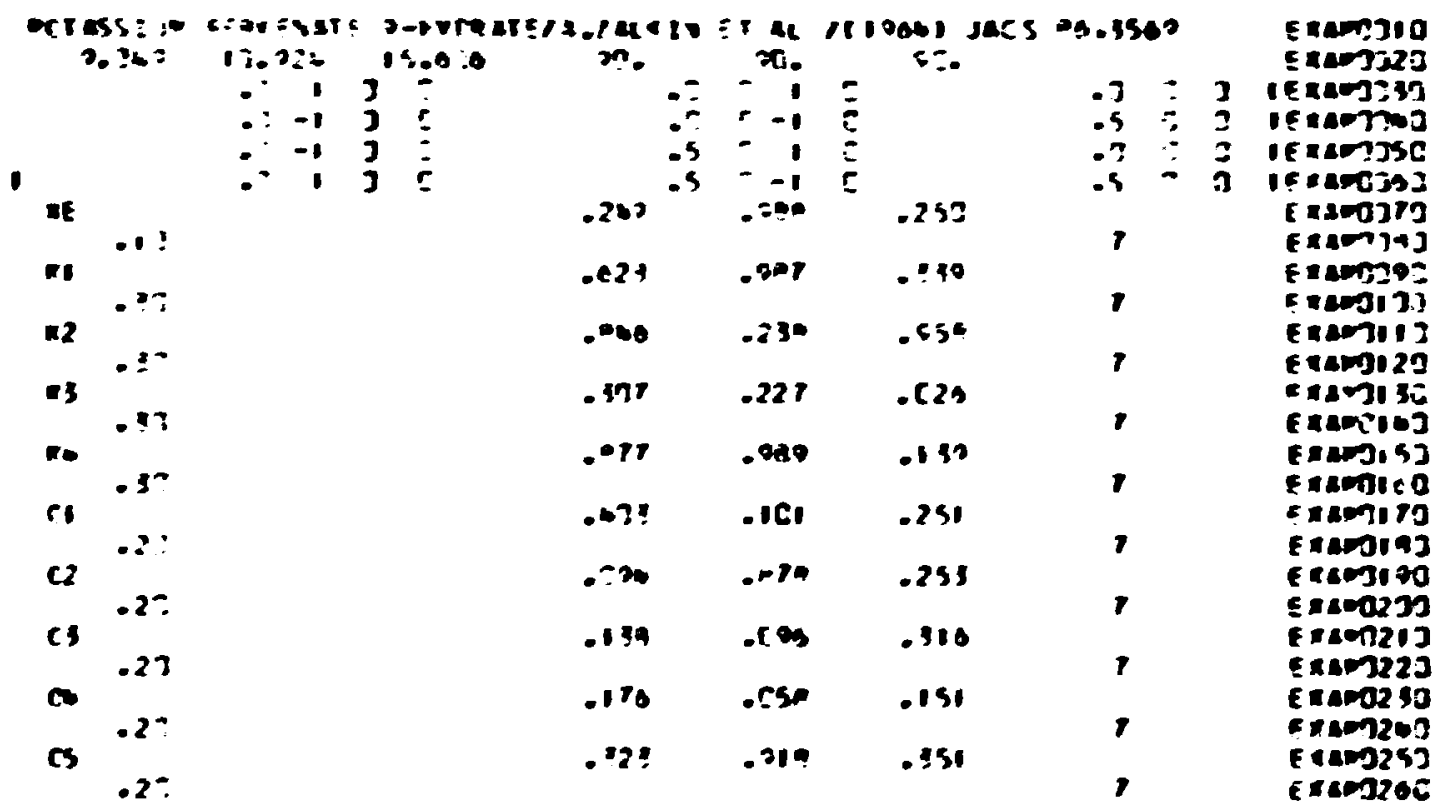




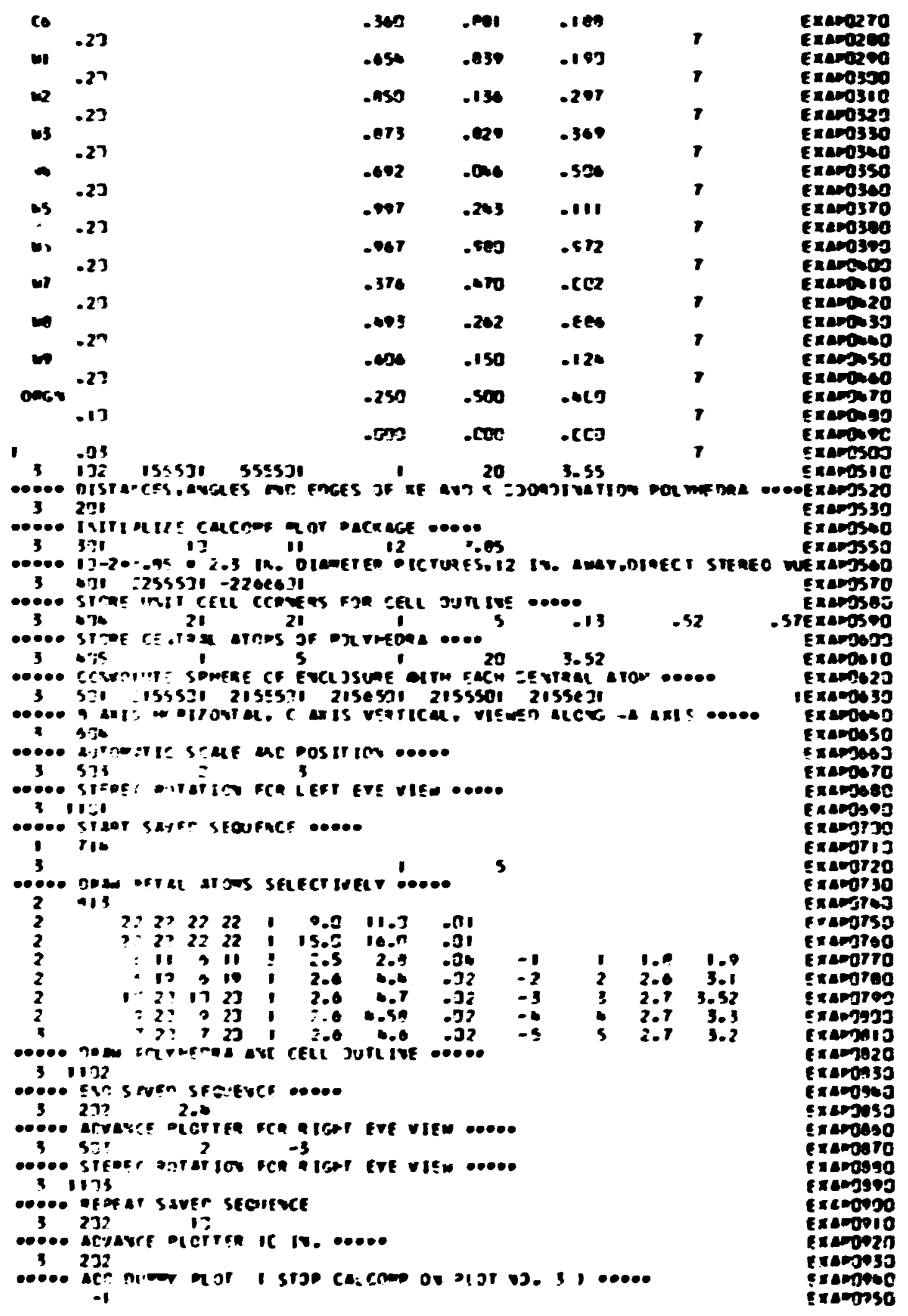




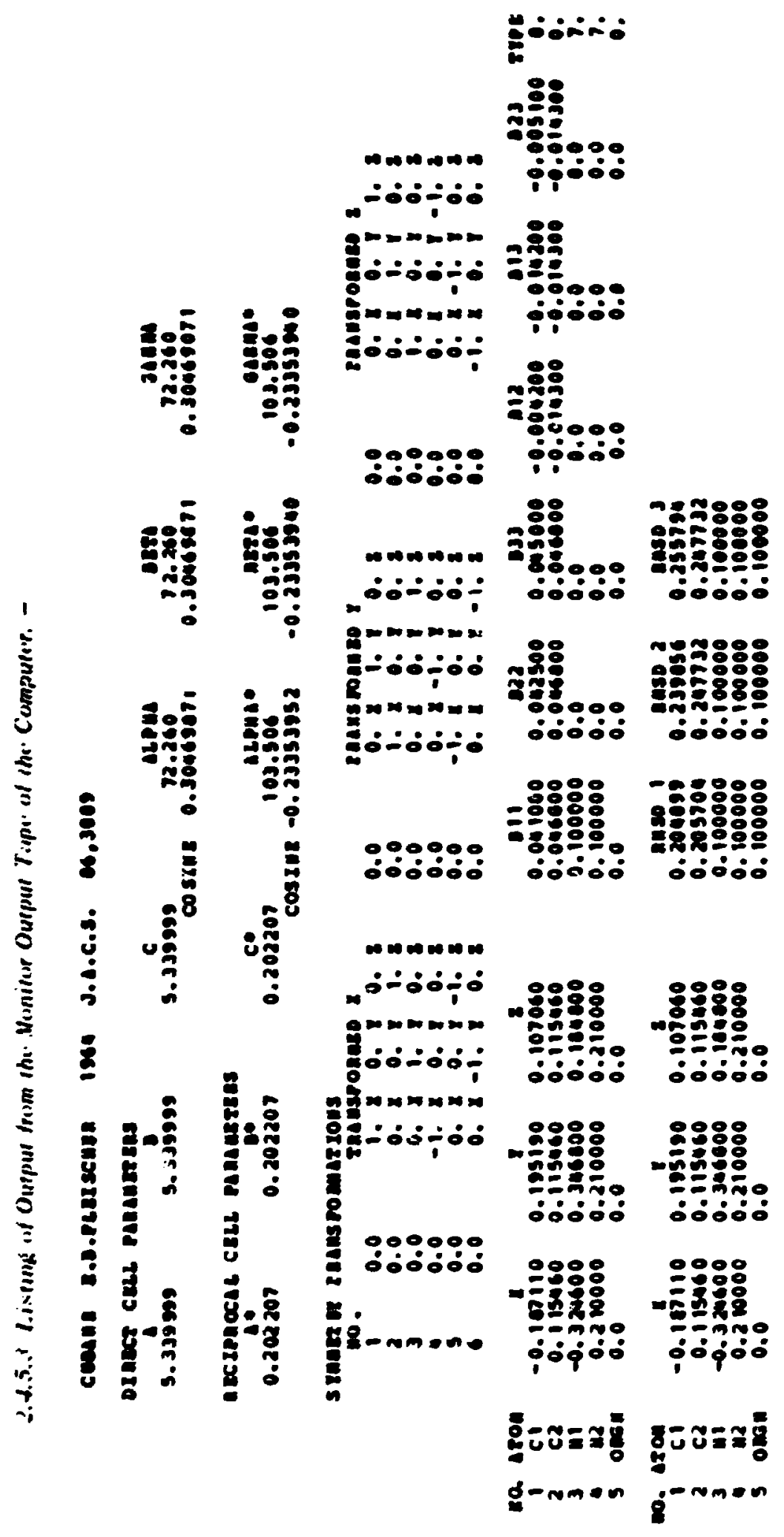




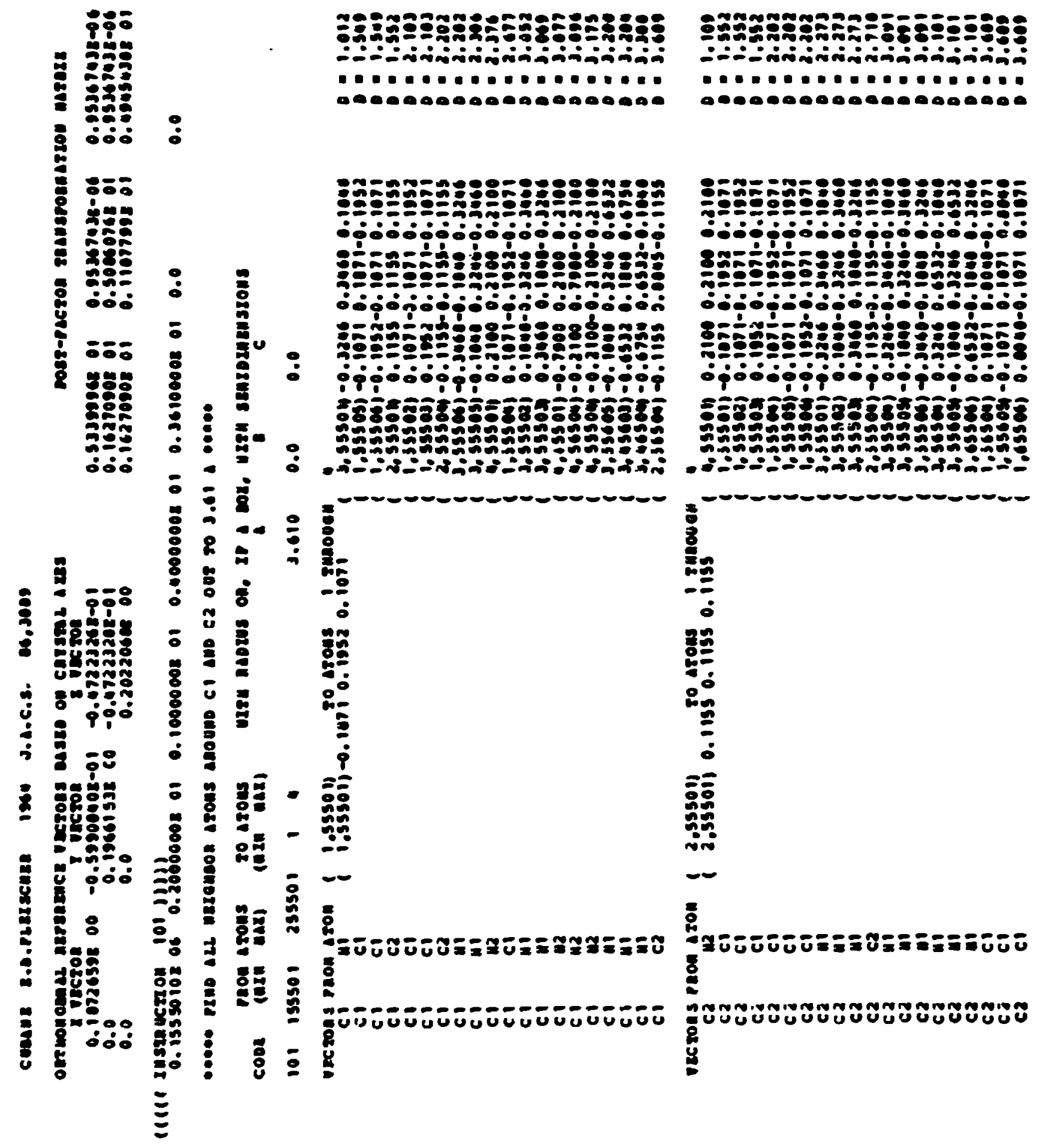




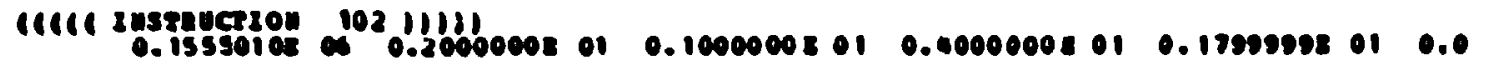

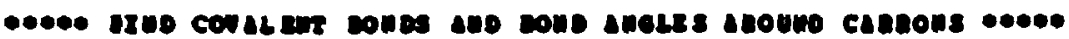

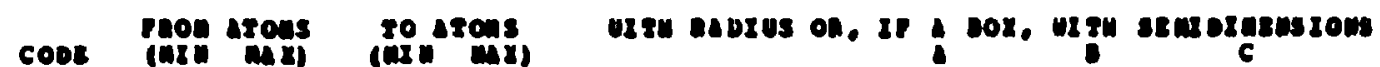

$102135501253501,0.0000 .00$

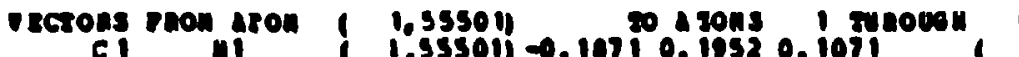

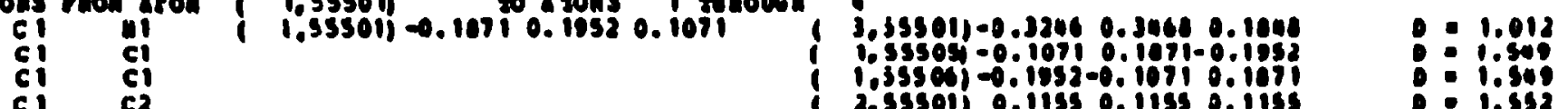

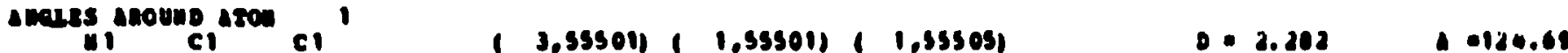

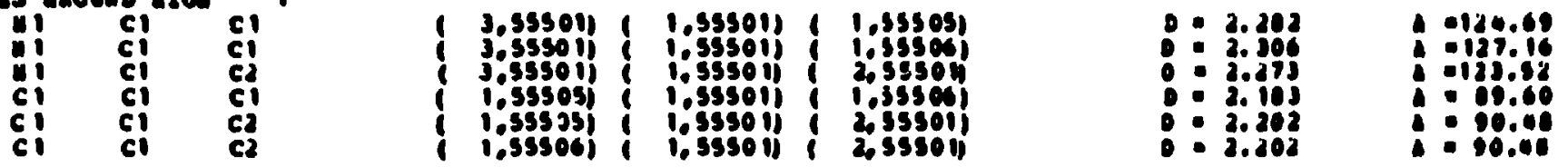

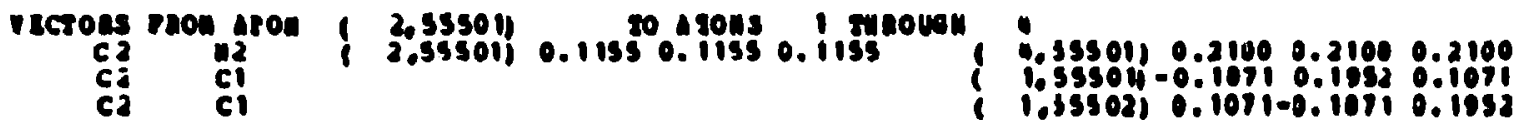

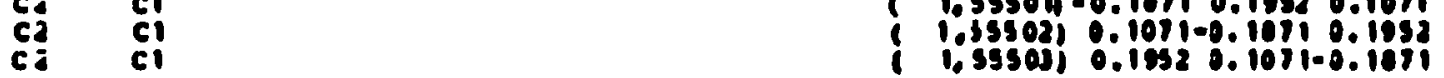

01.108

0.1 .553

- 1.5s

- 1.352

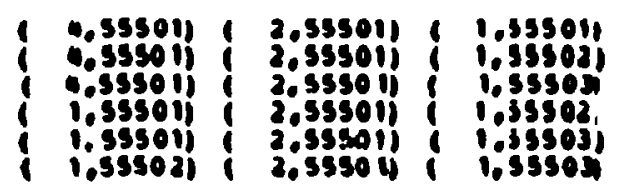

2.316 0.376 : 3.103 2.103

10.129 .64 12125.60 a.

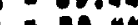
-

201,1313

0.0

0.0

0.0

0.0

0.0

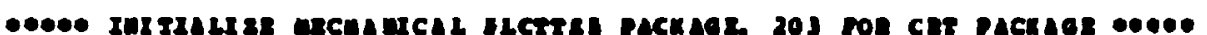

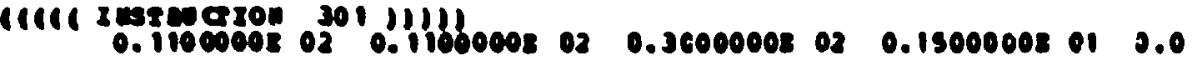

0.0

0.0

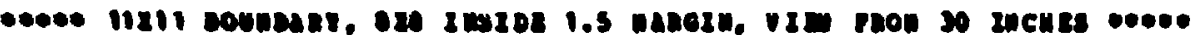

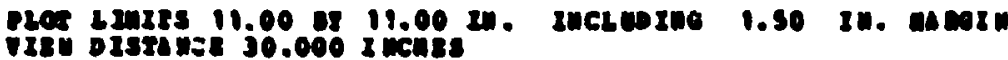




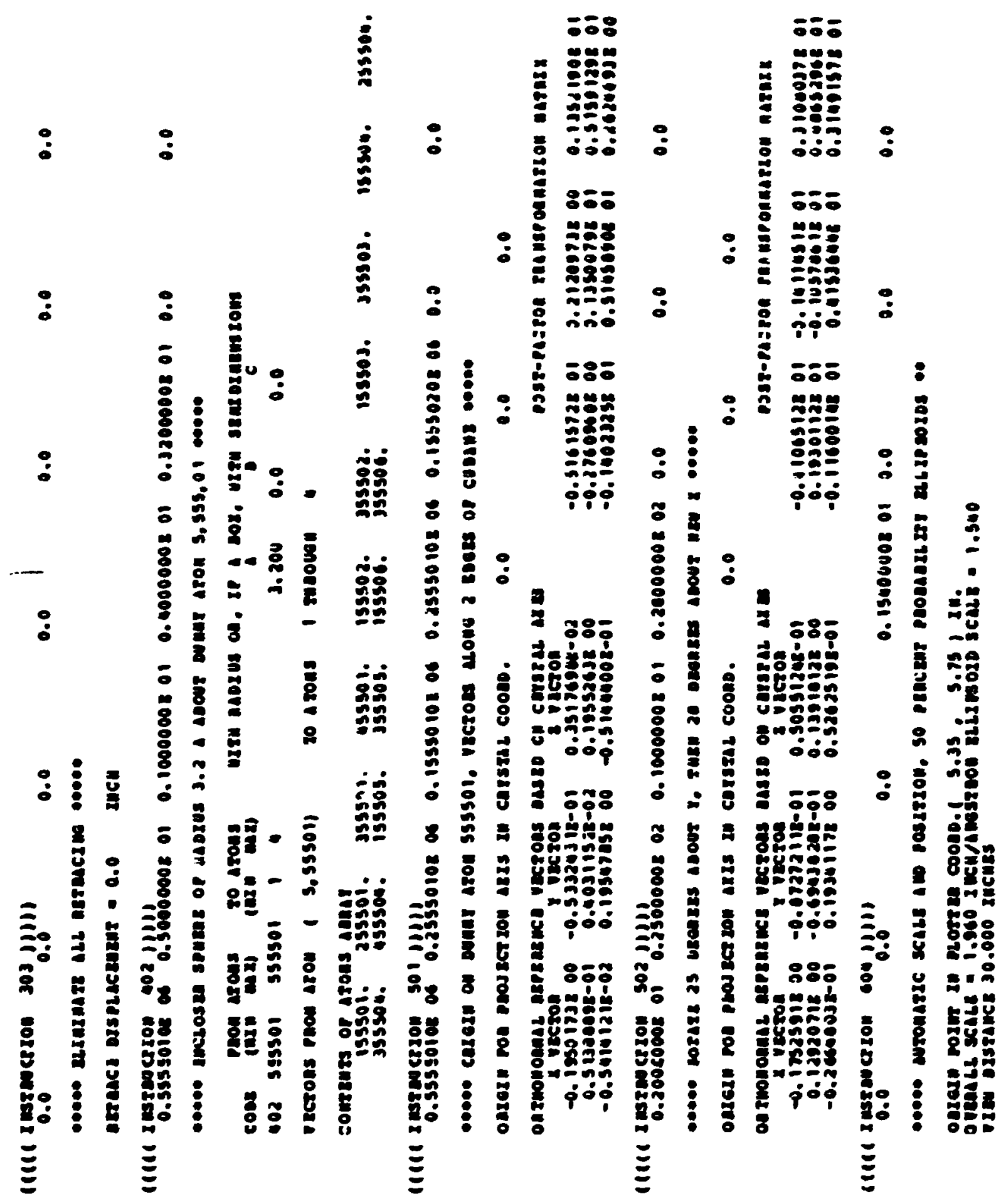




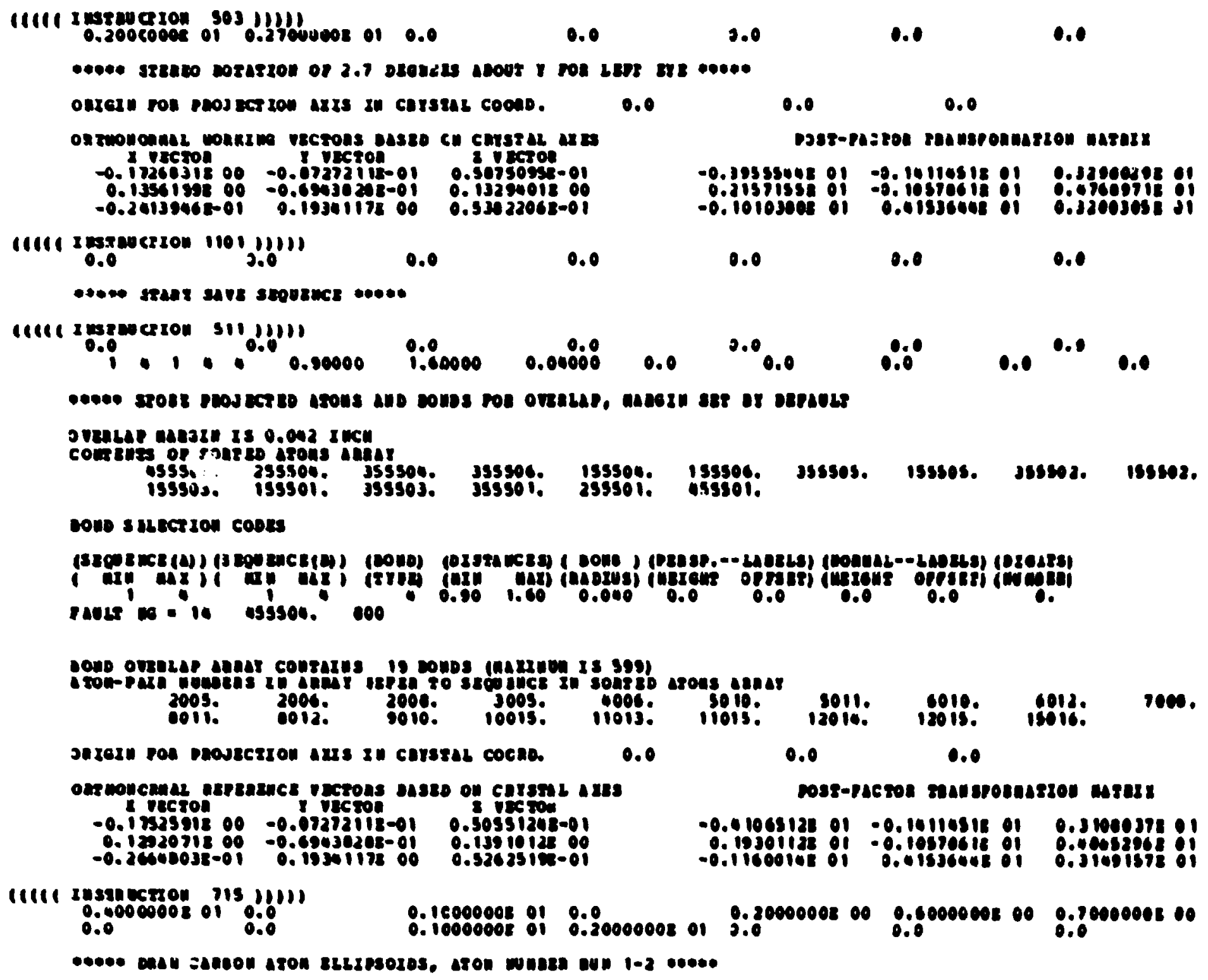

0.0

os monchar wonkim vecrons passo cu carsrel ar as

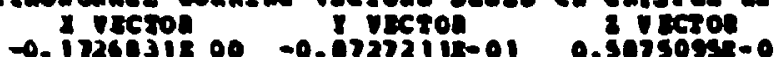
$-0.172631800-0.07372115-01 \quad 0.5075094-01$ $\begin{array}{rrr}0.1356190800 & -0.69434208-01 & 0.1329001800 \\ -0.20139465-01 & 0.1934117800 & 0.33522068-01\end{array}$ 


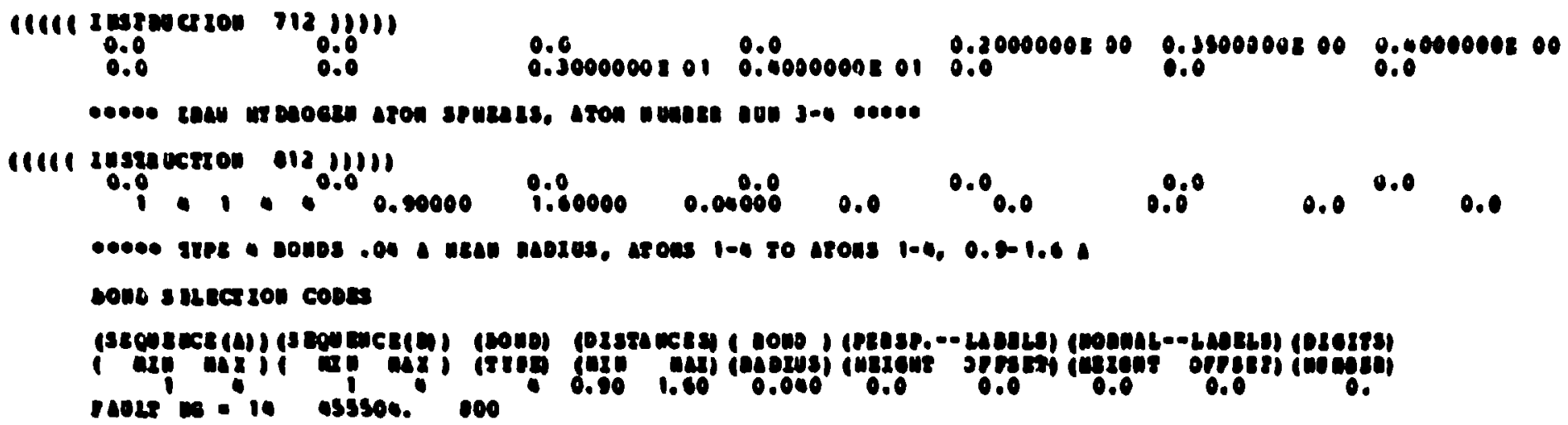

0.0

$0.10000002010 .2540000800 \quad 0.0$

Cosed

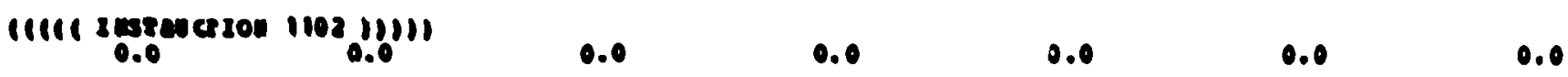

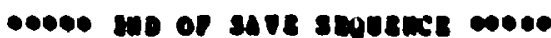

11111 163209esion 20211111

$0.0 \quad 0.0$

0.0

2.0

0.0

0.0

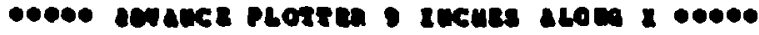

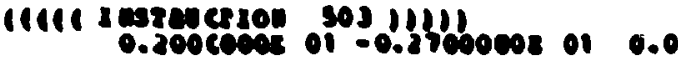

0.0

2.0

0.0

0.0

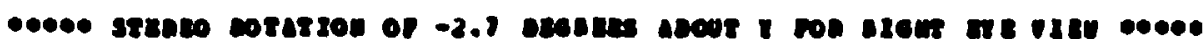

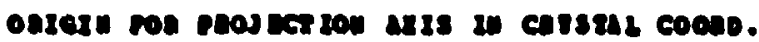

0.0

$\bullet .0$

0.0

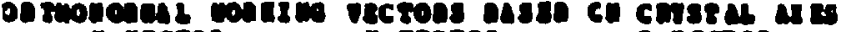

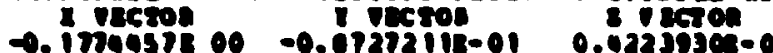
$-0.1770453800-0.07272118-01 \quad 0.0223934-01$

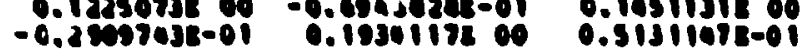

posf-7hapon ranuspounasson masosz

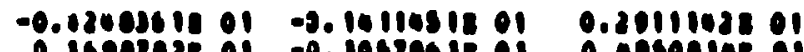

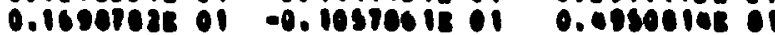

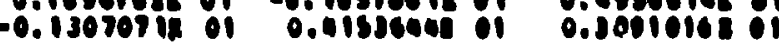


1111 Inssemeson 110311111

0.0

0.0

0.0

0.0

0.0

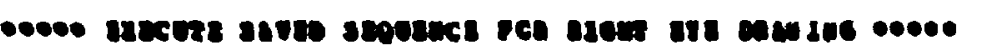

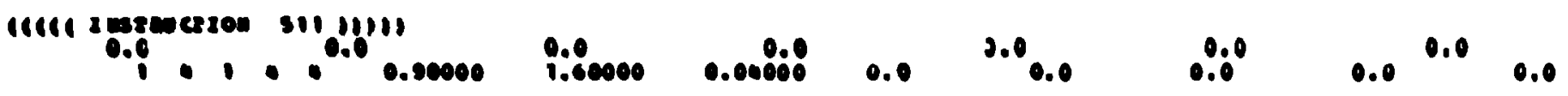

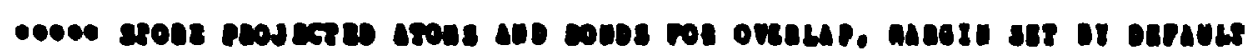

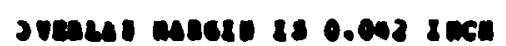

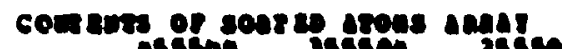

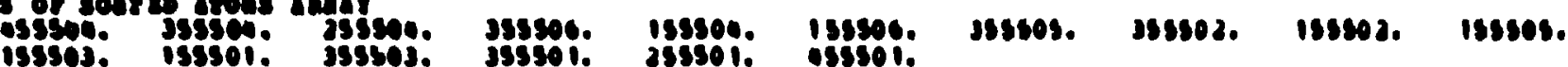

now s ucsien coess

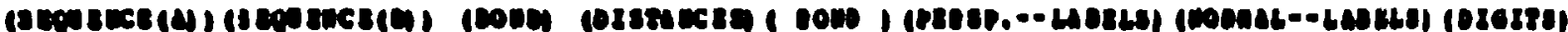

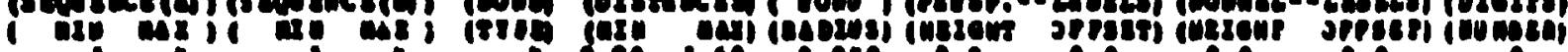

pares o is asssen. 000

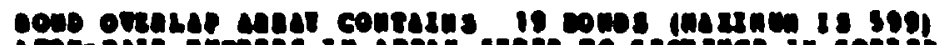

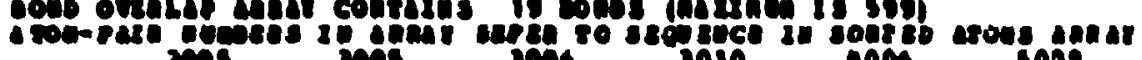

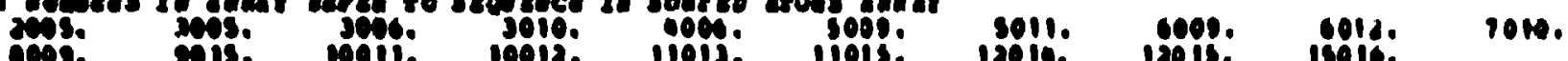

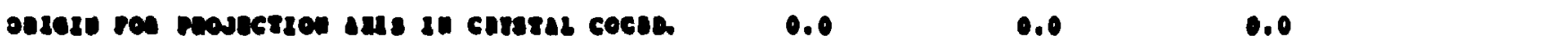

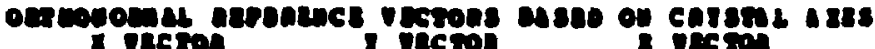

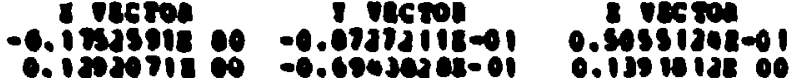

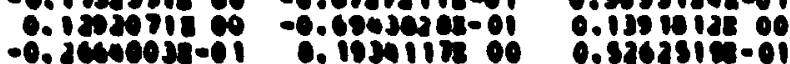

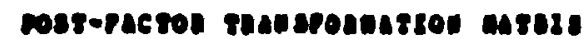

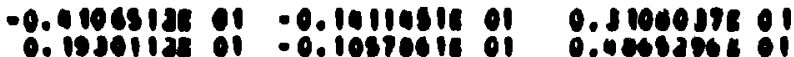

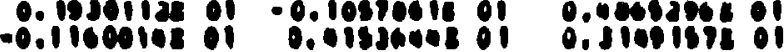

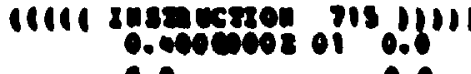

0.000008 oi $0 . f^{\prime \prime \prime} \quad 0.10090008$ or 0.0

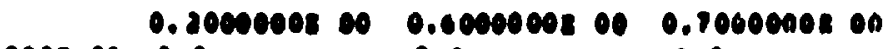

.

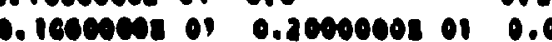

0.0

0.9

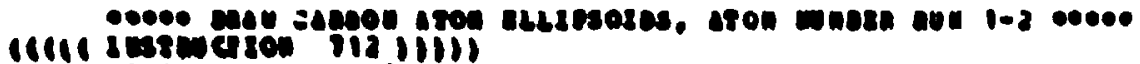

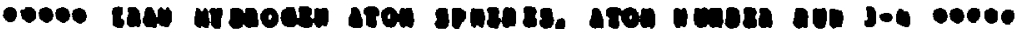

0.20000008 os $0.3500200800 \quad 0.4000000800$

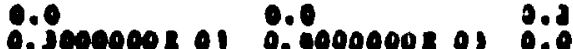

0.0

0.0 


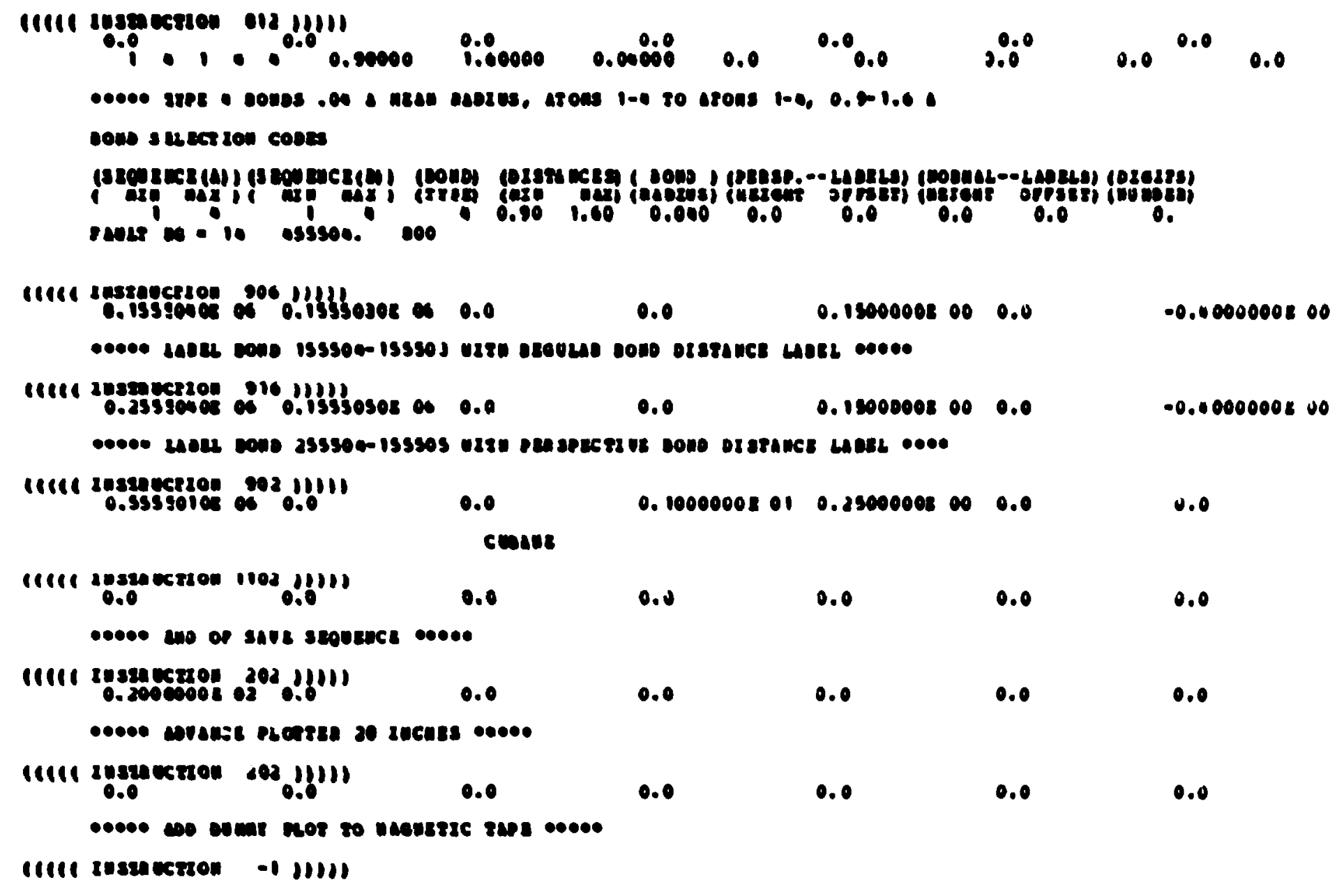




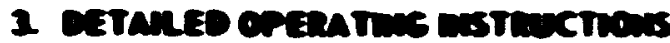

\section{1 onvisivina}

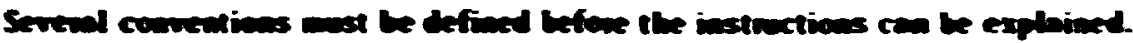

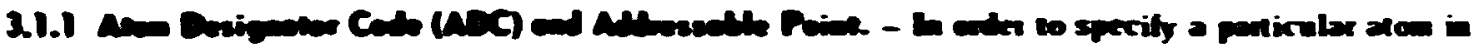

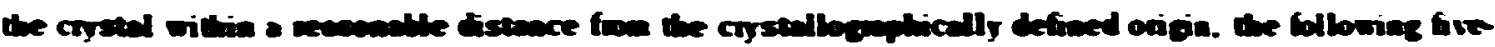

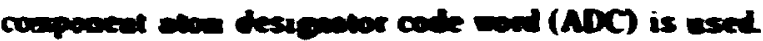

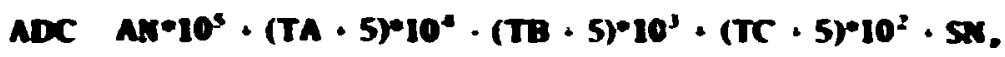

Dere

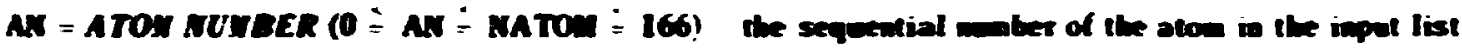

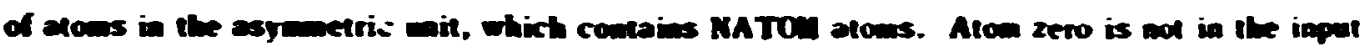
eter list bet refews to the crystal arigis point $(0 ., 0 ., 0$.

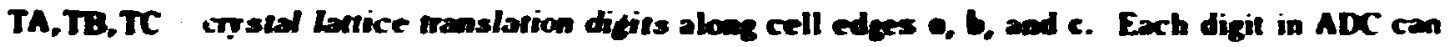

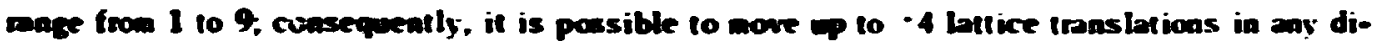
nection from the origia cell $5,5,5$.

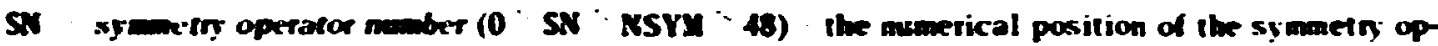
erator in the iapot symetry operator list which contains NSYM entries. Syma try operator aumber zero is not in the iaput list but refers to an identify operator. However, the identity operation (comesponding to position $x, y, z$ ) anst in enerol also be somewhere in the input symetry cperotor list and is asually the first operator.

Example: An atom desigation code of $3 \$ 7562$ refers to zeom 3 moved through symmetry operation 2.

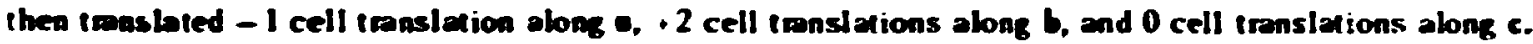

An adtrexsable point in the crystal is any point for which an atom designator code exists. In kenetal. Itr: oddressable region is approximately a 9.9 . 9 block of unit cells.

3.1.2 Vecter Dasigmerer Cels (VOC). - A rector dinection is specified by two atom designitor codes. The vector direction is from the first to the second.

Enample: 253704263704 is a vector along the positive e divection of the crystal lattice.

3.1.3 Am Dasigmer Rem (AOX). - A stroight run sequence of atoms can be defined using (wi) atom desigator codes with a negative sign preceding the second of the two. The run hierarchy is: first, atom number AK; second, symaetry operotion SN; third, e iranslotion TA; fourth, b iranslation TH; and last. $e$ iranslotion TC.

Exampl.:: ADR (145502 - 245603) will generate the 8-stom run 145502, 245502, 14550.3, 24550.3, 145602, 245602, 145603, 245603.

3.1.4 Awo Mumber Rom (ANR). - The Atom Number Run is a subset of the Aton Designitor Run. In this cose, only the atom number AN is allewed to chonge. Nomally, on ANR is entered by using only the atom number (AN) values for the first and last members of the sequence without a minus sign.

Eximple: (1 4) will der: gnate atoms 1, 2, 3, and 4 of the input list. 


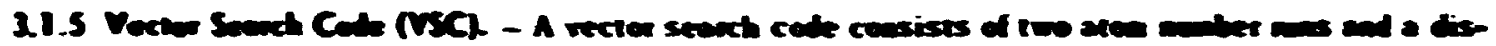

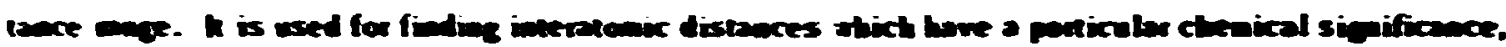

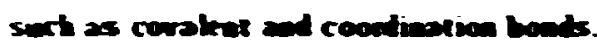

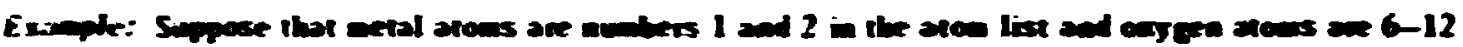

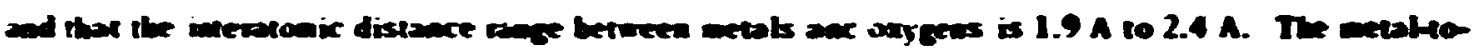

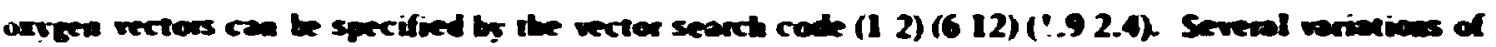
thes basic cole ane esed in the poopon.

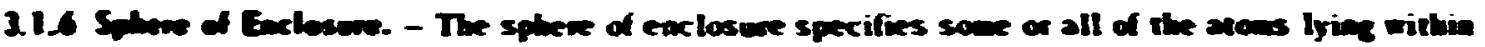

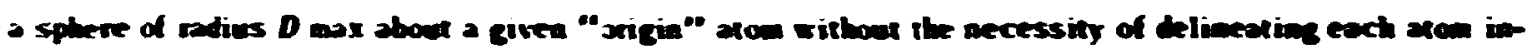

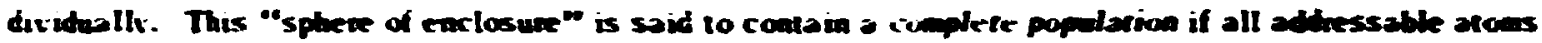

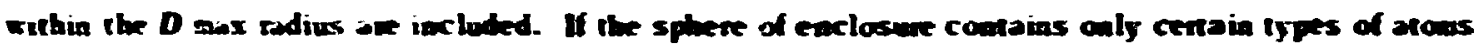

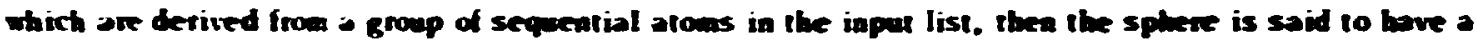

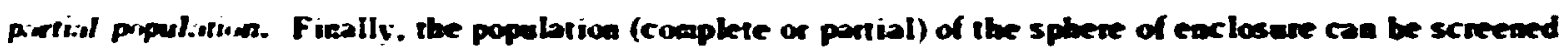
as selectively as desined through the use of vector seanch codes (3.1.5), and the nesultian content is called

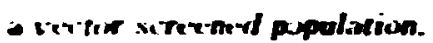

A sphere of exclosure can be ceatened oa any addressable rtom. bat one shomld aot use poiats in the ute-rmost cells os centers because of the possibility of having nonaddressable points within the $D$ max :adius.

3.1.7 Lax of Enclosore. - This is a paralletepiped which can be centend about any addressable point and assigaed arbitery orientation and dimensions. This "box of eaclosure" can have a complefe popelation or a partial popu'arion as described for the sphere of enciosure (3.1.6). However, vector sceening is not allowed with the box of enclosure.

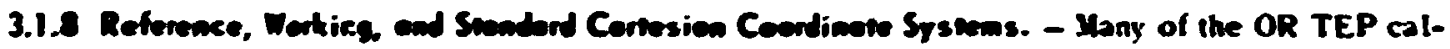
culotions use fractional coondiaates based on the crystal axes $\bullet, b$, and 6 (triclinic coordinate system); but other steps necessitate the iatroduction of orthonomal base vector iriplets (Cartesian coordinate sistems). Two Cartesian systems (reference and working) are ubilized. The referer.ce (major) systen is used for all uperitions except plotting. where the working iminor) system is used. For a righteye or lelitue stermo view, the working system is noved fron the reference system by rotation about an ixis of the refetence system. However, centain decisions mad while plotting must still be referned Io the reference system in maintain accurate stereopsis. The user can define and orient the two Cancsian systems through the instructions of series $\mathbf{3 0 0}$. Until a 300 -series instruction is given, a "standard Cartesion system" is utilized for both the reierence and working systems. The orthonormal buse vecturs of the sfindird system are oriented as follov s:

$$
\begin{aligned}
& x \text { axis along } \bullet \\
& \text { y axis along (a b) - } \bullet \\
& x \text { axis along (a.b) c*, }
\end{aligned}
$$

where $\bullet, b$, wad 6 ate crustal axes and - denotes the outer vector product (cross product). The symbol c" reiers to a reciptocial ixiss. 


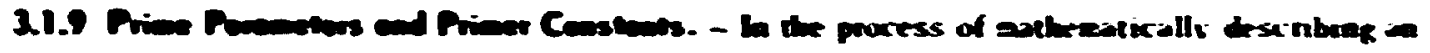

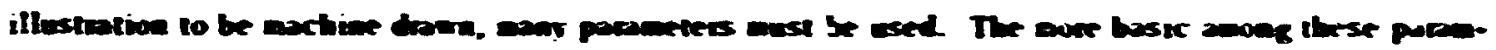

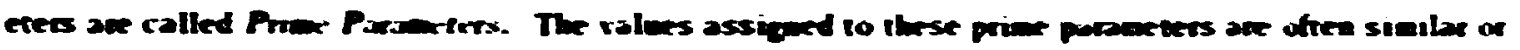

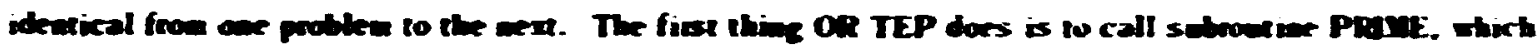

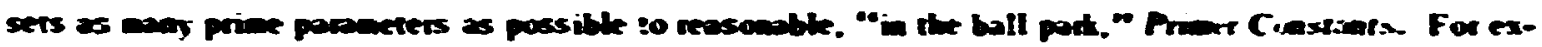

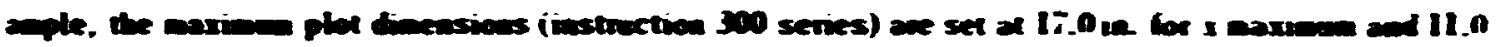

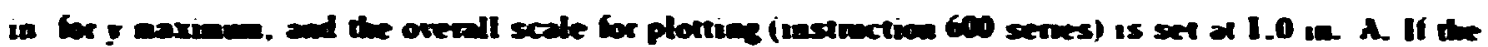

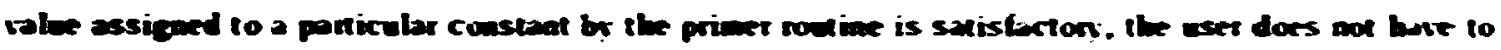
wetet this comstant witi OR TEP iestenctions.

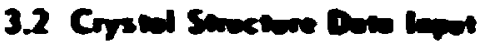

\section{Tint Con. - Forinat (12A6)}

Colomas

1-.2 Tirle consisting of any desined alphanouseric identification information.

This will appear periodically in the catpal.

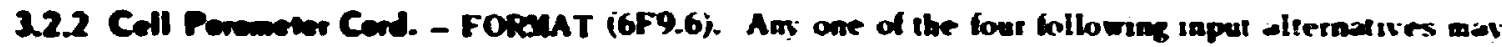
be ased (no indicator is needed to specify which iype i."

\begin{tabular}{|c|c|c|c|c|}
\hline Colonns & True A & Tree & Troe C & Trwe $\mathbf{D}$ \\
\hline $1-9$ & - $(A)$ & e(A) & $e^{\circ}\left(A^{-1}\right)$ & $\cdot\left(A^{-1}\right)$ \\
\hline $10-18$ & $b(A)$ & $G(A)$ & $b=\left(A^{-1}\right)$ & $b *\left(A^{-1}\right)$ \\
\hline $19-27$ & $C(A)$ & $c(A)$ & $c=\left(A^{-1}\right)$ & $c *\left(A^{-1}\right)$ \\
\hline $20-36$ & $x(d-x)$ & $\cos :$ & $: *($ dez) & $\cos :=$ \\
\hline $37-45$ & $\beta$ (des) & $\cos \beta$ & $\beta^{*}$ (deg) & $\cos \beta$ \\
\hline $46-54$ & $y(d e d)$ & $\cos :$ & $y \bullet(d e g)$ & $\cos y$ \\
\hline
\end{tabular}

The pormeters e*. etc., refer to the reciprocal unit cell such that - 1. All fout types will be priated out recordless of which type was used for input.

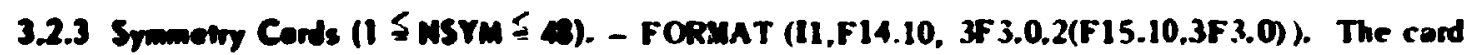
will be interpreted in one of two ways, depending on the numetical value of the number un columns $70-72$. If that nuaber is $: 5.0$, the card is interpreted as a crystallographic symmetry operotion; but if the nuaber is 5.0 , the cand is interpreted as a general helix-screw symmetry operotion" along the ce crystal axis

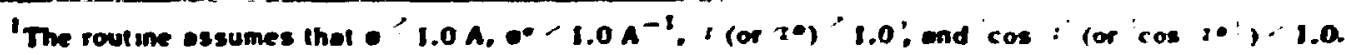

'The rimial helix-screw symmetry operetion is not on sllowed element of a crystallogrophic group, so thal :he molecular environment of the transformed unit will not in cenerol be identical to thot of the untransformed unit (unjezs the crystol is considered to be one dimenssonel). This input is supply on expedient for use in plottine tuelicel polymer structure models wath minimum input. In generol if would be possible lo produce the some resulis by spec ily sne the

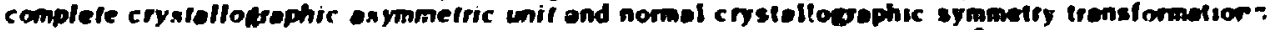

This input mode is only meanindul if the cell ancles 2 and $\boldsymbol{H}$ are $90^{\circ}$. so that e liee along so and the helisx can continue uniniemupted from cell to cell blone the caxis.
} 


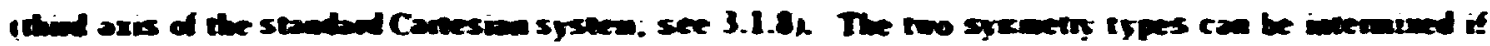
aximed

\begin{tabular}{|c|c|c|}
\hline Colvenes & 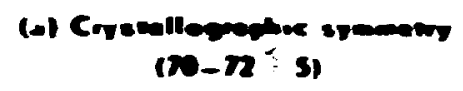 & 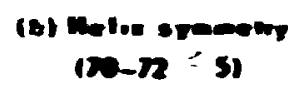 \\
\hline $\mathbf{t}$ & fo best cand colt & jo Laxi cand only \\
\hline $2-15$ & $\boldsymbol{T}:$ & $\boldsymbol{T}:$ \\
\hline $16-18$ & $s_{28}$ & - \\
\hline $19-21$ & s:: & - \\
\hline $22-24$ & $s_{1,}$ & - \\
\hline $25-39$ & $T_{z}$ & $T$ \\
\hline $90-42$ & $s_{21}$ & - \\
\hline$+3-45$ & $5::$ & - \\
\hline$x-4$ & $s_{i,}$ & - \\
\hline $39-63$ & $\boldsymbol{r}$ & $\boldsymbol{T}$ \\
\hline $64-66$ & $s_{1:}$ & $t$ \\
\hline $6 ;-6$ & $s_{1:}$ & $\boldsymbol{u}$ \\
\hline$: 0$ & 5, & $x$ \\
\hline
\end{tabular}

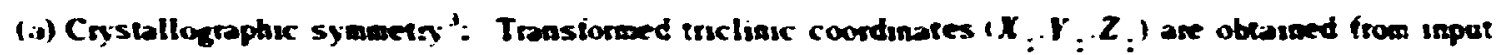
tnclunc coordinotes $(X, Y, Z)$ by

$$
\begin{aligned}
& x_{1} T_{:} \cdot 5_{::} x \cdot 5, Y \cdot 5, Z, \\
& r: r_{2} \cdot s_{21} X \cdot s_{32} Y \cdot s_{2,} Z \cdot \\
& z_{1} T_{1} \cdot 5_{1,} X \cdot s_{12} Y \cdot 5_{, 2} \text {. }
\end{aligned}
$$

or un matrix notaliun

$$
x, T \cdot 5 x
$$

where

$\left.T, T_{1}, T_{2}, T_{,}\right)$as (ructions of cell edges.

(b) Ifelix screw symanetry:

$$
x_{2}+5 x
$$

othere

$T(T, \cdot T, t, \cdot L, W)$ as fractions of cell edge and

5 counterclockwise rotation of L.U $V$ cycles about $c^{*}$ axis.

For example, the Pauling and Corey righthanded olpha helix repeats after 5 tums and 18 residues and caa

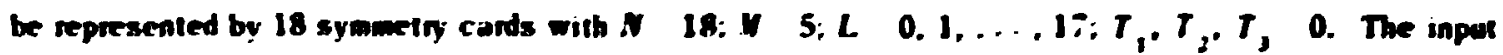
tom ist contans the contents of one axidue.

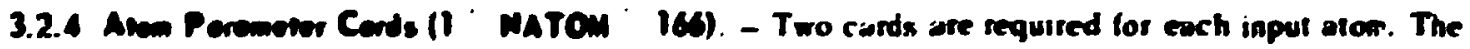
firsl continins the chemical symbol and poxitional parameters. and the second contouns tempetoture foctor

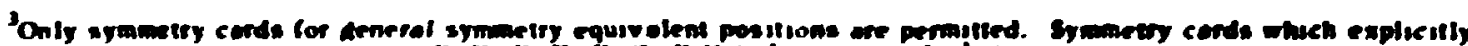

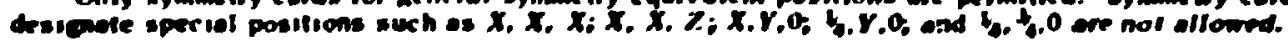




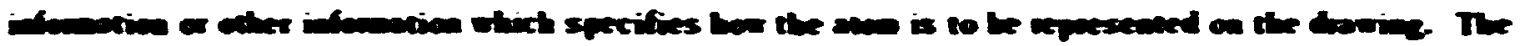

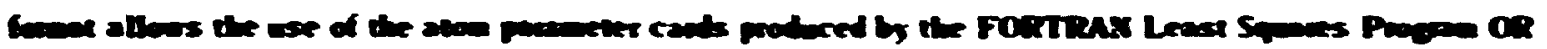

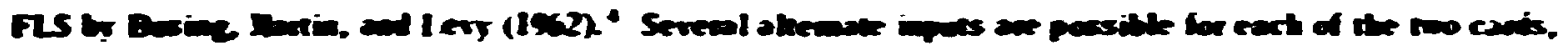

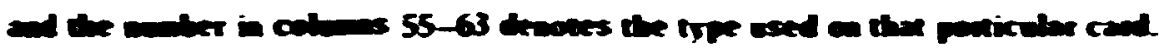

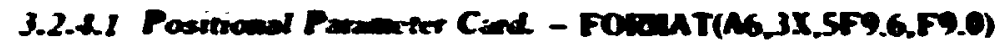

\section{Colomes \\ 1-6 \\ i-9}

$10-18$

19-2.

$22-36$

3.- -45

$6-54$

$55-63$

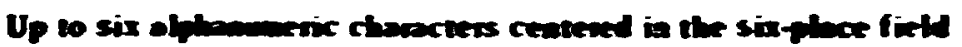
Blank

$$
\text { Troe }
$$

Troe 1

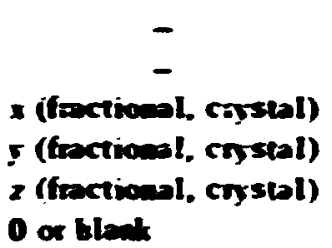

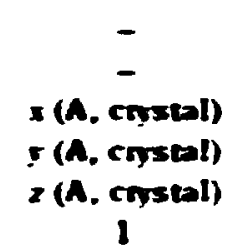

1
Trom 2

$-$

I (A. Comesien)

(A. Contesion)

I (A. Cancsion)

2
Troe 3

I. (A) Cactersian Y. (A) Cansion (A) cylindical o( ) crliantical I(A) crlindical 3

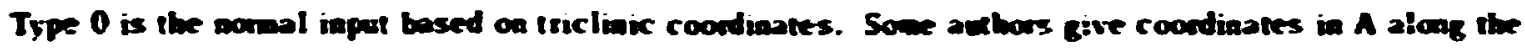
mit cell vector, type 1 would be used in suct a ease. Type 2 allows une to place a model described in

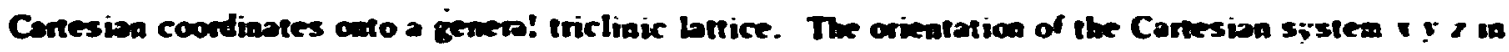

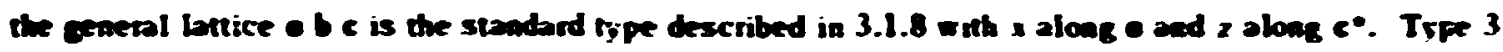
is similar to type 2 except that cylindacal coodtinates ro in $z$ are used and the axis of the system can

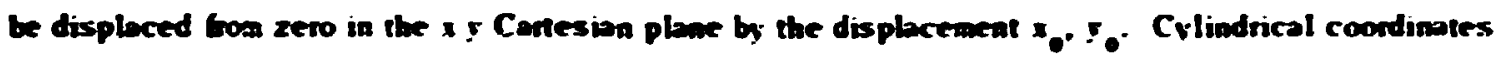
an ofter used in the literature to describe a helical structure. The $x_{0} . y_{0}$ transtarion should be zero if thelical symetn opetators are used. This trastation froture is meant to be used in explicitly discribiag the contents of a maltiplo belix cell.

3.2.4.2 Temperarure Facror Cand. - FORuAT(II.F8.6. 5F9.6,F9.0)

\section{Colomes}

1

$\begin{array}{cc}2-9 & b_{11} \\ 0-18 & b_{21} \\ 9-2 & b_{33} \\ 28-36 & b_{12} \\ 37-45 & b_{11} \\ 16-54 & b_{21} \\ 55-63 & 0.1 .2,3.10\end{array}$

A sentinel $/ 0$ for last atom only

$T_{\text {ree } 0.1 .2 .3,10 \quad T, 5,4.9}$

$u_{11}$
$c_{22}$
$u_{13}$
$u_{12}$
$U_{1,}$
$u_{2,1}$
$4,5,8,9$

\begin{tabular}{|c|c|c|c|}
\hline \multicolumn{2}{|c|}{ Trea 6} & \multicolumn{2}{|c|}{ Tret } \\
\hline$B$ & $B$ & $\boldsymbol{R}$ & $\boldsymbol{R}$ \\
\hline 0 & 0 & 0 & 0 \\
\hline $\begin{array}{l}0 \\
0\end{array}$ & \} (vac) $\mid$ & $\begin{array}{l}0 \\
0\end{array}$ & \} $\mid$ VDC $_{1} \mid$ \\
\hline $\begin{array}{l}0 \\
6\end{array}$ & $\int\left|v x c_{2}\right|$ & $\begin{array}{l}0 \\
0\end{array}$ & $\mid$ tome $\mid$ \\
\hline $6(0,0)$ & $6(\cos 0)$ & 7 & 7 \\
\hline
\end{tabular}

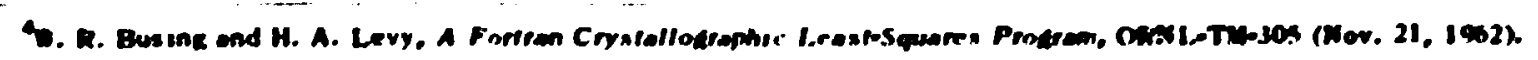




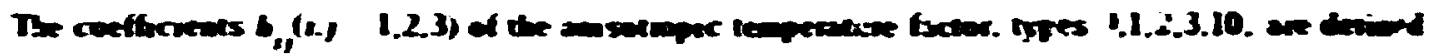

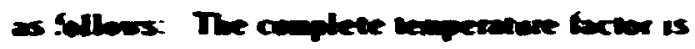

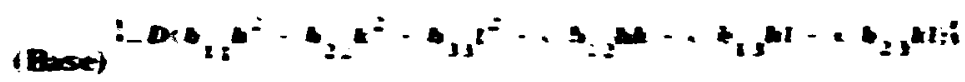

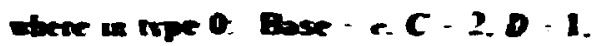

sppe 1: Base c. C-1.D - :

tere 2 Bose 2. 20.1.

tope 3: Rose - 2.C I. D-I.

type 10 Bose c. C - 2.0-2-:

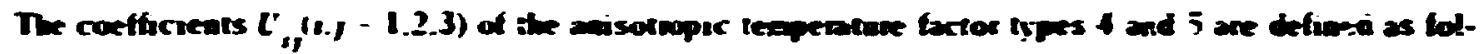

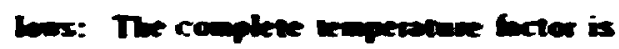

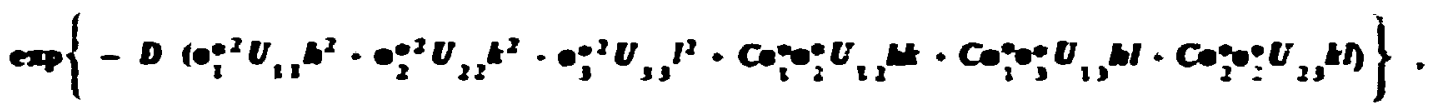

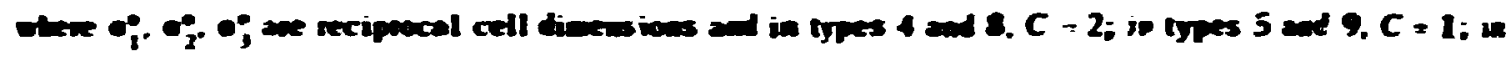

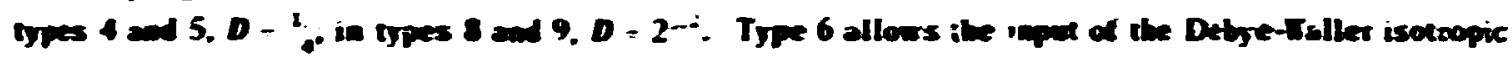
enperature factor $B$, whech is ased as bollows:

$$
\exp \left(-\theta \sin ^{2} y \cdot \lambda^{2}\right) \text {. }
$$

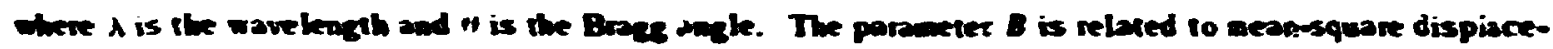
ween $\mu^{2}$ of the atom from its wean position by the relation

$$
s=8 s^{2} \bar{\mu}^{2} \text {. }
$$

When the isotropac temperatise fartor is used, the atom is represented as an isotropic ellipsoid (spiner-) with equal pnacipol axes of length $\mu$. When the field in coluans 19-2\% is 0 or bank. the direcions or the principil dxes are along the standbrd Cartesian system axes (see 3.1.8). However, one can reoriest these arbition unhogonal vectors by using the two rector cesignator codes VDC $\dot{1}_{1}$ and VDC $_{2}$; then the thre new priacipalexis vectors will be VDC, $\left(V_{1} C_{1} \cdot V D C_{2}\right)$, and VDC, $\left(V D C_{1} \cdot V D C_{2}\right)$. Thas is s'rictly an artistic featare of no physical sipaificance.

Trpe : allows the input of arbitron spheres of radiss $\vec{\mu}-R$ in angatwoms. The rector triplet orien:io tion is specified as with type 6. An additional feature allows one to use a completely bionk card iexcep: pethaps column 1$)$ for a temperoture factor cand. In this case the progran assumes t!pe : with an $R=0.1$ t.

A iype 10 tetiperature-factor input card mey be used to loud Cartesian temperature factors hiving components in the standard Cartesian system (3.1.8). This feature complements the type 3 Cartesinr positional parameter input sistem $(3.2 .4$.I) and is useful lor plotting mean-square displace ments cassec by intemal molecular motions is calculated from spectroscopic nomal-coordinate analyses. $\$ . \bullet$

\subsection{Insmoctica laper}

The instructions are the commands used in programming an illustration, and there is no required sew pasce for the instnctions, except $7 s$ indicated by the propromming lopjc. Some instructions require

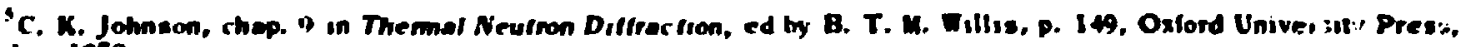
Lendon, 1970.

"R. R. Holmes and R. M. Detters, J. Chem. Phrs. S1, +043 (1969). 
taiker cands, which ay have three differeut formats. The progeno is informed what the format of the next card will be gith the "look abead" field, colwans 1 to $\mathrm{J}$. The propren action is also irfluenced by this information.

"Look abeed"*

(calunns $1-3$ )

0 or blank

1

2

3
Ment cerd will be -

Formal No. 0, a new instruction

Format No. 1, coatinuation of present instruction

Format No. 2, rector search code

Focmat No. 3, alphanumeric inlo.
Preprea ectien

Execute present instruction; then read next card.

Read continuation card; then check "Look ahead."

Read (VSC) cand; then check "L ook abead."

Read alphanumeric inio. and execte instruction: then read next cird.

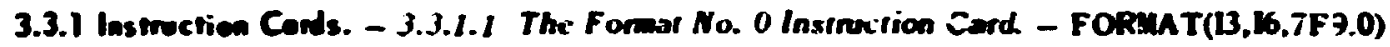

$\begin{array}{cl}\text { Columns } & \\ 1-3 & \text { "Look ahead" (C,1,2,3) } \\ 4-9 & \text { Instruction number } \\ 10-18 & \text { Ist parameter } \\ 19-27 & \text { 2nd parameter } \\ \cdot & \cdot \\ - & \cdot \\ 64-72 & \text { 7th parameter }\end{array}$

3.3.1.2 Formin No. I. Instruction Continuation Card. - FORMAT(13,16,7F9.0) A maximum of 19 conlinuation cands per instruction is permitted.

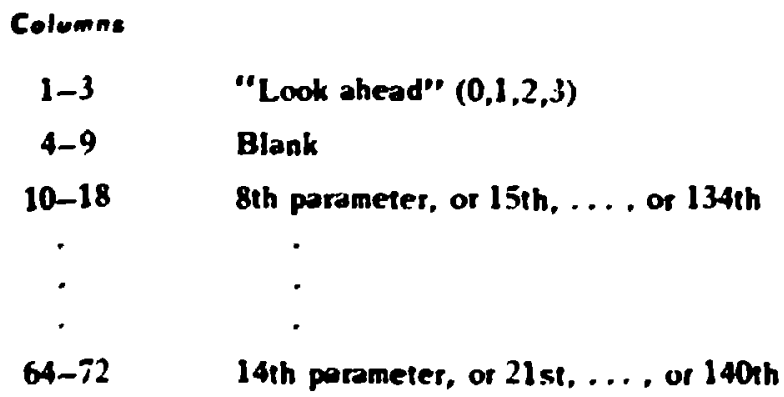

3.3.1.3 Format No. 2, Vector Scarch Code (VSC) Card. - FORtu. T(13,6X,513,8F6.0) A maximum of ten VSC cards is allowed. These cards can be entered with any instruction, but only certain instructions will use them. They must be entered with the porticulor instructions thot require them; that is, they are not held over. Toble 3.1 will be referred to os the individual instructions are explained. 
Toble 3.1. Veater soereh code cards

\begin{tabular}{|c|c|c|c|c|c|c|c|}
\hline \multirow{2}{*}{ Columns } & \multirow{2}{*}{$\begin{array}{l}\text { Search instructions } \\
101+02 \\
100412\end{array}$} & \multirow{2}{*}{$\begin{array}{l}\begin{array}{c}\text { Inertial } \\
\text { wxe. }\end{array} \\
\frac{505.506}{4}\end{array}$} & \multicolumn{3}{|c|}{ Hund plollink inxiructionx } & \multicolumn{2}{|c|}{$\begin{array}{l}\text { Nopurive No. in celumns } \\
\qquad 3 \text { is } 48\end{array}$} \\
\hline & & & 801.811821 & 002012022 & $\cos / 01 \mathrm{~s}$ & $902 \cdot 112 \cdot 22$ & $\cos / a 13$ \\
\hline $1-3$ & Look ahead & Louk whead & Look ahead & l.ooh ahead & Leok ohead & Laok anoed & Leak ahead \\
\hline $4-9$ & - & - & - & - & - & - & - \\
\hline $\begin{array}{l}10-12 \\
13-15\end{array}$ & \}ORG ANR & \}ANR & $\begin{array}{l}- \\
-\end{array}$ & fANR (A) & \} ANR (A) & $\operatorname{ANR}(A)$ & \}AWR (A) \\
\hline $\begin{array}{l}16-18 \\
\mid 9-21\end{array}$ & \} TAR. ANR & - & - & $\int A M R(B)$ & \} ANR (B) & $\int A N R(B)$ & ANR (B) \\
\hline $22-24$ & - & - & Bond type & Bond type & - & Dond iver & - \\
\hline $25-30$ & $D$ min $(A)$ & Weicht & - & $D \min (A)$ & $D \min (A)$ & $D \min (A)$ & $D$ min (A) \\
\hline $31-36$ & $D \max (A)$ & - & - & $D \max (A)$ & $D$ max (A) & $D \operatorname{mon}(A)$ & $D \max (A)$ \\
\hline $37-42$ & - & - & Bond radius (A) & Bond radius (A) & - & Band redius $(A)$ & - \\
\hline $\begin{array}{l}43-48 \\
49-54\end{array}$ & $\begin{array}{l}- \\
-\end{array}$ & - & $\begin{array}{l}\text { Porapective label hal. (in.) } \\
\text { Perpendicular diepl. (in.) }\end{array}$ & $\begin{array}{l}\text { Permpective label hat. (in.) } \\
\text { Perpendiculer diepl. (in.) }\end{array}$ & - & \} ANR (P) & $\int A N R(P)$ \\
\hline $35-60$ & - & - & Nonperspeclive Iabel hal. (in.) & Nonperapective Iabol hal. (in.) & - & $D_{0} \min (A)$ & $D_{p} \min (A)$ \\
\hline $61-66$ & - & - & Perpondirular diepl. (in.) & Porpendiculer displ. (in.) & - & $D_{D} \operatorname{man}(A)$ & $D_{0} \operatorname{men}(A)$ \\
\hline $67-72$ & - & - & Digits indicetor & Digilly indicelor & - & - & - \\
\hline
\end{tabular}


1-72 Up 1072 digits of alphanumeric label information centered about columas 36 and 37. Note: There is no "look abead" coluan in Formot No. 3; the next cand wust be 2 new instnction cand. Instructions 902, 903, and 913 are the oniy ones which require this input. It mar be used with other instructions as a device to iransfer comments about the particular instruction to the monitor output listing.

3.3.2 Snweture Amalysis lnstwetions (100 Series). - This series of insinctions is not connected with drowing illustrotions. It is used to obtain on the standard output medium of the computer a conveaient tabubtion of the chemically interestint aspects of a crystal stmcture, such as interatomic cistances, interatomic angles, and principal axes of thermal motion.

3.3.2.1 Inxtrutrions 101 and 102. - These instructions call subcoutine SEARCH. which finds all "target" a'ons within a sphere of eaclosure of edius D wax about a particular "orizin" atom. The instrection card has an atom designator run (see 3.1.3) of origin atoms (Ore. ADR) aad an atom number nu of tarzet atoms (Tar. ANR). The Or. ADR allows one to calculate setreral spheres successively with a printout of results after each cne. For example, suppoce there are nine atoms in the inpul list and we want the total surroundings of atoms 365502, 465502, and 565502 out to a maximum radius, D max, of 4 A. The Or. ADR is designated (365502, 5) or (365502, 565502) $)^{*}$ and the Tar. ANR is desipated (1,9). Further seleciion of the intertomic vectors from a particular origin atom to the target atoms which fall within the limiting sphere is possible with vector search code (VSC) cards of Format No. 2 (see 3.3.1), which can be entered with the instruction. If VSC cards are present, then the vectors must also satisfy one of the VSC's in ordet to be saved. A VSC card to specify the sclection of a shell $x$ vectors in the above example might be coded as follnws: Or. ADR (3,5) Tar. ANR (1,9) Dist. range (2.0, 2.7). More selective VSC's are also possible. They are meant to be based on known interalomic distance ranges, such as those tabulated in Vol. III of the Intcrmotioniol Tiubles for $X$-Rily Crystallography."

Vectors found about a panticular origin alom are stored in a toble of dimension 200 sort . $t$ un distance. Duplicate vectors (not duplicate distances) are eliminated. If more than 200 acceptable atoms are found about an origin atom, the $\mathbf{2 0 0}$ shortest vectors are saved. At the end of the search about each origin atom, the distances are printed out along with the atom designator codes (ADC), chemical symtols, and triclinic crystal coordinotes for the origin and target atoms. If the instruction is 102, all possible interatomic angles and interatomic distances for the edges opposite the angles are also calculated and printed for the stored vectors. There will be $n(n-1) / 2$ angles for $n$ vectors.

'For the origin sequence 355501, 455501, 555501, on Ort. ADR inpust $(3,5)$ is allowed os well as $(355501,5)$ and (355501,555501 $x$ however, the Tor. ANR must olways be designated as shown. in sect. 2.1, Cre. ADR is des iglated as ORG 1, ORG 2; and Tar. ANR is denoted by TAR 1, TAR 2. A minus sien preceeding the second member of the Ore. ADR is nol required.

"H. Ondik and D. Smith, "Interatomic Distances in Inorgonic Compounds," p. 257 in Intemational Tablex lor X-kay Crysiallo graphy, vol. IIf, ed. by K. Lonsdale, Kynoch, Burmingham, 1962. 


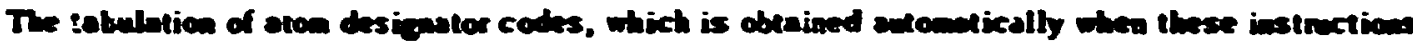

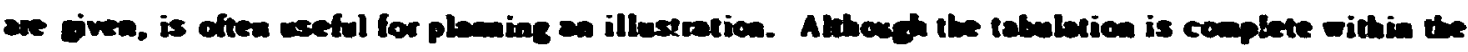

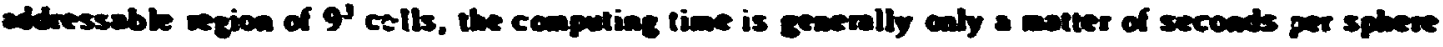

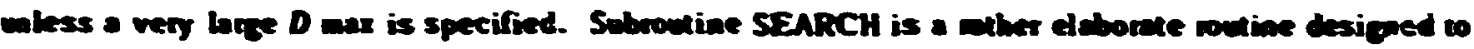

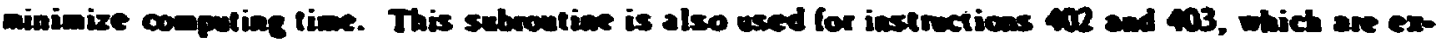
plained in 3.3.5.

Eastruction card for instructions 101 and 102:

Colemas:

\begin{tabular}{|c|c|}
\hline $1-3$ & 0 or 2 (bolk alnead) \\
\hline $4-9$ & 101 or 102 \\
\hline $\begin{array}{l}10-18 \\
19-27\end{array}$ & 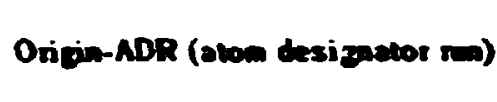 \\
\hline $\begin{array}{l}27-36 \\
37-45\end{array}$ & Target ANR (atom maber $\mathrm{nm}$ ) \\
\hline $46-54$ & $D \operatorname{anc}(A)$ \\
\hline
\end{tabular}

3.3.2.2 Instruction 103. - Principal axes of therimal motion (or arbitrany spheres, according to the temperature factor inper) for all atoms in the input list are calculated. The priatout contains root-meansquare amplitedes of displacement alone the principol axes of the trivariate nonal probability density function and direction cosines for the principal axes nelative to the reference Canesian bese vectors. A symetric covariance dispersion matrix based on the reference Cantesian system is also printed out. The diagonal elewents are the mean-squore displacements along the reference Cartesian axes.

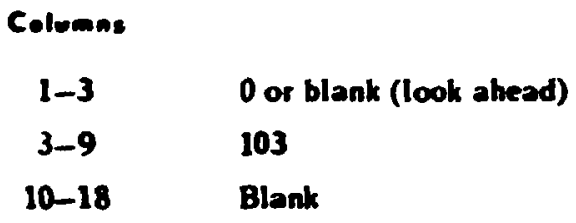

3.3.2.3 Instructions 105 and 106, Cowoluting Sphere of Enclosure and Reiterative Comoluting Sphere of Enclosure. - These instructions utilize the ATOuS table and can only be used after one or more atoms have been placed in the table by a 401, 402, 103, or 404 instruction. The contents of the toble are retumed to the condition of entry at the conclusion of instructions 105 and 106.

All atoms in the ATOuS table which have atsm numbers within the origin atom number nun (Org. ANR) of the instruction are used as origin points. Interatomic distances for all neighboring atoms (whether or not in the ATOMS toble) are found out to the specified radius. Vectos-search-code (VSC) cards moy be used for screening if desired.

Instructions 105 and 106 are similer, except thet instruction 106 keeps repeoting the "convolution" process until no new atoms with atom numbers within the Org. ANR are found. 
lastruction 106 is useful for molecular structures where the atoms in the ingut asymetric wait do not form an intact molecule. In a case of this antare, it is advisable to place a single atoo iato the ATOMS table with a 401 iastruction and let a 106 iastruction find the molectele. Care wust be taken to specify a D wax which will eaclose caly bonded atoms. The 106 instruction should mot be used for structures formine infinite chains.

Columes

\begin{tabular}{|c|c|}
\hline $1-3$ & 0 or 2 (look alead) \\
\hline $4-9$ & 105 or 106 \\
\hline $\begin{array}{l}10-18 \\
19-27\end{array}$ & Oriein ANR (atom number run) \\
\hline $20-36$ & Taret ANR (atom number run) \\
\hline $37-45$ & \\
\hline $46-54$ & $D \max (A)$ \\
\hline
\end{tabular}

3.3.3 Plomer Compl lastrectiens (200 Sevies). - The 200 series is a group of instructions that control the plotter initialization, frame advance, termination, and any other peripheral cummands that are $x$ quired for a particular equipment configuration or plotting package. When the program is modified for a different equipaent configuration, these series 200 instructions, which are executed through subroutine F200. should be redefined to sait the user's requirements. Instructions for cont rolliag the CalComp 765 and 835 off-line magnetic tape plotting systems" are given here.

3.3.3.1 Instruction 20I. Plot Packafe Inirialization. Mechanical Plotter. - This instruction (or a 203 instruction) must be executed before any plotting can take place. It is a safe policy al ways to make this the first instruction card. It should be used only once per computer job regandless of how many plots are to be drown during the job. If the 201 (203) and 301 instructions are omitted. all calcular tions are carried out but no plotting is done.

3.3.3.2 Instruction 2\%2, Plot Terminate and Fraber Adtance. - This takes care of putting the correct plot temination information onto the magnetic tape 10 inform the plotter that the current plot is finished. It also allows advance of the paper so that the old plot is removed and new papet is in pasition for the next plot.

$\begin{array}{ccc}\text { Columns } & \text { Instruction 201 } & \text { Instruction } 202 \\ 1-3 & \text { Blank } & \text { Blank } \\ 4-9 & 201 & 202 \\ 10-18 & - & \text { Plotter wovement along } x \\ & \text { edse of poper in inches }\end{array}$

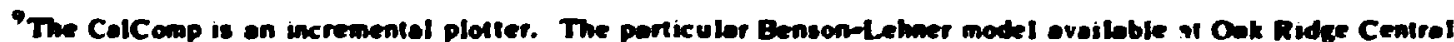

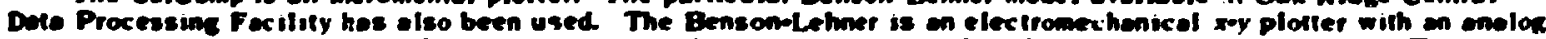
converter. in general it seems that en iacremental ploter is better sujted to the requirement of OA TEP. The user showld be womed thot in the wuthore experience the megnetic tepe ploting systems are noteriously troublesome; en

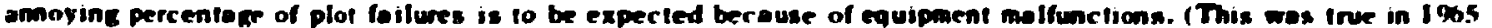
and is still irue in 1975.$)$
} 


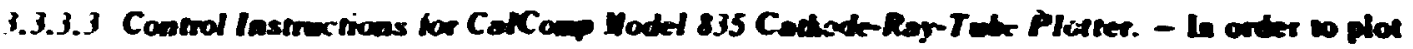

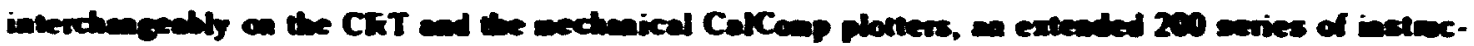
lions is necerengs.

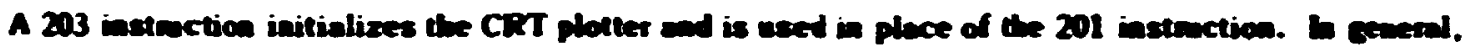

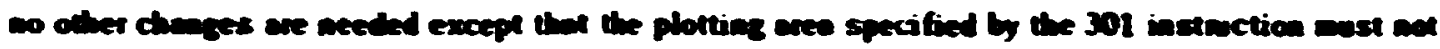
exceed 15 in. in 5 and 11 in. in $y$. (The 301 primet consteats are set accoedindy.)

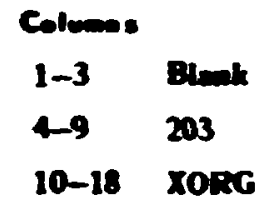

10-18 XORG (new position of the origin of plonet coondiantes reletive to the lower leththad

19-27 Yorkg coset of the nownel CRT ploting ence)

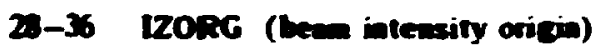

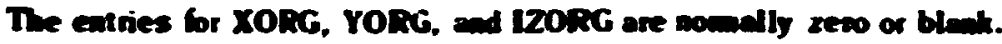

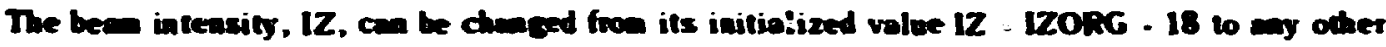

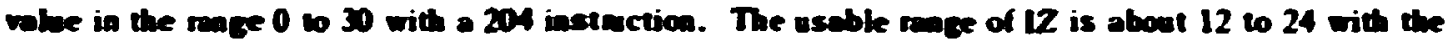
hidet voles producing dater lines.

$$
\begin{array}{ll}
\text { Colenas } & \\
1-3 & \text { Blank } \\
4-9 & 204 \\
10-18 & 12-120156
\end{array}
$$

The frane advance instaction 202 is iaterpreted differently for CRT usage; however, the some 202 instruction cands used for a mectusaicol plotter plot can also be us d for a CRT plot. Any positive cumbet in colmans 10 to 18 of she 202 instnuction (3.3.3.2) will add a block address (i.e., plot anber) to the mogeretic tope and will odvence the film to a new frome. A value of zevo in colmas 10 to 18 will add a block address but will not adveace the film to a new frime, and a netalive value will temisate

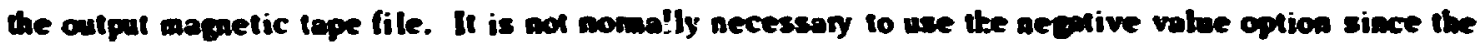

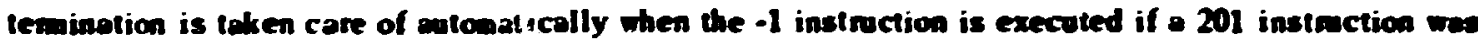
not executed after the 203 initializetion instuction; howevet, if the mechoaicel plotter is to be wed dring the sane job, the negptive value option ollows the CXT to be temianted property before initialization of the mechanical plotter.

3.3.4 Plet Lowbry lastructiems (300 Sories). - This is a set of miscellaneous instructions for specifying the dimensions of the druwing, viewing distance, generol lettering orientotion, and pen displecement for line retracing.

3.3.4.1 Instrurvion .30I. - This instructiun defines the limiting $x$ and $y$ dimensions, in inches, of the plot boundory and the bonder indentations. The boundary dianensions must not exceed those allowed by the plotter. The program will prevent the pen from getling closer than 0.1 in. to any bouadary. The border indentation is an equal margin insids :he entire boundary. When automatic scaling is wed (600 series), the center points of the atoms are prevented from folliag in the wortin; but the aton represen- 


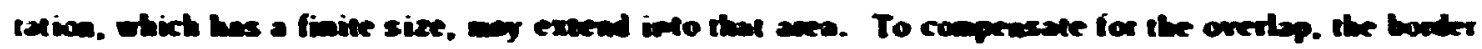

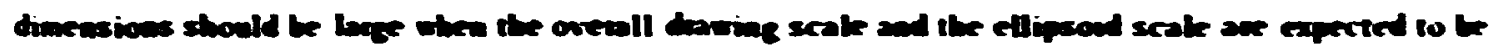
Inter.

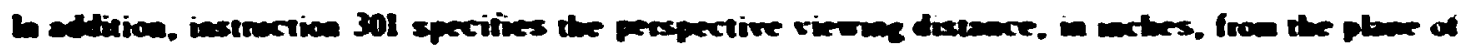

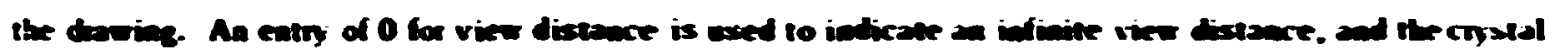

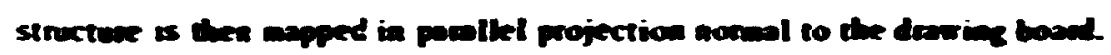

\begin{tabular}{|c|c|c|}
\hline Colon: & & Primer Cemenese \\
\hline $1-3$ & - & - \\
\hline $4-9$ & 301 & - \\
\hline $10-18$ & Plat x Itis (in iverlas) & $\because:$ \\
\hline $19-27$ & 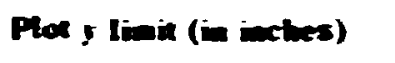 & 11. \\
\hline $2-35$ & Vien distence (in inctirs) & a. (pallel proj.) \\
\hline $37-45$ & Banker (in incthes) & 0.5 \\
\hline
\end{tabular}

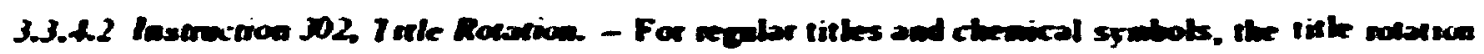

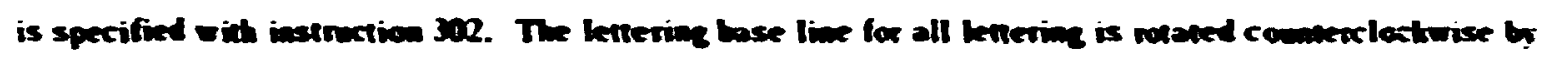

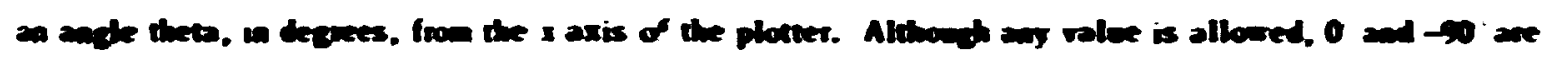

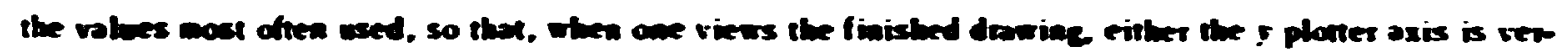
tical or the a plotier axis is renical.

\begin{tabular}{|c|c|c|}
\hline Colvons: & & Primer Comerest \\
\hline $1-3$ & Bloak & - \\
\hline 4-9 & 302 & - \\
\hline $10-18$ & Thet in depees & o. \\
\hline
\end{tabular}

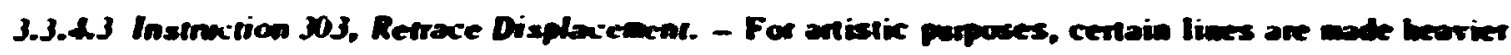

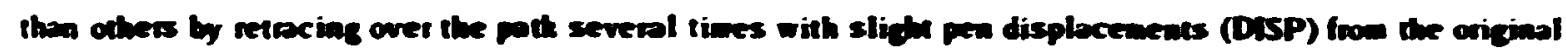

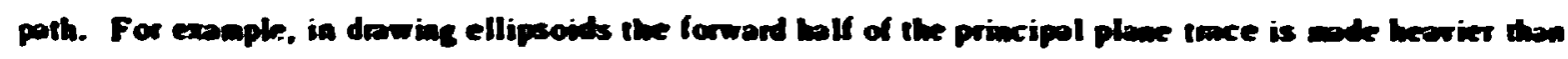

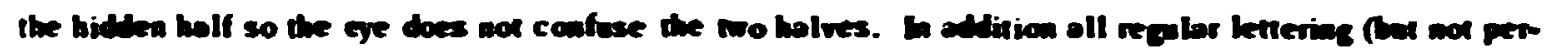

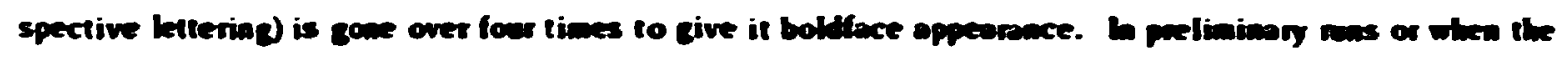
plotet is not of the incrementel iype, this embellishment moy be objectionable to the wer becase of the

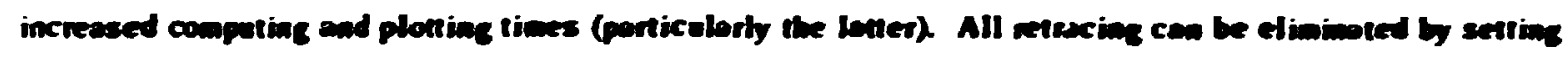

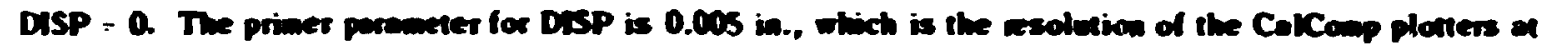
ORvl. For other plotters or for venous inking pen staes. DISP can be reset of the asei's discretica.

Retrociag should not be used with a CRT plotting device.

$\begin{array}{lll}\text { Colomas } & & \text { Primer Consoent } \\ 1-3 & - & - \\ 4-9 & 303 & - \\ 10-18 & \text { DSSP (in inclues) } & 0.005\end{array}$




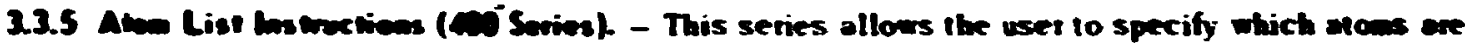
to be iacloded in the illustration. The aton desigantors for the chosen otops are stored in the ATOMS

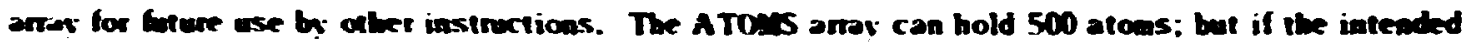
illustrition bas wove than this. the illustrotion can be seguented and the segmeats drown segnentiolly con the some plot.

Croups of atoms are suled to or eliminated from the ATOuS azay (which is set to zero et the stan of the progera) with the 400 and 410 series respectively. The groups can be denoted by atom desipalot tuss (see 3.1.3). spberes of atoms about any center point (see 3.1.6), and boues of atcoss cemtened on env poin! (sec 3.1.7). Deplicate atries of the same atomic position are prevented by the propros. The content of the ATOMS list is priated on the monitor output tope after each 100 series ine strextion.

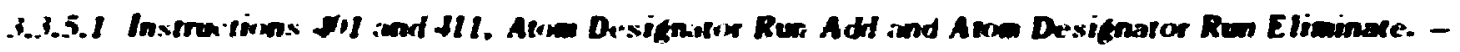
These instuctions cea contain: (a) atom designatot codes (ADC) for a siagle otom, (b) atom desigetor nos (ADR) for several stoms in a run. (c) blank fields (except between the iwo emtries of a ma), and (d) ans combinations of (a). (b). and (a). Since up to 19 Format No. 1 continuations are possible per iastruction, up to TO ruas can be made pe: iasinuction and an unliated muber of iastauctions can be used. The ATOSS Iist, however, will only accept the first 500 toms.

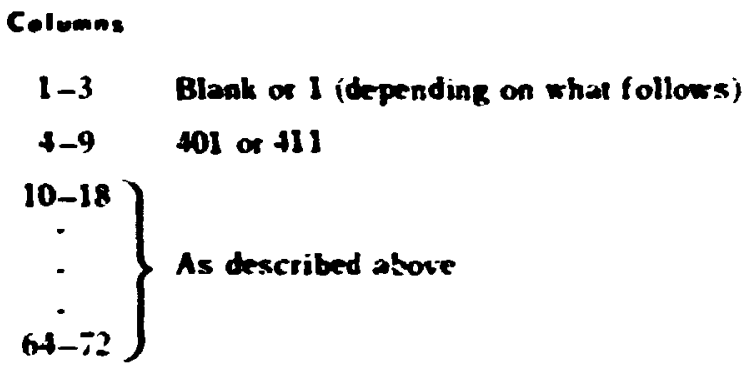

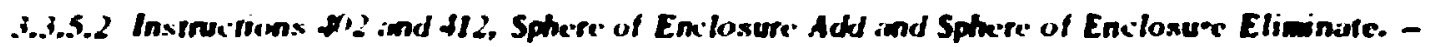
These unstuctions allow the usort to build or modify the subject iy specifying the contents (complete, portiol. or vector screened, see 3.1.6) of a sphere of enclosure about any addressoble poiat. For iastruction 402, the contents of the spheres are added to the atom list excep for positional duplications, which are caitted. In the $\mathbf{1 1 2}$ instructions. all points in the spheres are clibinitrd from the atows list if thet are present in that list. The instructions call subroutine SEARCH, and the instruction input deleils are identixal to those of instructsons 101 and 102 (see 3.3.2.1) excep for the instruction numbet. In the monition output, only. the ATOahs list dtom designator codes are printed and nut the coordinates and iateratomic distances. If the origin atoms on which the spheres of enclosure are centered are to be saved, the tarket atom number run (Tar. AXR) must contain this atom number. Furthermore, if vecior seonch cole carts of Fomat dio. 2 are used, one of them must satisfy the intrabtom aull vector for the origin atom in onder to retoin it. 


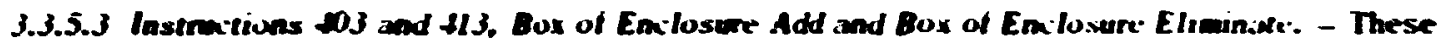
instructions allow the user to build or modify the subject by specifyiag the conteats (complete or partial bat not vector sctwened, see 3.1.7) of a bou of enclosine about any adbessable point (or atom desigator ter of addessable poiats). The three axes of the bor are parallel to the three bose vectors of the refereace Cartesian system, and the setwidimensions of the box are specified on the instruction iard. If an crientation of the box different from the standord otientation (see 3.1.8) is desiced, than a 501 or a 502 instnction, of both, should be used before his instmction to reorien the reference Cartesian system. Aftet this instmction has been eru cuted, the refenence system can undergo furthet reorientation as d:sired for ploting pupposes, etc.

As in the case of the sphere of exclosure (see 3.3.5.2). the origin atom on which the box is centered will pot be included unless the target atom moder ran includes the origia dion number. Vector search codes ane not ased by this instnection. Sobmonine SEARCH is used by this instruction, and the instruction ia pet details ar siailar to thoce described in 3.3 .2 .1 except that $D$ max is replaced by the semidiacusion a:2 of the bou and the followine fields on the cand are used to specify the other two setaidimensions b 2 anci2. One mest use cantion in choosing the box dibensions so that the atom table does not overtlom.

$$
\begin{aligned}
& \text { Columos } \\
& \text { 1-3 Blank } \\
& \text { 6-9 } \quad 103(\text { or 413) } \\
& \text { 19-18 } 1 \text {-27 Origin ADR (see 3.3.2.1) } \\
& \left.\begin{array}{l}
28-36 \\
37-45
\end{array}\right\} \text { Target ANR (see 3.3.2.1) } \\
& \text { 46-54 a/2 (A) } \\
& \text { 55-63 b!2(A) } \\
& 64-72 \quad-12(A)
\end{aligned}
$$

3.3.5.t Instructions the and 14 , Triclinic ilox of Enclosure Add and Triclinic Box of Em-losure Elimiane. - These iastructions are similar to isstnctions 403 and 413, except that the iricliaic box of

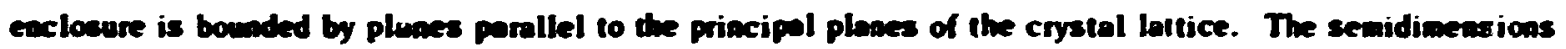
a/2, b/2, c/2 refer to frectional (triclinic) coordiades. To specify the contents of the conventionol ani: cell, one would use $a / 2=b / 2-c / 2-.5$, and the Ore ADR woold reter to a point in the input atom list at 1/2. 1/2, $\$ 1 / 2$.

3.3.5.5 Instructiona 05, \$05, 415, 416; Convolutins Salvere of Enclosure Add, Reiresative Comolut-

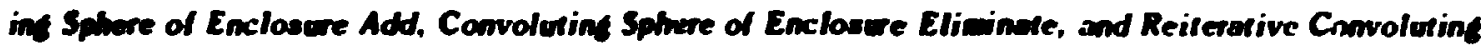
Sphere of Enclosere Eliwinate. - These instructions one used is the same wownet as instructions 105 and

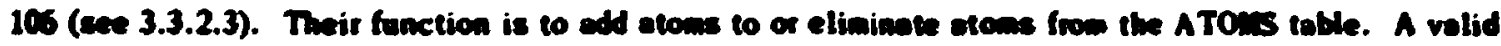
origin stom must be pleced in the ATOus list with a 401, 402, 403, or 404 instruction before the present instnctions are used. All atcons in the ATOMS toble which hove otom numbers within the origin atom nember run (Ore. ANR) of the instruction ore used as origin points of convolution. 
An inportant use for the 405 instuction is 20 complete the coodination shells around wetal atoms vitbout haviag to describe any of the atoms individbatisy. Another we might be to obtaia a cluster of

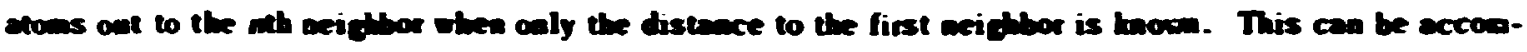

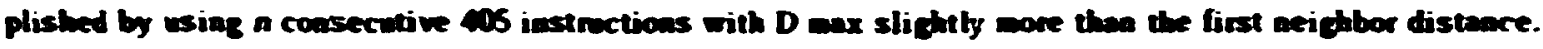

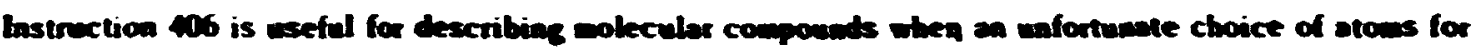

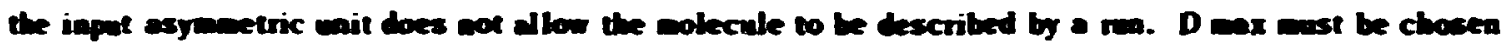
judiciomsly so thet the seach does not croses molecular ionabries.

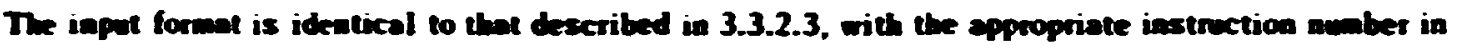
colmeness i-9.

3.1.5.6 Option for Examining E-1/ap Resul's - Stereoscopic drawiags are eseful for the

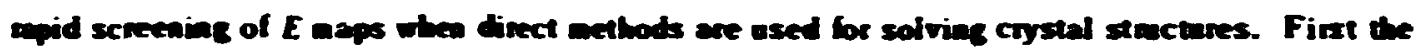

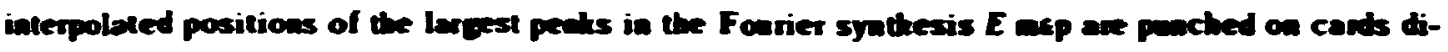

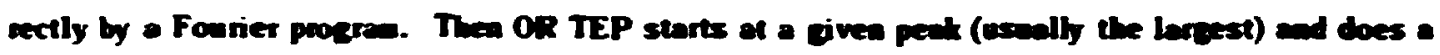

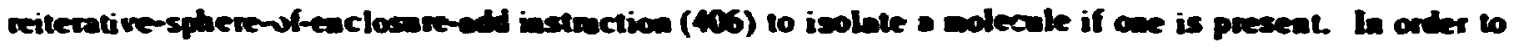

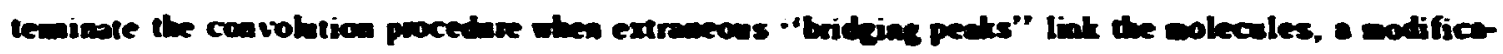
tion was asted to the 40 instuction which allows an etom (in any of its equiveleat positions) to be entered in the ATOuS list caly cace. To invole this feoture, a type 1 contimation cand (3.3.1.2) with

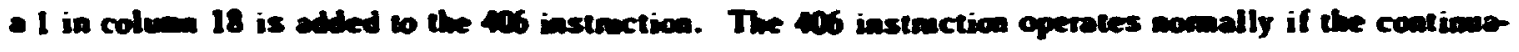
tion cand is coitted (3.3.5.5,

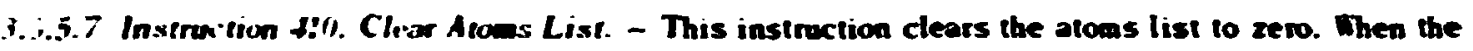
program is first eatered. the list is automatically set to zero.

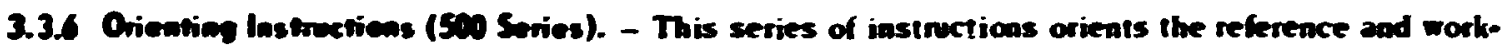
ing Cartesian systems (see 3.1.8). Each time the reference system is redefined with a 501 or rotacd with a 502. the wotking system is aotomatically made coincideat with the reference system. The working sysrew can be dsploced from the reference systea by rotatiag about an axis of the neference system with a 503 instruction. The wosking system is always positioned by a ropation from the refereace system and does not depend on the previous working system orientation. After each 500 seties instruction, the base vectors of the relevant Cuntesian system are printed out. These vectors are based on the triclinic coordinate syste an. The postifacto transfonation matrix for converting from triclinic coordinates to Catesian coordinates is also printed out. The inverse tmasfosmation matrix moy be fomed by placing the three bose vectors together in row vertor form.

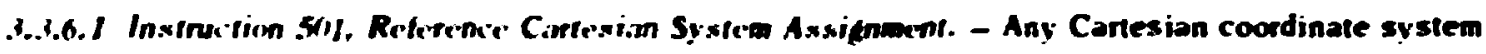
is bused on three onhonomal bese vectors and an ostigin point. The origin potat in the model (ORGN) is specified with an atom dexignator code. The three onhonormal base vectors con be described by twc aorcollinear vectors, and OR TEP provides the two following separate kechniques for performing this operi tion, using vector cross products of the two vectors 0 and $v$. 


\begin{tabular}{|c|c|c|}
\hline & Tren a & Tree 8 \\
\hline Bose vector I (x axis) & $\bullet$ & $\bullet$ \\
\hline Base vector 2 (y axis) & $\bullet \cdot \nabla$ & $(\omega \cdot-) \cdot \omega$ \\
\hline Base vector 3 ( 2 axis) & $\cdot(0 \cdot v)$ & $\bullet \cdot \bullet$ \\
\hline
\end{tabular}

The reference system $x$ and $y$ axes -ill porallel the plotter $x$ and $y$ axes, ard the origin point Mixis will lie in the plane of the plotter. The viewer will be looking into the $z$ axis vecta $;$ of the courdinate suster: from a distance VIEW in inches (see 3.3.4.1) dixectly above the otigin point.

$$
\text { Colonos }
$$

$$
\text { 1-3 }
$$$$
\text { 6-9 }
$$$$
10-18
$$$$
\text { 19-27 }
$$$$
\text { 28-36 }
$$$$
37-45 \text { ) }
$$$$
\text { 46-54 }
$$$$
55-63
$$

64-72
501

Oripin (ADC)

Vector $-(V D C)$

Vector $\nabla($ VDC $)$

0 = Type A, $>0$ = Type $B$
Zuetive

Primer Consone

00000

155501

165501

155501

156501

$I$

3.3.6.2 Instruction 502, Reterence Cartesian Sysfem Rotation. - The crystal model can be given any orientation desired with a series of rotations of the model about the neference system axes. In general. thre rototions (e.e., those of an Eulerian system) are sufficieat to achieve aay orientation. but for convenience an unliaited aunber of rotations are permitted in the program. In addirion, rotations of 120 ' about the body diagonal of the reference Cartesian system are perwited (this is achieved by a cyclic permutation of reference bse sectors).

Each operation requires two fields in the instruction card. For axial rotations, the fust fieit of each poir will huv: the number 1,2 , or 3 to indicate rototion about the $x, y, 0$ axes of the referem: system. The second field will have the rotation agle in degrees for a righthanded rotation of the model tbout the designated axis (i.e., o positive angle signifies a countexclockwise pototion of the structure wish the desigated axis pointiag toword the reader). The body diogonal rototion is designoted by either a (-. 1) or a $(-2)$ in the first field to indicate $120^{\circ}$ or a $240^{\circ}$ rifhthanded rotation about the body diagomal, ind the second field is blonk. A (-3) would rotote de structure completely oround and thus not chorege its previous orientotion. 


\begin{tabular}{|c|c|}
\hline \multicolumn{2}{|l|}{ Colomas } \\
\hline \multicolumn{2}{|r|}{ Firse Cord } \\
\hline $1-3$ & 0 (or 1 if contisued on wext cand) \\
\hline $4-9$ & 502 \\
\hline$|0-18|$ & $1,2,3,-1,-2$ \\
\hline $19-27\}$ & $0_{i}$ \\
\hline $28-36 !$ & $1.2 .3 .-1 .-2$ \\
\hline $37-45$ ? & $\delta_{2}$ \\
\hline $46-54$ ! & $1,2,3,-1,-2$ \\
\hline $55-63$ & $0_{j}$ \\
\hline $64-72$ & $1.2,3,-1,-2$ \\
\hline & secead Cord \\
\hline $10-18$ & $\dot{\phi}$ \\
\hline
\end{tabular}

If desined, eacl rototion con be executed with a seporate 502 anstouction card.

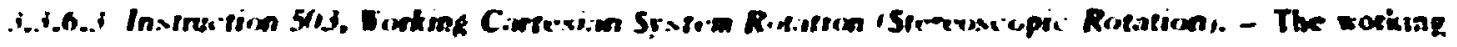

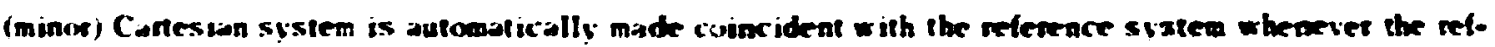
ereace system is redafined with a 501 instruction or rotated with a 502 iastruction. To defise an onentation of the working system which is aof coincident with the seference system we uxe a 503 instructson. which allows une rotation about one ixis of the refeneme system. Actuolly any number of successive notations cion be mide. Wut the effect is not cumulative sunce the stanting poiat for each gotation is always the reference system. Hody diagoal rototions uer not permitted.

A 503 rotation nomilly precedes exch member of a stereoscopic pait of plots. The totatios is about axis 2 if the stereo pait is to be viewed with the axis porollel to the obaener's interoxulat lue and about sxis 1 if the $y$ ixis is to be parallel to thit line.

$\begin{array}{cl}\text { Columns } & \\ 1-3 & - \\ 4-9 & 50.3 \\ 10-18 & 1.2 .3 \\ 19-27 & \ldots\end{array}$

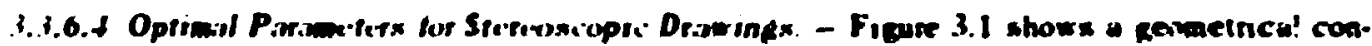
sinuction which an be used to denie the paraweters used in making sterexiscopic draw ings. "0 1:

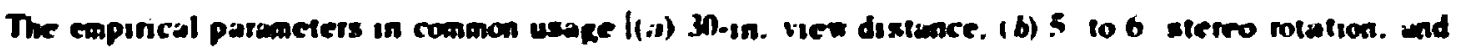

10.. T. Rule, S. Opl, Sor. Am. 20, j13 (1939).

"R. G. Smaders, Appl. Opd. 7, Itrou 19sel. 


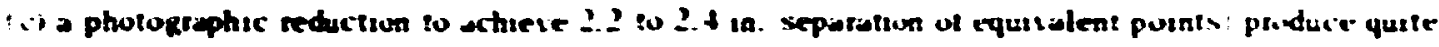

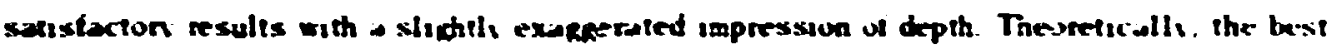

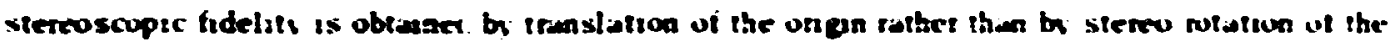

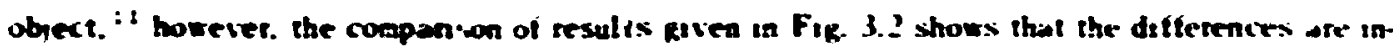

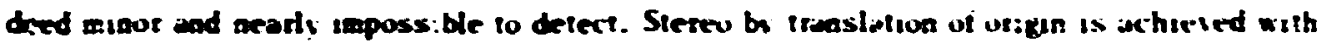

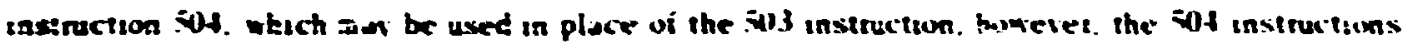

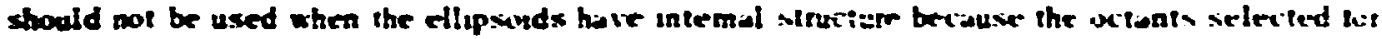
shading =st not be the sime on both sterev viens.

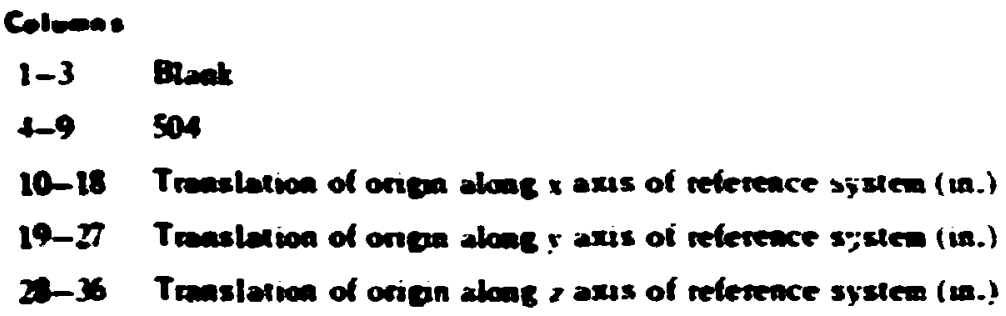

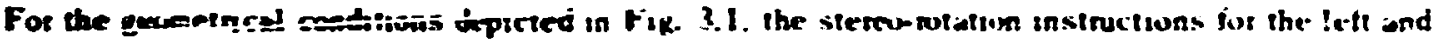
nat exts.

$\begin{array}{rrr}503 & 2 & 2.45 \\ 503 & 2 & -2.45 .\end{array}$

apleced by the ateneo iransletion wastractioas

sos -1.2300

and

5942.5600

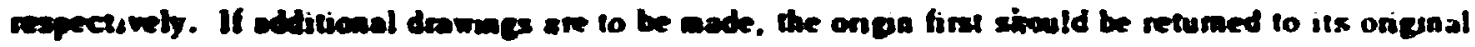
position with the iasterctica

$504-1.4000$.

in oxier lo provest confesican.

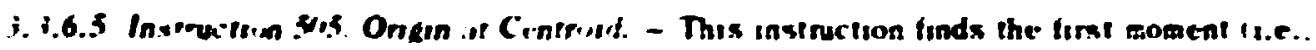

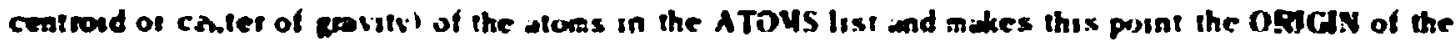

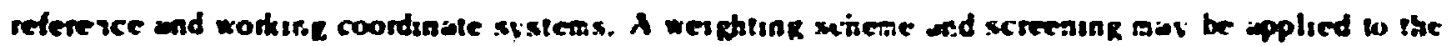

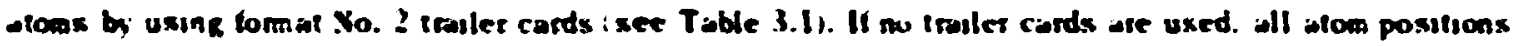
are eatered with uni? wetghts.

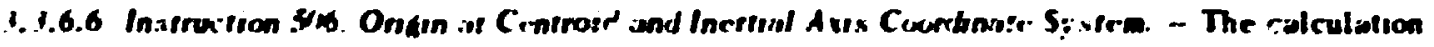

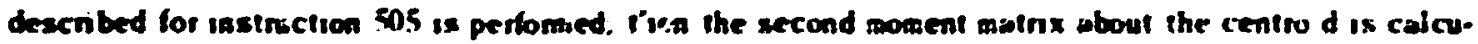
ided. and the relereace and woking coondinale systews ine set up wlong the principol axex of this mutrix.

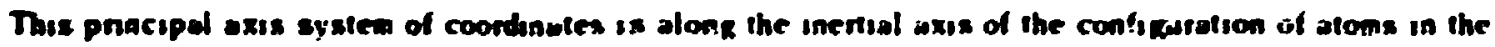

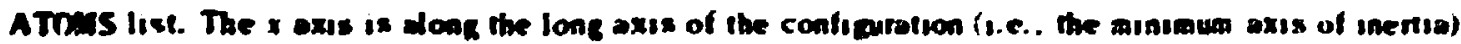
wad the $x$ axis is aloag the short axis of the coafigurdion (1.e. the maxumal axis of inertia). The overlap 
OAmL-OWG. G9-7541

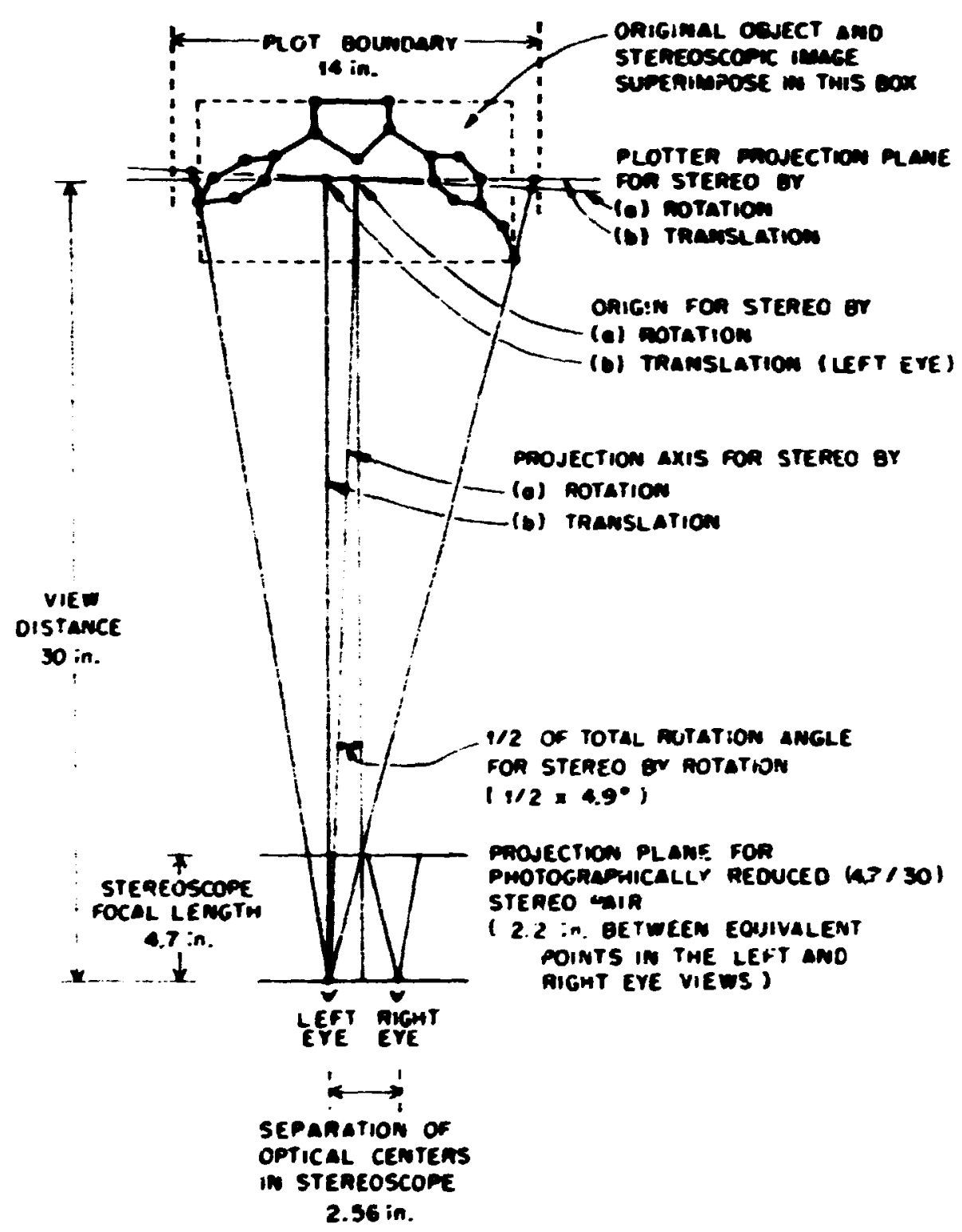

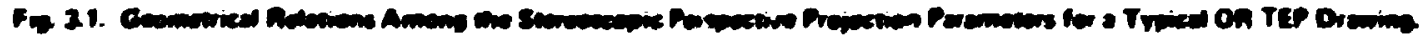

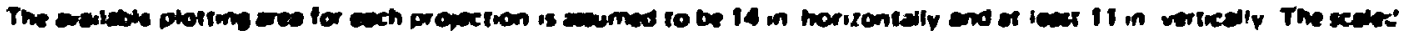

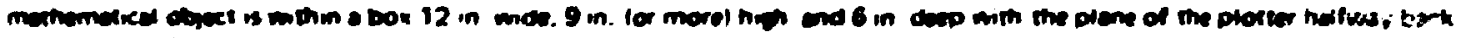

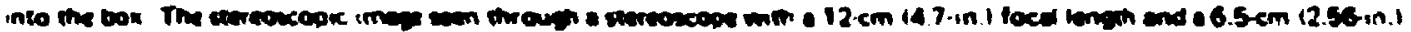

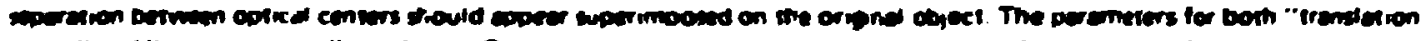

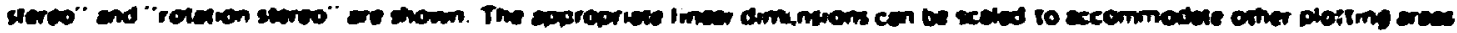

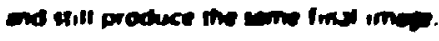


ORiit Sist. c9-812\%
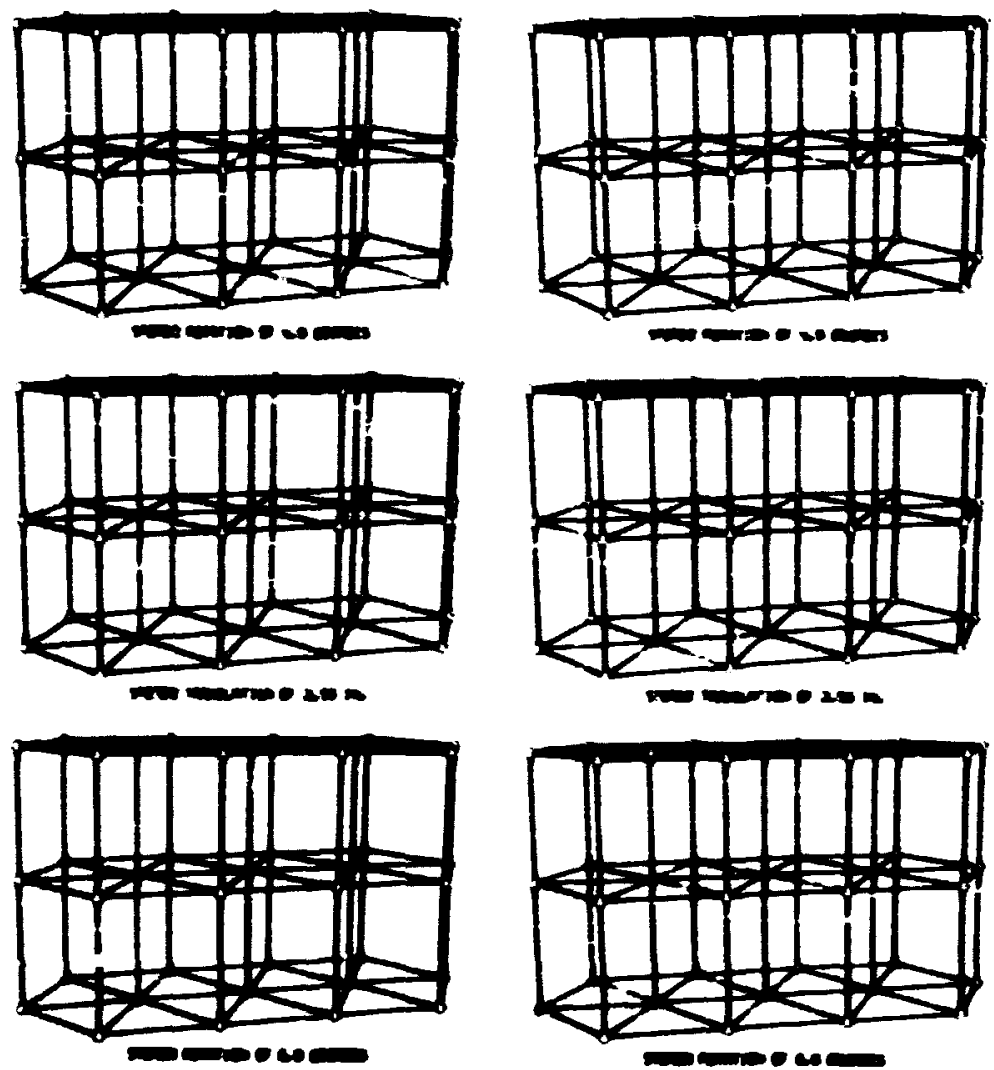

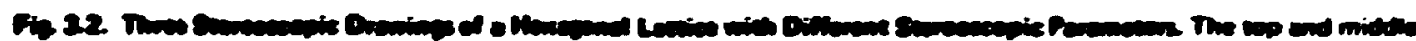

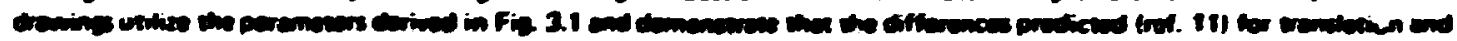

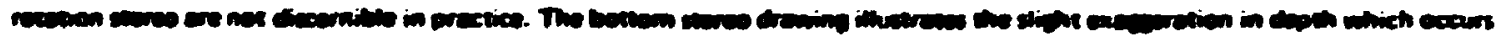

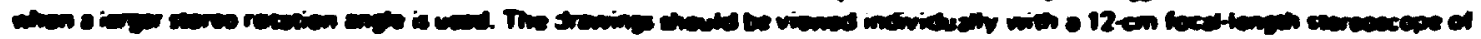

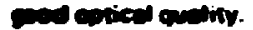

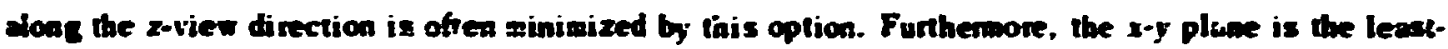
saperes best plece for the stomic configurotion. Foswat No. 2 troilet conds may be used to suply weights and screening (see Table 3.1).

3.3.6.7 Instrucion 51I. Overlap Elinination. - See Section 3.3.14.

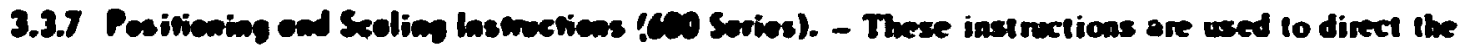

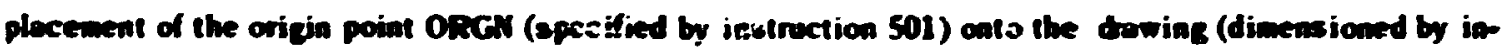
struction 301). In addition the threediancwional sacembly of ofoms (chosen by the 400 series instnuction) constituting the model is scoled. The gtomic centers of the model will then be aonciag in space obove and below the drowing boand converly positioned to be projected from the eye poial described with 301.

3.3.\%.I Nonal Iodes of Positioning and Scaling. - Severol normal nodes of operotion are available fo the user for positioning and scoling the model. Instruction 601 requires the wet to supply a canplete explicit description of position ( $\left.x_{0}, y_{0}\right)$ and scole (SCALI). At the othet extreme, instruction 604 outomotically sci. ies and positions the model so thot the peripherol projected otom centers will touch iwo 


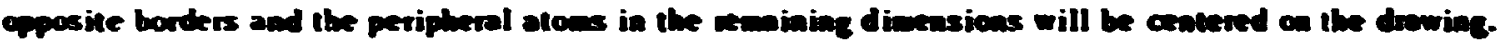

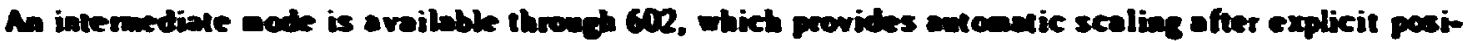

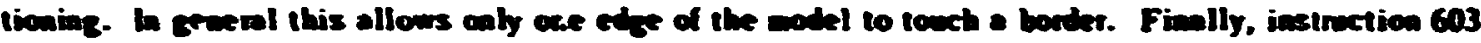
anuives an explicit scole ead bess antomatic centering.

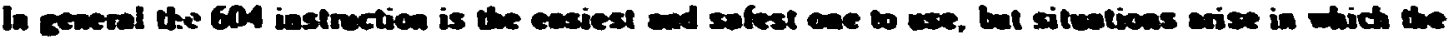

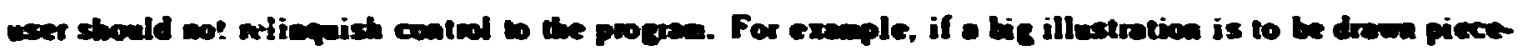

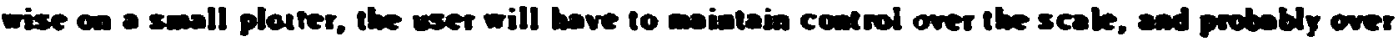
positicaiac so that the panisl plots can be fitted together correctly.

A second scale fertor SCAL2 is required in consection with the ellipsoid (or spiben) size. It is - dimensioaless scale factor atio used to modify all ms displeceneat values befone plottias equipabbility ellipsoids or spheres. A table of SCAL2 valees vs probsbility is given in Sect. 5.2 The primet constant lor SCAL2 is 1.54, corvespoediag to 505 probebility. If the iastretion's entry lor

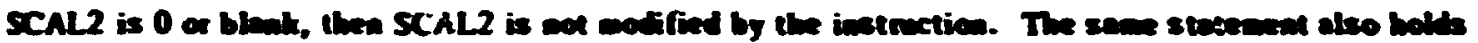

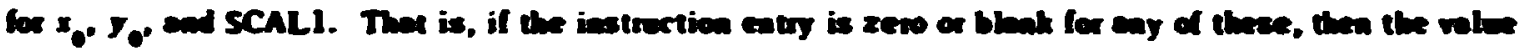

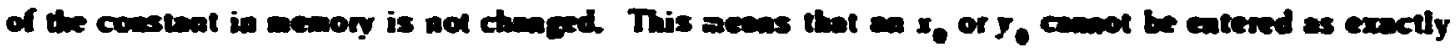

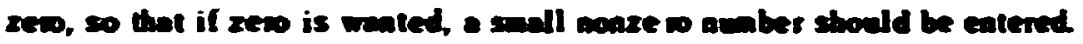

\begin{tabular}{|c|c|c|c|c|c|}
\hline Colvones & $\omega 1$ & $\omega 2$ & $\cos$ & $\mathbf{1 0 4}$ & Primer Cenevent \\
\hline $1-3$ & - & - & - & - & - \\
\hline $4-9$ & 601 & 602 & 603 & 601 & - \\
\hline $10-18$ & $x_{\bullet}$ & $x_{0}$ & - & - & 8.5 \\
\hline $19-27$ & $y_{0}$ & 5 & - & - & 5.5 \\
\hline $28-36$ & SCALI & - & SCALI & - & 1.0 \\
\hline $37-45$ & SCAL2 & ScAL2 & SCAL2 & SCAL2 & 1.54 \\
\hline
\end{tabular}

3.3.7.2 Incremental Modes of Posibioning ind Scaling. - Adtitional flexibility is provided throuch the incretaental iastructions 611, 612, and 613. These allow the uset to "andse" the molel or modify the scale factor (SCALI), or both, after the porameters have bera iaitially set with a previow 600 series in. struction. The 611 instnction adds $1 x_{0^{\circ}}$. I $y_{0}$ to the previous $x_{0^{*}} y_{0}$ position for the OxGy plecenent and multiplies the existing SCALI by $\mathbf{W}$ (except if $\mathrm{W}-0$, SCALI is unmodified). Instruction 612 increments the position and then does an automatic scoliag; 613 first increments he scale (by mu'tiplyias by $\mathbf{W}$ ) and then automatically repositions.

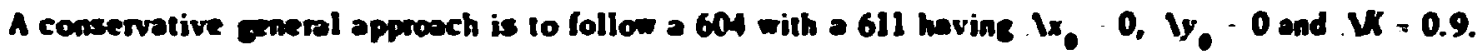
This will siaply reduce the scale $10 \%$ so that there is more spoce for bbels, ete. 


\begin{tabular}{|c|c|c|c|}
\hline Colone & 611 & 612 & 613 \\
\hline $1-3$ & - & - & - \\
\hline $4-9$ & 611 & 612 & 613 \\
\hline $10-18$ & $\mathbf{x}_{0}$ & $\mathbf{u}_{0}$ & - \\
\hline $19-27$ & 15 & 15 & - \\
\hline $20-36$ & $\mathbf{x}$ & - & $\mathbf{x}$ \\
\hline $37-15$ & SCAL2 & $\operatorname{scal} 2$ & SCAL \\
\hline
\end{tabular}

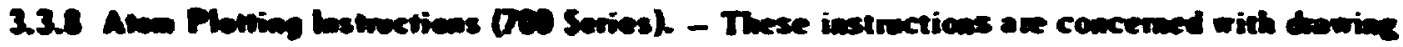

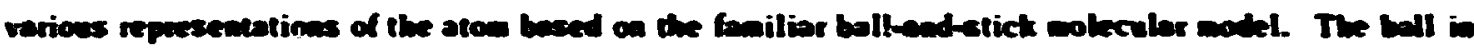

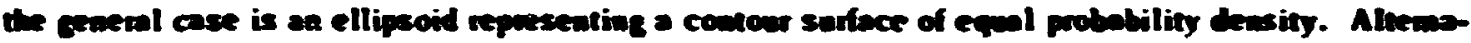

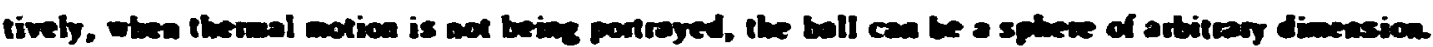

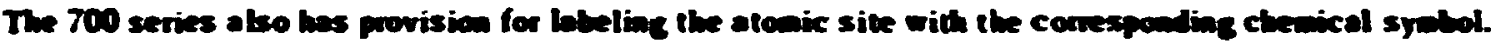

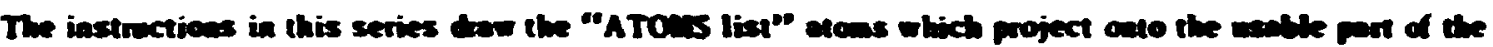

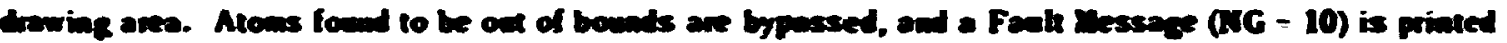

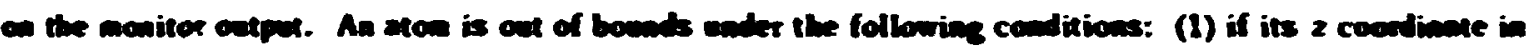

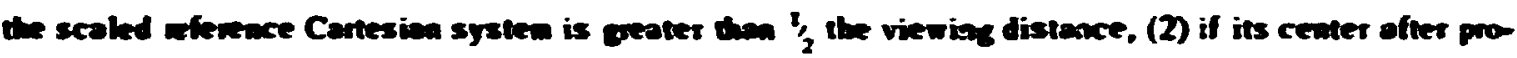

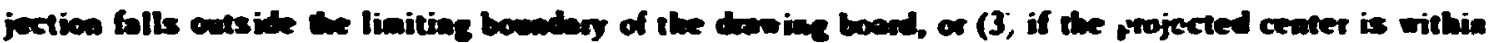
3. of the mergin with (BROR) of a liaitine boundory.

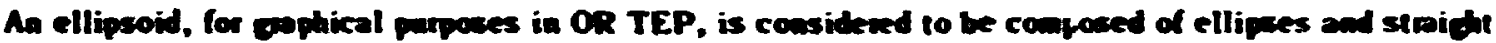
liwes. The ellipaes are of two iypes, priacipal ellipses and boundony ellipses. Debtive to the vienpoiat, - priacipal ellipare is forther sobdivided imto a froat balf and a back, or hidken, beif. There are troee

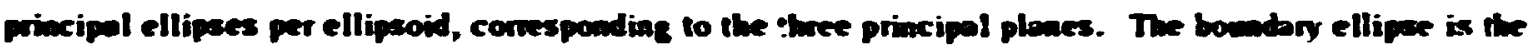

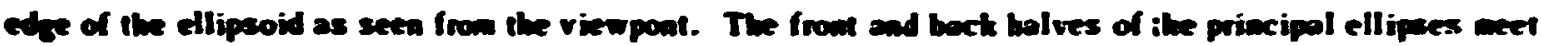

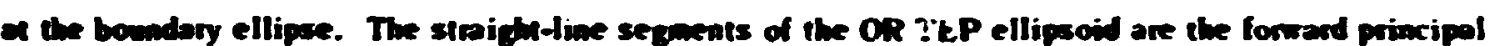
awes, weres principal axes, and acteat shadias liass.

Fiene 3.3 shows varions combiantions of these elenenta. It is obvions thet certain of these copr-

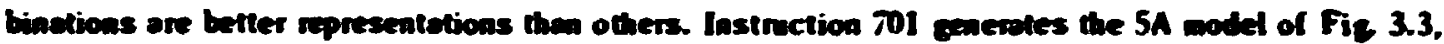

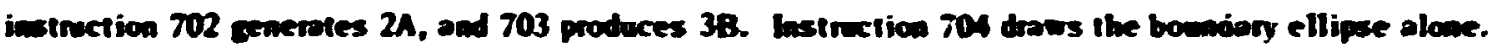

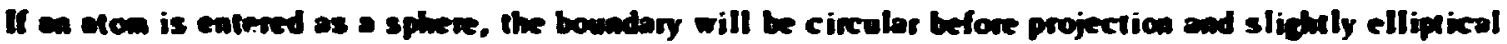
after perspective projertion. Instruction 705 allows the user to mabe up any representotion from the besic components.

Chemicel symbols op to six alphomanetic chorocters in leagh one incladed with the inpat sfoncturel

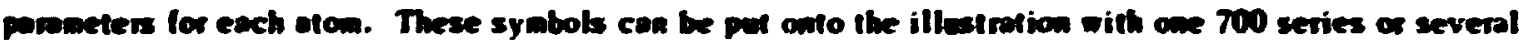
900 series instnctions. The 700 series pleces the center of the six-charecter field of each afom in the

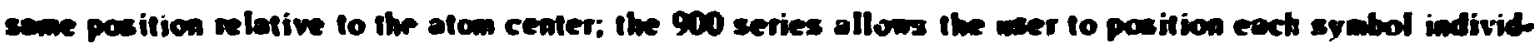

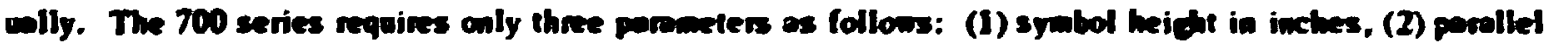
(keft-ight) offset in inches, and (3) perpendiculor (updown) offeet in inches. The porameters nefer ro the model before projection, and they will chenge slightly during perspective projection. ithe porallel and 
concencens

A.

\section{Without beck}

or reverse axes

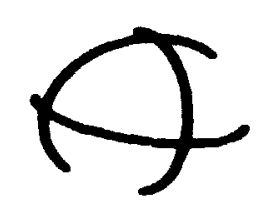

2. Principol and enveloping evipises

1. Principal ellipses

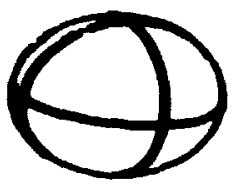

8.
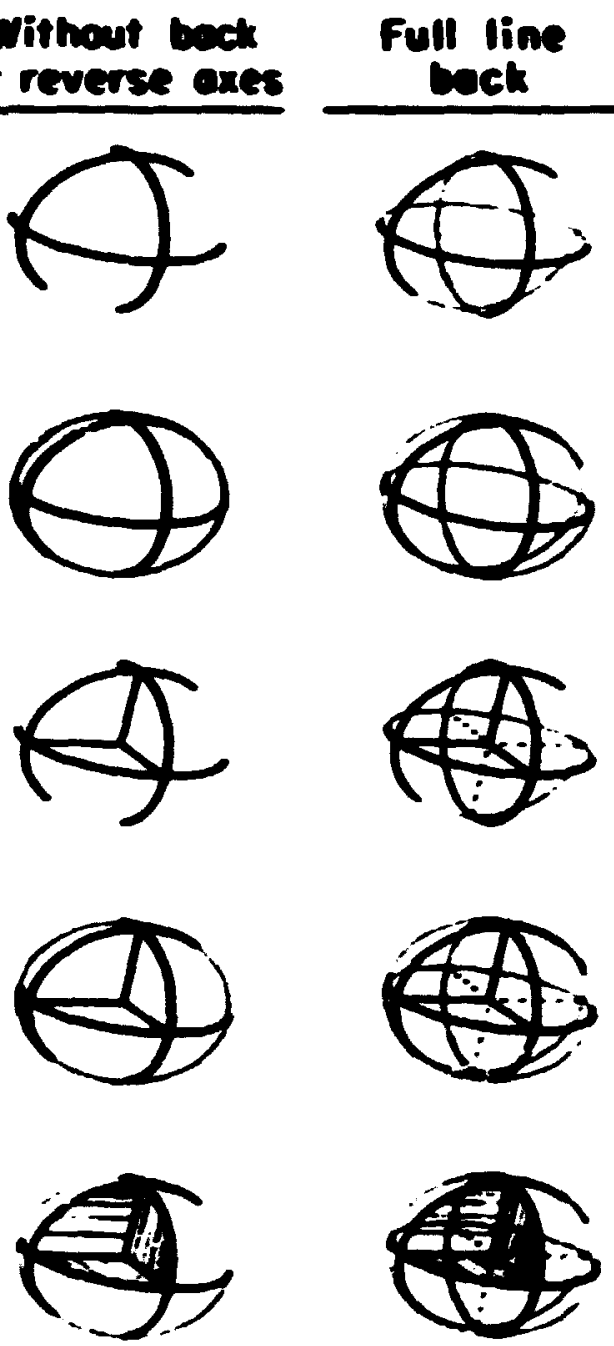

C.
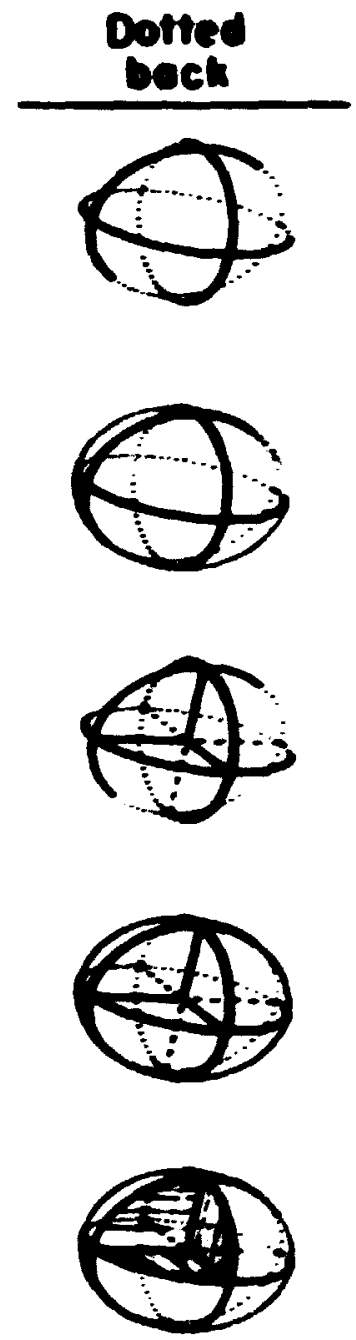

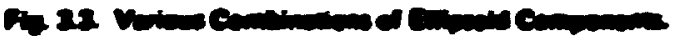

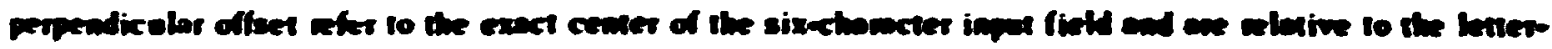

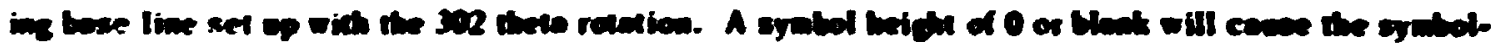

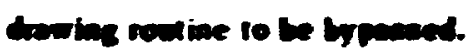

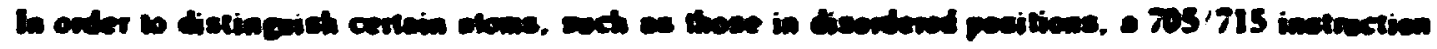

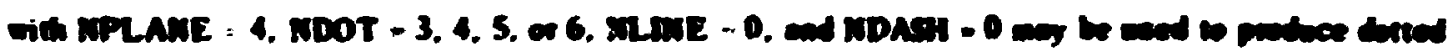

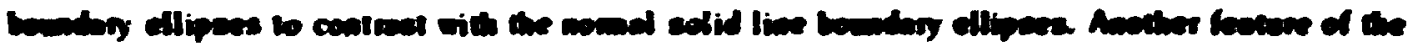

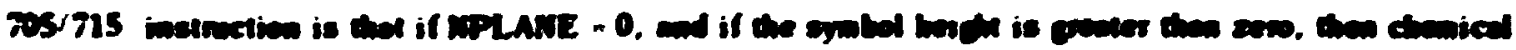

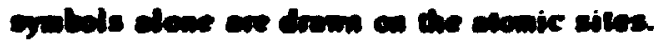




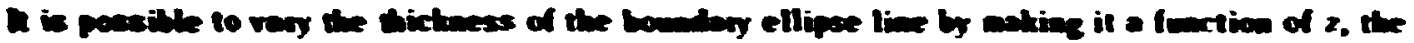

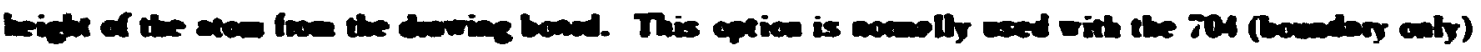

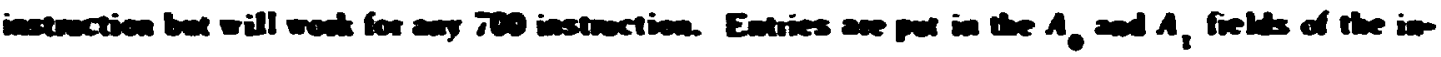

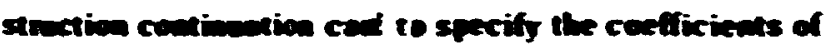

$$
V(x)-A_{0} \cdot A_{1} x
$$

Dreve

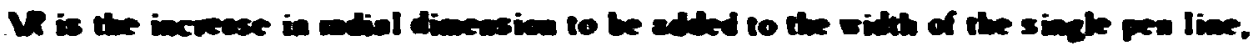

$A_{0}$ is V V fin an atcen at $x-0$, and

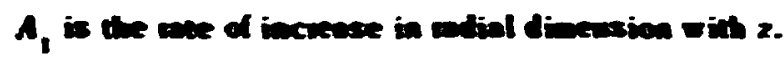

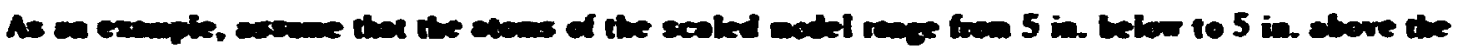

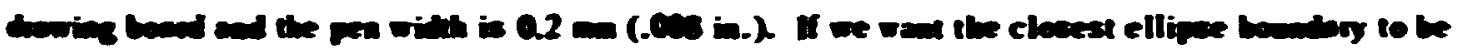

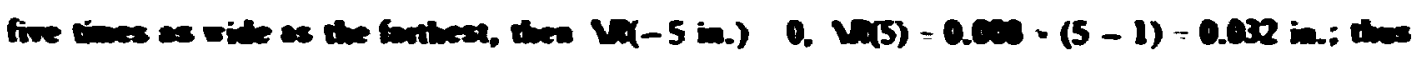
$A_{0}=0.016$ in and $A_{1}=0.0032$ in.

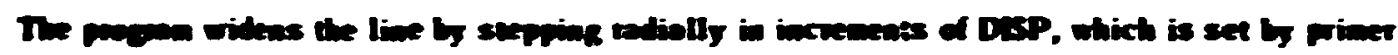

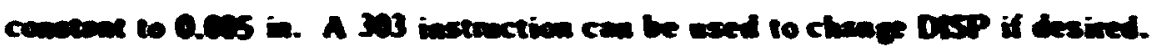

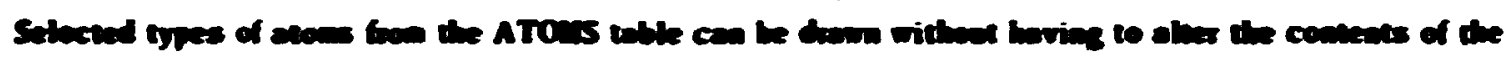

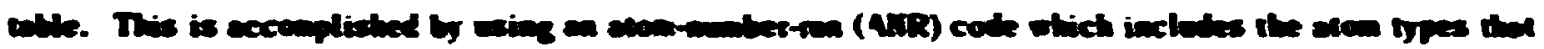

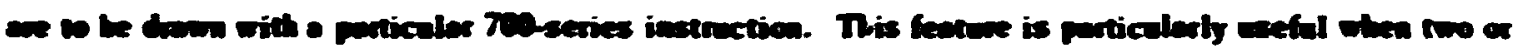

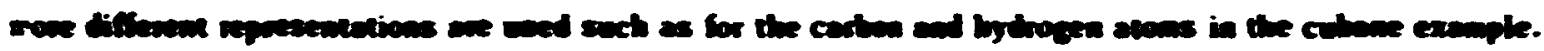

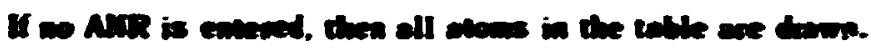

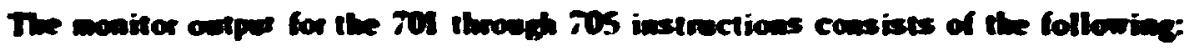

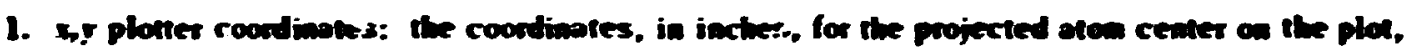

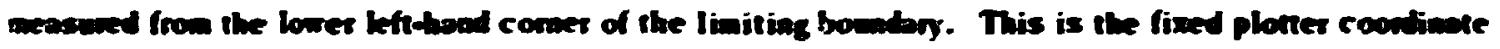
system widh origin point set by the plotier operotor.

2. 5y,z wothine Cantesian coodinoves: the coondiastes, in inctwes, for the oriented and scoled

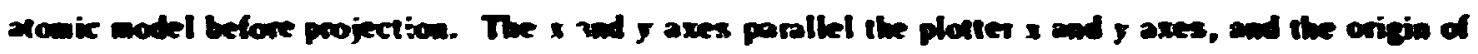
the system is in the plase of the plonter at the point $x_{0.05}$ (see 3.3.j) in plotret coondinares. The point Oacs of the scoled molkel is at this point (see 3.2.6.1).

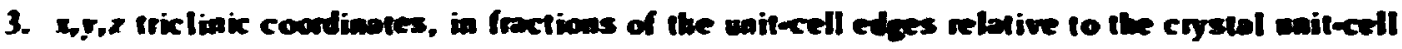
coripin.

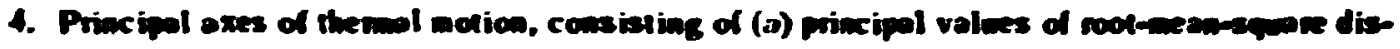

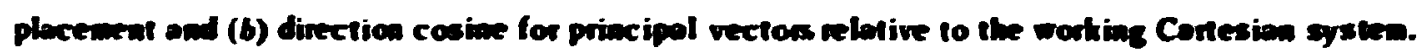

5. The atom desipatior cate and cliemical symbol for the atom.

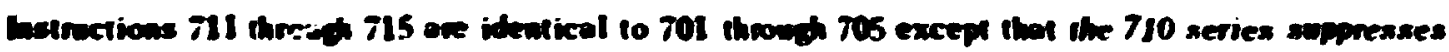

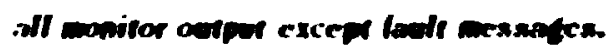




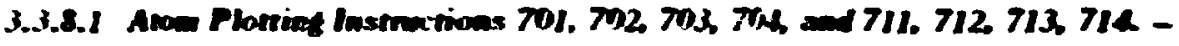

Colomos

$$
\text { Fires Cod }
$$

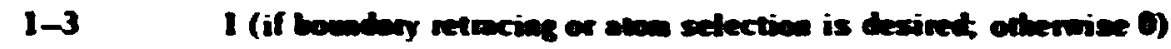

49 $201,700,703,704, \pi 1,712,71, \pi 4$

$10-45$ Bank

4-54 Symbol beiten (in.)

55-63 Pagllel offere (i..)

C4-72 Prypendicaler ditset (i.)

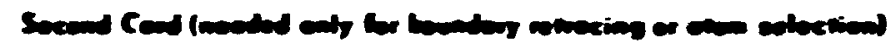

1-3 Diont

4-9. Dim

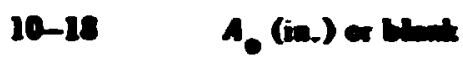

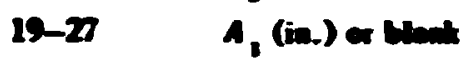

$\left.\begin{array}{l}2-3 \\ 37-5\end{array}\right\} \quad$ andi entrat

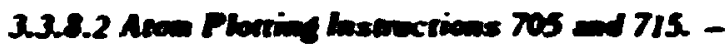

Colnome

Fines cond

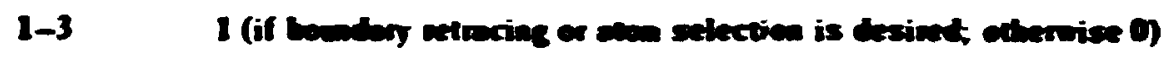

$\rightarrow$ Tis $\rightarrow$ TS

10-18 NPLAx:

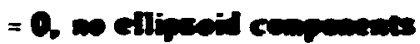

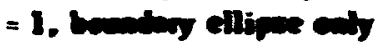

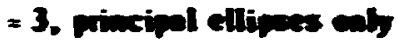

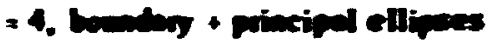

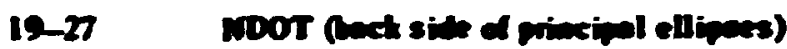

<Q, selied live beth sille

x Q, betr sill comint

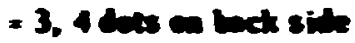

- 4. 8 low en lact sill

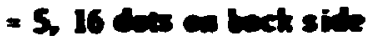

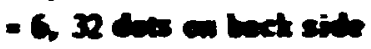

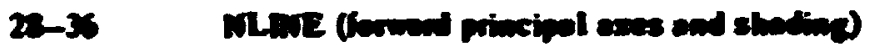

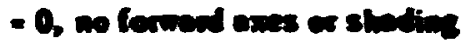

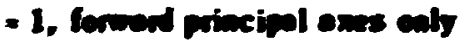

- N. formad anes + $(\boldsymbol{H}-1)$ live sharimas

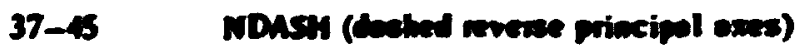

- 0, wo neverestes

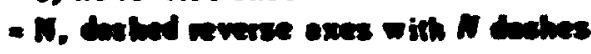

46-s4 Symbal beich (m.)

55-63 Parllat citen (in.)

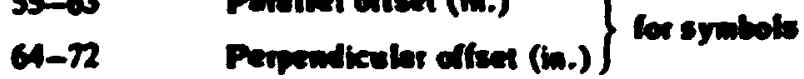

secend Cort semes os 


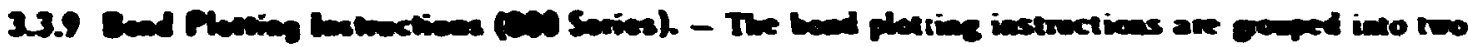

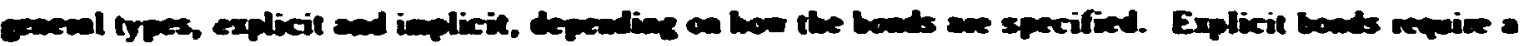

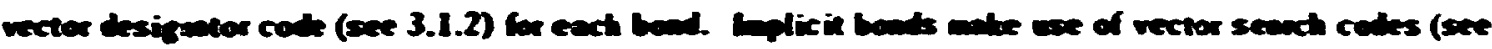

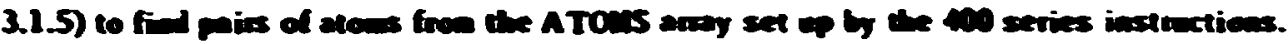

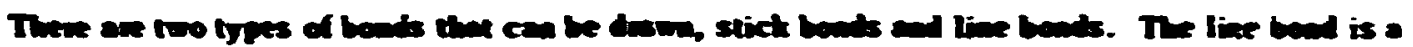

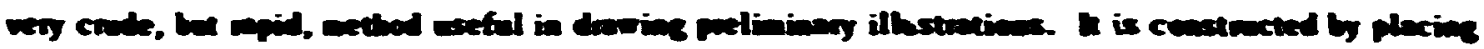

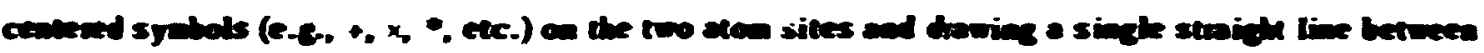

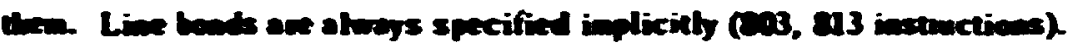

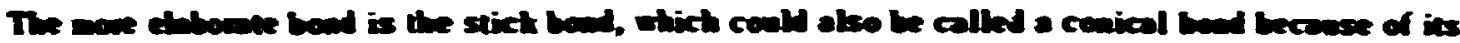

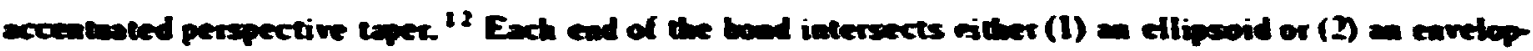

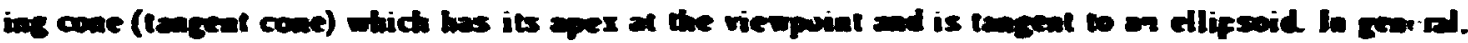

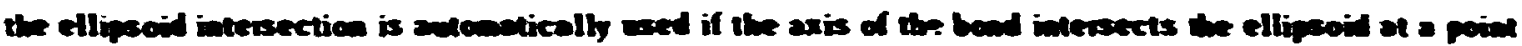

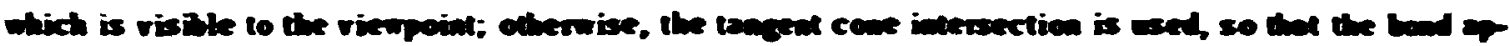

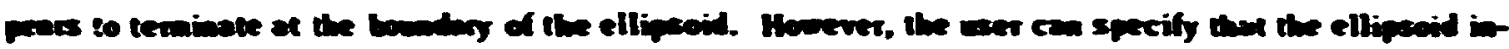

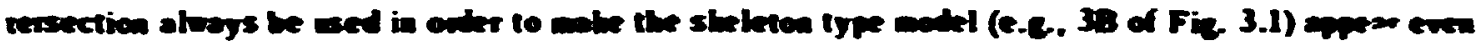

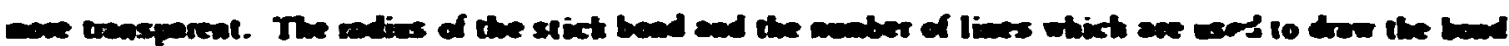

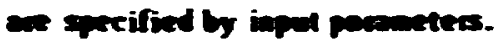

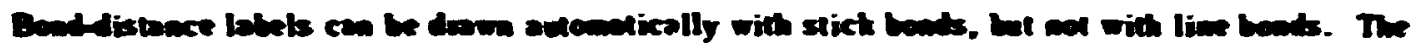

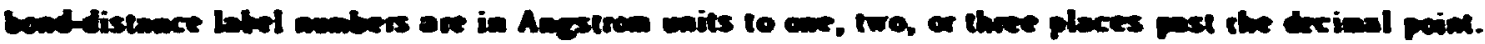

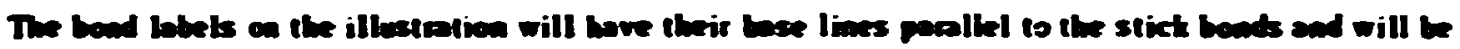

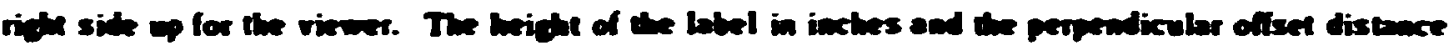

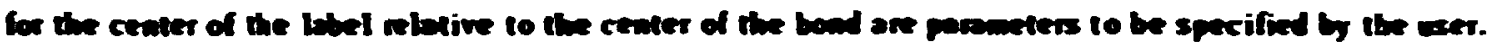

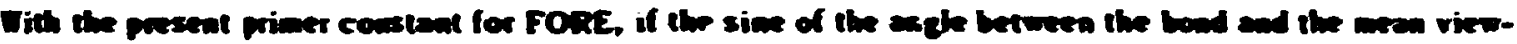

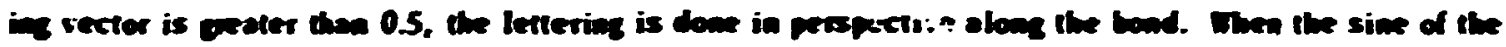

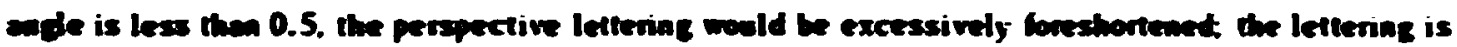

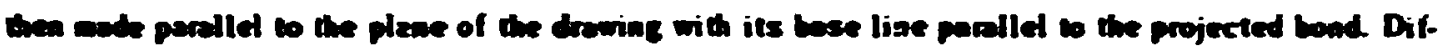

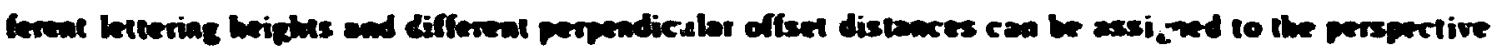

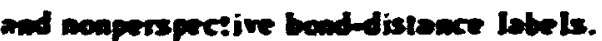

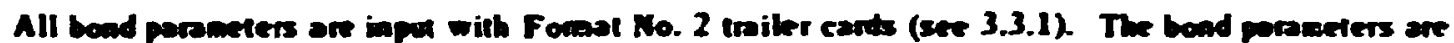
as bilows:

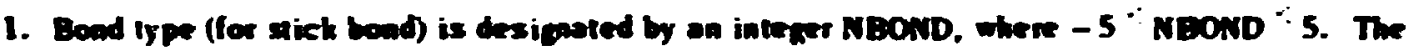

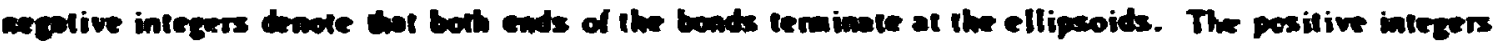

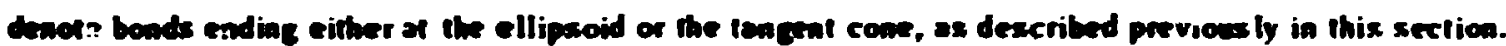
An eniry of zero drows no bond. A magaitude of 1 for NBOND prodeces two liacs, one for eact boad de, 180" apan in the plane anomal to the bond axis. Lines are drown 90: 45", 22.5", or 11.25" apart for NBOND magnutudes of 2, 3, 4, or 5, mspectively. The boch side of the boad is not drown. Representalive somplex are thown in Fin 6.1 .

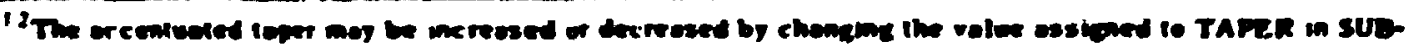

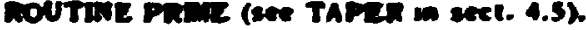




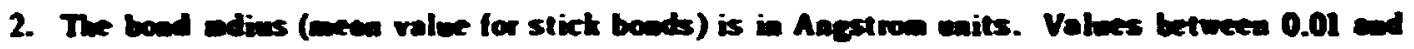

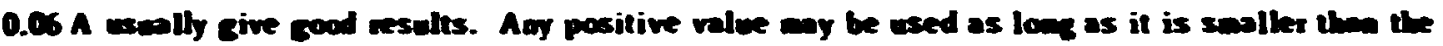

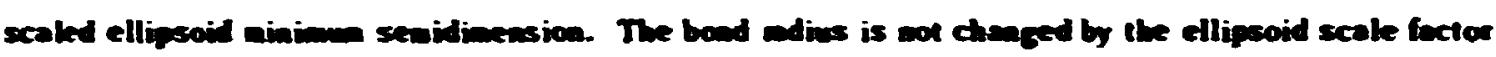

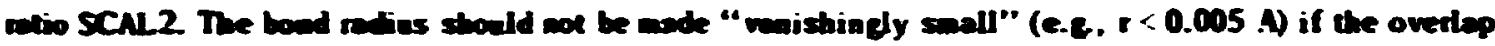

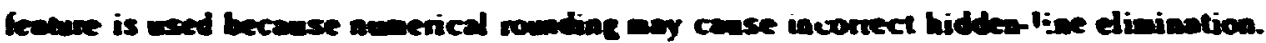

3. The heidu of paspective labels for boud distances is enteved as zero if an bond distances are

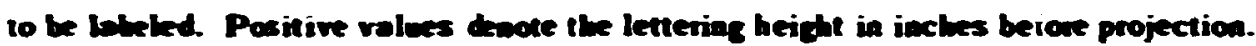

4. The peppendiculaz offset for bond distance perspective bbels (in incses) pertains to offset of the criber of the distance bbet selutive to the center of the bad.

5. The height of reglar blets for tond distances is entered as zero if no boud distances connespond ine to fonshortened bands are to be down. Positive values give the letteriag beiflt in inches before pryjecticen.

6. The peppedicular effset for bonddisteace regalar bobels has the same definition as parameter 4 store.

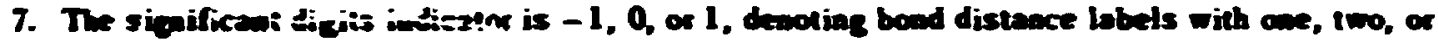

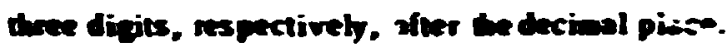

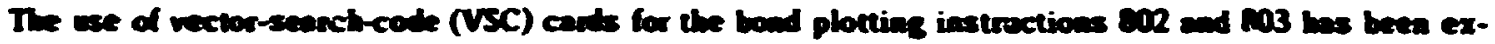

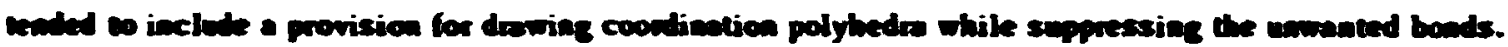

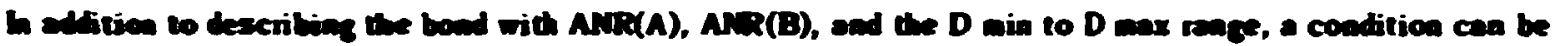

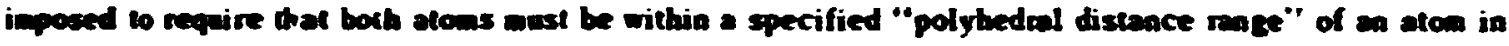

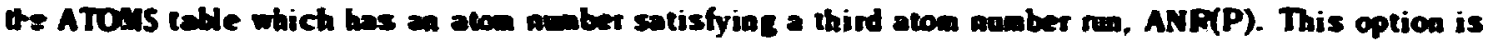

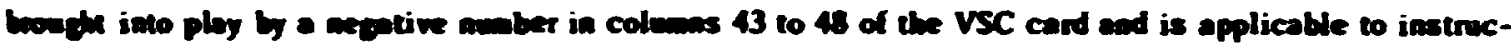
iiens $802,813,812$, and 813.

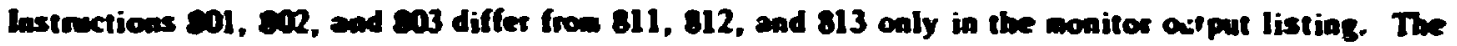
second grop has no cotput except error messages. The first poup lists: (1) plottet ccondinates in inctive, (2) sceled Cartesian coodinates (in inches) of atom before projection, and (3) triclinic crystal coodinates for the atoms of roch bond. The interatomic bond distence in angestroms is also listed. If an $210 \mathrm{~m}$ of a banded pir is out of bounds, a fault message (NG = 10 ) is printed on the monitor output. If the bond is hidden and cannct be bow, fault message NG $=14$ is priated. Foult NG $=13$ sienifies that an inagiang intersection was foud with a bond adius breer than the ellipsoid semidimension.

3.3.9 I Instructions 801 and 8II. Fyplicil Stick Bonda - The bonds ane described with two atom

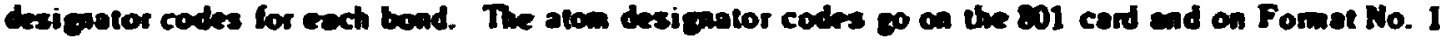
Ipilet cons (see Table 2.1 for fomat). The tro atom designator codes for a bond must be in adjacent fields, but bleak fields can be insertird between the different bonds. Since there are seven fields availaile per cand. it is a cood idea to use only two. four, or six of them so that the card sequence within the instruction (othet then first and last cards) will be unimportant. In addition, a Format No. 2 iniler card is requined with the fields specified under coluan 801 in Table 3.1 property filled in.

3.3.9.2 Instnuctions 802 and 812. Implicil Stick Bonds. - All parameters are input with Fomat No. 2 railet cards (see Table 3.:). The oniy entry on the instruction card is the instruction numbet and look aldered (2). 


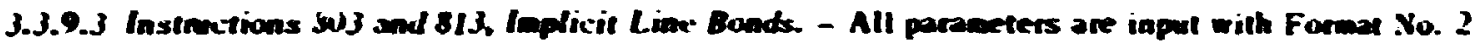
twiler conts (see Table 3.1). The centened symbol pleced on a given aton will be the ceatered syabol

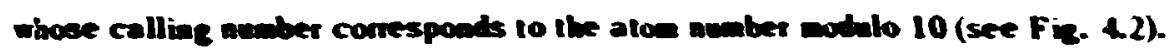

The centend symbols drown on the atonic sites by the 003.813 iastractions aov be aade larger or sealler by redefining the SCAL2 factor. Which is contwolled by the 600 series cf instenctions (3. 3.).

3.3.9. Insfructions 821 and 822. Oterdap Elimianion. See Section-3.3.14.

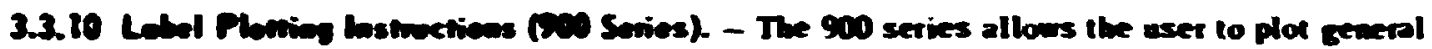

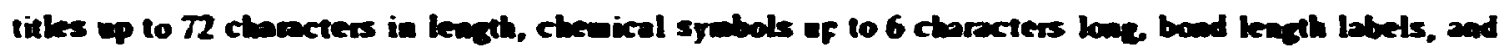
centered symbols. The bond lendt bbels can have two decinal places before the decinol point and we, two, or thee pleces afver the decimal point. The 700 and 200 series instructions can plot chemical

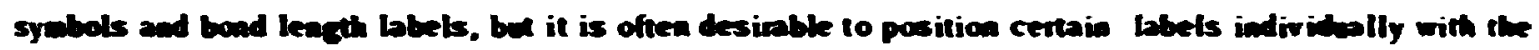
900 series.

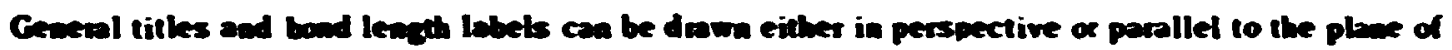
the dowiag. Chemical symbols and cenvened symbols are always drawn paralkel to the ploter pleme.

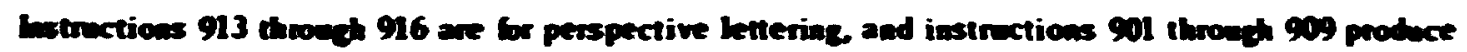
ngalar keterine.

Two vectoss, the upright vector and the buse-line vector, are needed to bescribe a letteriag plane. In OR TEP the upright letteriag vector is alweys parillel to the plave of the dewinc. For perspective letbering the bse-lise vector is a gewer al vector in three dimensions. In the nosperspective case the base-diace vector is either aloas te projection of a general vector or aloag the vector (in the plowe of the plotiet) which is orieated with a 302 tive rotation instruction (dheta base lise). If theta (set by 302) is zeto, then the thet beseline vector is aloag the plotter positive $x$ axis.

The exact center of the bbel is always referred to when specifying the position of the label. The prozas goes trough the followiag steps to position the center poiat of the label onto the dawing. (I) A poiat $P$ is found which is either the position of aton $A$ or the wean of two atom positions (atom $A$ and atom B). The aton A position is used if no atom desiopator exists in the atom B field of the instruction card. (2) A poiat $P 2$ is found by (a) tansloting from $P 1$ along the besedine vector for the distance specified by parallel oflset, then (b) transtatiag along the upright wetot by the aerpesticular offset distance. (3) A point P3 is found by projecting $P 2$ onto the plane of the plotter. (A) If the $x$ cdie reset is $>0$, then $x$ is reset to this velue. If $x$ edie reset is $\cdot 0, x$ is reset to the positive $x$ plot bowndary minus [x edice rese?!. No resetling is done if $x$ edfe reset is zero. The $y$ popmeter is bandled in the same manner with $y$ edice reset. 
The format for the eative 900 series is as follows:

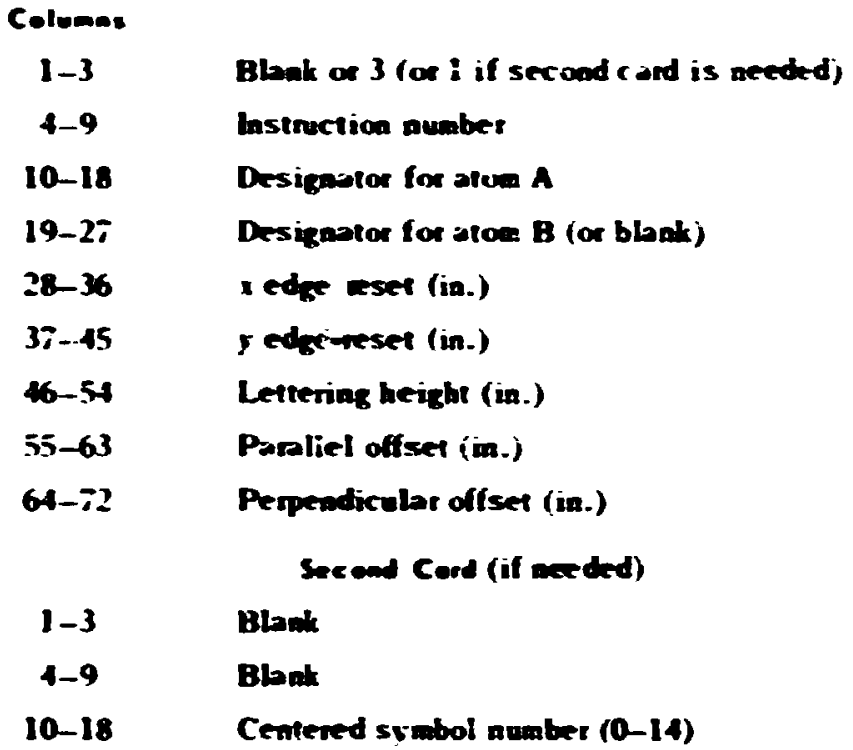

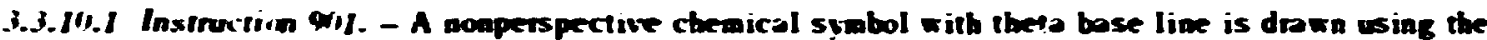
chemical syobol for atom A.

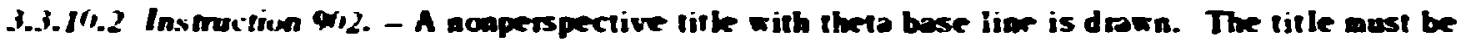
eptered with the iastrections on a Format No. 3 troilet card. The title should be ceatered about coluons 36-35 of that cond.

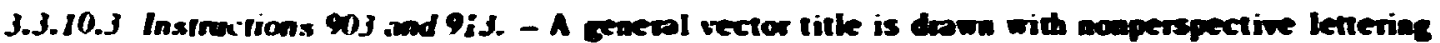
for 903 and petspective letteriag for 913. The erwerol vector is fro atom $A$ to atom B. The title is ewlenel as describnd for 902 (see 3.3 .10 .2 above).

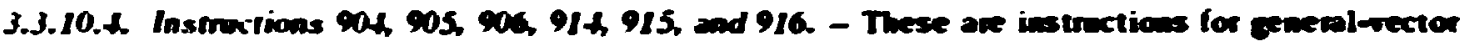

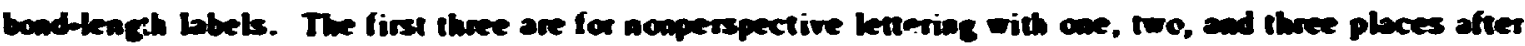
the decinal point; and the last three are for the correspondian bond-bengh blels with perspective lettering. The gemeral vector is from atom A 10 atos B. Note that the sense of the vector is ingortan in onder to have the label right side ep.

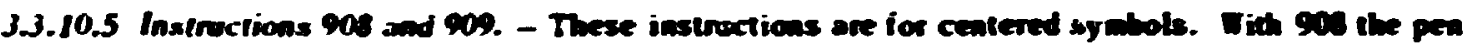

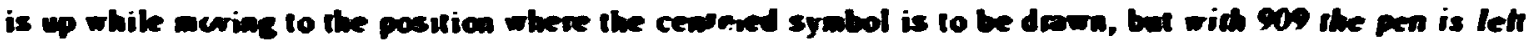

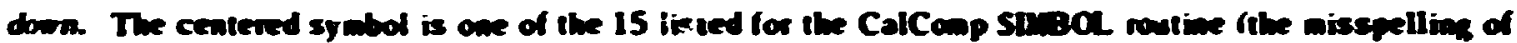

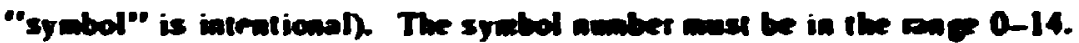

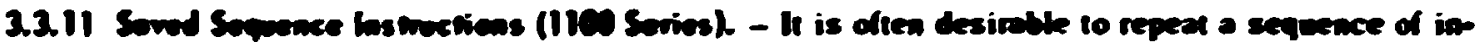
structions une ox mone tives with ofver iastnctions insened between the repetitions. The 1100 series

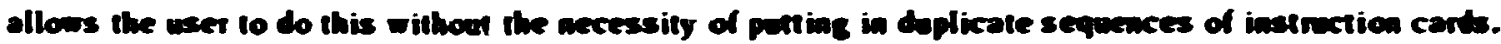
It is not an elaborote looping device, bet it does give aditional flexibility to the systern.

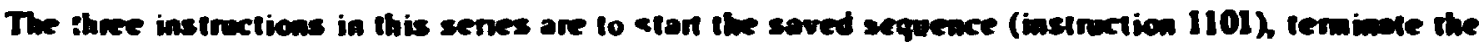
soved sequence (instraction 1IOZ), and execte the soved sequence (ins turction 1103). All iasthuction 
cants and heir triber cants between the 1101 and 1102 instructions are execuled and saved on a mac netic scrotch tape. A 1103 instruction rewiuds this scalch tape and repeots all the instructions stuned there before another instmetion is read from the woaitor iapre. There are ao parancters to be eatered with the 1100 series instructions.

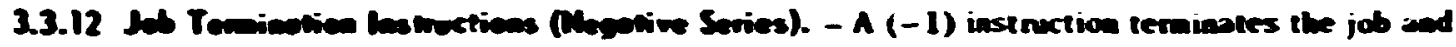
exits via SUB:outhe EXT.

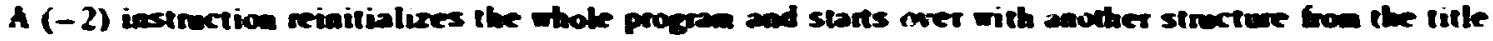
cad on. As magy structures as desired ay be ran in seppence in this maner befoce exitiag with a (-1)

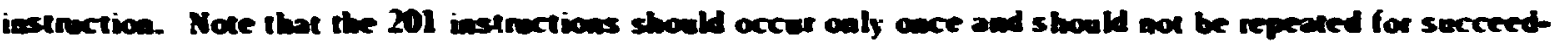
ing jols.

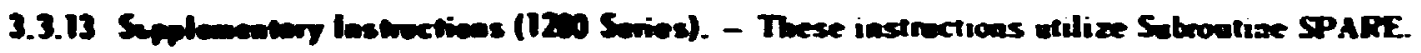

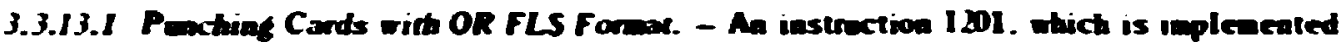

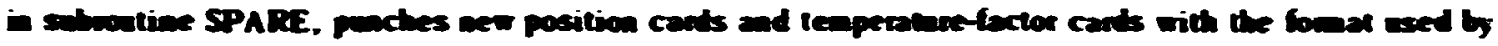

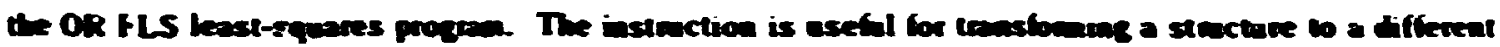

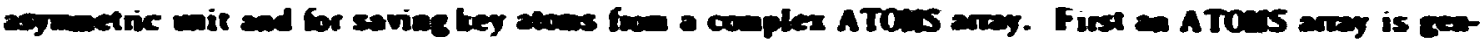

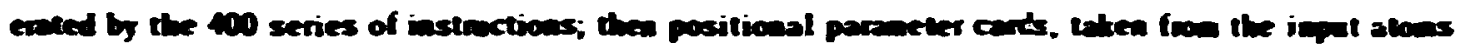

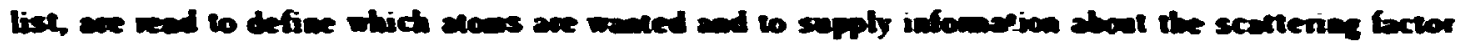

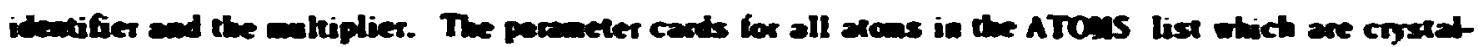

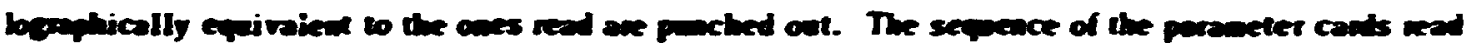
by this instenction meed not comespond with the seypence of the original inget atoms.

Colomos

1-3 Bind

49 1201

10-18 $n$ (the anabet of positional paraneter cands to be read $n$ position paremeter cands fou the odifinal inpet atom dect west follow this instenction cord)

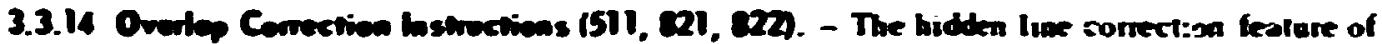

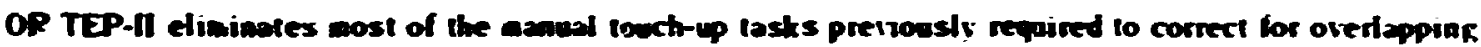

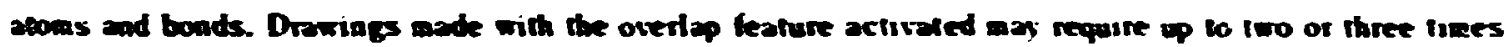

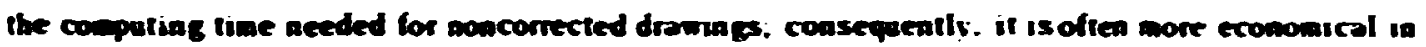

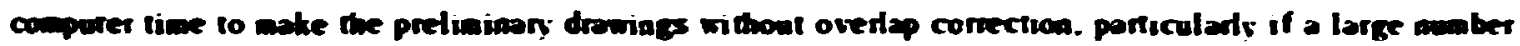
of atons ase present in the draviag.

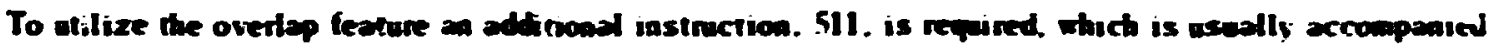

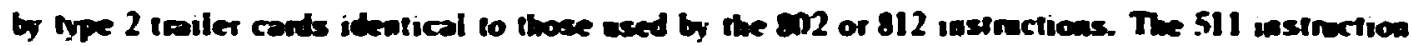

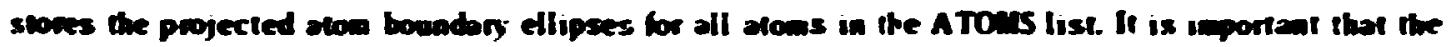

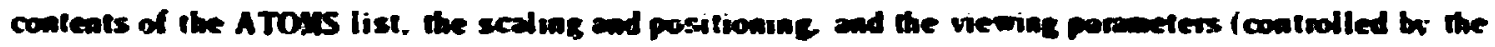
W0. 600. and 500 series of instructions respectivety) not be chenged between the 511 ustrinction and the drewing of the aloms and bonds br the 700 and 800 series of instanction; oftermse. the projected cotives ans be destroyed or any be ineppopnote. 


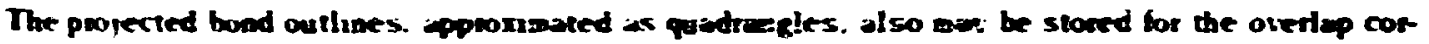

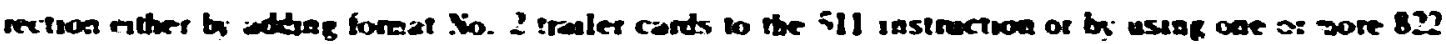

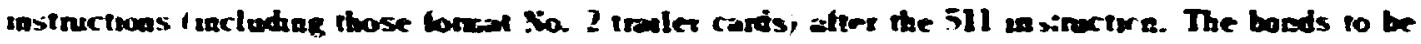

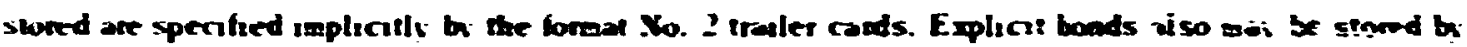

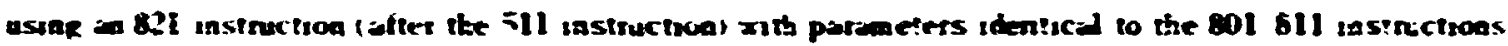
to bre exed fot ploting the explicit bouds.

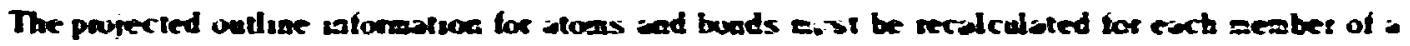

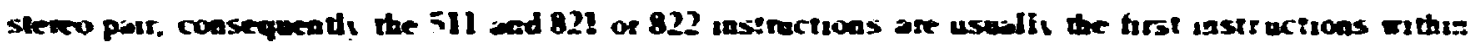

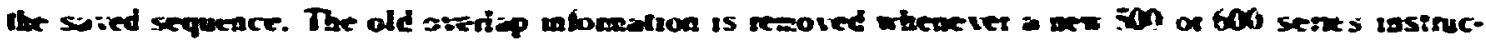
trod is executed

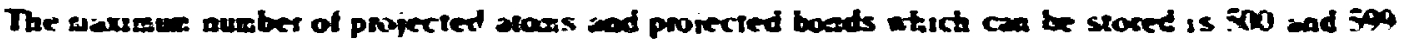

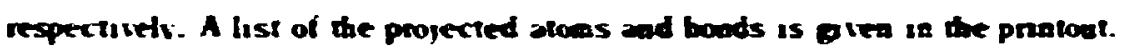

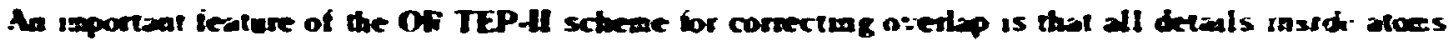

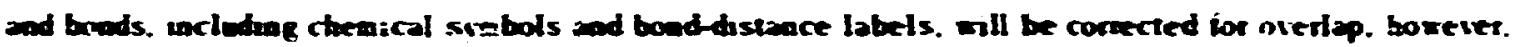

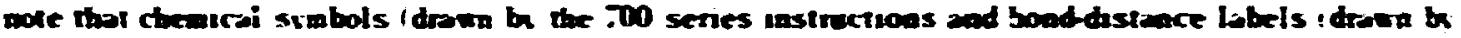

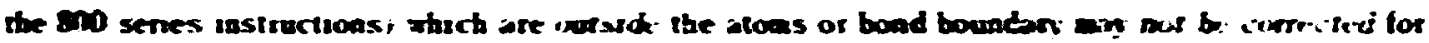

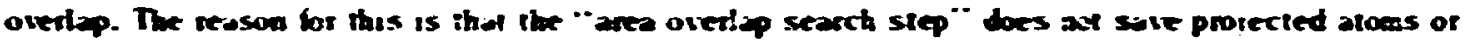

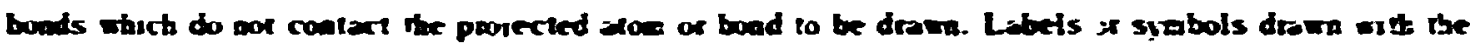
930 senes instructuas mill aot be cornected lor onerlap.

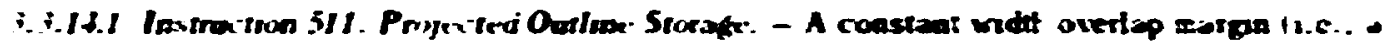

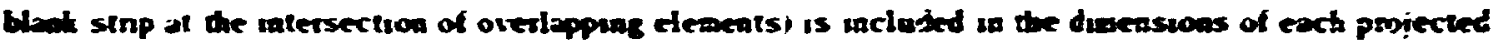

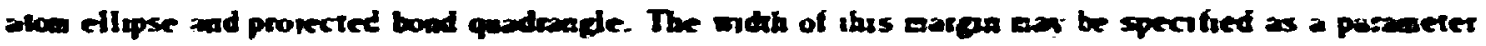

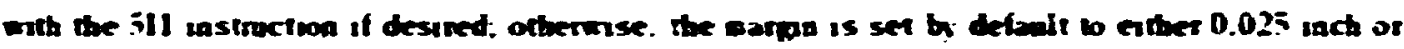

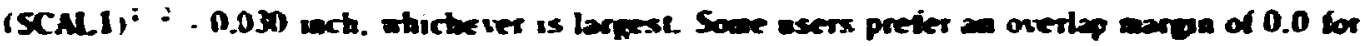
sienescopic drantex

$$
\begin{aligned}
& \text { Colomas: } \\
& \text { 1-3 I i if bonds are to be sloned of werwise } 0 \text { ) } \\
& +-9 \quad 511
\end{aligned}
$$

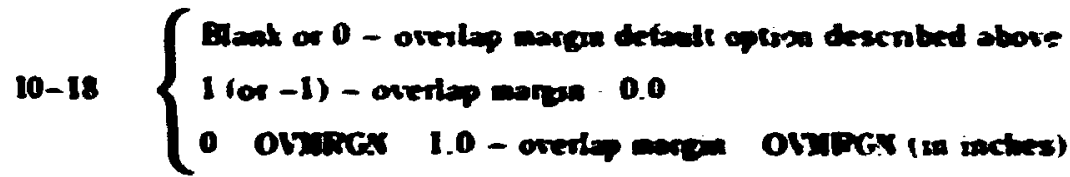

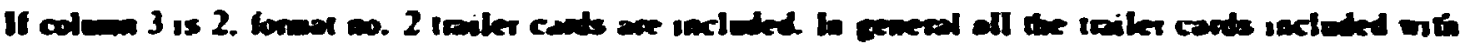
the 002812 asetructions ace ased

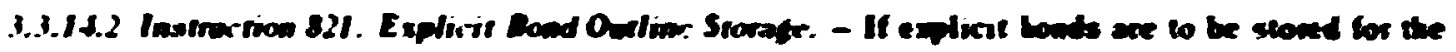

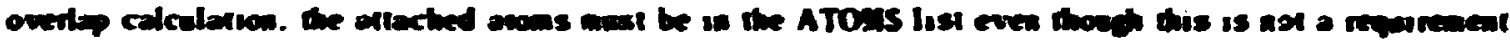

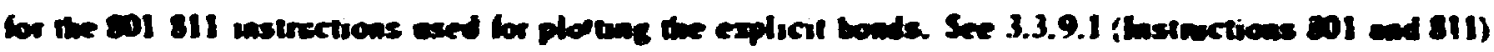

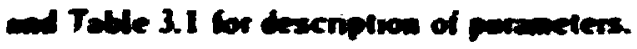




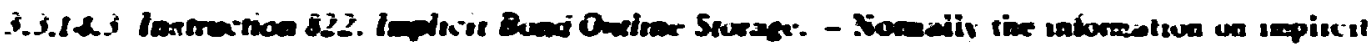

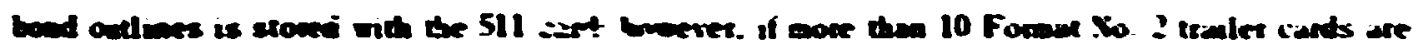

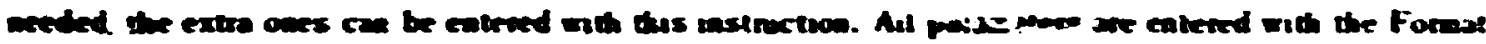

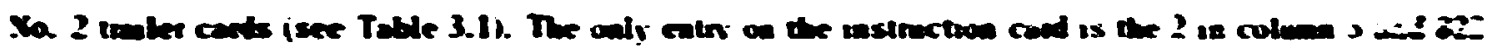
in codmos $7-9$.

\section{Lise of Foub hationese}

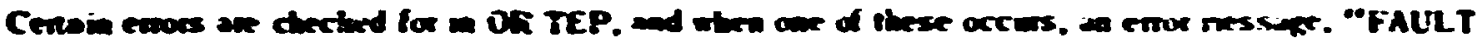

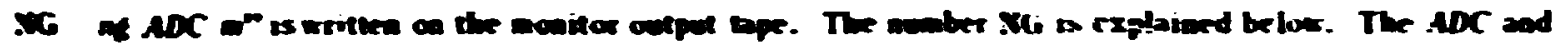

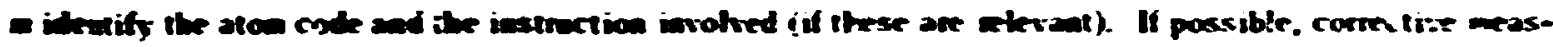

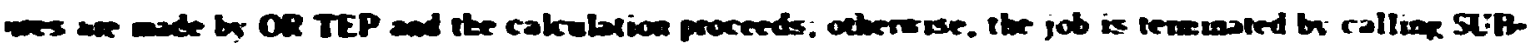
DOOTLE EXT.

\begin{tabular}{|c|c|c|c|}
\hline me & bedted & Foul, & Actoon \\
\hline $\mathbf{1}$ & Piald & $\begin{array}{l}\text { So seretinet fond afrer reading } \\
\text { is syminetsy cands }\end{array}$ & Tries to read patanent canks \\
\hline 2 & PiEll & 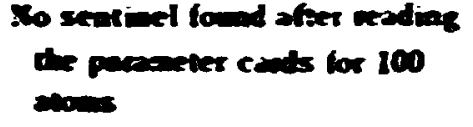 & Trues to sead $=-$ inction cands \\
\hline 3 & pirlu & 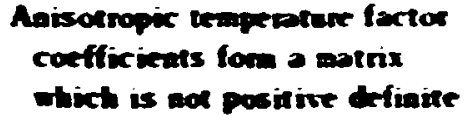 & 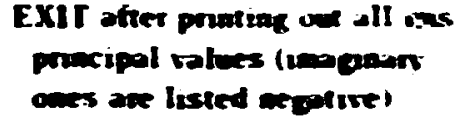 \\
\hline 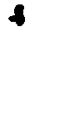 & ATOL,PAXES & 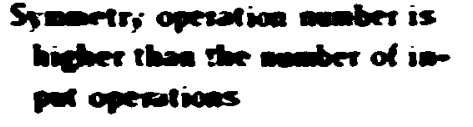 & Oali atom \\
\hline 5 & ATOA,PATES & 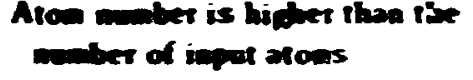 & Oait atos \\
\hline 6 & Eeres & 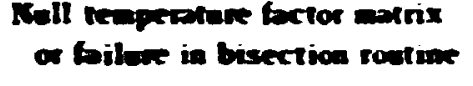 & $\begin{array}{l}\text { EXIT, afiet pristing on all } \\
\text { poincipol ralues }\end{array}$ \\
\hline 8 & ECER & 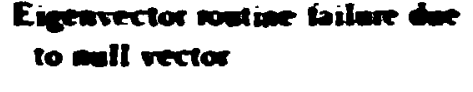 & 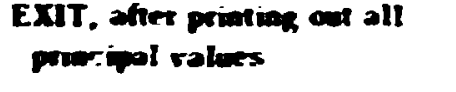 \\
\hline 9 & 2Wr,SPARE & $\begin{array}{l}\text { Uaikentified instenction } \\
\text { mabet }\end{array}$ & Obut foulfy mostroxtija \\
\hline 10 & EOND.FT0 & Arom onf of hands & Omin 250 \\
\hline 11 & & Wo rector serecth coles & Obit instraction \\
\hline 12 & FEO. SEARCA & 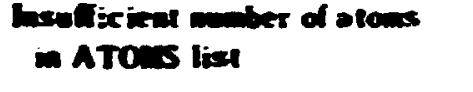 & EXIT \\
\hline 13 & $: 0,10$ & 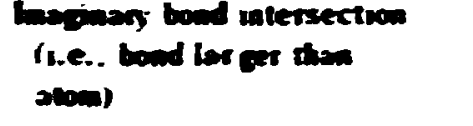 & Omit low \\
\hline 14 & :OnD & 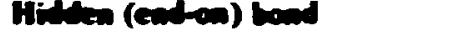 & Onit lem \\
\hline 15 & & Difll verses as bere line & Onit Lei \\
\hline 16 & stoir & ATOW list is Gall & Raif all secceveling atoms \\
\hline
\end{tabular}




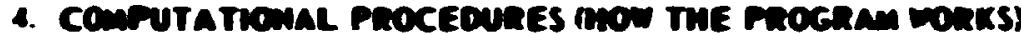

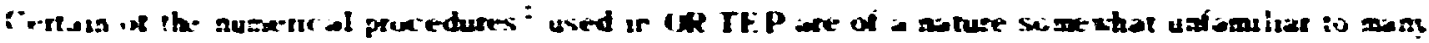

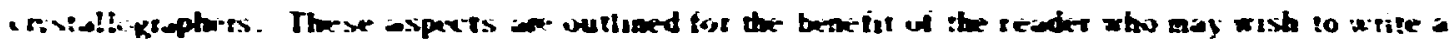
imsise proverse or modify the presieds une.

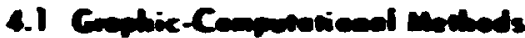

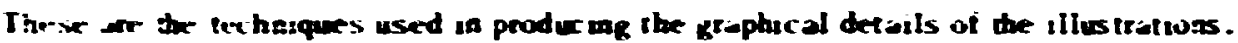

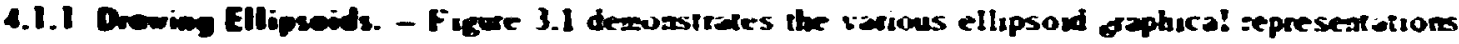

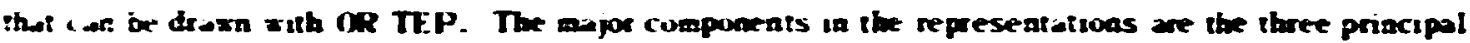

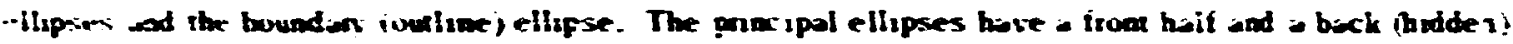
beit. Tine entre boundat elipose as visible.

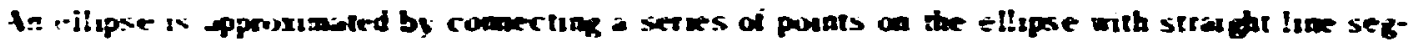

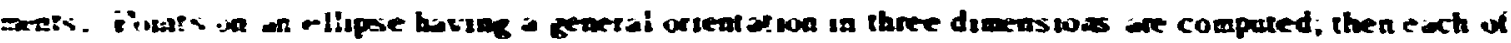

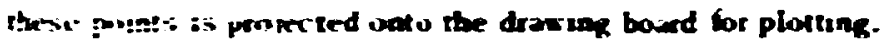

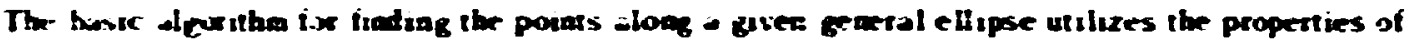

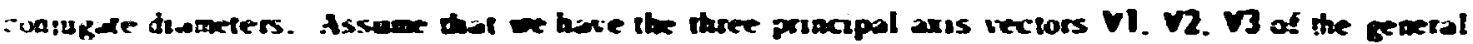

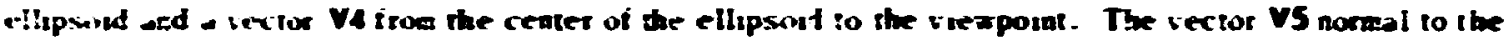

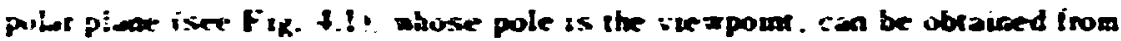

$$
\mathbf{v S}-\boldsymbol{A v 4} \text {. }
$$

xhere $A$ is the motis tor the ellipsond which is defued by

$$
\boldsymbol{x}^{\boldsymbol{T}} \mathbf{A} \boldsymbol{X}: \boldsymbol{d}
$$

where i as a constant.

The bowadin ellapse is defined by iwo coajugate vecrors, one of which is anj vector VG perpendiculis to VS and the second is $\boldsymbol{V}$. where

$$
\boldsymbol{V}=\boldsymbol{V} \cdot \mathbf{A v 0}
$$

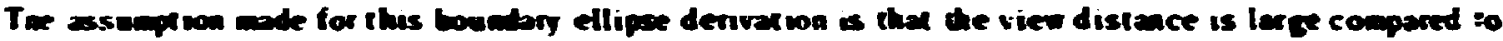
the elispsod size. Therefore, the bondary ellipse defined abore abrags lies on the diameirai polar piane (see Fic. \$.1)

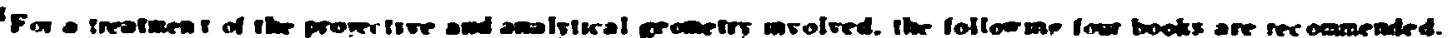
Thr imat ane is perticularlt Eseffel.

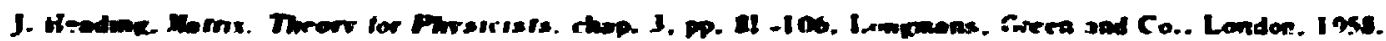

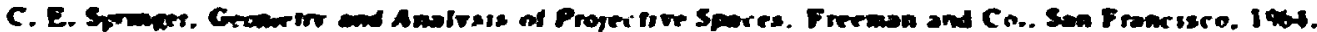

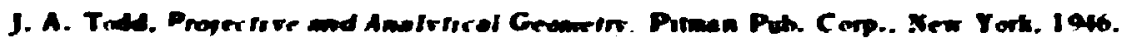

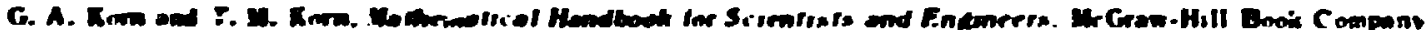
Nive Yart. I isht. 


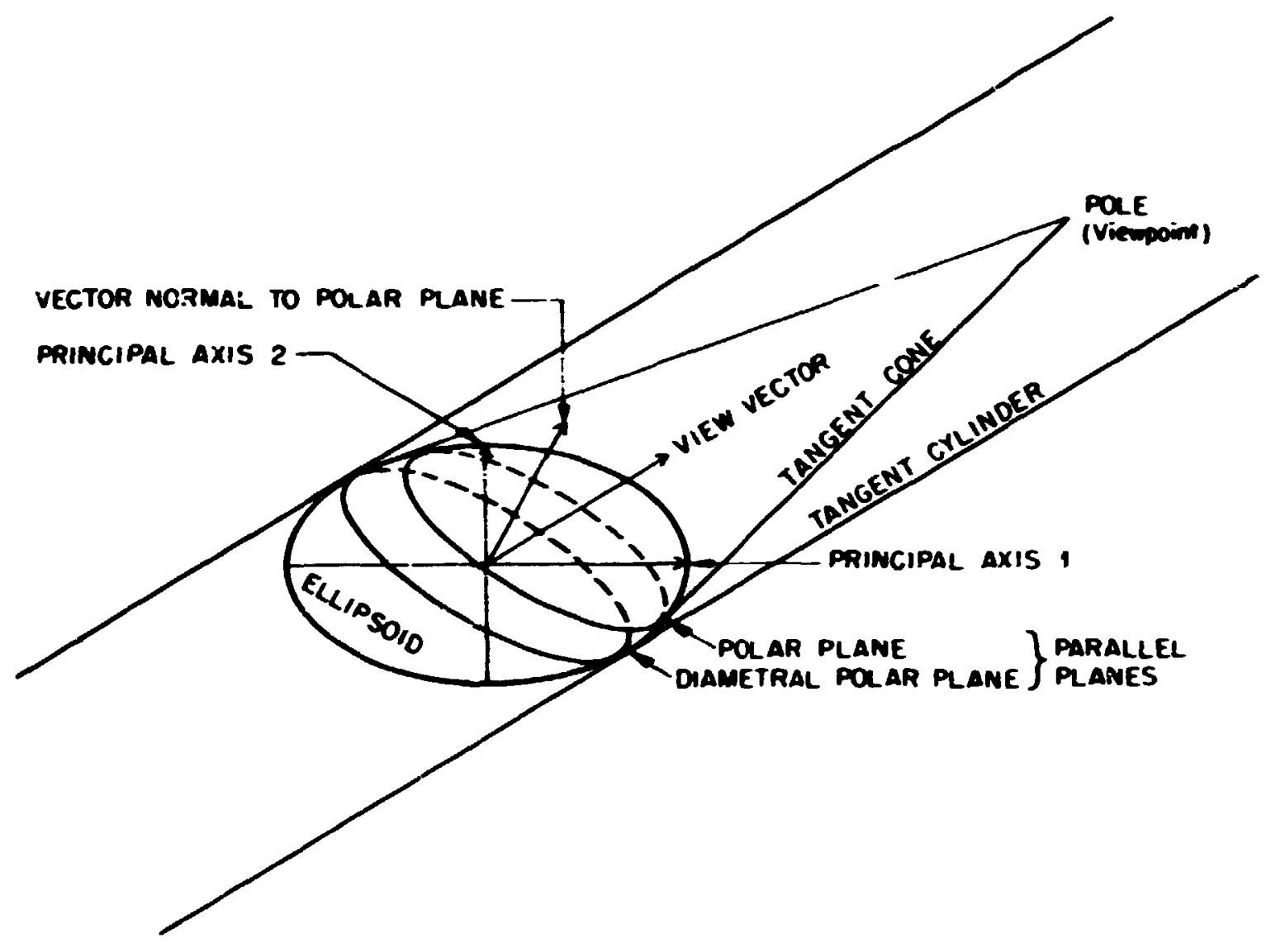

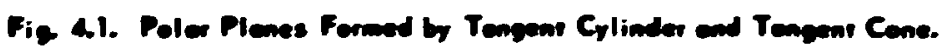

A principal ellipse which lies in the plene of the principal axis vectors $\mathbf{V 1}$ and $\mathbf{V}$ will have the third principal axis vector $\mathbf{V} 3$ normal to the plane of the ellipse. The intessection of this principal ellipse with the boundary ellipse is along the vector $V 8$ where

$$
\mathbf{V}=\mathbf{V} 5 \times \mathbf{V} 3 .
$$

This vector divides the front and back (hidden) sides of the principol ellipse. A vector conjugate to Vo and in the principal plane containing $V 1$ and $V 2$ is $\mathbf{V}$, where

$$
v 9=v 3 \times A v 8 \text {. }
$$

After the r.mjugate vectors have been bound, their len ahs are adjusted to make them satisfy (4.1.1.?! by letting $X$ : $s I$ where $l$ is a unit vector. Solving for $s$, we oblain

$$
s=\left|d /\left(I^{T} A \mid\right)\right|^{1 / 2}
$$




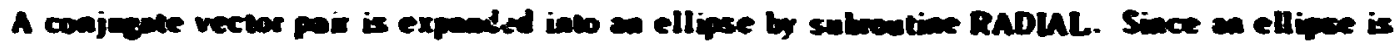

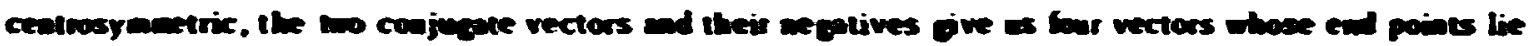

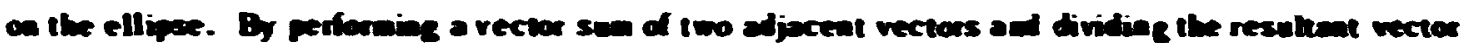

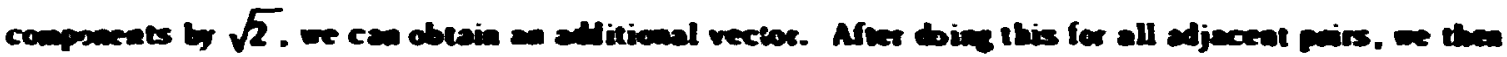

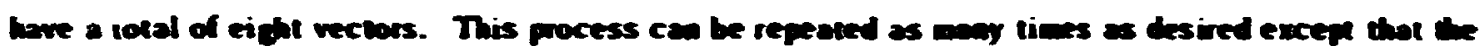
sraling constant will be differeat for each cycle. The constant is deseribed by

$$
\operatorname{con}(i)=1211+\cos (-i 2) \mid 1^{i} 2=2 \cos \left(-i 2^{i+1}\right)
$$

Dhere i is te cycle unabe.

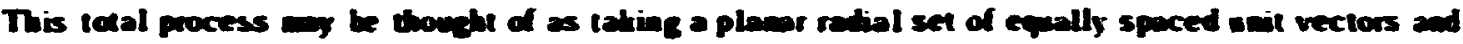
performing a deformation and scaling on the spece in which it is described beometry this deformation is called on affice trensformotion.

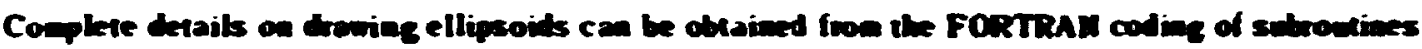
FTOS and RADIAL.

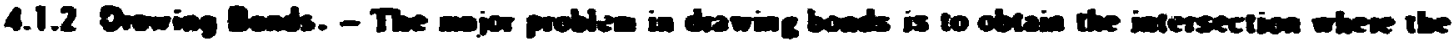

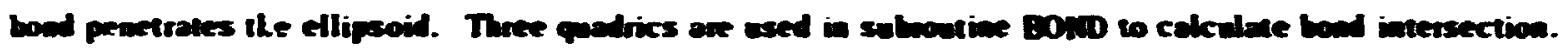

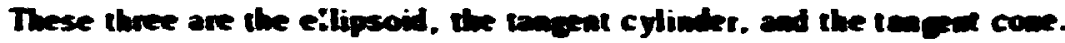

The ellipsoid is described in metrix motion ax

$$
\boldsymbol{x}^{\mathbf{T}} \mathbf{A x}=\boldsymbol{d}
$$

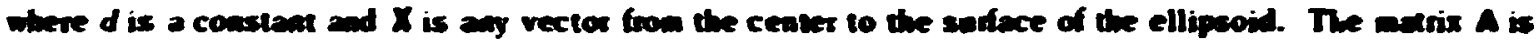
3 by 3 symetrical with componems $a_{i f}(i . j=1,2,3)$

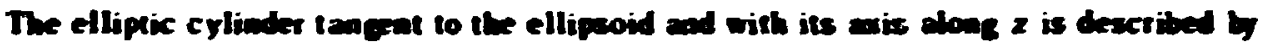

$$
\mathbf{x}^{\mathbf{r}} \mathbf{B}=\mathbf{d}
$$

were

$$
B=\left(\begin{array}{ccc}
a_{13}-\frac{a_{13} a_{31}}{a_{33}} & a_{12}-\frac{a_{23} \Delta_{31}}{a_{33}} & 0 \\
a_{12}-\frac{a_{13} a_{32}}{a_{33}} & a_{22}-\frac{a_{23} \Delta_{32}}{a_{33}} & 0 \\
0 & 0 & 0
\end{array}\right)
$$

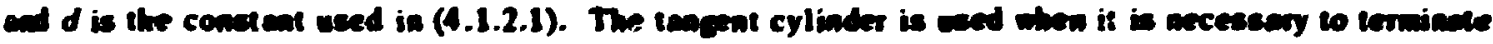

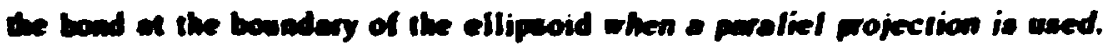

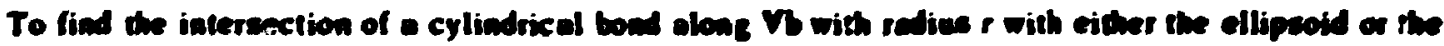
tem ent cyliader, we procen a follows:

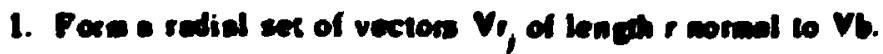




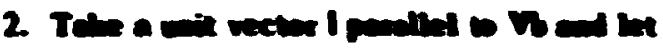

$$
x_{j}=n_{j}+1
$$

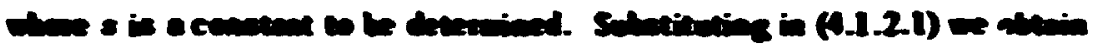

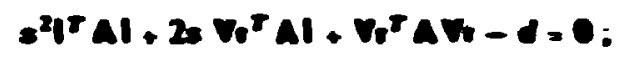

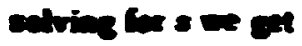

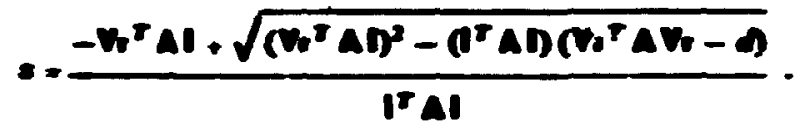

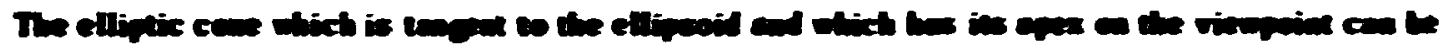

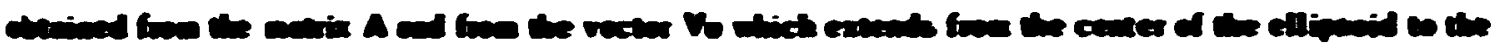

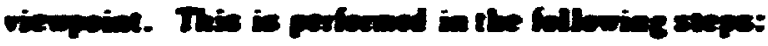

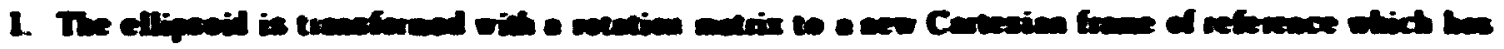

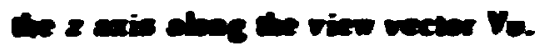

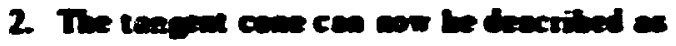

$$
T^{T C T}=0
$$

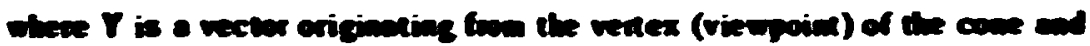

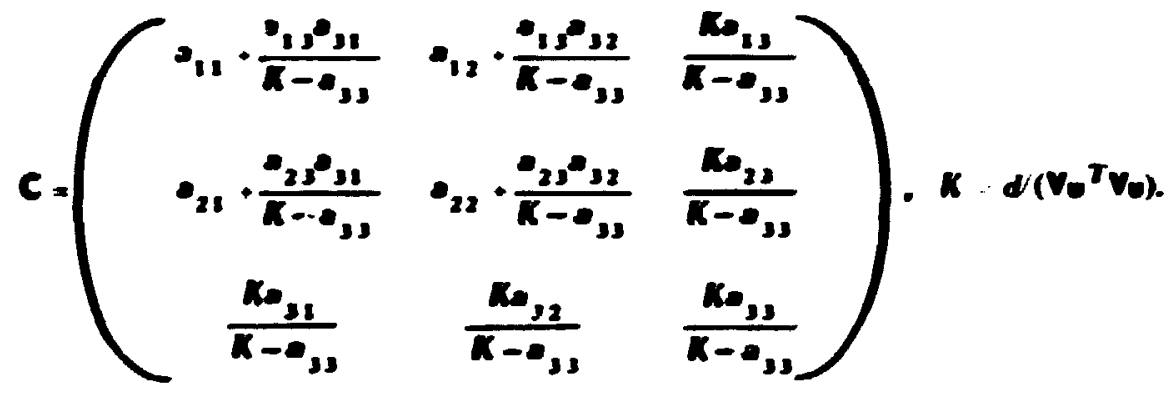

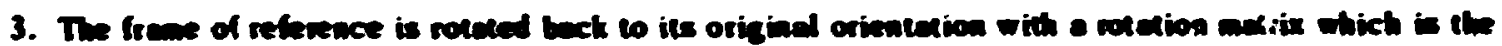

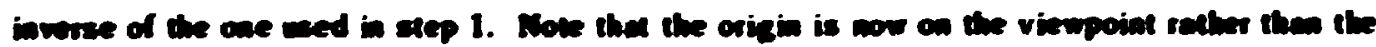
ellipaid cemer.

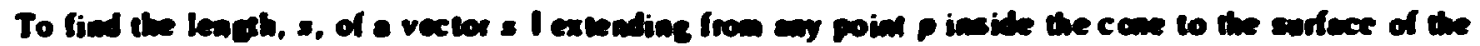
cone we lee

$$
r \cdot v_{p} \cdot=1
$$

and obleix from (4.1.2.7)

$$
\left(v_{p} \cdot .\right)^{r} C\left(V_{0}+. .1\right) \cdot 0 ;
$$




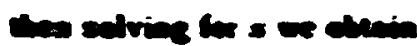

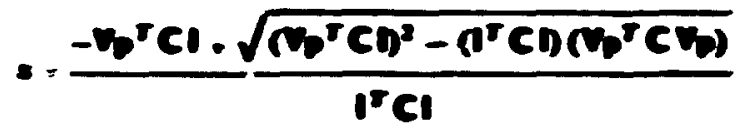

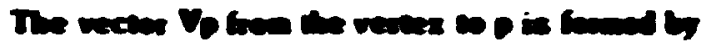

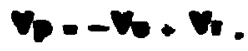

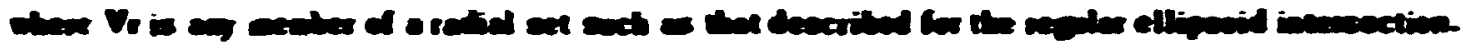

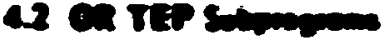

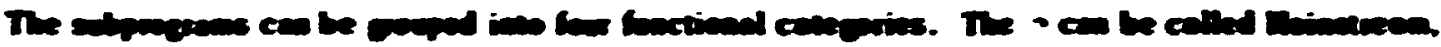

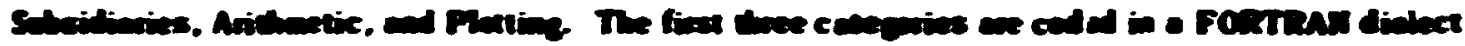

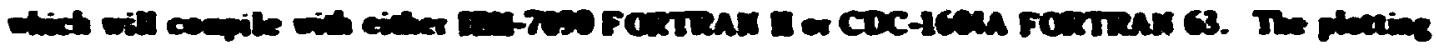

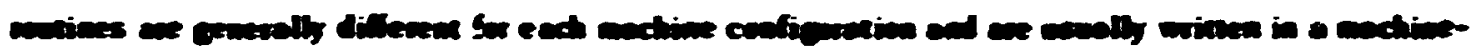

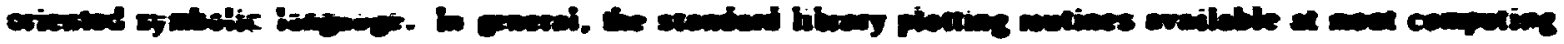

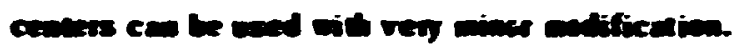

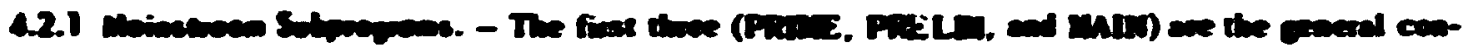

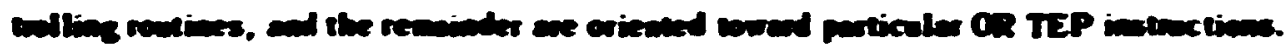

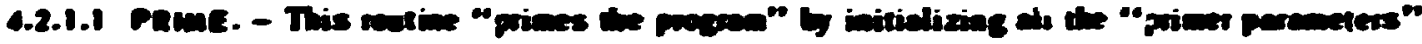

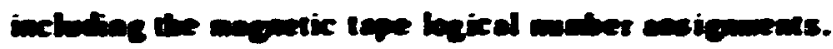

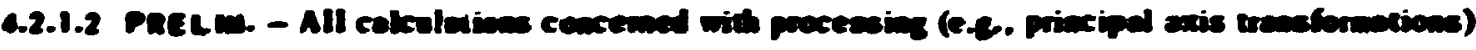

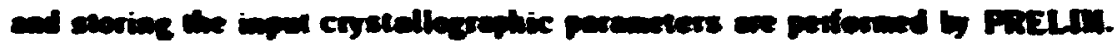

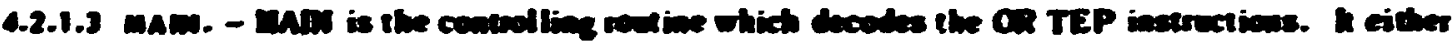

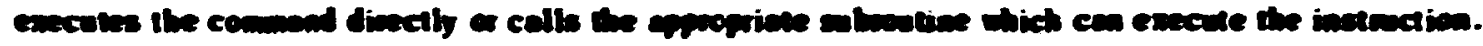

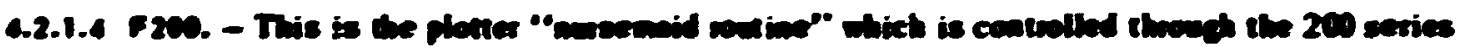

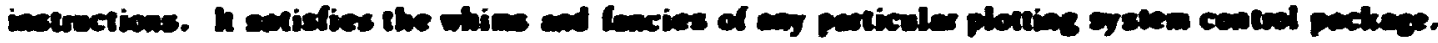

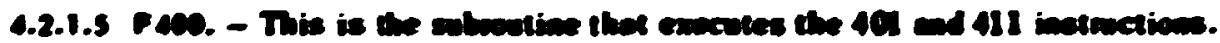

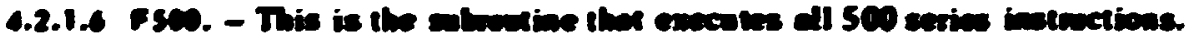

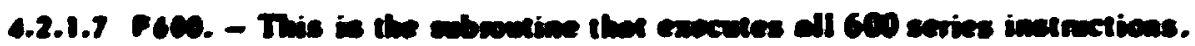

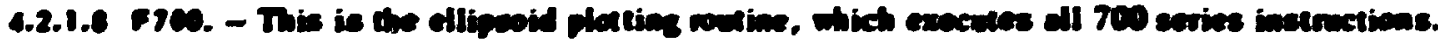

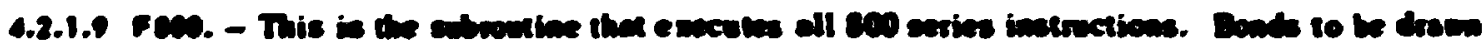

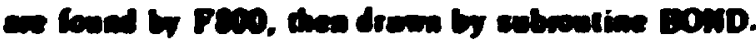

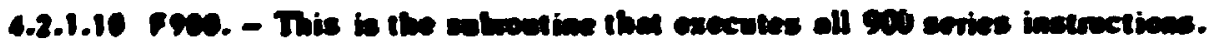

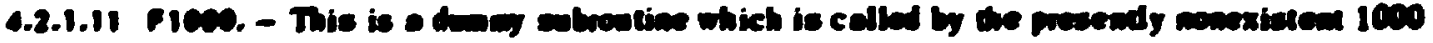

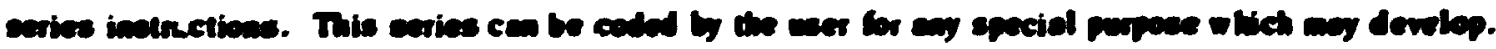

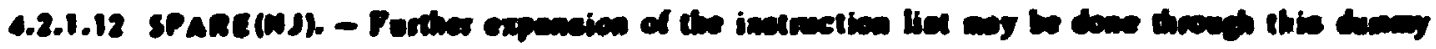

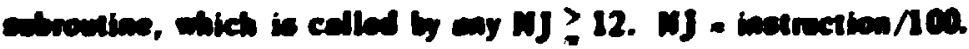




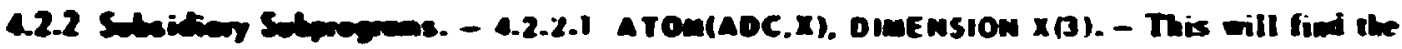

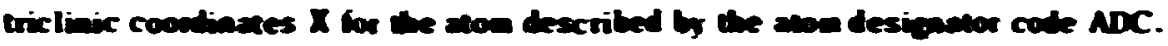

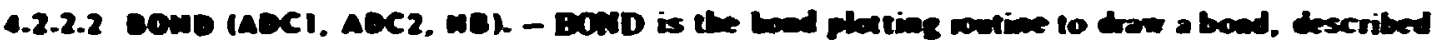

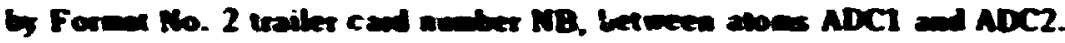

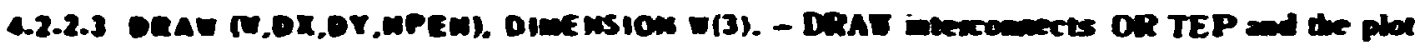

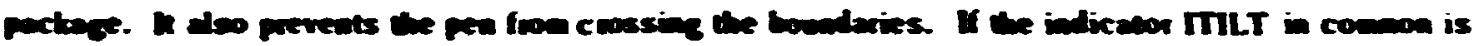

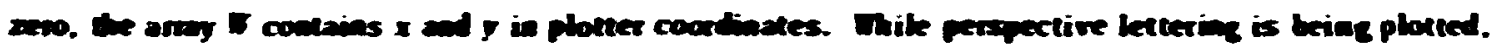

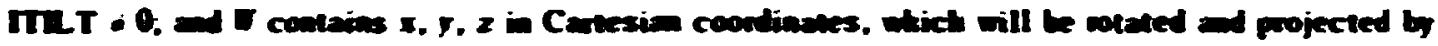

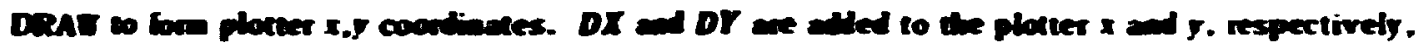

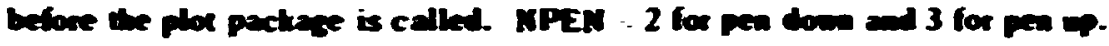

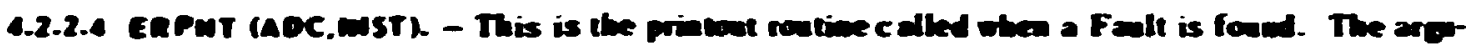

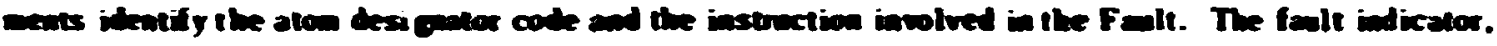
BC. is in conmen

4.2.2.5 PAXES (ADC.1T rPE1. - Ne coreciance (Jispersion) mentin for the therml ellipsoid or its

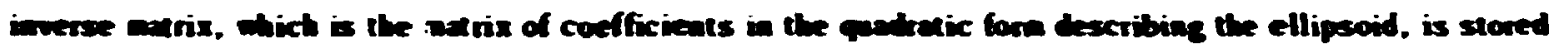
in conmen a $Q$ for the 200 ADC.

ITIPE - O for covanasce mand

ITYPE . O for ellipsoid quatratic borm motrix

ITYPE. - 1 besed on triclinic system

ITYPE: - 2 bosed on morkine Cartesien system

ITYPE: $=3$ besed on reference Cartesian system

4.2.2.6 PLTXY (X.Y). DImE usion X(3), Y (2). - This calcables the ploter coordianes $Y$ fron the encaled Cartesian coondinates $X$. The distance to the closest boundary of the plot is pleced in common a location EDGE.

4.2.2.) PaOJ (D,DP,X,X0,VIE W,11,12,13). DIMEMSION 0(3,129),DP(2,129),X(3),XO(3). - This routide is used to obtain an arrey. DP. of ploter coordiabtes from a scaled arroy. D, of points described in Carresian coondinakes. X, XO, and VIEV are parameters involved in the projection, and I1, 12, 13 are DO losp paraneters for indexing throuth the array.

4.2.2.8 RaDiaL(WD). - Given two conjugate radius vectors of an ellipse in the arrey DA in common, RADIAL eanetates a "redial" aray (D in common) of points lyiac on the ellipse. From 8 to 128 points

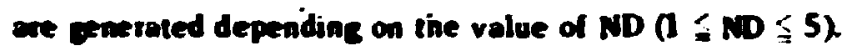

4.2.2.9 SEARCH. - batructions 101, 102, 402, and 403 utilize this routine to conduct an exheust ive (but educated) search to liad all points within a sphere or rectangular box. Interotomic distances and andes are olso colculoted for the 100 series.

4.2.2.10 stont. - This routine stores atoms in (or removes atoms from) the A TOuns array. Coondinetes in whichuret system is in use and the atom designotor code are communicated to STORE vis arrey VI of common.

4.2.2.11 XV2 $(A D C, X, 1 T Y P E)$, DIMENSION $X(3)$. - Coordinates for atom ADC are returned in $X$. ITYPE $=0$ : triclinic coordinetes 


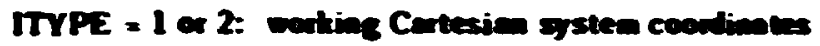

TYPE = 3: refenesce Contesion systed cosulindes

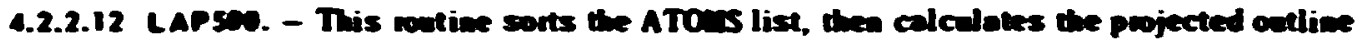

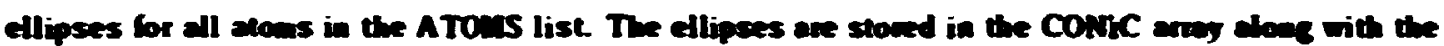

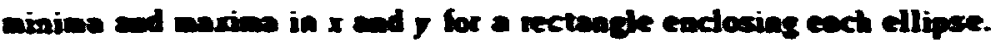

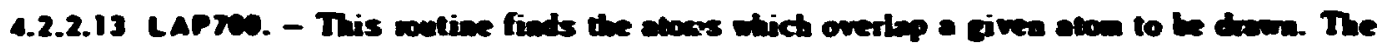

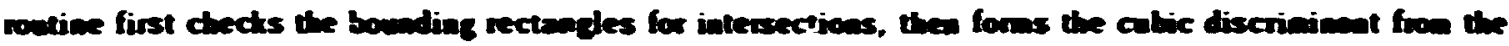
Podetic descriptions of the two projection ellipses. The discriaient provides a specification for conplete overlep. pertial ovedlep or wo overlap. A list of 9 to 20 interferiag ellipes is compiled

4.2.2.14 LAPEN. - This watine is used in the "Projected Ontline Stonge Step" to stoce the projected quadeades for the boads specified by the twiler conds of the 511. 221, and 202 instructions.

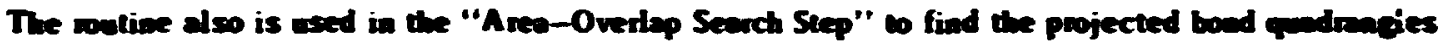
which overiep a given boud to be drow. A list containing op to thirty interferiag qudrandes is conpiled

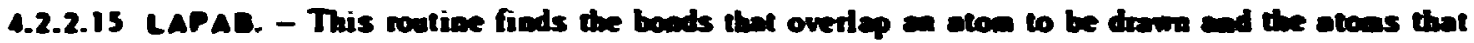
overlap a bood to be drawn. It is used is the "Anea-Overlap Seach Siep."

4.2.2.15 LAPDRw. - This metiae chects each line segnent to be drawn for intersection with the interferiag ellipses and qudreagles and compiles a list of intersections. The intersection list is sorted accordiag to distonce aloag the line sejent, ad the intersection pottern is enalyzed to deternise which subserments ase visible and which are hidden. The line subsegments are pased to the SCTaEE notiae.

4.2.2.17 SCRIDE. - This reutine filters out the hidden line sepents and passes the visible line sewpents to the DRAH routine.

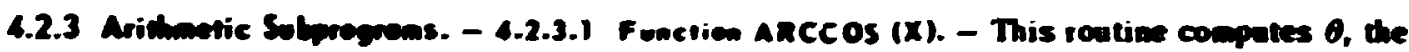
axc cosine of $X$ in degres; $0 \leqq \theta \leqq 1800$.

4.2.3.2 AXEO $(A, X, B, N)$, DImE NSION A(3,3),X(3,3),8(3,3). - This wortiae solves the matrix equation $A X=B$ for $X$. The motrices $B$ and $X$ ore $(3, N)$ and $A$ is always $(3,3)$. To iavert $A$, ande an ideatity matrix.

4.2.3.3 AXES (X, Y. A, ITYPE), DIME NSION X(3),Y(3),A(3,3)- - This routian provides three orthogonal colum vectors in A, each $1 A$ long, from the $t$ wo vectors $X$ and $Y$.

ITYPE > 0: Cartesion system

ITYPE $\leq 0$ : triclinic systea

$|\operatorname{ITYPE}|=1: A_{1}: X_{;} A_{2}=(X \times Y) ; A_{3}=X \times(X \times Y)$

|ITYPE| $=2: A_{1}=X ; A_{2}=(X \times Y) \times X ; A_{3}=X \times Y$

ITYPE = 0 : same as type 2 except $X=a$ crystol axis, $Y=b$ crystal axis.

4.2.3.4 DIFV $(X, Y, Z)$, DIMFNSION $X(3), Y(3), Z(3)$. - This routine performs the vector subtraction $X-Y=Z$. $Z$ mory have the seme locotion $X$ or $Y$.

4.2.3.5 EIGEN (A,X,B), DIMENSION A (3,3),X(3),8(3,3), - EIGEN determines the three eigenvalues $X$ and the three column ei genvectors $B$ of the matrix $A$. Indeterminate eizenvectors are replaced by zeros and the Foult indicator NG set to a negotive value (eigenvectors art assigned for the indeterminate cases by PRELIM). 


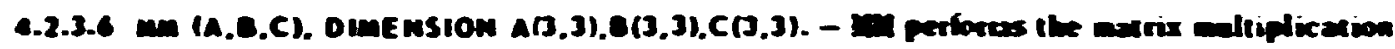

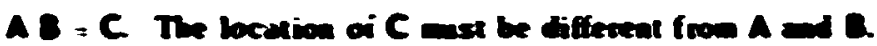

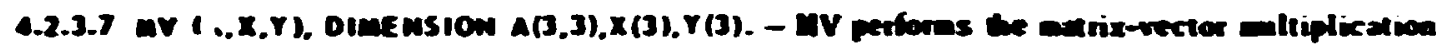
$\Delta X=Y$. The bedion of $Y$ ant be differen froe $A$ and $X$.

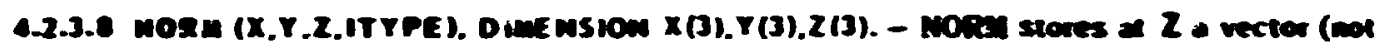

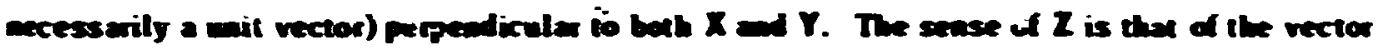
poodect $\mathbf{X} \times \mathbf{Y}$.

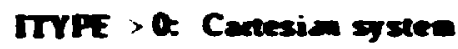

ITrPe $\$$ a tricliaic system

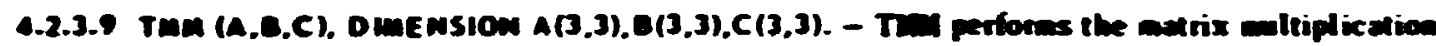

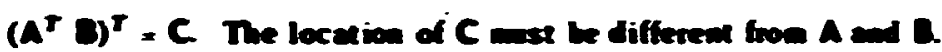

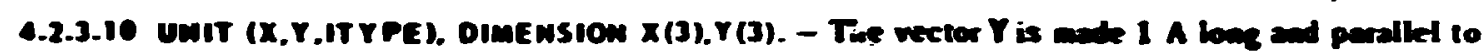

$X$. The vectors $X$ a $Y$ arg have the same bection.

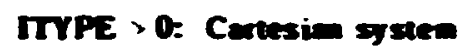

ITYFE < 0: tricliaic sostem

4.2.3.11 Vn (X,A,Y). DunE NSION X(3),A(3,3), Y (3). - Vil performs the nector-matrix maltiplication $X^{T} A=Y^{\top}$. The bection of $Y$ was be difienent foon $X$ and $A$

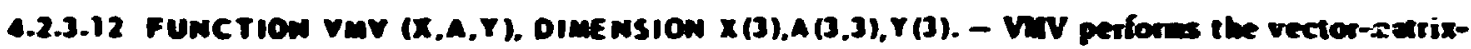

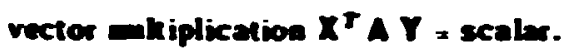

4.2.3.13 Function $\because(x, y)$, DIME wSION $x(3), Y(3)$, - VV performs the vector-vector maltiplication $\boldsymbol{X}^{\mathbf{T}} \mathbf{r}=$ scolax.

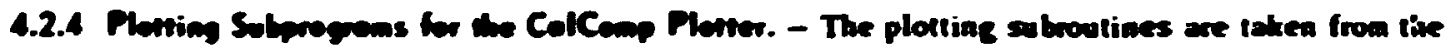
Librery routiones curreatly in we at Oak Ridge National Laboratory with the CDC 16OAA and the IBM 7090 computers. A CalComp nodel 520 ubpetic Tape Plotine System is used. The three major rove ines required ane detived from the CalComp sobroutines PLOTS, SYMBOL. and NUImBER. The OR TEP modifications an called PLOTS, SHMBL, and NUMBUR.

4.2.4.1 subrestine plots. - This is an unmodified CalComp Libary routine with two eats points.

b) ENTRY - PLOTS (A, LENGTH. LTNO)

This is the initializatica eatry for the plotter packace and should be used enly once in the program. This call must be made prior to usage of any other subroutines in the pactege.

$A$ is an exey wich mey be used by the ploting peckere for storine deta to be written on the plot tepe.

LENGTH is the number of locations in A available to the plotter packap.

LTNO is an integer which tells the plotter package the logical tepe number of the plotter tape. 
b simative F20 the here

Direnson ilsolisio)

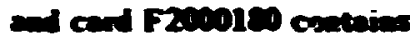

"210 CALL PLOTS (PLA,150, LTNO)"

tor the Coc ICath ot

"210 CALL PLOTS (PLAMISO).150,LTNO)"

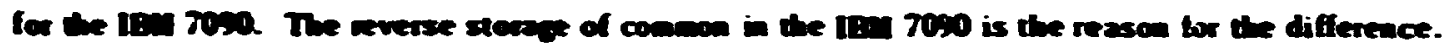

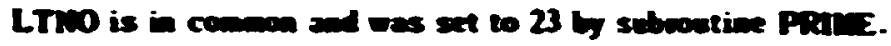

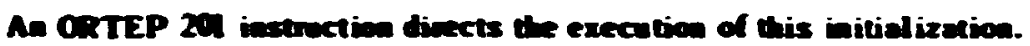

b) घRTR - PLOT (R.TIPEN)

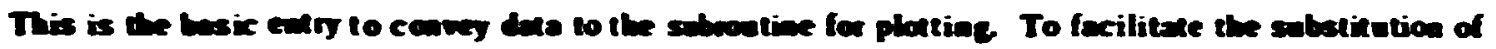

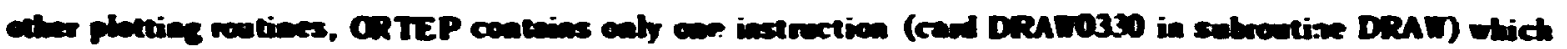

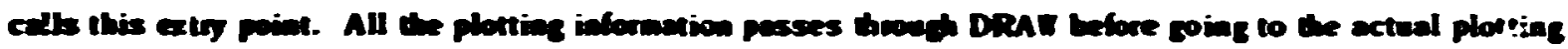
netive PLor.

$X$ is the alscissa expesed in inches.

$Y$ is the odinate expessed in incles.

IFEX = 3, the pen will be lafied prise to enecution of the movenemt to the civen (X.Y) position.

IPEN = 2, the pea will be lowened to the popet and a straith tine will be drawa from the cureat (X.Y) to the given (X.T) pasition.

IPEN = -3, te whontine will iaverpart this a beine the end of the curreat plot; and. Followine aovenemt to the wew $(X, Y)$ position, it will set $X=0.0$, so that a new erieia is established for the Gollowiag plot (a OxTEP 200 instruction execeles this termination procedbre).

This sabootian beeps track of cursent $X$ and $Y$ positions, and whether or not the pea is in contact with the paper. I storts dato in the array A provided by the prograner and wites sat a record on the specified tape each time the storocr aree is filled or an end-ofplot call is made. It also tenerates sequential plot abrescex for each plot on the mapetic tape, so that physical plotting of the plats cas be dose in any order, meardleas of the order in which tey wete placed on tape.

4.2.4.2 Sebcoine smeOL. - SMBOL differs from the standerd routine SYMBOL in two respects:

1. The input positional porameters specified in the inpul arganent should be an array containing $X$. $Y$. and $Z$ in adjacint memory locations. Three-dimensional parameters are requined to produce perspective labels. The $Z$ pameter is not used by SIMBOL but is transfersed to another army that is referenced when SHMOL calls DRAB.

2. The slandard routine SYMEOL calls PLOT directly while SIMEOL calls DRA which in turn calls PLOT. When perspective labels are used, DRAW will perform a three-dimensional rotation and a projection of the grid points on which the letters are foimed, to obtain true perspective. The calling sequence for DRAW is dexcribed in \$.2.2.3. 


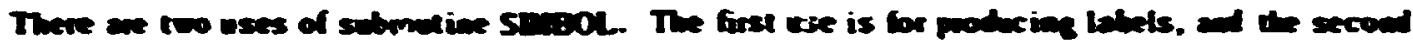
i for pletting one of 15 special centered symbols.

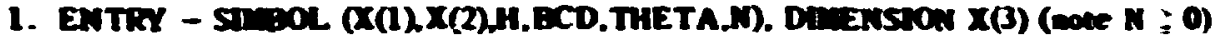

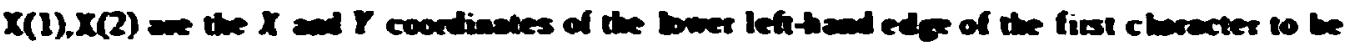
dremen.

$X(3)$ is the 2 coosinate. In is ased only with perspective labeline

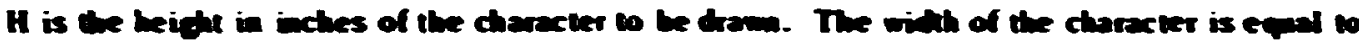
is be beifen and the character spacing is ; the beide.

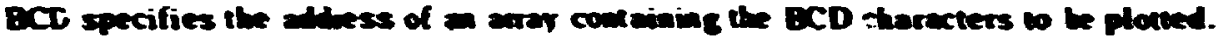

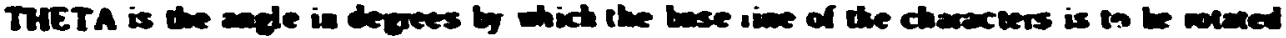
consenclechise from the positive $X$ aris.

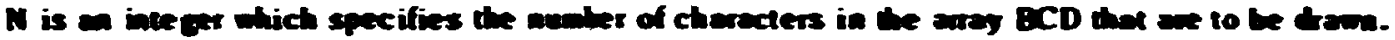

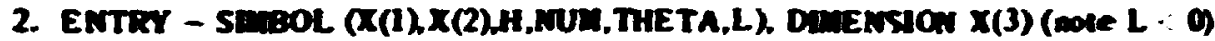
$X(1) X(2)$ ace the $X$ and $Y$ coordiantes of the center of the syobol.

$H$ is the heidte of the syabol wo blated.

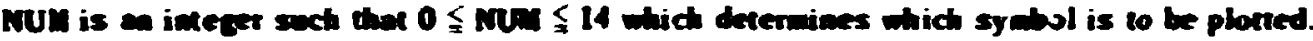

A list of the invegers and tere symbols generated is show in Fig 4.2.

THETA is the ande of rotation as described previoushy.

$L=-1$ : the ceatered sybuol will be ploted withont a line being drown from be previons (X.Y) position.

$L<-1$ : a straith liae will be dram from the previous $(x, y)$ position to the given $(x, h)$ position.

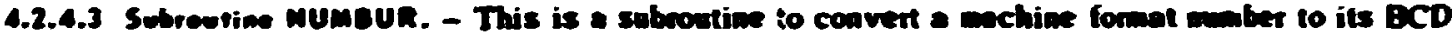
equavalent and plot it eccording to a specified fomat.

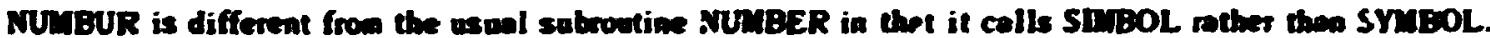

ENTRY - NUIMUR(X(1),X(2),H,A,THETA,N)

$X(1), X(2), H$ and THETA are described in Sect. 1 of the SIMBOL roatine

$A$ is the address of the flosting or fixed point nubber which is to be plotted.

$N$ is the nubber $a$ digits to the right of the dacinal point. $A(-1)$ value will suppress the deciand poiat. 


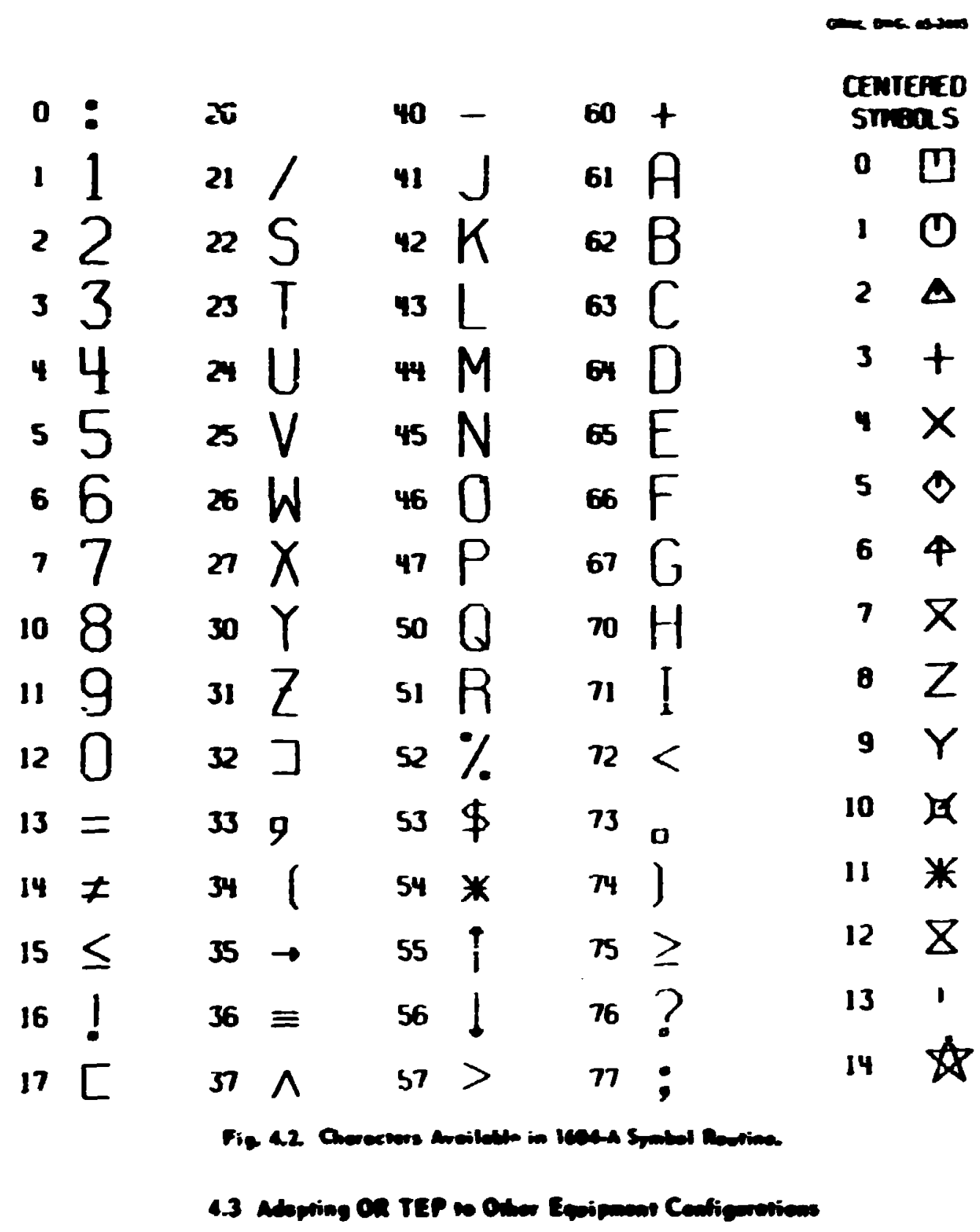

Cord images ${ }^{2}$ for OR TEP will be provided to crystallognophers and others who request thet the proprem be sent to there.

FORTRAN decks are available in IBm 360 fORTRAN IV ad IE 7090 FORTRAN IK The FORTRAN subprograns are amanged alphobetically withia the FORTRAN source dechs. An exception is maIN. Wich is first in each deck.

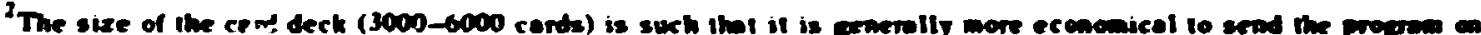
mepnetic tope. If conve aient, the user should send a blonk mogoctic tope to the evether. Cord iesages will be written on that tope in on ecoed upon lomat and the tope rerumed to the sender.
} 


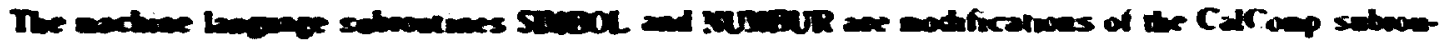

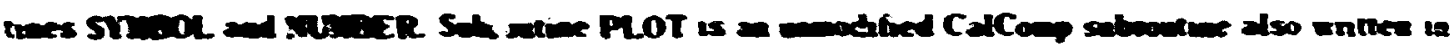

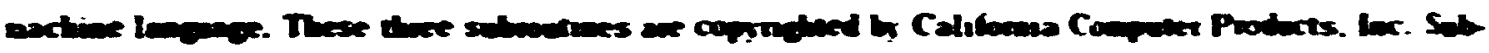

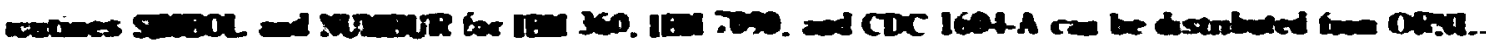

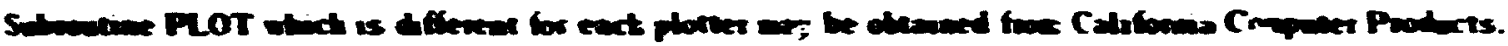

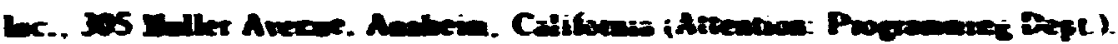

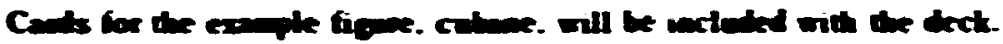

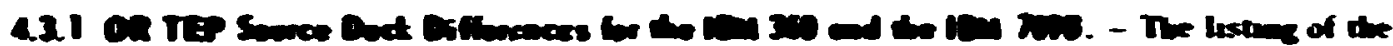

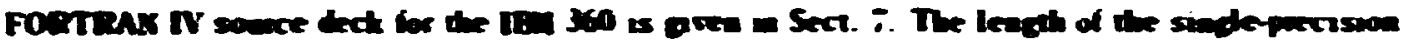

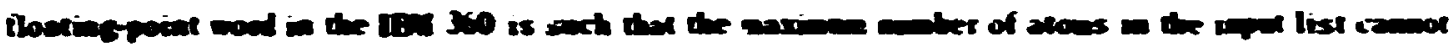

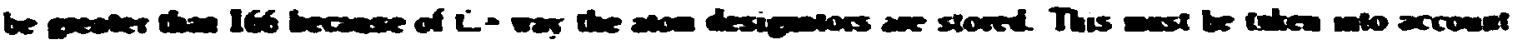

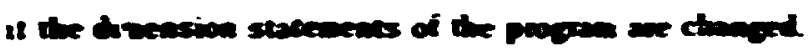

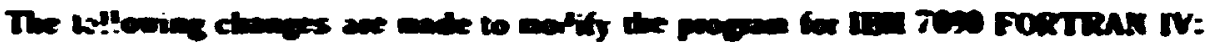

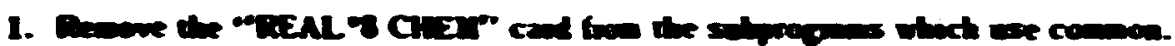

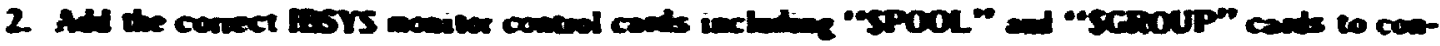
sedve newors spere.

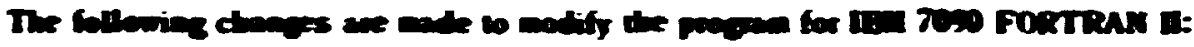

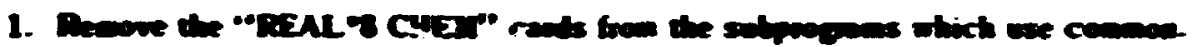

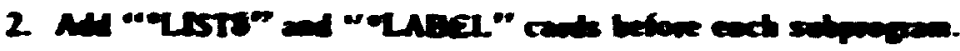

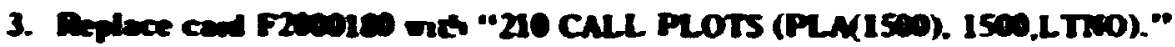

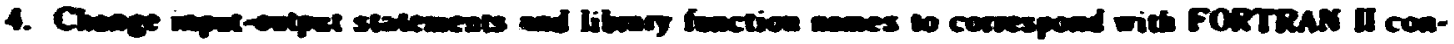
nention.

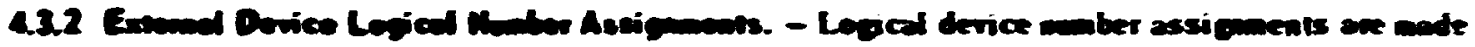

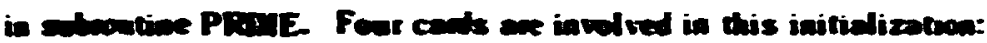

\begin{tabular}{|c|c|c|c|c|}
\hline Teape Forevic & Syebolic & & Primer & $\begin{array}{l}\text { Lecenion } \\
\text { in Preve }\end{array}$ \\
\hline -) Enates lapt & $\mathbf{m}$ & - & $\mathbf{s}$ & pisines \\
\hline 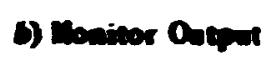 & mont & $=$ & 6 & Pidinese \\
\hline c) Scruach & ast & $=$ & 8 & Pinges: \\
\hline d) Plottins & LTIO & $=$ & 23 & \\
\hline
\end{tabular}

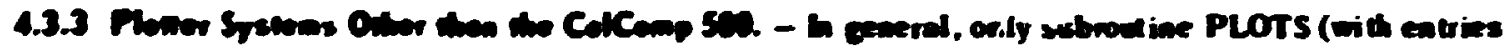

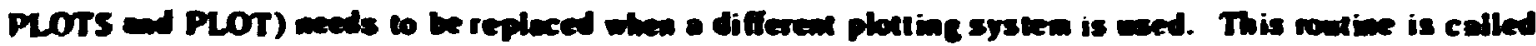

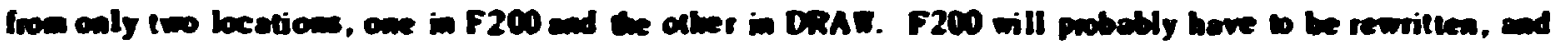

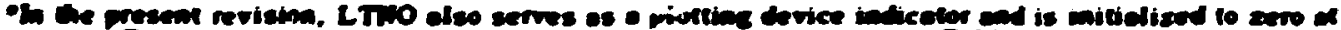

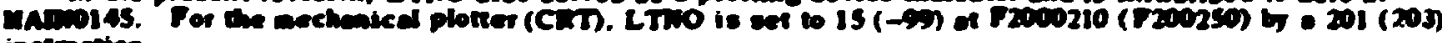
inctinctien. 


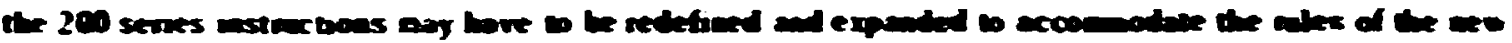
syster.

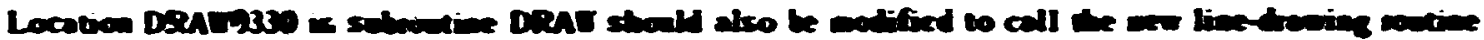
with de conect aromeat.

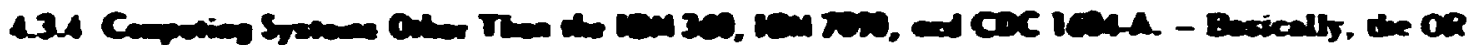

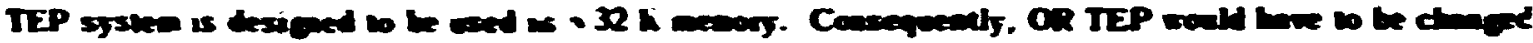

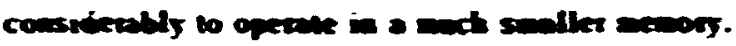

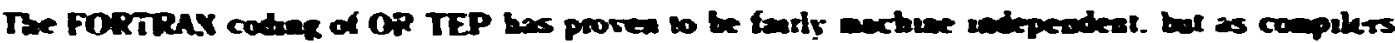

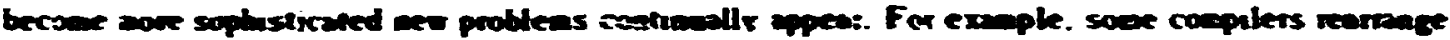

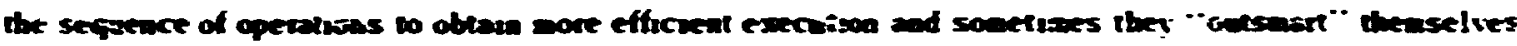

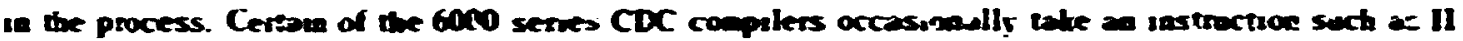

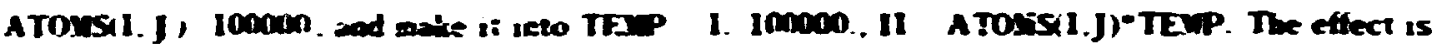

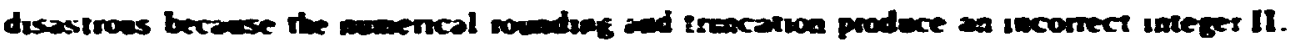

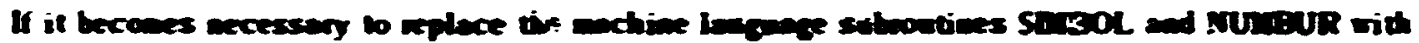

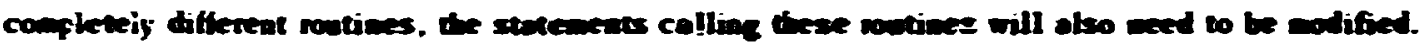

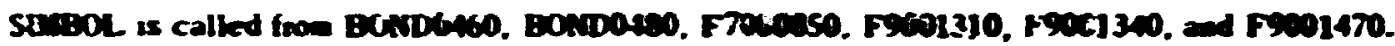

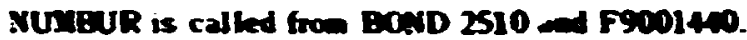

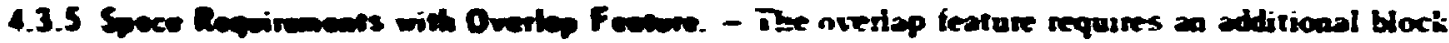
of apfroxuavielv $15 \mathrm{k}$ wonds of computer mewory an will casse ORTEP to eIceed the memory of a $32 \mathrm{k}$ computes. For computers with a working storage wader $45 \mathrm{a}-60 \mathrm{~K}$ wonds, the oved ap feature mon be deleted br cemoving subroutines LAP500. LAPTOS. LAPEM. LAPDE. LAPAB. and LAPCOA and substituliag ommy subnoutiaes for the first foer of these six sabroutines.

\subsection{Adlitien of Now ON TEP batuctions}

Occasions wll anse when additional spiciad purpose instroctions would be useful. For example. perheps a cell outline routine would be desurable. (Originaily. the 1000 seties of iastructions mere planned for draming a parallelepiped defined b; fow genetal vectors. Howe:ser. this feature latet seemed some what redundaat and was omided. since cryalal cell oullines can be produced with jodicions usage of smoll diviny atoms and the 800 seties instructions.)

The subroutine: F1000 and SPARE, are intended to be used for additional instanctions. All 1000 series insiructions call suboutine F1000. which is currently just a dunby routine. Iastructions : 1200 call wother dunny wutune, sut routine SPARE(NJ). nhere NJ - instruction number 100.

All Arithnet :c subprogrems (see \$.2.3) and mony of the subsidiany su.progroms (see 4.2.2) ase aralable for coding these Mainstream subprokrans (see 4.2.1) 
A9)

(.2333)

Aarevis.

Aativis.3)

$A D(3,3)$

Antan

ATosect 500

Be(3.3)

p POT?

core.10)

crentios

P Costrot

Dr3.130)

DA(3.3)

DP2.130)

P DISP

EDCE

EV(3.100)

P Fone

FS(3,3.4)

P IN

P ITILT

$\mathrm{KO}(5,10)$

P LAT

P LTNo

NATOM

P MCD

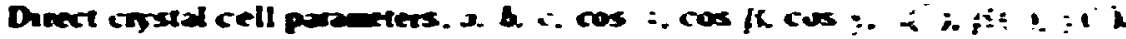

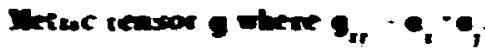

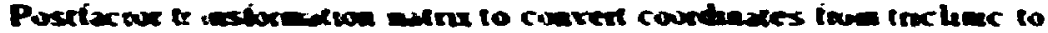

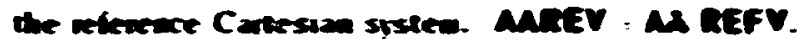

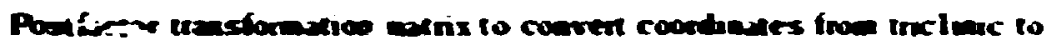

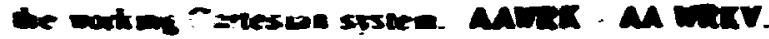

Mentury eatre

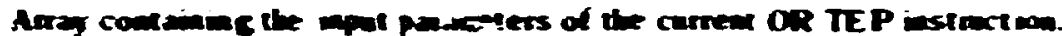

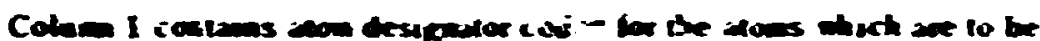

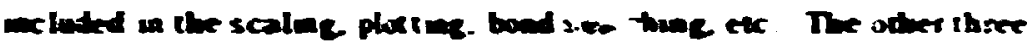

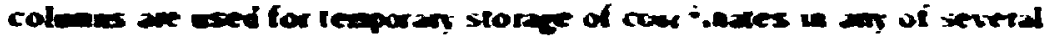
coondacte systers.

Reciprocal setric reasor. A $\boldsymbol{M}^{-1}$

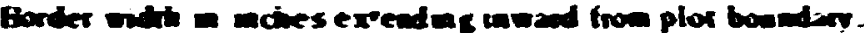

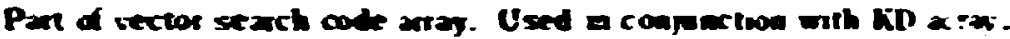

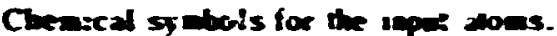

Comorats used a sobrouthe RADMI.

Arrey ta which thre dmensioad potats on a elipse ine stoned be RADR:.

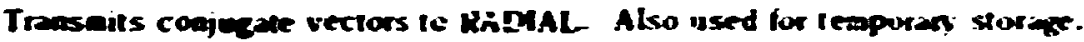

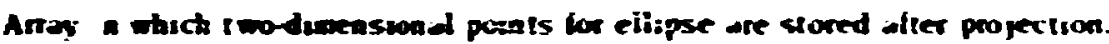

Displacemear purameter loc tetraciar-

Disrace in inches foom a projected point to the closest boundary. Set in PLTXY.

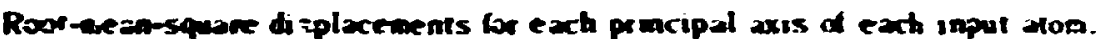

Cosine of crifical agle between boud and Cartes:an $z$ exis vectors tor

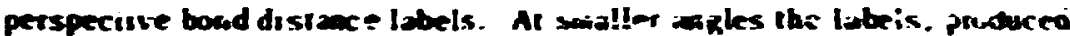
from suboutine BOSD. are drawn withod herspective to preveni eyressive loreshortenuac.

Rotation andices for input symactry operations bosed on iriclinic sy $\mathbf{e m}$. Used with TS arty;.

Logical aumber frex sonitor isfut mogetic lape.

Indicator used to sigral subrowtine DRA th. Whether or not io do perspective labelias ("Tilned Tilles").

Part of vector seanch code arry. Used in conjunction with CD.

Number of eatries in A TOMS arras.

Logical tape nomber for magnetic plotting tape.

Nunber of inpet etoms.

Number of Fonnet Ho. 2 Iroilet cards for an insinclion (rector search condes).

Note: (P) indicates "prime parameters," which are initialized in subroutine PRINE. 
\$3.1001

PA(3.3.100)

PACi3.5;

Patr(3.3)

PFF ;(3.3)
FAULT IEDACATOR (see 3.t).

Hstuction manbed/100.

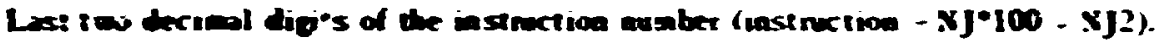

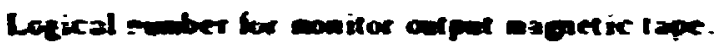

Logical ander for scrath appetic tape.

Nesber of inpel stmanets; operation:-

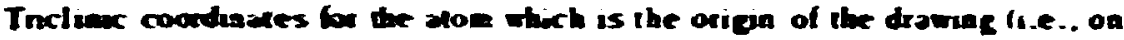
the optic aris for the projection).

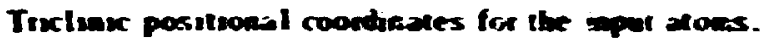

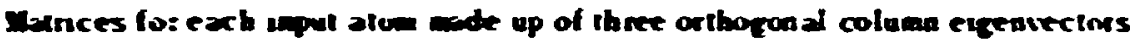
each 1 A loog. besed on the inclinic sy stest (principol axis vectors?.

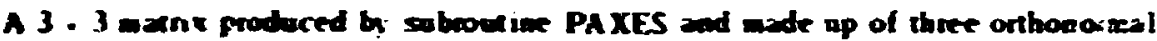
pnacipal axas columa vectors. based on enther the working or refenence Cirtesias. sistern. Columas 4 and 5 are used in seburwine F.OO to duplicate coive.n. 1 and 2 br ease in iadexiale.

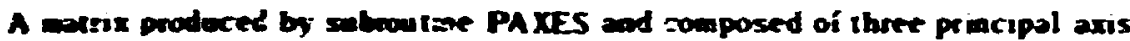
colena vecturs exch I a loag. based on the tnchianc sistre.

A morrix podaced by sobroutine PAXES. Coatouns either the dispersion matrix or its inverse. based on either the woking or reference Cartesian systeas.

A matrx made up of three orthogonal column vectors, each 1 A bang. based in the inclunic system. This is the bose recto t ciplet for the reference Cortesuan coordinete sistem. The ironspose is the posifactor transformetion man for converting coodmates from the reference othogonai systern :o the trxiluic system. REFV' ANREY-"

Reguiztes the resolution of the plotung of a pren ellipse as a function of the inges! priacipal axis " in the piven ellipsoid of the scaled modet.

$$
\begin{array}{ll}
x: \operatorname{Res}(1) & \text { 128-point ellipse } \\
\operatorname{Res}(1) \cdot \operatorname{Res}(2) & \text { 6-point ellipse } \\
\operatorname{Res}(2) \cdot \operatorname{Res}(3) & \text { 32-point ellifse } \\
\operatorname{Res}(3) \cdot x & \text { 16-point ellipse }
\end{array}
$$

Res( $(5)$ is not used.

The thas displacements along the principal axes in arrays PAC and PAT.

The suble of ti.e model in iaches per anstrom before projection.

The scale factor ratio which sets the ellipsusd sale relative io SCALI. If SCAL2 : 1.54. then the instantaneous position of the atomic canter will be within the ellipsoid 5\%. of the time 450 . probability ellipsoid).

SCL - SCALI times SCAL2.

A oration matrix based on the andle THE.TA which is set inseruction 302.

The exagkerated iond taper parameter. The rop and bollom ends of a bond have radii: RADIUS - 1. TAPFR *T6 whete T6 cosine of anple between bond and $x$ axis $x$ Cortessin system.

Note: (P) indicates "prime parameters." which are initialized in subroutine PRIMF.. 
P THETA

TITLE(12)

TITLE2(12)

$T S(3,48)$

P VIET

$\operatorname{vT}(3,4)$

V1(4)

WRKV(3,3)

P XLNG(3)

$P \quad X O(3)$

XT(3)
Angle in degrees between plotter $x$ axis and lettering base-line vector.

Alphanumeric job tilke storace.

Alphanumeric information storage for Fonat No. 3 trailet card.

Translation vector for each input symactry operation. Used with FS array.

Vieving distance in inches.

Perspective title rotation matrix and translation vector. Alsu used for tewporaty storage.

Array to transfer data to subroutine STORE. Also used for temporary storage.

Temporary sto:age.

Same definition as for REFV except that this onc is for working Cartesian sysi=m. WRKV ${ }^{T}$ - MAmRK-1.

Elezrenis (1) and (2; are $x$ and $y$ pint dimensions. Element (3) is not used.

Eiements (1) and (2) denote the position in plotter coondinates (:n inches) where OPGN is placed. Element (3) is used to transfer $Z$ coordinates to subrowine DRAW when perspective lettering is used.

Triclinic coordinates for an aton position are flaced here by subrouline XYZ.

Note: (P) indicates "prime parametets," which are initialized in subrout ine PRRE. 


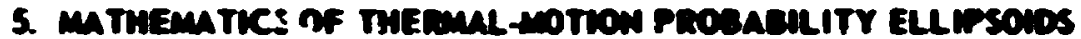

It is cowresien to develop the physical sigaificance of the amisotropic tereperature factor with the

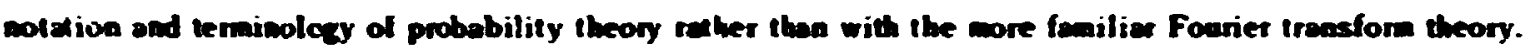
The results are, of coorse, identicai regordless of the terminolosig used. The reason for this choice is that the literature of mabeanical statistics and probability theory is somewhot meater and easier to

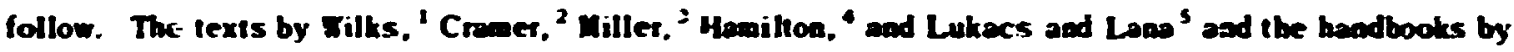
Buriagton and lay ani Owen' are found to be paricularty useful.

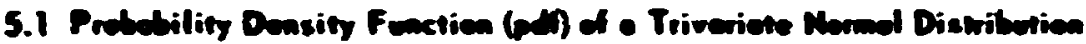

Given three chance variables $X_{2}, X_{2}, X_{3}$ and 5 which is a region in $X_{2}, x_{2}, X_{3}$ space. The probability $R(S)$ that the pcint $\left(X_{1}, x_{2}, x_{3}\right)$ falts in the reqion $S$ is given by

$$
P(s)=\iiint_{5} a x_{1}, x_{2}, x_{3} ; d x_{2} d x_{2} d x_{3}
$$

If the integration is carried over a:l space. then

$$
\left.\iint_{-2} \int d x_{1} \cdot x_{2} \cdot x_{3}\right) d x_{1} d x_{2} d x_{3}-1
$$

The fuaction $\alpha x_{1}, x_{2}, x_{3}$ ) is called the probzitity deasity function (pd) for the joint distribution of $X_{1}, X_{2}, X_{,}$Using vector notation, we can designate the pdf as $d(X)$.

When the distribation is the type said to be nomai or Gaussian, the pdf is

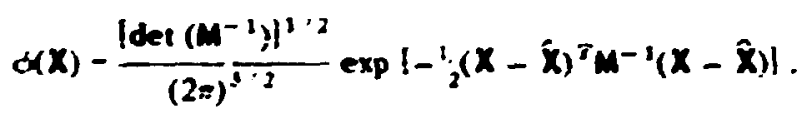

The matrix $M^{-1}$ is the inverse of the symatrical dispersion (variance-covariance) matrix $M$ where

$$
M=\left(\begin{array}{lll}
\sigma_{1}^{2} & \sigma_{-n_{2} p_{12}} & \sigma_{1} \sigma_{3} p_{13} \\
\eta_{1} n_{2} p_{12} & \sigma_{2}^{2} & \sigma_{2} \sigma_{3} \rho_{23} \\
n_{1} n_{3} \rho_{13} & \sigma_{2} \sigma_{3} p_{2} & \sigma_{1}^{2}
\end{array}\right) .
$$

The symbols $\sigma_{\text {? }}^{2}$ represent the second moments or variances about the mean poxition $\hat{x}$. The symbol$\sigma_{j} o_{j} p_{1,}$ are the corresponding covariances and $p_{1,}$ are the correlation coefficients.

'3. S. Wilks, Methemeticel Srotiefice, Wiby, New York, 1962.

2H. Cremer, Renden Veriebles and Probebility Dieuributions, Cambridee University Press, London, 1 cb2.

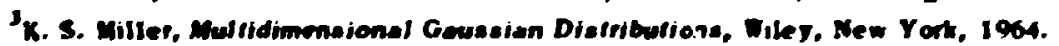

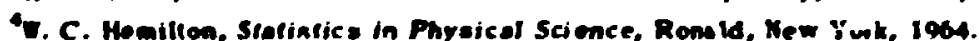

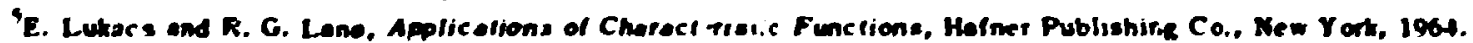

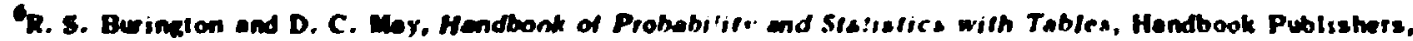
Sandusky, Ohio, 195.3.

'D. B. Owen, Handbook of Elofinfical Tablen, Addison-Wesley, Reading, Mass., 196... 


\subsection{Eqpipmblabiliny Ellipsoids}

For a proper nowal distribution tbe quadratic form $(x-\hat{x})^{7} y^{-1}(x-x)$ is positive defiaite, and a priacipal axis transtonation is possible which will make the cross corretation coefficients $p_{j}, 0$ (i $\left.+j\right)$. This transformation is discussed in 5.4. The result of the transformanion is the pdI

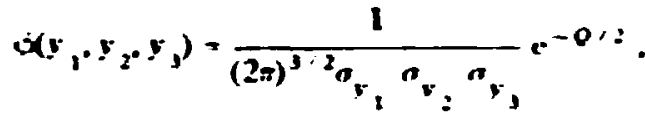

where

$$
0=\frac{\left(y_{2}-y_{1}\right)^{2}}{a^{2}} \cdot \frac{\left(y_{2}-\hat{y}_{2}\right)^{2}}{a_{2}^{2}} \cdot \frac{\left(y_{3}-\hat{y}_{3}\right)^{2}}{a_{2}^{2}}
$$

The $y_{1}$ are coordinate: Jased on the Cuntesian pnncipal axis system and ": are the variances slong the principal axes. $i=1.2,3$.

The nomal probability density function is constant for poims on the ellipsoid $O-C^{*}$ where $C$ is a constant. The probability that a randim point $\left(y_{1}, y_{2}, y_{0}\right)$ in the distriburion will fall inside the ellipsoid

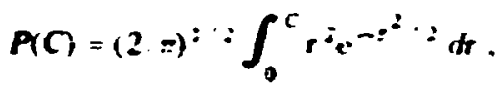

This tesult is derived from (5.1.1). (5.2.i). and (5.2.2) by transforming to spherical coordinates.

When $C=1.5382 . P=0.5$ a-t the corresponding ellipsoid is called the 50 ; probsoility elligsoid. A able of $P$ us $C$ values is found on page 203 of Owen's Handbonh of Stintisticial Tiable.s." For conven. ience, that table is reproduced here as Tablo 5.1 .

\subsection{Omanecheristic Functien (c.f.) of e Triveriente Monmal Distributien}

The charerteristic fuaction on corresponding to a :rivanate distribution $\delta(X)$ is the expected value of $e^{i T} x$, nanely.

$$
N T)-\int_{-\infty}^{x} d(x) e^{. T^{T} x} d x
$$

For the trivariate nomal pdf (5.1.3) the conesponding characteristic function is

$$
\phi(T)=\exp \left\{i T^{T} X-1,2 T^{T} M T i\right.
$$

where $M$ is the variance-covariance dispersion matrix described in 5.1 and $\dot{X}$ is the center of mass of the distribution.

The cryst.dlogrephic structure foctor quation which inrorporates general anisotmpic tempersture factor coefficients is

$$
F(h)=\sum_{n} f_{n}(h) \exp \left(2 \pi i h^{\top} \hat{X}_{n}\right) \exp \left(-h^{T} B_{n} h\right) .
$$




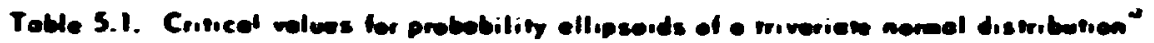

\begin{tabular}{|c|c|c|c|c|c|}
\hline $\boldsymbol{P}$ & C & $\mathbf{p}$ & c & $\mathbf{P}$ & c \\
\hline o.ni & 0.3149 & 0.41 & 1.3842 & 0.81 & 2.1824 \\
\hline O.0! & 0.4299 & 0.42 & 1.801 .3 & 0.82 & 2.2114 \\
\hline c.0.3 & $0.49 \times 1$ & 0.43 & 1.4183 & 0.83 & 2.2416 \\
\hline 0.04 & 0.5470 & 0.46 & 1.4354 & 0.84 & 2.2730 \\
\hline 0.05 & 0.5932 & 0.45 & 1.4524 & 0.85 & 2.3059 \\
\hline 0.06 & 0.6334 & 0.46 & 1.4695 & 0.86 & 2.3604 \\
\hline 0.07 & 0.6699 & 0.47 & 1.4066 & 0.87 & 2.3767 \\
\hline 0.08 & 0.7035 & 0.48 & $1.503:$ & 0.88 & $2.4 ; 53$ \\
\hline 0.09 & 0.7349 & 0.49 & 1.5209 & 0.89 & 2.4563 \\
\hline 0.10 & 0.7644 & 0.50 & 1.5382 & 0.90 & 2.5003 \\
\hline 0.11 & 0.7924 & 0.51 & l.ssss & 0.91 & 2.5478 \\
\hline 6.12 & 0.8192 & 0.52 & 1.5729 & 0.92 & 2.5997 \\
\hline 0.1 .3 & 0.0487 & 0.53 & 1.5902 & 0.93 & 2.6571 \\
\hline D.14 & 0.8694 & 0.54 & 1.6000 & 0.94 & 2.7216 \\
\hline 0.15 & 0.8932 & 0.55 & 1.6257 & 0.95 & 2.7955 \\
\hline 0.16 & 0.9162 & 0.56 & 1.6436 & 0.96 & 2.8029 \\
\hline 0.12 & 0.9386 & 0.57 & 1.6616 & 0.97 & 2.4912 \\
\hline 0.18 & 0.9605 & 0.5e & 1.6797 & 0.96 & 3.1365 \\
\hline 0.19 & 0.9818 & 0.59 & 1.5680 & 0.04 & 3.3682 \\
\hline 0.20 & 1.0025 & 0.60 & 2.9364 & 0.991 & 3.4019 \\
\hline 0.21 & 1.0230 & 0.61 & 1.7351 & 0.992 & 3.4390 \\
\hline 0.22 & 1.0430 & 0.62 & 1.7540 & 0.493 & 3.4806 \\
\hline 6.23 & 1.0627 & 0.63 & 1.73 .30 & 0.994 & 3.5280 \\
\hline 0.24 & $1.005: 1$ & 0.64 & 1.7924 & 0.995 & 3.5830 \\
\hline 0.25 & 1.1012 & 0.65 & 1.8119 & 0.996 & 3.6492 \\
\hline 0.26 & 1.1200 & 0.96 & 1.8318 & 0.497 & 3.7325 \\
\hline 0.27 & 1.1386 & 0.67 & 1.8519 & 0.998 & 3.8465 \\
\hline 0.28 & 1.1550 & 0.60 & 1.8724 & 0.999 & 4.0331 \\
\hline 0.29 & 1.1751 & 0.69 & 1.8032 & 0.9991 & 4.0607 \\
\hline 0.30 & 1.1932 & 0.70 & $1.91 \%$ & 0.9592 & 4.0912 \\
\hline 0.31 & 1.2110 & 0.71 & 1.9360 & 0.9993 & 4.1256 \\
\hline 0.32 & 1.2280 & 0.72 & 1.9580 & 0.7994 & 4.1648 \\
\hline 0.33 & 1.2464 & 0.73 & 1.9904 & 0.9996 & 4.2107 \\
\hline 0.34 & 1.2638 & 0.74 & 20034 & 0.9996 & 4.2661 \\
\hline 0.35 & 1.2812 & 0.75 & 2.0269 & 0.9997 & 4.3365 \\
\hline 0.36 & 1.2995 & 0.76 & 2.0510 & 0.999 & 4.4335 \\
\hline 0.37 & 1.3158 & 0.77 & 2.0757 & 0.9999 & 4.5443 \\
\hline $0.3 n$ & 1.3330 & 0.78 & 2.1012 & 0.99999 & 5.0074 \\
\hline 0.39 & 1.3501 & 0.79 & 2.1274 & 0.999999 & 5.5316 \\
\hline 0.40 & 1.3672 & 0.80 & 2.1544 & 0.9999999 & 5.950 \\
\hline
\end{tabular}

-Reproduced from Ref. 7 by permission of Addison -wesley Publishine Company, Inc., Reading, Mass. The orieinel caption wes "Critical Volues for the Spherical Nomal Distribution." 
Whene

b is a vector giving the niller iadices.

$X_{n}$ is a vector giving the fractioan anit cell coordinates of the mh otom.

$B_{n}$ is the anisotropic temperature factor coefficient matrix, and

$f_{n}(b)$ is the atom forn factor value for atom $n$.

If a chance of variables $T=2 \pi \mathrm{h}$ is aade, thes $(5.3 .3)$ can be rewritten as

$$
F(T)=\sum_{n} f_{n}(T) \exp \left(i T^{T} \hat{X}_{n}-{ }_{2}^{1} T^{T} \frac{B_{n}}{2 \pi^{2}} T\right)
$$

The scaled anisotropic temperature factor matrix $\left(12 x^{2}\right) b$ is seen to be identical with the variancecovariance dispersion matrix $M$ in (5.3.2).

The corresponding crystal spoce trivariate normal poff for any porticular atom $n$ is

$$
\alpha(x)=\frac{\left[2 \pi^{2} \operatorname{det}\left(B^{-1}\right) !^{2} 2\right.}{(2 \pi)^{3}{ }^{2}} \exp \left|-\pi^{2}(x-\hat{x})^{T} B^{-1}(x-\hat{x})\right|:
$$

or if $M^{-1}=2 z^{2} s^{-1}$ then

$$
d(x)=\frac{\operatorname{det}\left(m^{-1}\right)}{(2 \pi)^{3 / 2}} \exp !-\frac{1}{2}(x-\hat{x})^{T} m^{-1}(x-\hat{x}) !
$$

which is identical to (5.1.3).

\subsection{Prinenpil Aris Trenstermetien}

The transformation of anisotrcpic temperature factor coefficients (for the general triclinic case) to principal axes of thermal motion is discussed by Waser." Busing and Levy. and Cruickshank ef al. 10

The principal axis transformation is necessary to find the themol-motion probability ellipsoids discussed in 5.2. The principal axes of the matrix $M^{-i}$ in (5.3.6) are the vectors $y_{1}, y_{2}, y_{3}$ for which the inner vector product $\left(y_{i}, y_{i}\right)$ has a stationary value subject to the constraint

$$
\left(y_{i}, M^{-1} y_{i}\right)=1 . \quad i=1,2,3 .
$$

Fot the general tricliaic crystal systen this means that the quadratic form $y^{\top} G^{-1} y$ has a stationary value subjected to the constraint

$$
y^{T} G^{-1} M^{-1} y=1
$$

J. Waser, Acro Crysr. B, 731 (1955).

7. R. Busing and H. A. Levy, Acre Cryar. 11, 450 (1958).

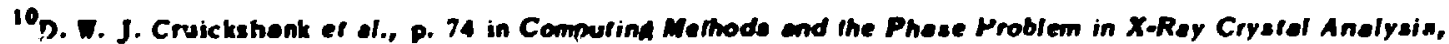
ed. by R. Pepinsky, J. M. Robertson, ent J. C. Speakman, Percamon, New York, 1961. 
where $G^{-1}$ is the metric tensor with components $\bullet_{i} \cdot \bullet_{j}$ and $\varphi_{i} \cdot \bullet_{j}$ is the scalar vector prodect of two of the three uait cell veckers. Iatroducies the Lagrage multiplier $1 / \lambda$ leads 20

$$
\left|G^{-1}-\frac{1}{\lambda_{i}} m^{-1}\right| y_{i}=0 \quad(i=1,2,3) ;
$$

premultiplying by un yields

$$
\left|M G^{-1}-\frac{1}{\lambda_{j}}\right| y_{i}=0 \quad(i=1,2,3) .
$$

Or we can do some additional rearragiag and obtain

$$
\left[G M^{-1}-\lambda_{i} \|_{y_{i}}=0 \quad(i=1,2,3)\right.
$$

Equation (5.4.4) is equivalent to one of the results derived by Busine and Levy, except the $\lambda_{j}$ obtained here ore the reciprocals of their $\lambda_{j}$ because we are doiag the priacipal axis trasformation on $M^{-1}$ mile theis formulation performs the transformation on $M$ The anerical procedure used in OR TEP fiads the eigenvalues and eigenvectors of the unsymmetrical matrix $\mathrm{MG}^{-1}$ in (5.4.4). 


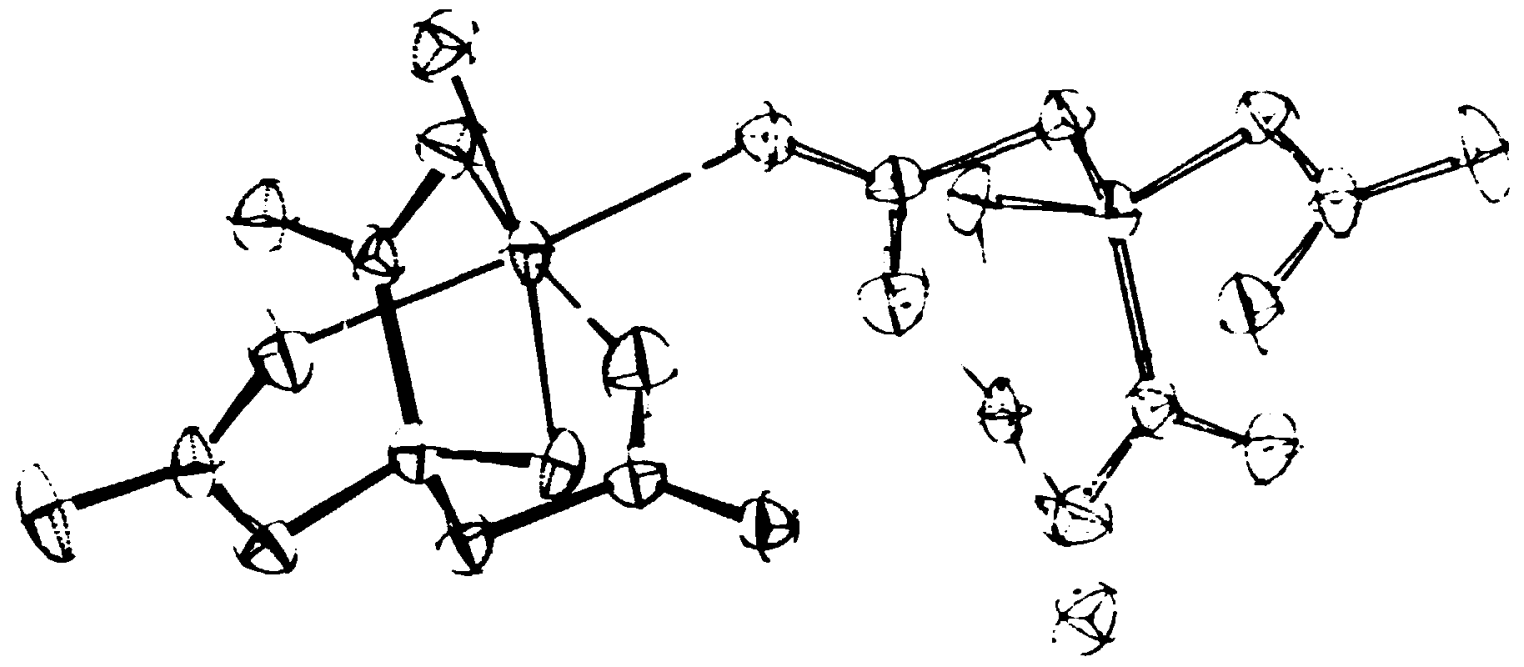

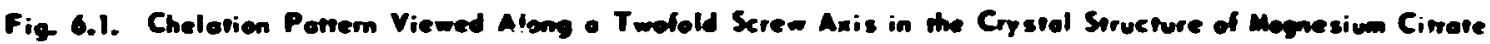
Oecohydrote. Ellipsords represent equiprobobility surfoces of thermal displacoment end contain 65\% of the prob. obiliny distribution.

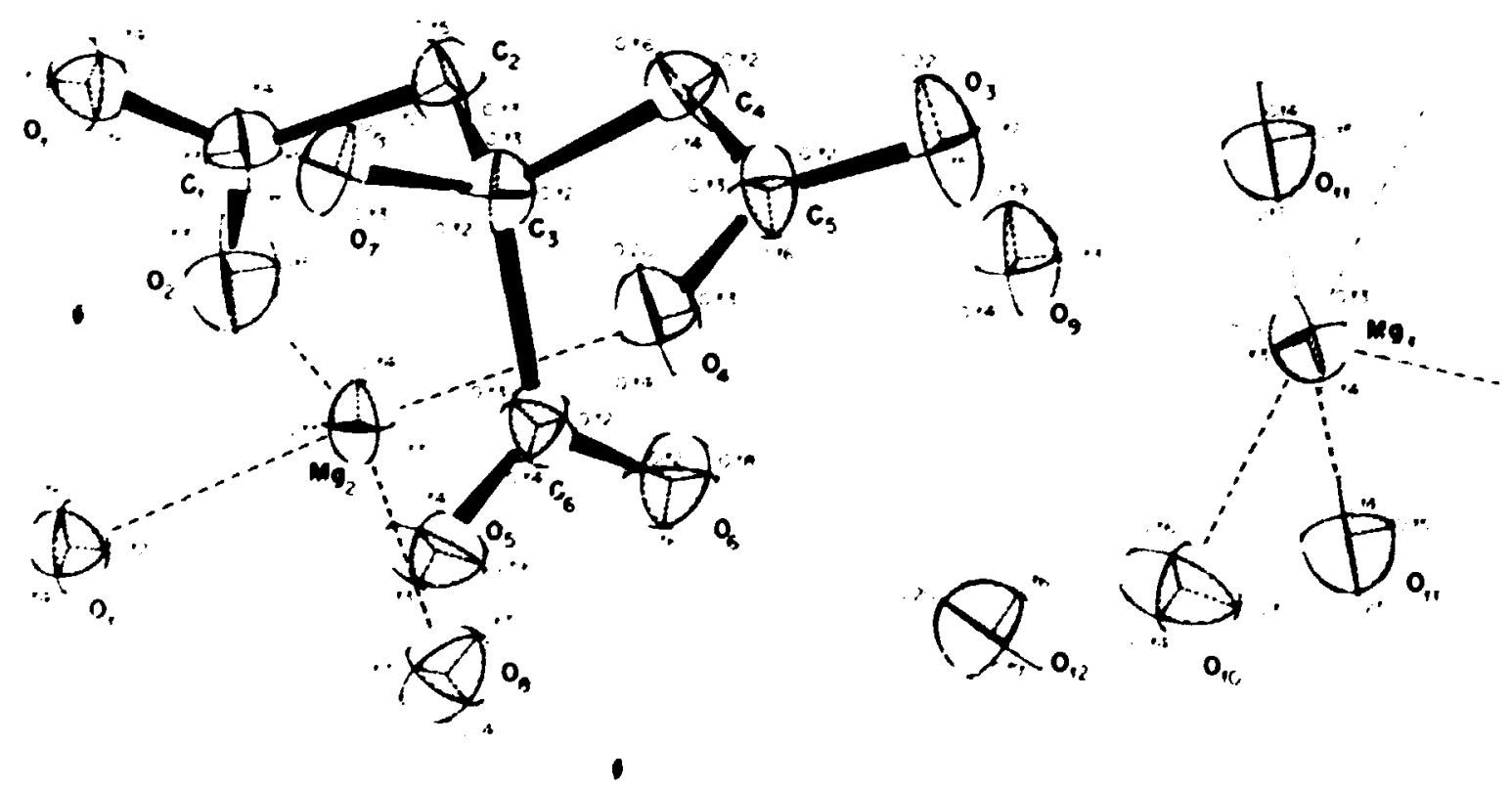

Fig. 6.2. Thermal-Ellipsoid Representotion for Magnesium Cimare Decahydrese with Principal Volues of RmS Displocement in Angstrom Units. Ellipsoids enclose 745 probobility. Seructure is viewed olong $h$ axis. 


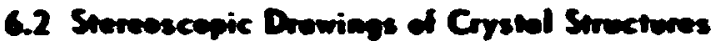

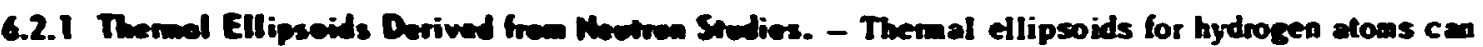
be derived from neutron diffraction data. Some recent crystal structure results refined from theee-diatensional neutron dat a are show here as stereoscopic pairs of perspective projections. The thermal ellipsoid for a hydrogen atom is almost always larger than that of the heavier neighbnt atom because of zero-point energy.

6.2.1.I Chloral Hydate. - Figure 6.6 features two molecules $v$ chloral hydrates related by a center of symetry. The neiphboring bydroxyl groups which ar istolved in hydrogen bonding to the two molecules are also included.

6.2.1.2 Sugars. - A single molecule of sucrose ${ }^{6}$ is shown in Fig. 6.7 with the six-membered glucose ring to the lef: and the five-membered fructose ning to the right. Two intramolecular hydmgen bonds are drawn between the two moieties. Only one bydroxyl group in the molecule does not form a hydrogen bond; this group has the abarmally large themal ellipsoid for bydrogen on the left side of the figure.

The thermal motion of a glacose molecule in the 2 -glucose crystal structure ${ }^{7}$ is illustrated by Fig. 6.8 . This figure was dram with OR TEP by G. M. Brown.

6.2.1.3 Lithiven Sulphare Monohydrare. - The inorganic structure lithium sulphate monwhydrate has bean refined with three-dimensional $x$-ray data by Larson and with three zones of two-dimensional neutron data by Smith and Levy. Figure 6.9 illustrates the characteristic atomic anangement in tiat structure. The hydrogen thermal ellipsoids were taken from the neutcon analysis and the remainder from the $x$-raj; results. The outstanding feature in this illustration is the lange thermal motion of the water molecule, which indicates much looser binding than in the rest oi the structure.

6.2.I. + Polassium Hydrofen Chloromaleare. ${ }^{10}$ - This stmcture contains a centered hydrogen bond. The imfratomic bond distances and the surrounding $K$ atoms are also shown in Fig. 6.10, which was drawn with OR TFP by R. D. Ellison and H. A. Levy.

6.2.2 Thormal Ellipsoids Derived frem X-Roy Shudies. - The examples shown in this section were taken from the literature and from the worh of several ctystallographers who kindly sent their unpublished results to GRNL to be drawn.

6. 2.2.1 Long-Chain Aliphatic Organic Compounds. - Dihydromalvalic acid" (cis, 0, L-8,9-methyleneheptadecanoic acid) is shown in Fig. 6.11. The thermal motion perpendicular to the chain direction is seen to increase in amplitude toward the nonpolar end of the chain.

SG. M. Brown and H. A. I rev. Cryst. strui f. Conmun. 2, $10 ;(19 ; 3)$.

'C. M. Brown and H. A. Levy, Science 141, 921 (196.).

'G. M. Brown and II. A. Levy, Srience 147. 10.38 (1r.6.5).

A. C. Lerson, Acre Cryse, 18, 31 ? (196.5).

"H. G. Smith, S. W. Peterson, and H. A. Levy. J. Chem. Phy. 46, 5561 (1968).

${ }^{10}$ R. D. Fillison ard H. A. I.evy. A in Cryst. 19, 260 (1C.65).

I'G. A. Jefley and M. Sox, Acle Cryal. 16, 1196 (1963). 
Figare 6.12 illustrates the thernal axtion in the triglyceride beta-tricapria. ${ }^{2}$ Thr 1 wo molecules show are related by a ceuter of symmety. Agein the amplitude of motion perpendicular to the chain increases towad the end of the chain.

6.2.2.2 Copper Chelarion Compound. - The chelation pattem in bis-(3-amino-1-phenyl-2-butene-1-ono)Gu(II) ${ }^{13}$ is demonstrated in Fie. 6.13. The copper aton is on a symmetry ceruer.

6.2.2.3 Larfe Biolosical Molecule. - Harungain, ${ }^{10}$ which is a plent pignent, is shown in Fig. 6.14. The pair of "half atoms" at the upper right is an epproxiantion used in the least-squares refinement to correct for either very leze thenal wotion or disonder which occurs in that part of the cry stal structure. The thern ol paraneters are somewhat questronable siace the structure was not refined to convergence. However, the stereogran does perinit the molecular configuration to be readily visualized.

\subsection{2.t Abanomal Motian in Cr(III) Acetylaceionate. - Dr. Brumo Mocosin from Sandia Corporation} sedt this most unusual exaple of themal aotion. $C r(I I)$ acetylacr-baate ${ }^{\text {ts }}$ has three acetylacetonate ligads arraged to form an octabedral coordination of oxyzens about the C: aton, as shown in Fig. 6.15. One of the ligands displays very large thermal anisotropy. When a molecular packing diagram such as Fie. 6.16 is viewed, the large displacements are seen to be parallel to the b crystal axis. It appears that sheets of these ligands are either disordened or undergoing longitudinal vibration. Worosin has evidence from other diffraction experiments wich supports the hypothesis that it is a thermal vibration phenomeinon and not static disorder in the crystal.

6.2.3 Cryshl Smecture Pecking Dicgrems. - It is often desirable to illustrate the way that molecuies pack together in a crystal structure. Sometimes thermal motion can be interpieted on this basis, as was done in 6.2.2.4. In other instances one may be more interested in virualizing the general packing geomstry of the crystal structure. Stereograms are very useful for both applications.

6.2.3.I Potassium Hydogen Chloronaleate. - A molecule of this structure ${ }^{10}$ is shown in Fig. 6.10. Packing diagrams were also drown by Ellison and Levy and are reproduced here. Figure 6.17 shows the packing of anions about the two types of potassium ions. One coordination polyhedron is an irregular octohedron of cxygen atoms. The other is an irregulat 14 hedron having six oxygen aloms and four chlonne atans at its vertices. Figure 6.18 is a different view of the packing with a langer area included.

6.2.3.2 Packing Di.grams tor Inorganic Structures. - The reader may have noticed that most of the illustrations are of organic structures. The reason is that organic molecules are easy to draw. Considerably more planning is required to produse an informative illustration of an inorganic stnucture.

An approach which is fairly successful is the following:

1. Draw a preliminary stereogram of the contents of a box which encloses somewhat mors than one unit cell. Bonds should be drawn in accurdance with known interatomic distance ranges. The dimensions

${ }^{12} A$. J. Mobis and L. H. Jensen, Abstracrs ACA Meeiing, Bazemen, Monfana, Fa (1964) and L. H. Jensen, privete communicaition, 1964.

${ }^{13}$ G. E. Gurr, Acte Cryst. B24, 1511 (1988) and private communicetion, 1964.

I4R. A. Alden, G. H. Stout, J. Kraut, and D. F. High, Acra Cryat. 17, 109 (1944).

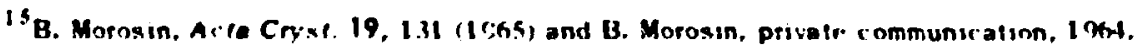


for this drawing may be such that the plot can be viewed directly with a stereoscope without photographic reduction.

2. Thile viewing the preliminary stereogran, pick out the basic stuctural units and decide on a grouping of these units for the desired figure.

3. Describe the intended subject with wichever technique is the most contenieak ami traw the new figure. Figure 6.19. potassium perxenate nonahydrate. "1" is an example of an illustration planned in this way. This figure was dram by J. H. Bums at ORNL.

6.2.3.3 Illustrations of the Contents of a Unit Cell. - A favorite method used by crystallograpters is to draw a unit cell out line and the cell contents within that outlime. Figure 6.20, which is a stereogram showing lithium amonodeutenglycolate, $"$ is of this nature. The molecules were kept intact rather than cur off at the cell ouline.

\subsection{Helicd Sincetures}

OR TEP has certain features which facilitate the drawing of nonintegral helical screw models such as those discussed in the field of molecular biology. The Pruling. Corey, and Branson alpha-helix model "0 for protein structure is an example. Figure 6.21 shows the modification of this structure which is prosent in the synthetic polypeptide poly-t-alanine. ${ }^{19}$

!6. Zalkin, J. D. Forrester, D. H. Templeton, S. M. Williomson, and C. W. Koch, J. Am. Chem. Soc. 86, 3569 (1964).

I'C. K. Johnson, E. J. Gobe, M. R. Fas lor, and :. A. Rose, J. Am. Chen. Soc. 97. 1802 (1965).

10L. Pautine. R. B. Corey, and H. R. Branson, Proc. Nell. Aced. Sci. C. S. 37, 235 (1951.

19. Elliolt and B. R. Molcolm, Proc. Roy. Soc. London A 249, 30 (1959). 


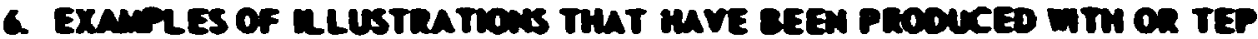

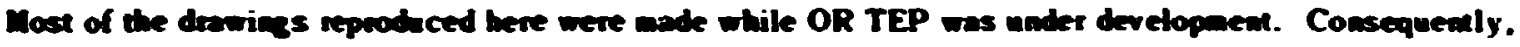
certain details in the figures are not the same as those produced with the present version of the progrem. In particular, the lines of shatine in the ellipsoid "open octem" are now always evenly spaced.

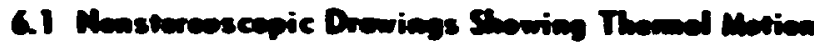

The figures in this section have tbe viewpoint of infinity (parallel projection).

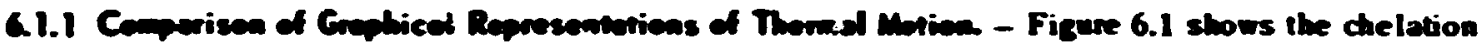
pattern of two citrate molecules related by a twolold screw axis in the crystal structure of mataesium citrate decahydrate." One wolecule has "transpareat ellipsoids" and the otber has "opaque. plussed ellipsoids." Bond iypes 1, 3, and 4 (scs 3.3.9) are illustrated. Note that certain bonds terminate at the ellipsoid boundary wils others intersect the ellipsoid. These variables are under the user's coatsol and can be used to advarage for special effects.

Figure 6.2 is another drawing of magnesium citrate decahydrate with the ims magnitudes of displacement alones principai axes i.idicated axound the equiprobability theraal ellipsoids.

Figure 6.3 illustrates the same figure with the thermal-motion representation mentioned by Waser, "in which the thermal motion is port:aven by a fourth-degree surface gene:ated by a radius vector with length proportional to the mas component of displacement in the direction of the radius vector. The characteristic peanut sibpe of this fourth-degree s:"riace is most apisiemt for am $0_{3}$.

The therma: - Ilipsoid seems to be the preferred representalion, and the present version of OR TEP will dra ellipsoids only.

6.1.2 Thernal Ellipseids Derived fren Iadependent Sets of Diffrecticn Dote. - Figures 6.4(a) and (b) show the thermal ellipsoids for potassium dihydrogen isocitrate ${ }^{3}$ obtained trom two independent sets of three-dimensional x-ray data (copper $K_{a}$ data and chromium $K_{3}$ data). Figure 6.4(i)) is presumably a better representation since it is based on a much larger number of measurements. In fact, it is rather suprising that the themal-motion figures are so similar, considering the limitet number of data obtainable with chromium radiation.

6.1.3 Thermal Metien in Moleckles Not Releted by Crysellegrephic Symmetry. - Myo-inositol has two molecules in its crystallographic asymmetric unit. Figures $6.5(a)$ and $6.5(b)$ pemit a comparison of the two sets of themal ellipsoids in identical moleculor orientations. The hydrogen bonds to neighboring atoms are also indicated. The similarity between the two ellipsoid sets is readily apparent.

'C. K. Johnsen, Acte Crysr.. 18, I 004 (I\%ss).

2J. Woser, Arte Cryst. 8, 731 (1955).

'D. van der HeIm. J. P. Glusker. C. K. Jahnsm. J. A. Minkın. N. F. Burow. and A. J.. Pallers:n, A. Ba C.,wI B.24. 578 (17\%s).

1. N. Rabinnwile and J. Krout, Arta Cryat. 17, 159 (1964). 


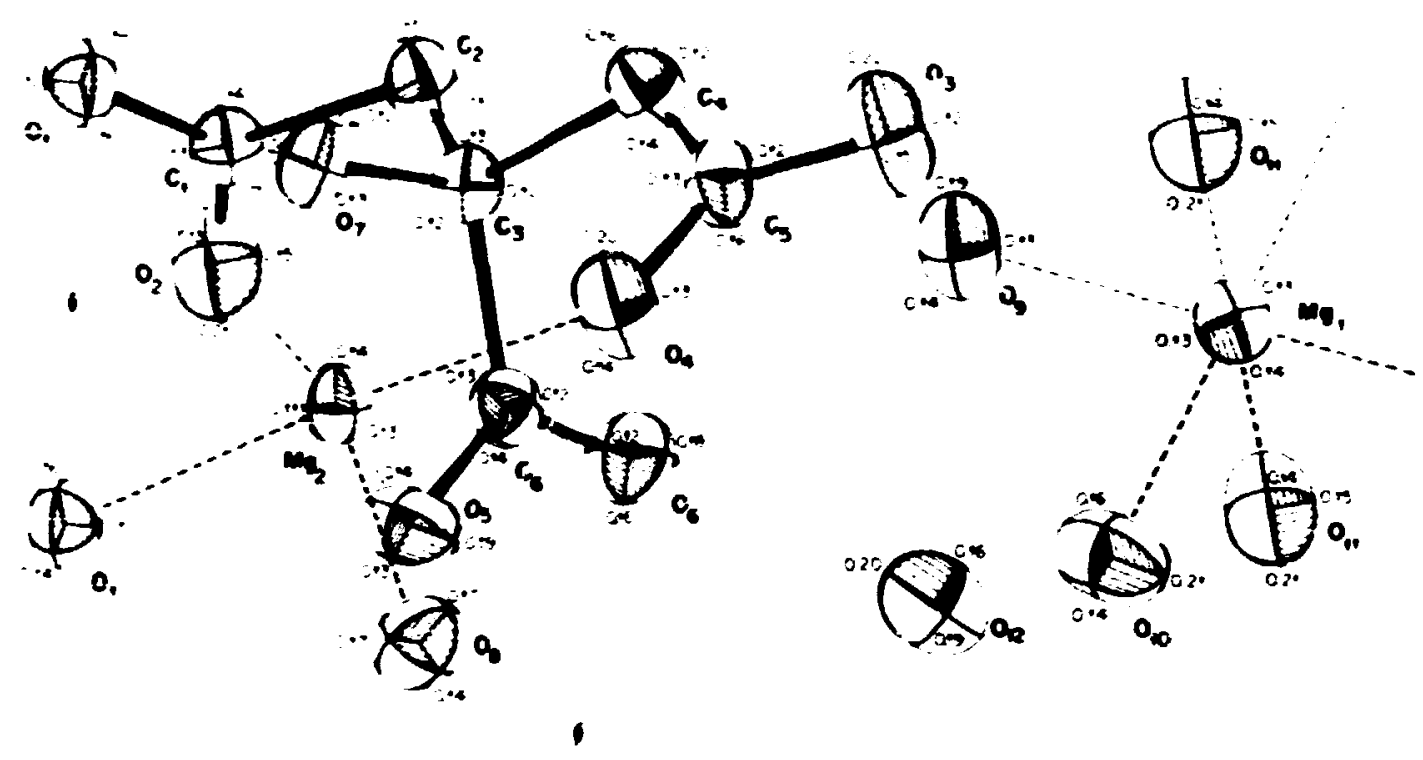

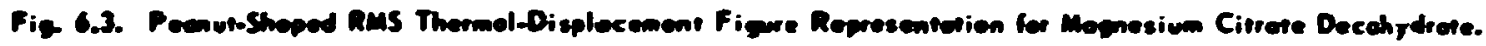
Principel values of ims displecement in Angstrom units ore indicetod ceund the displocoment figutes, which ore trown of double scale. Some vieur of structure os sthom in Fig. 6.2.

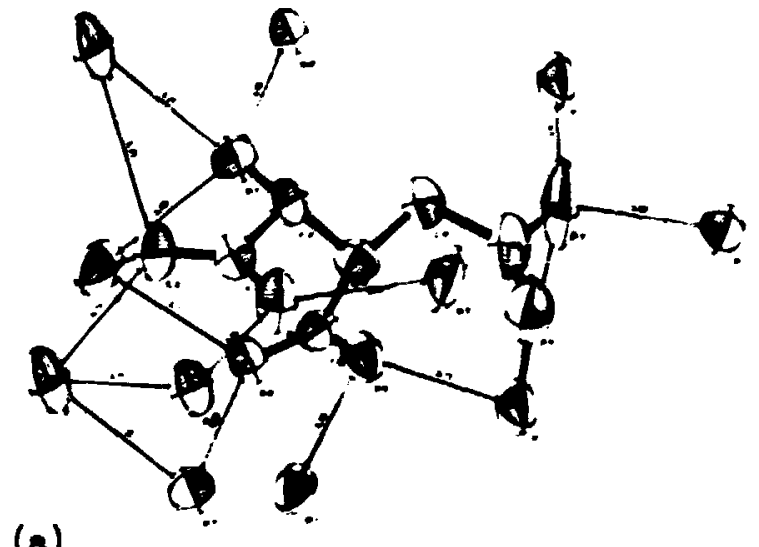

(a)

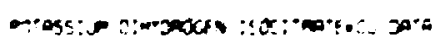

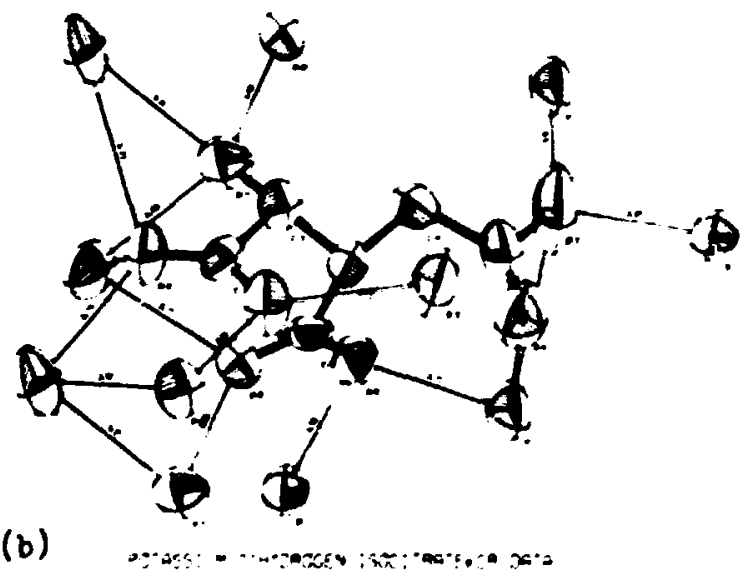

(b)

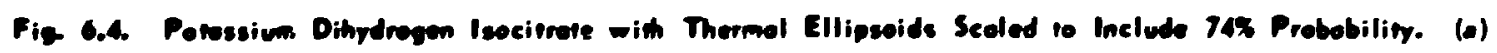
Rosules obreinod from 1350 threodimensienel copper $K_{a}$ dete (diseprement fecter 6.5\%). (b) Resulis obpained from

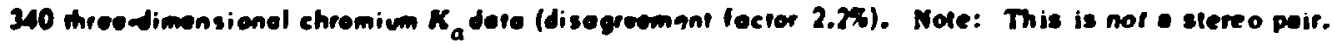




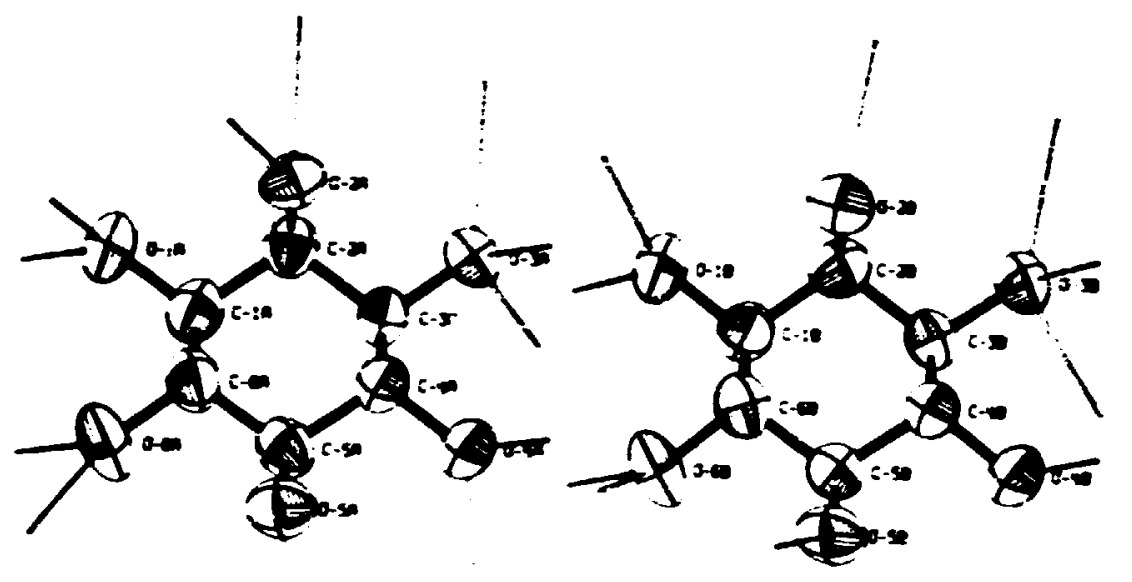

(a)

(b)

Mri-inosito

Fig. 6.5. Comporison of Thermal Ellipsoids in the Two Crystollogrophically Independent Molecules of Myoo Inosivel (6.52 and 6.56). Hy togen bending is shown, since this mighr influence the thermol morion. Eilipsoids ore scaled ro include 745: probobility. Note: This us not a stereo pair.

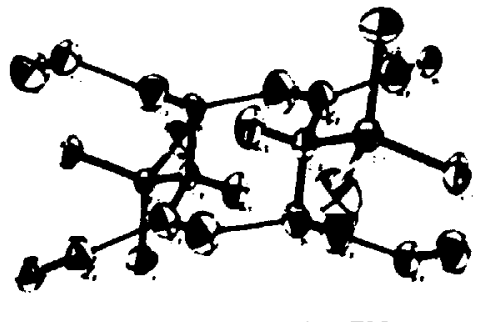

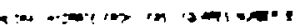

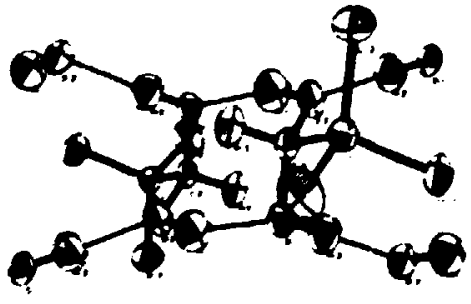

:

Fig. 6.6. Stereogrem (Spereesenpic Poir of Porspective Proiectiens) of Chlorol Mydrote Viemed Aleng the Reciprocel Axis $\because$. Two molecules ore shown reloted by a center of symmerry, with the hydrogen bonds connecting tham rogether end to orher molecules. Ellipsoids ore scolod to include $46 \%$ probobility. 

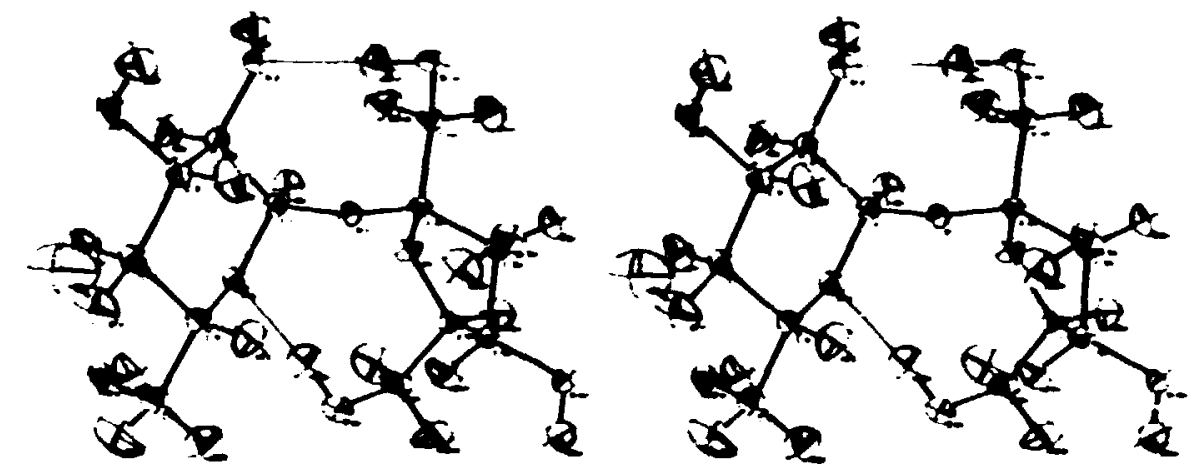

Fig 6.7. Sternogrom Showing the Sucrose Molecule with Thermol Ellipsoids Scaled to Enclose Sot Probebility.
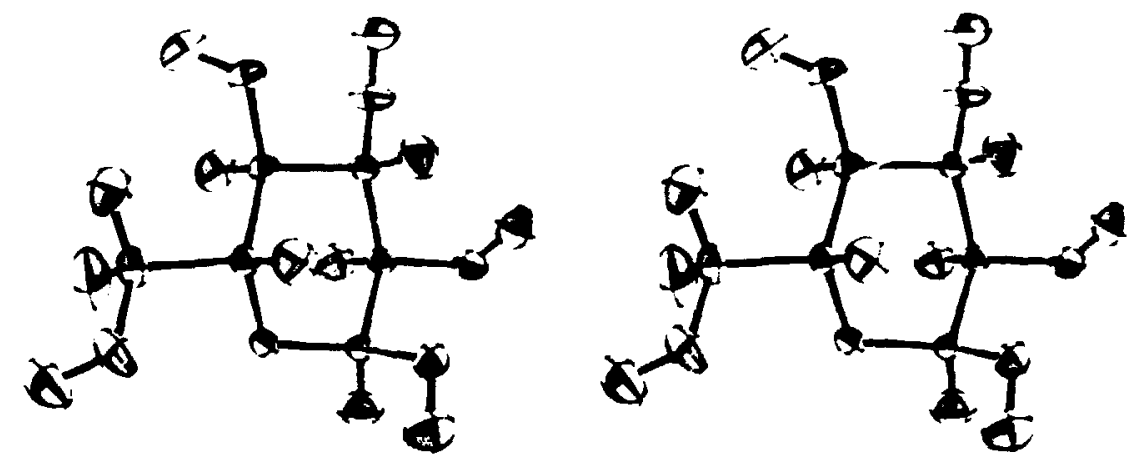

Fi. 6.8. A Molecule of Glucose with Thermol Ellipeoids Scaled no Enclose son Probobiling. 

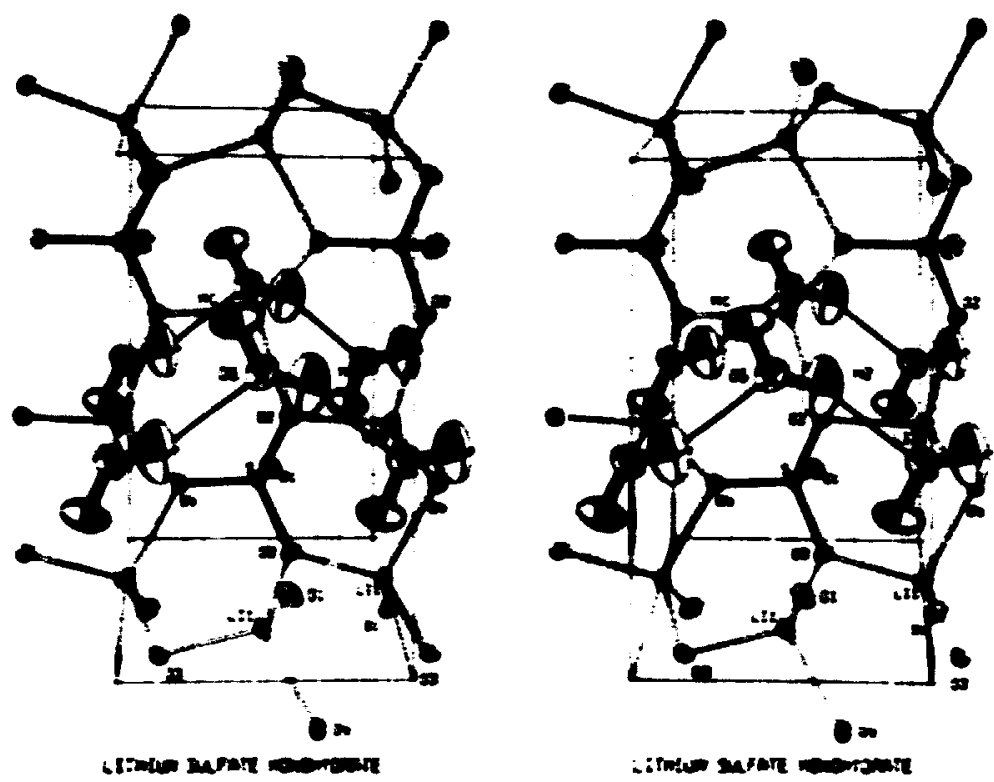

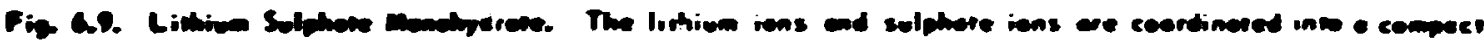

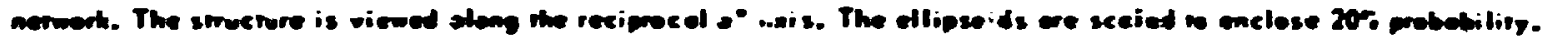
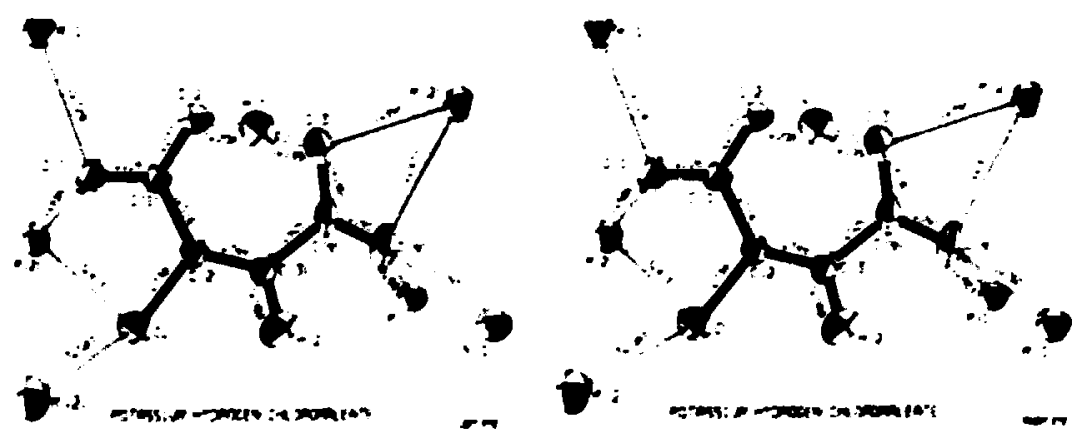

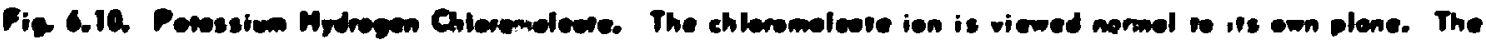
mermal allipsoids enelose Sar pobdiliry. 


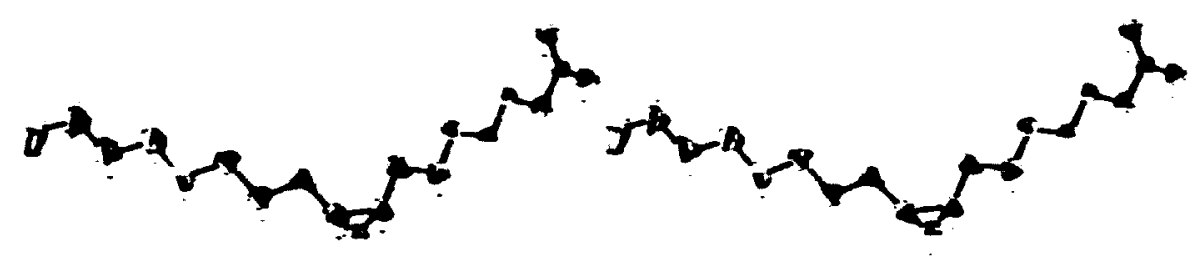

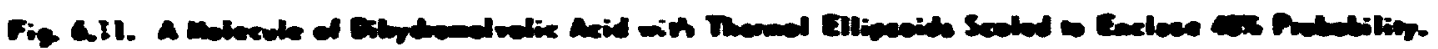
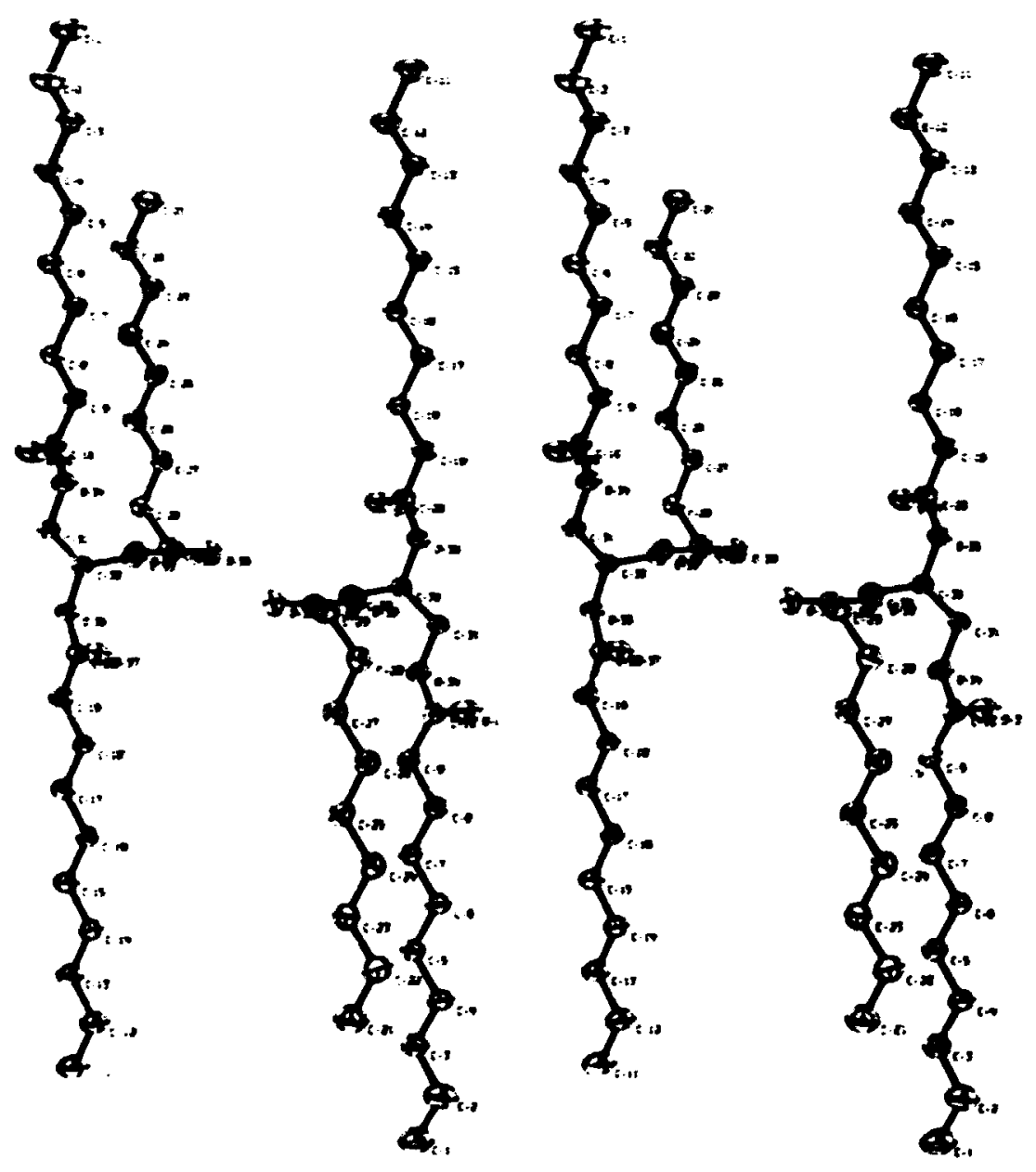

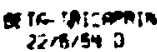

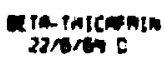

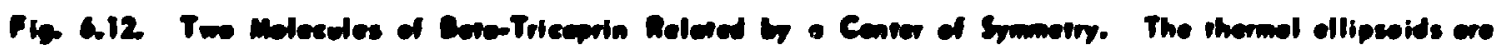
sealed so inelude $30 \%$ probebilin. 


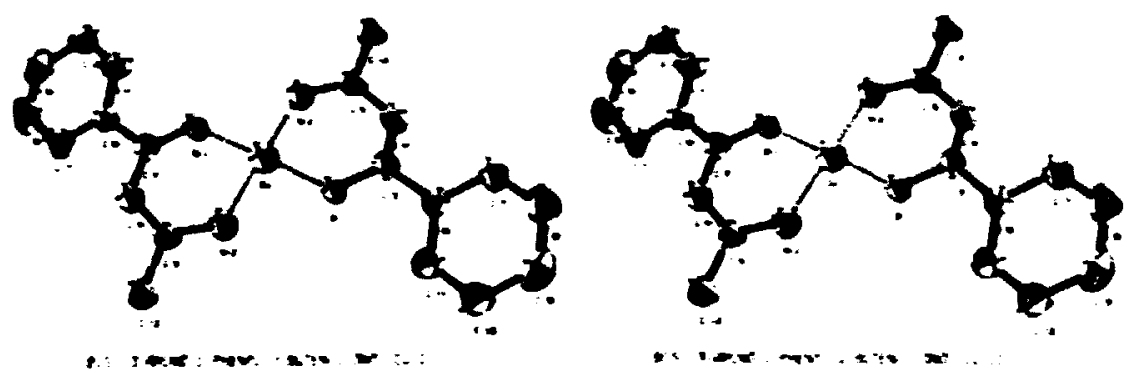

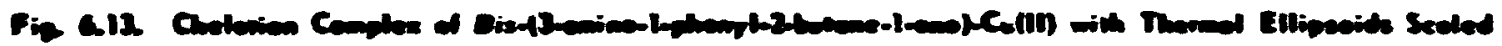

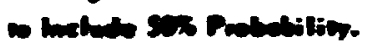
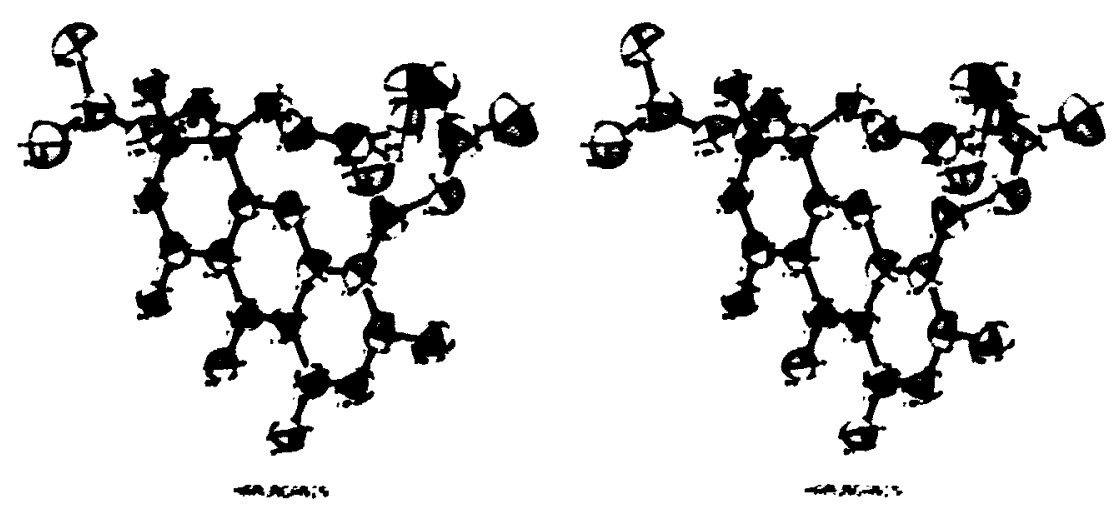

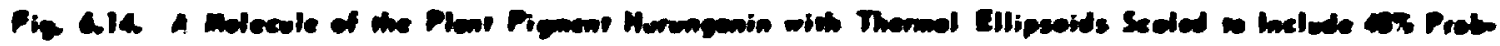
dilin. 

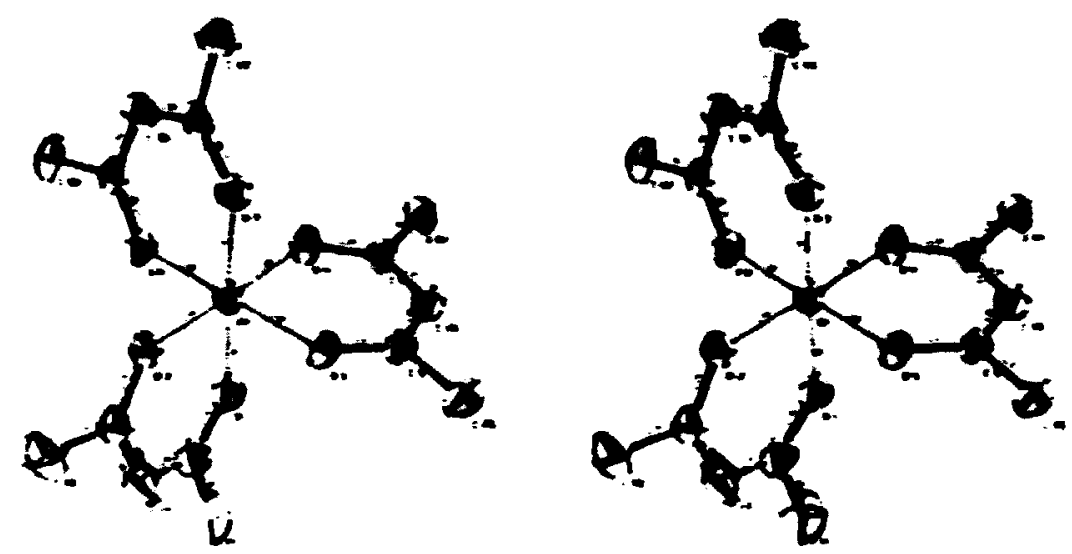

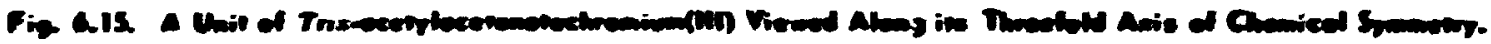

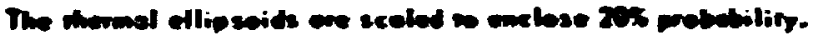
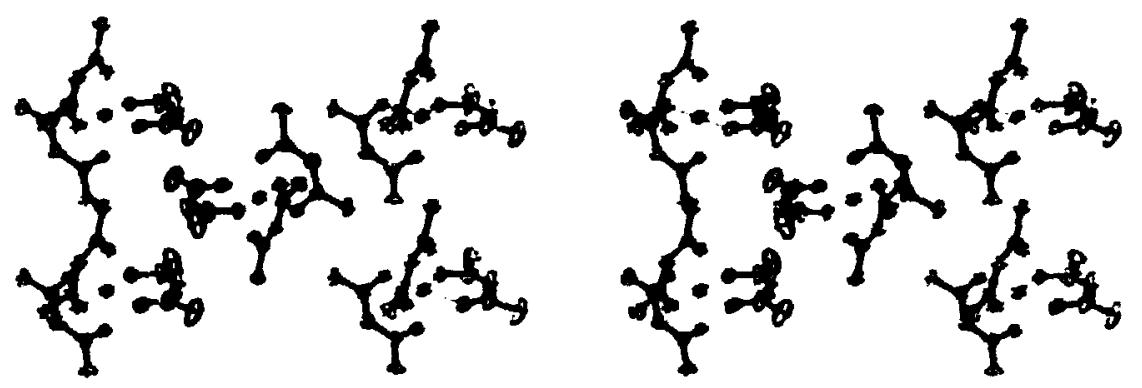

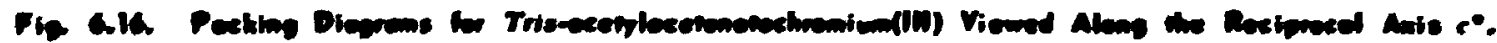

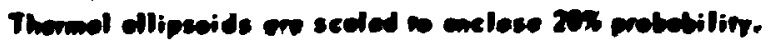



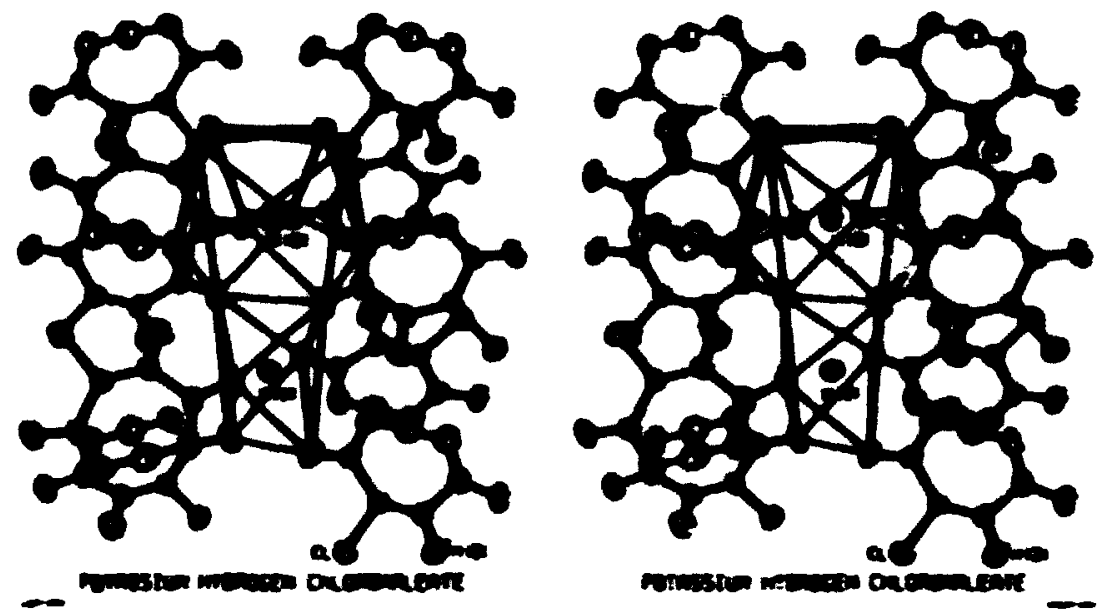

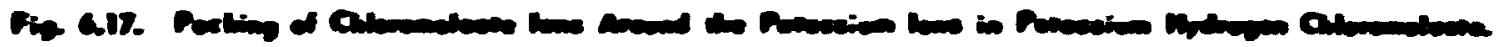

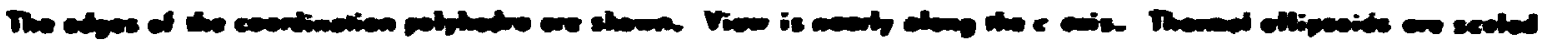

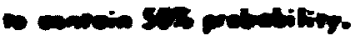

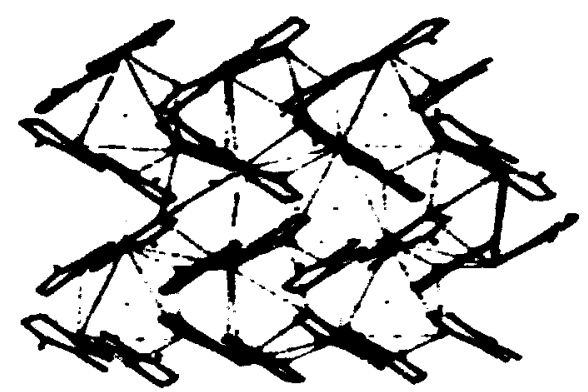

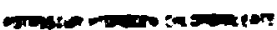

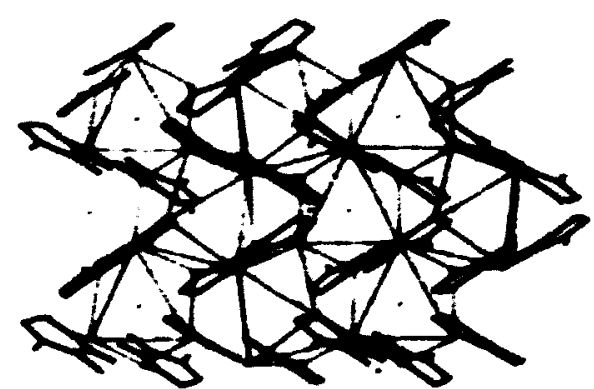

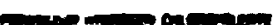

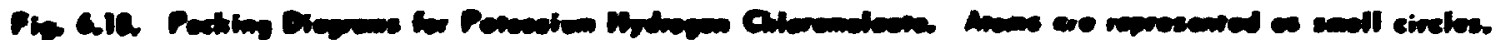

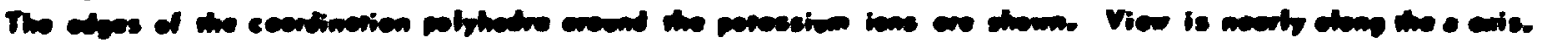



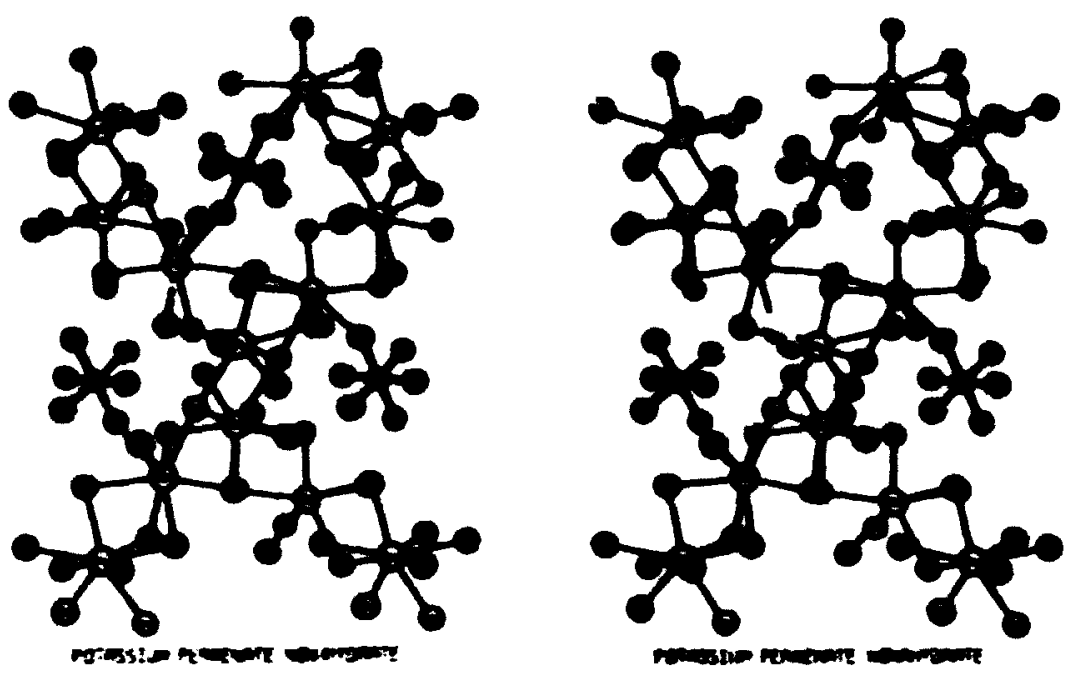

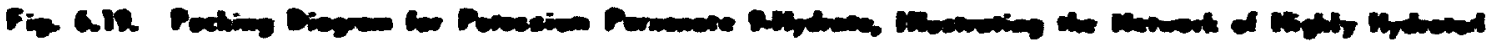

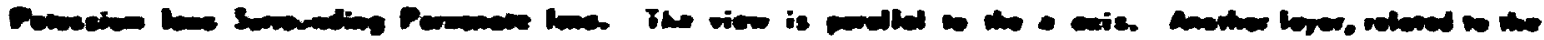

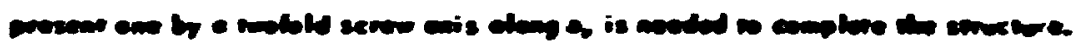
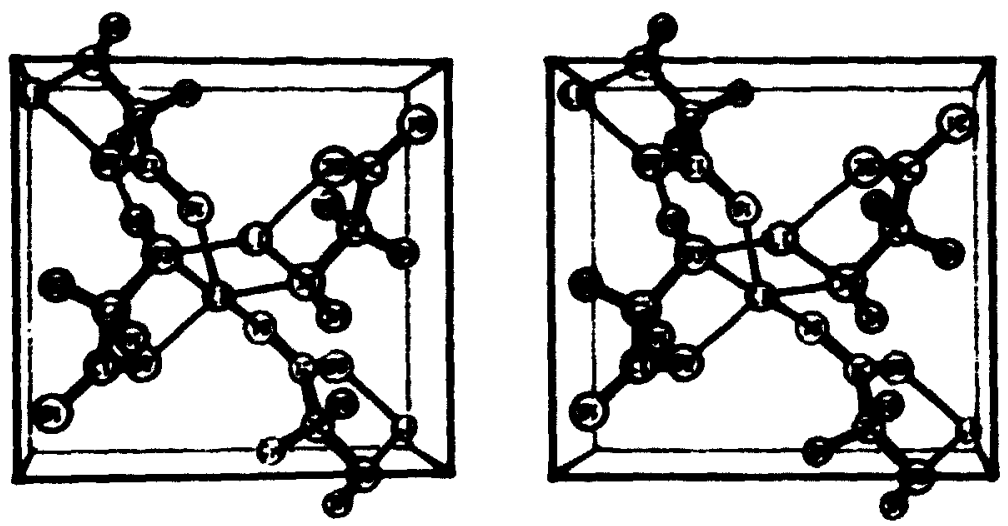

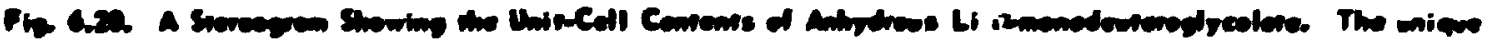

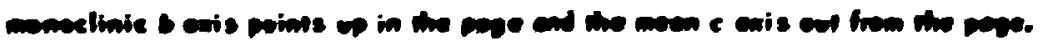




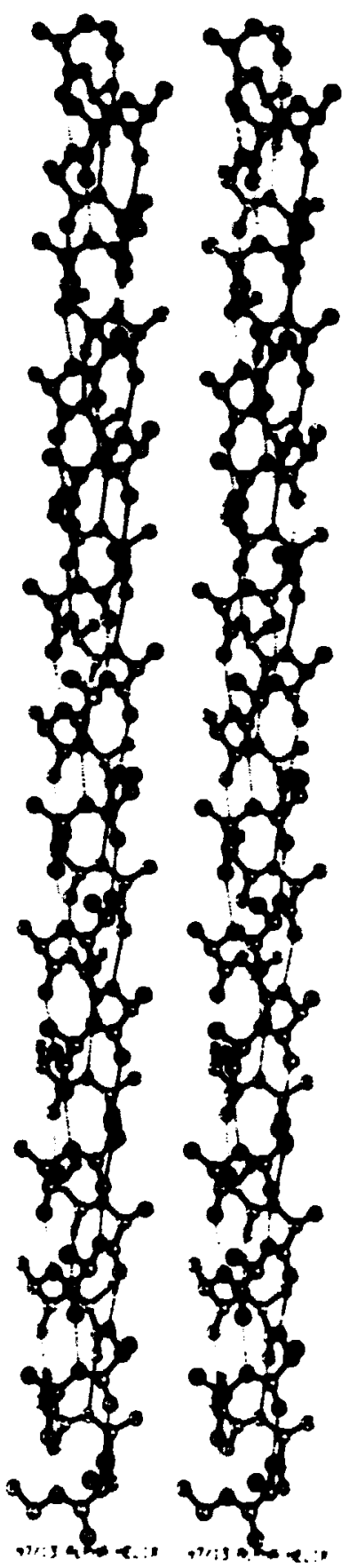

Fie 6.21. A Srevesescepic Pair of Perspective Prejecriens strowing the AlphorHelin Which Is Present in Pelyd-Alenine. There ore 47 emino-ecid iesidues in 13 wrn: of the helix. Sterco viewing is excomplished by plecing e sheet of cordboed botwen the helices. 


\section{FORTAAN LISTINO OF OR TEP-II}

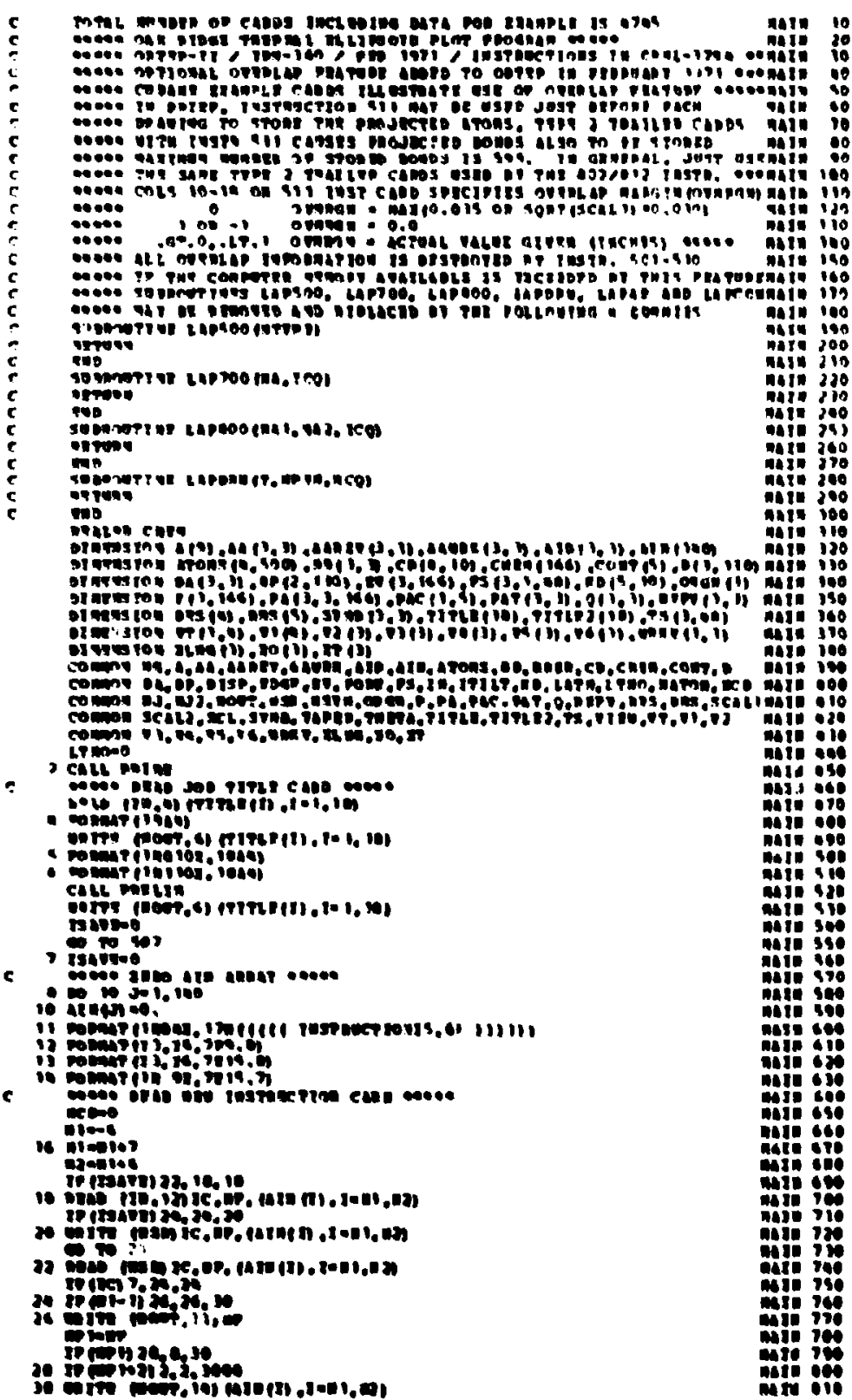

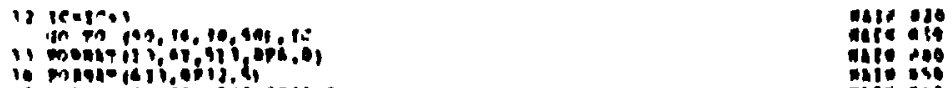

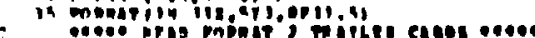

in incoesois

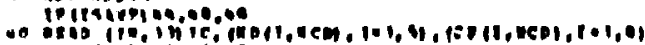

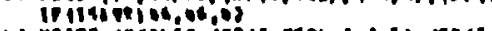

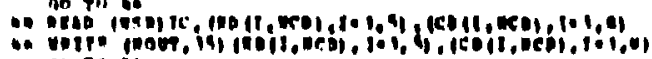

an If y.

a 9 Mrimitistiog

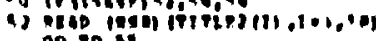

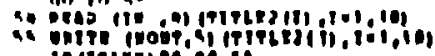

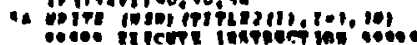

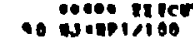

10.

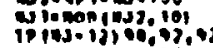

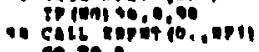

a colo

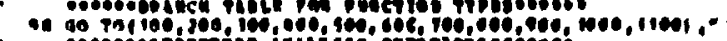

100 an $m$ 1101,101,100,14, 101,101,001,011

$$
101 \mathrm{cath} n \mathrm{nin}
$$

100

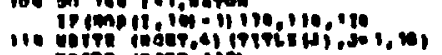

(a)

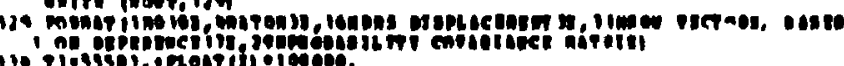

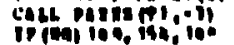

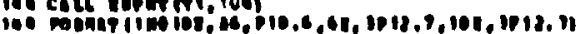

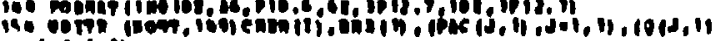

10. '.

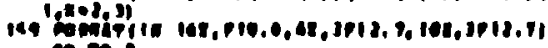

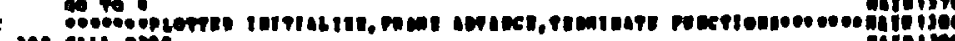

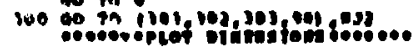

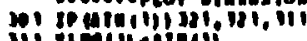

ii.

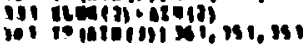

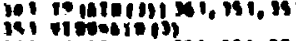

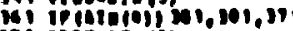

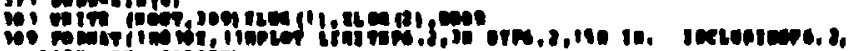
ilio Il. neniff.

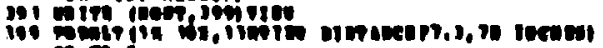

sos

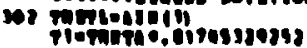

coptreosiny

nithentary 


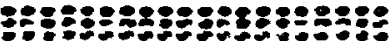

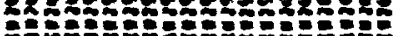

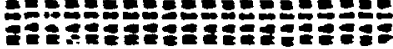

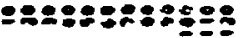

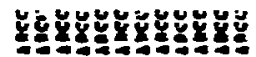

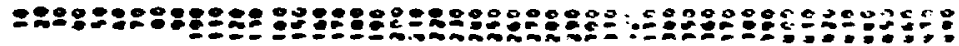

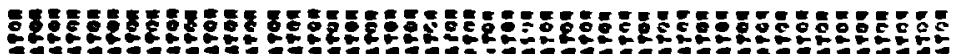

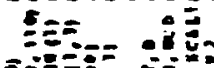

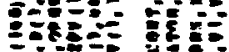

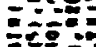

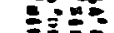

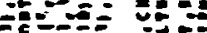

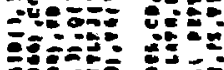
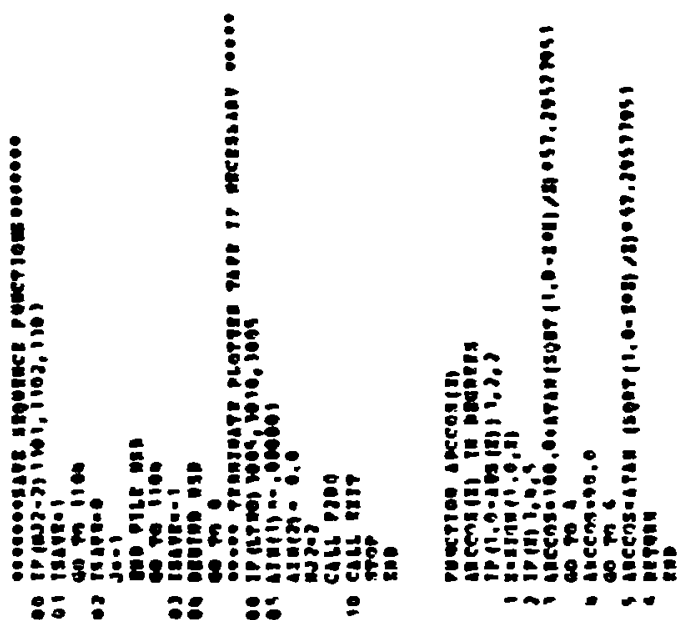

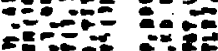

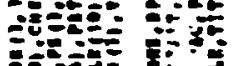

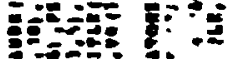

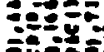

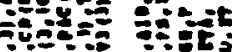

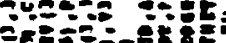

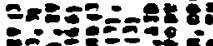

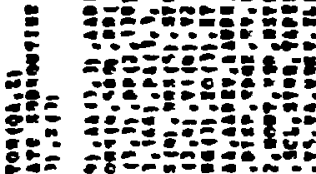
$\overline{5}$ E. Ê.

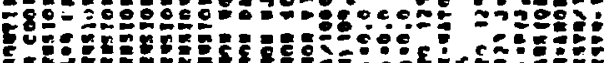

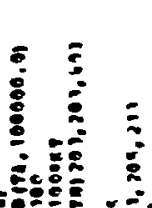
烈

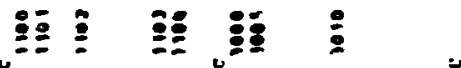

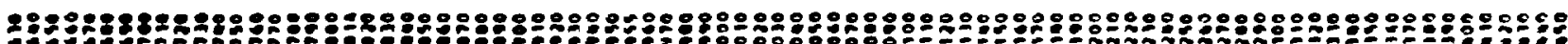

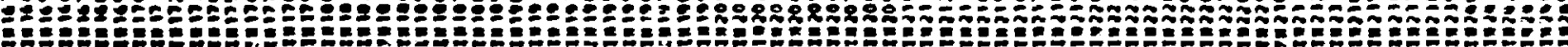

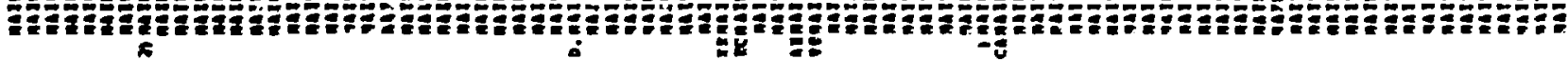
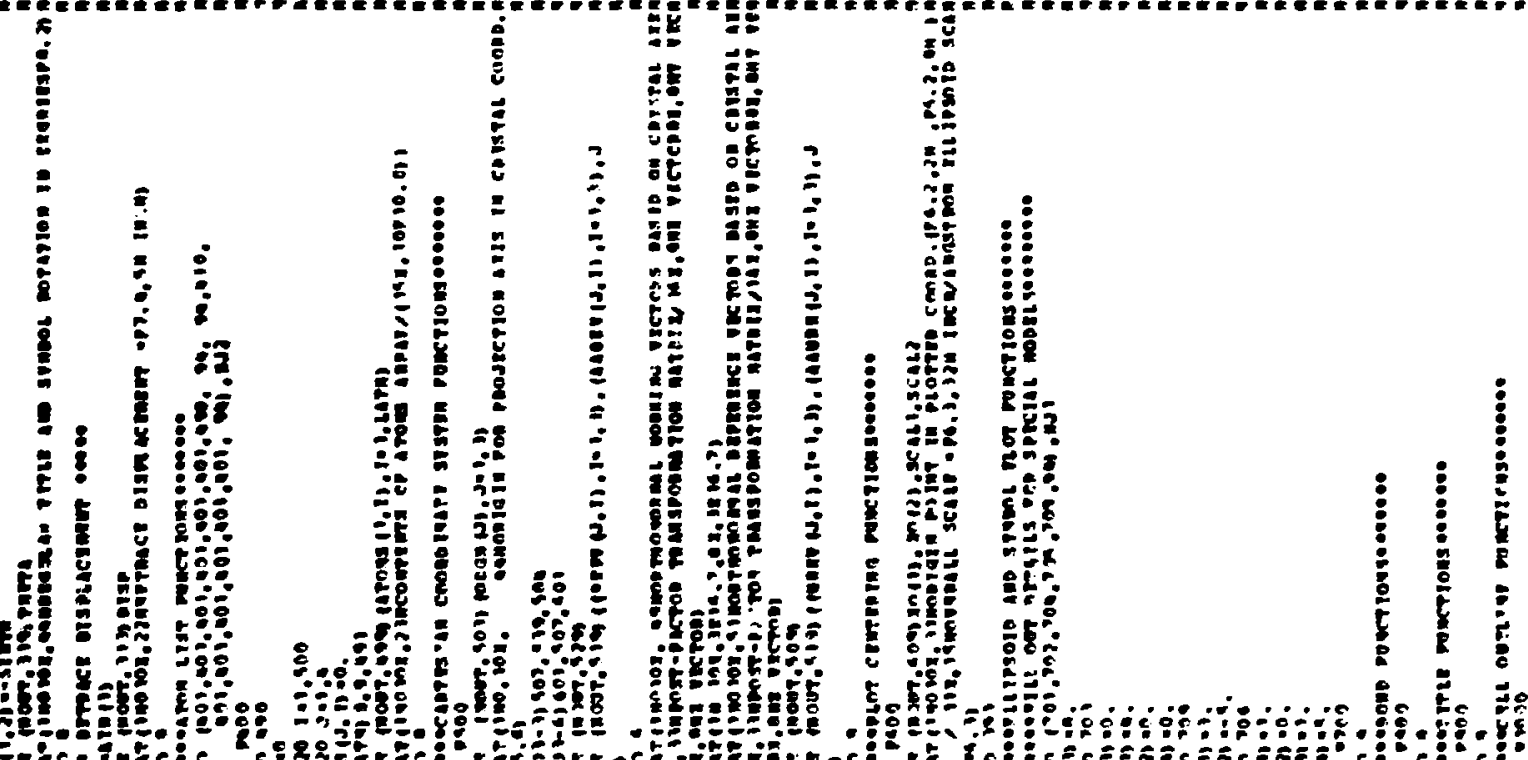

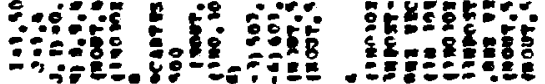

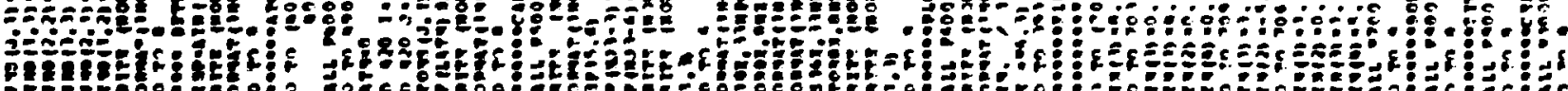

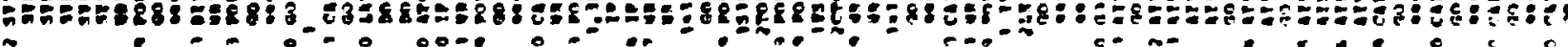
$\cong$

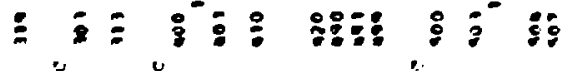
$38:$

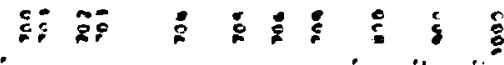




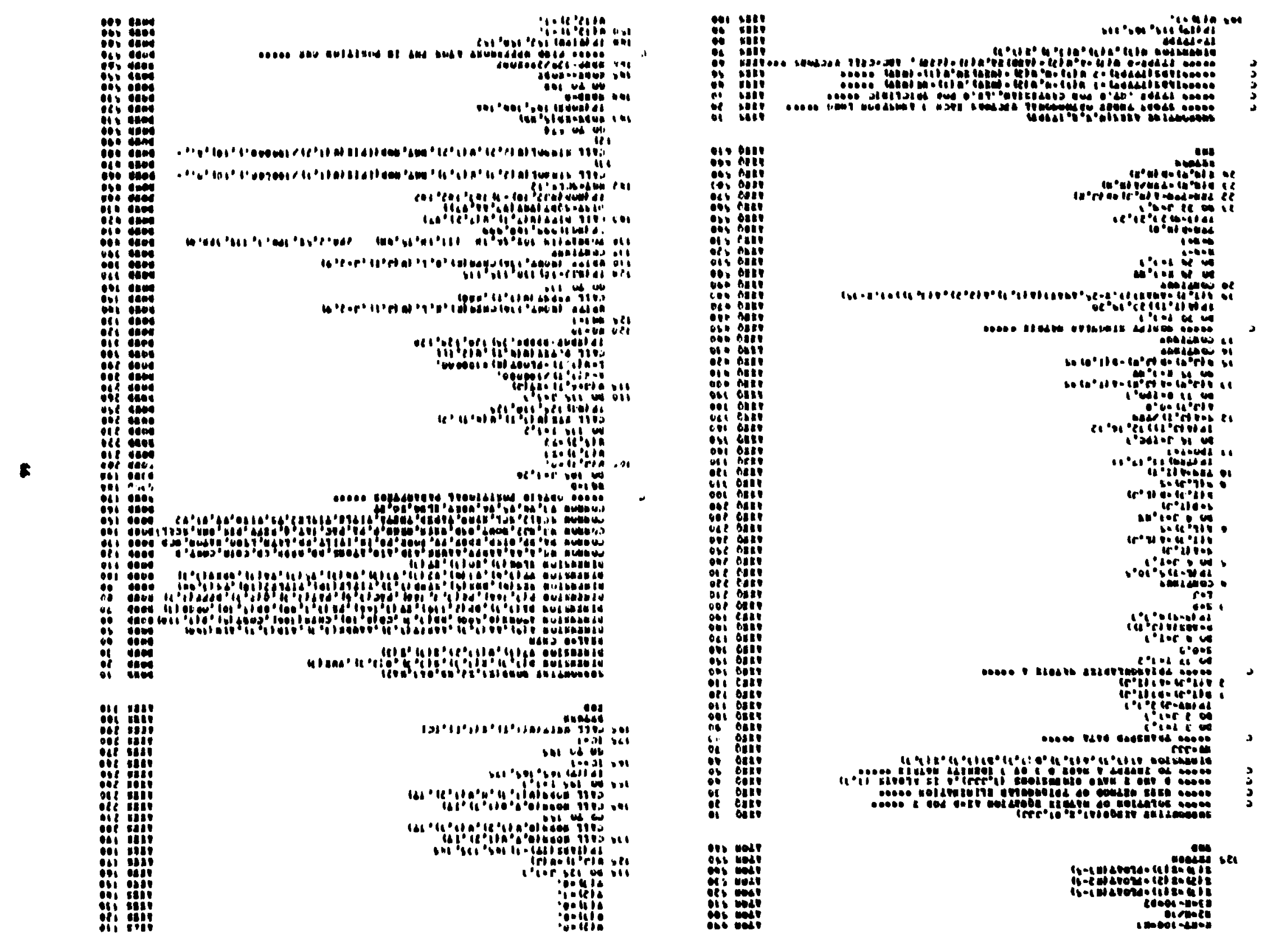




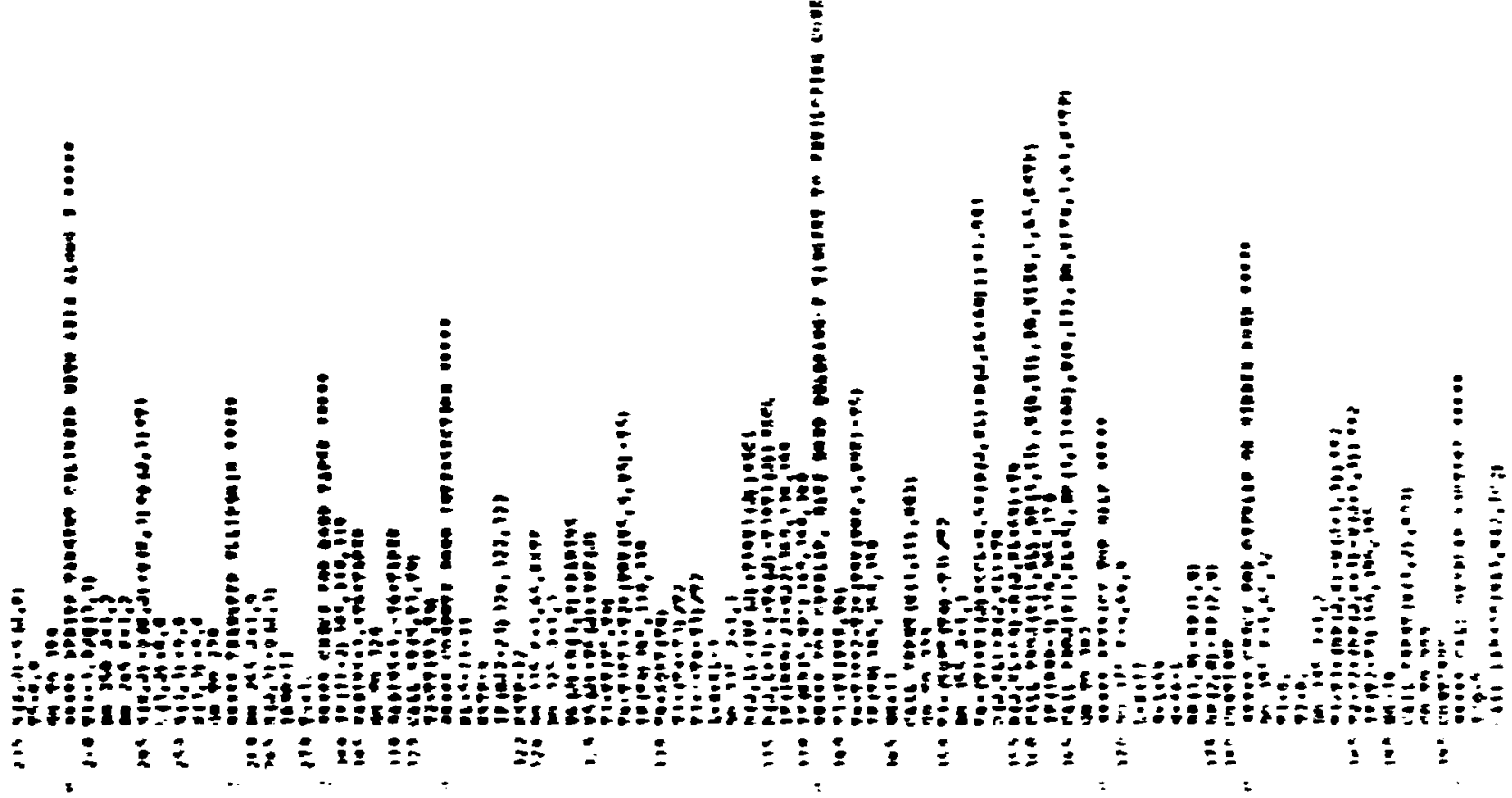

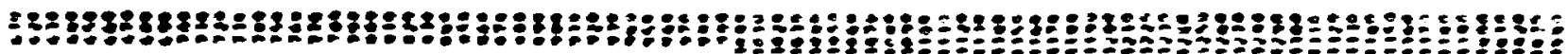

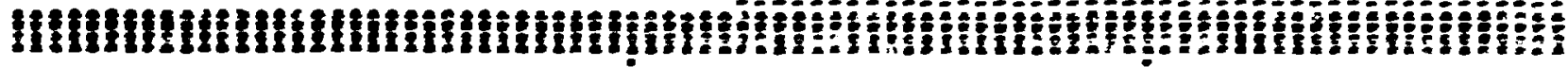

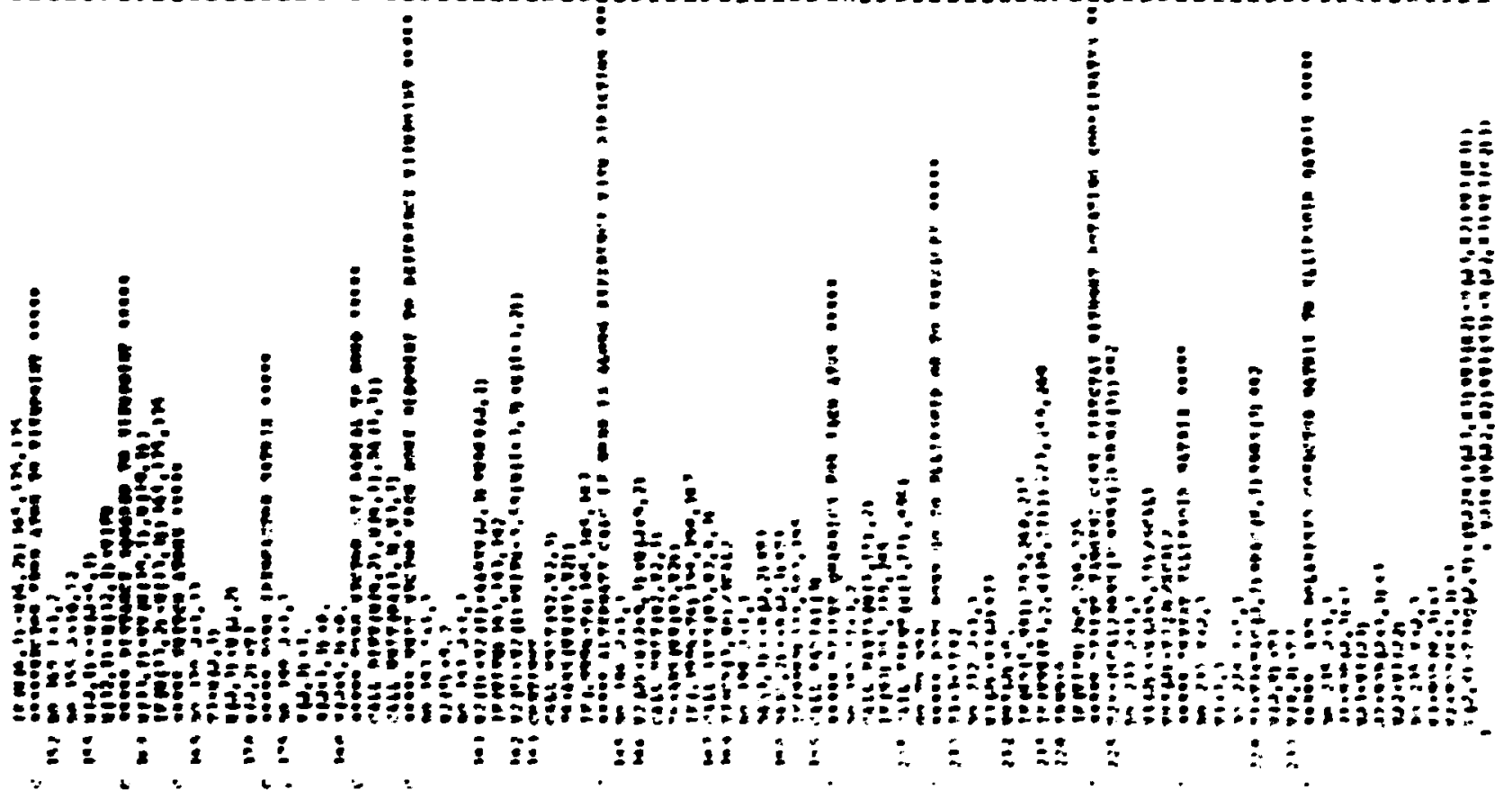




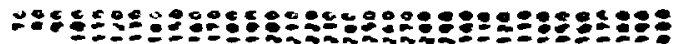

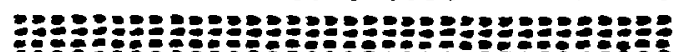

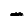

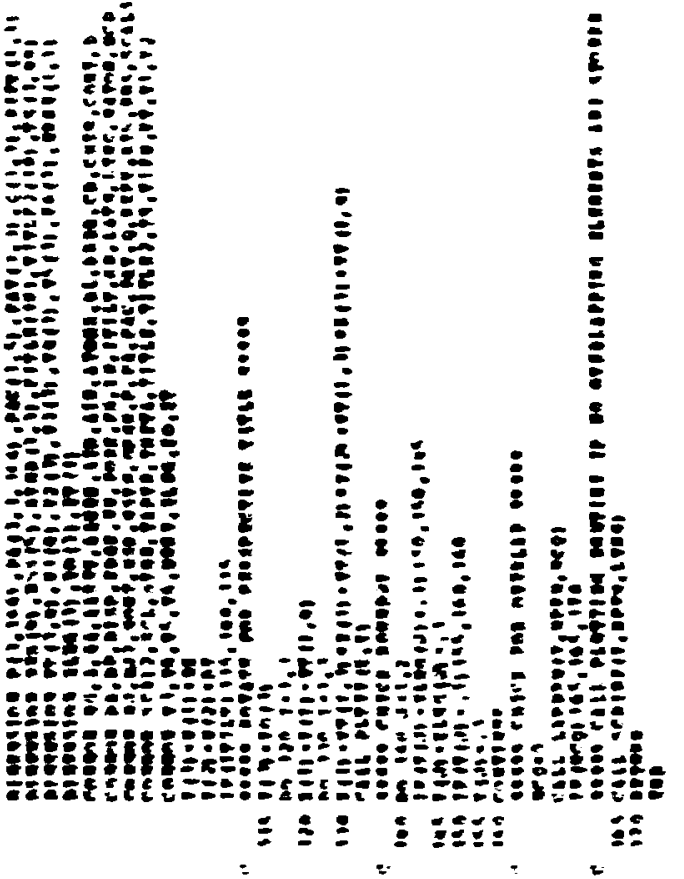

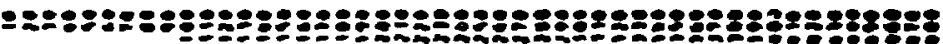

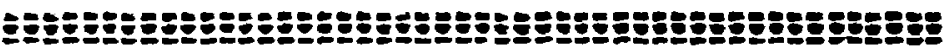
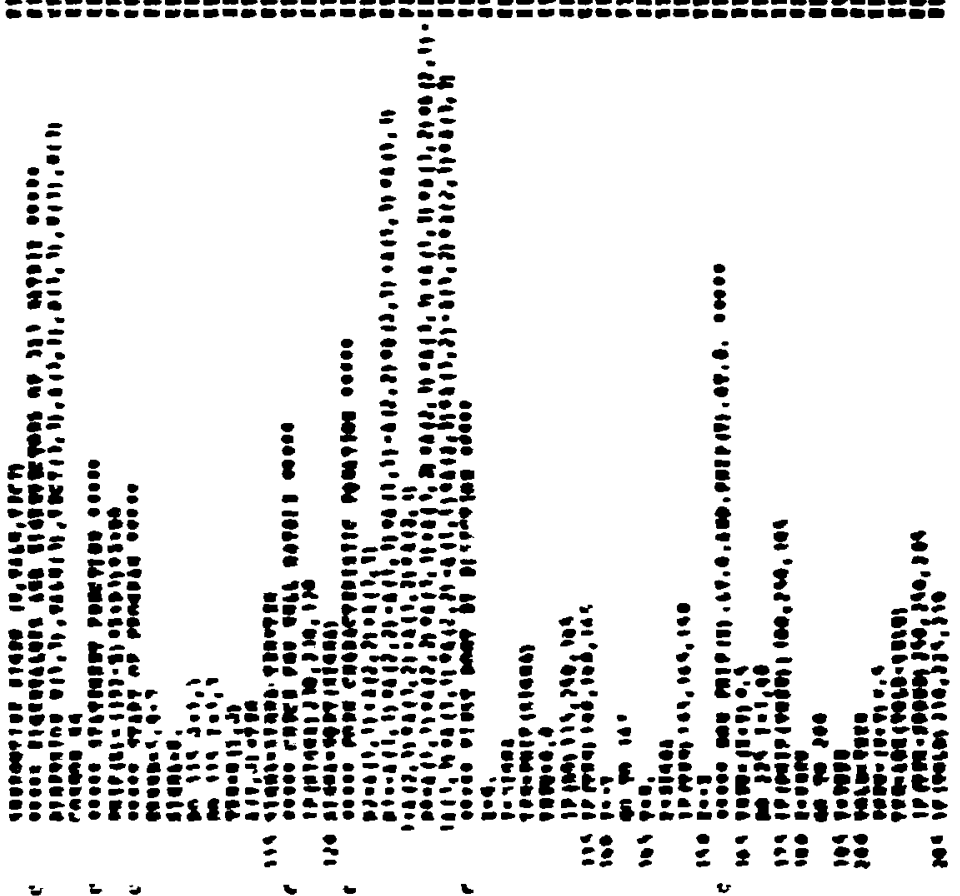

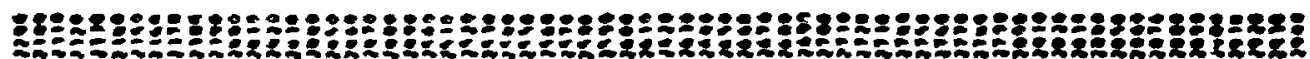

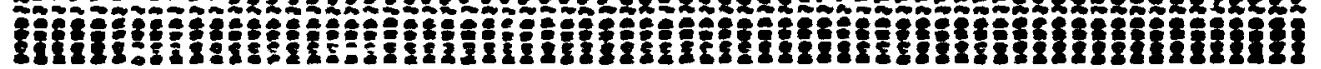

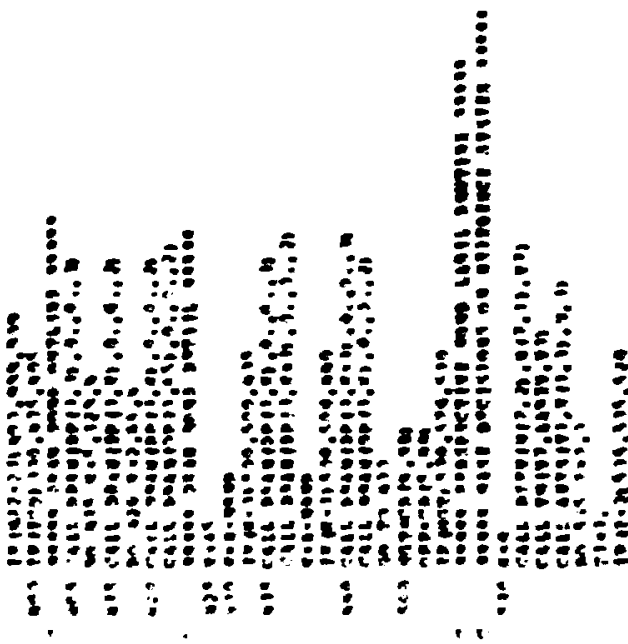

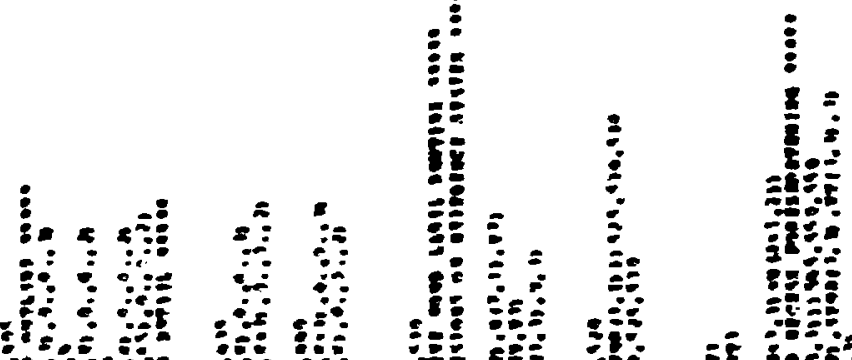

8

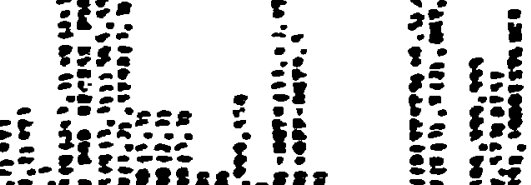

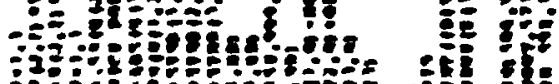

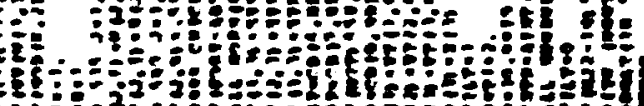

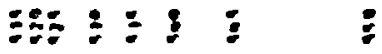

$\vdots 3$ 


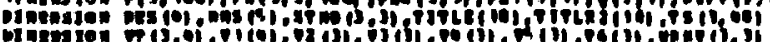
(5)

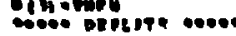

cines-1n

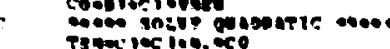

19

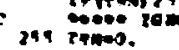

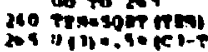

(1)

II:

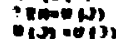

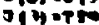

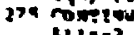

-

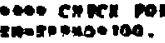

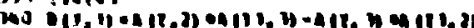

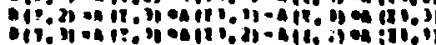

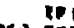

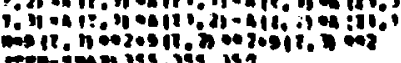

nes raviot

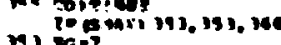

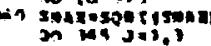

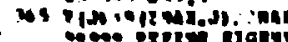

327

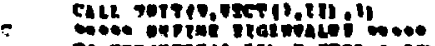

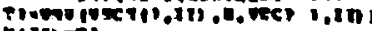

Bas

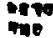
cononn st, Ai, tip.

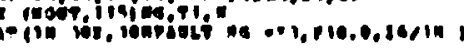
Pon

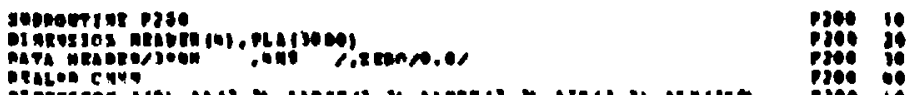

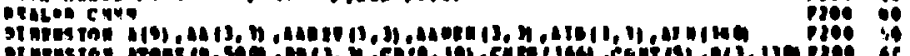

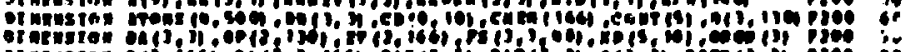

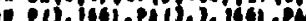

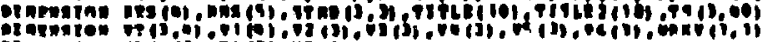

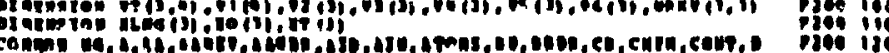

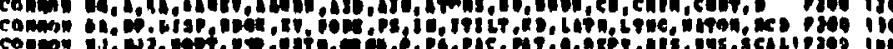
comene scit?

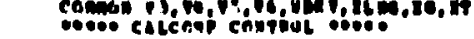

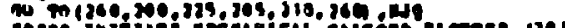

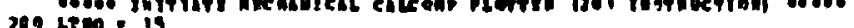
cill ploys (OLA, lees, tem

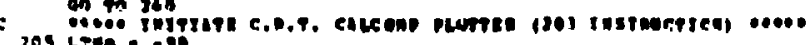

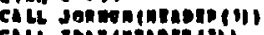

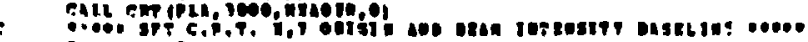

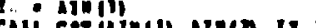
210 19

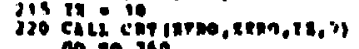

c

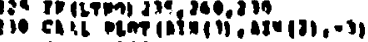

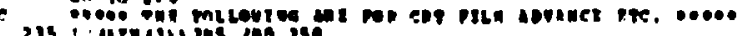

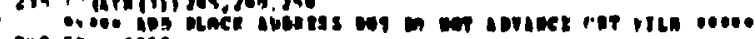
20070009

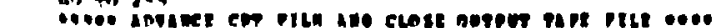
310.063

-

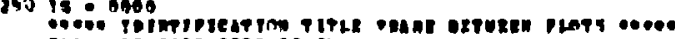

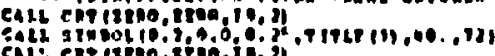

$39 .$, eAt: entor ivis

$3_{300}$

$=\quad$ masupy

.:.8. 


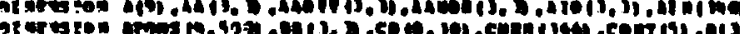

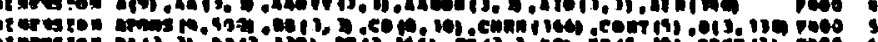

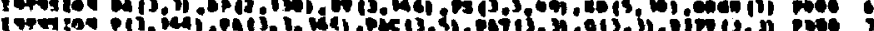

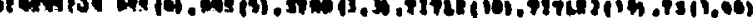

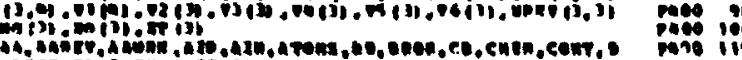
12 (1) .

$190,1001,001,400$

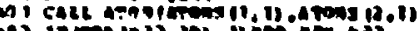

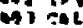

c

Wo 11:1,

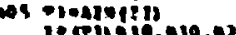

000

cos.ces

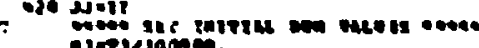

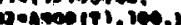

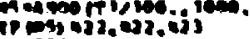

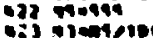

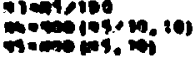

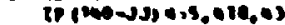

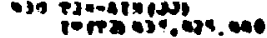

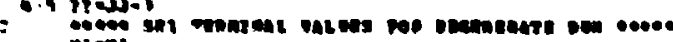

-

No itim

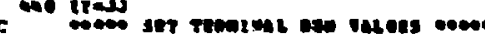

nomioced.

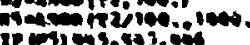

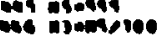

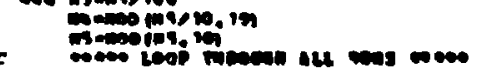

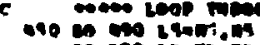

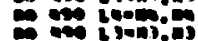

- im iponim

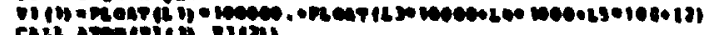

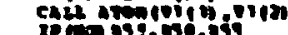

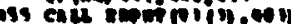

ase cill spes

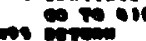

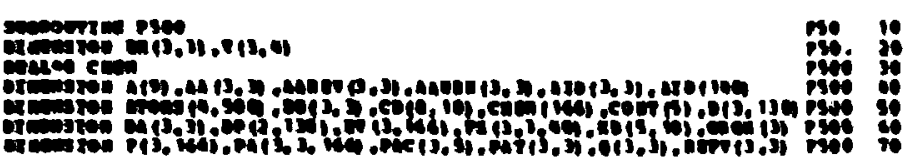

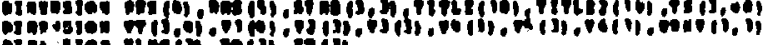

37.

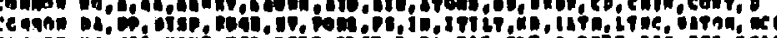

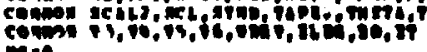

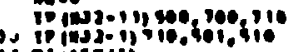

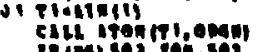

So, calt

ses

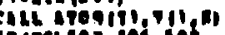

100 coints

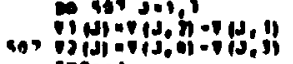

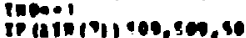

909 calt

110 1070 .

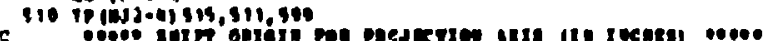

s11 s sil $3=1,3$

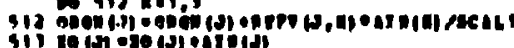

a a19 is

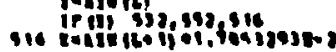

rioces'(I)

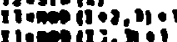

jombifithel

ays

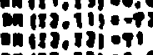

nitimeg.0

mithi:8

calt.

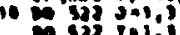

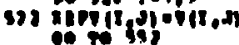

s2s 0$\}_{0}$

s, to the

33 if 4 (2)

ionof

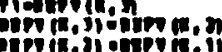

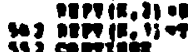

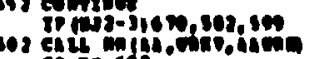

390 ip ing of

cos eits mom 10..94)

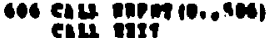

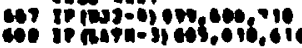

3900

7900140

19.0

9500

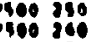

390

30

900

ispe

$\sin _{300}$

250

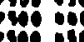

9

Ifie: 
010

$1,2011,1919$

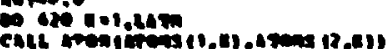

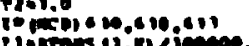

Q1)

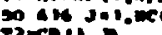

PCi! R

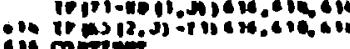

1.

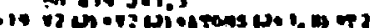

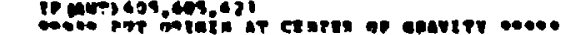

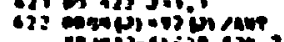

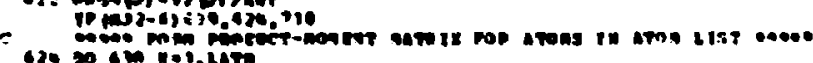

30 not.tatn

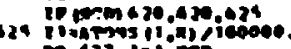

(T)

Piti:!;

30

420 -

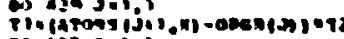

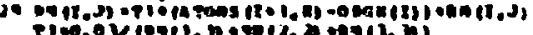

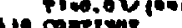

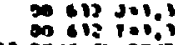

C12 Ep:

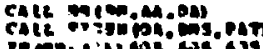

c19 70 tow till

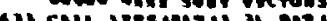

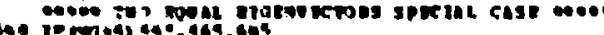

cates

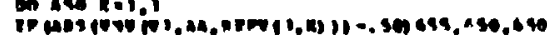

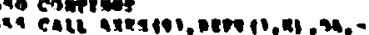

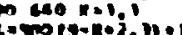

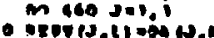

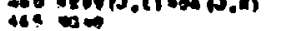

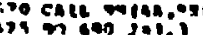

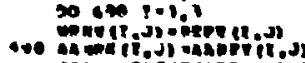

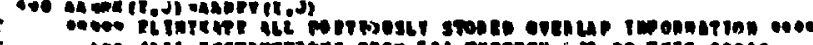

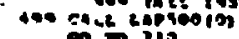

" iin

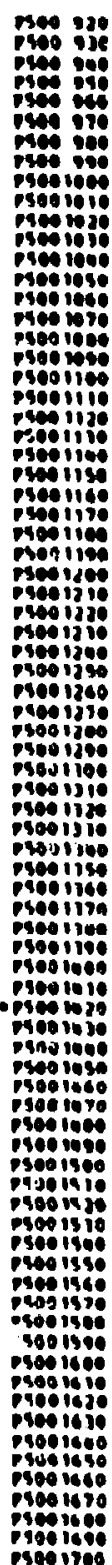

c $\quad 000$ :

pape 10

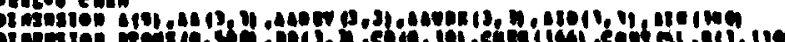

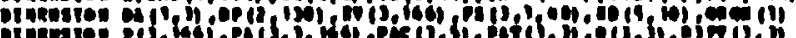

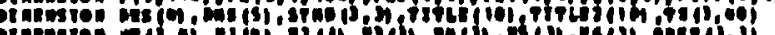

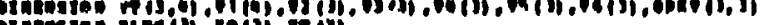

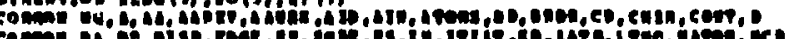

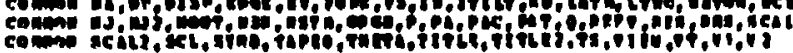

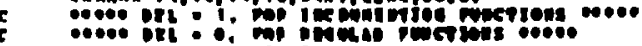

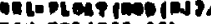

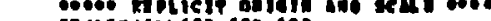

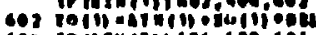

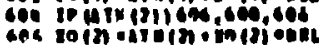

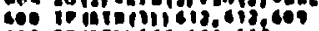

10 xation

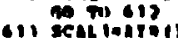

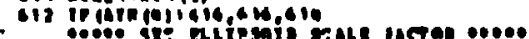

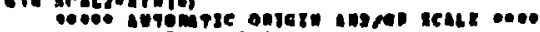

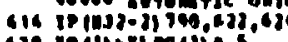

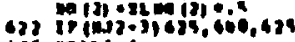

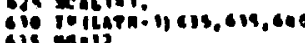

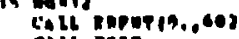

cos Chth kt!i!

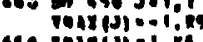

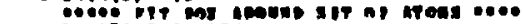

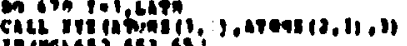

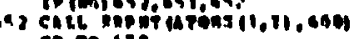

(a) on sal jol.

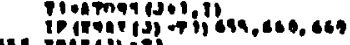

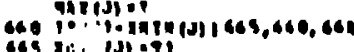

at: cnirrente

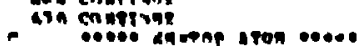

"undur? (1)

mino ino 1.

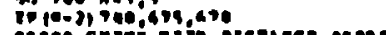

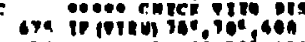

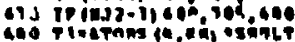

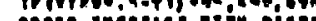

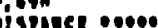

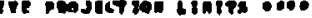

ace in ion 301,2

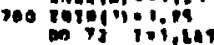

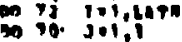




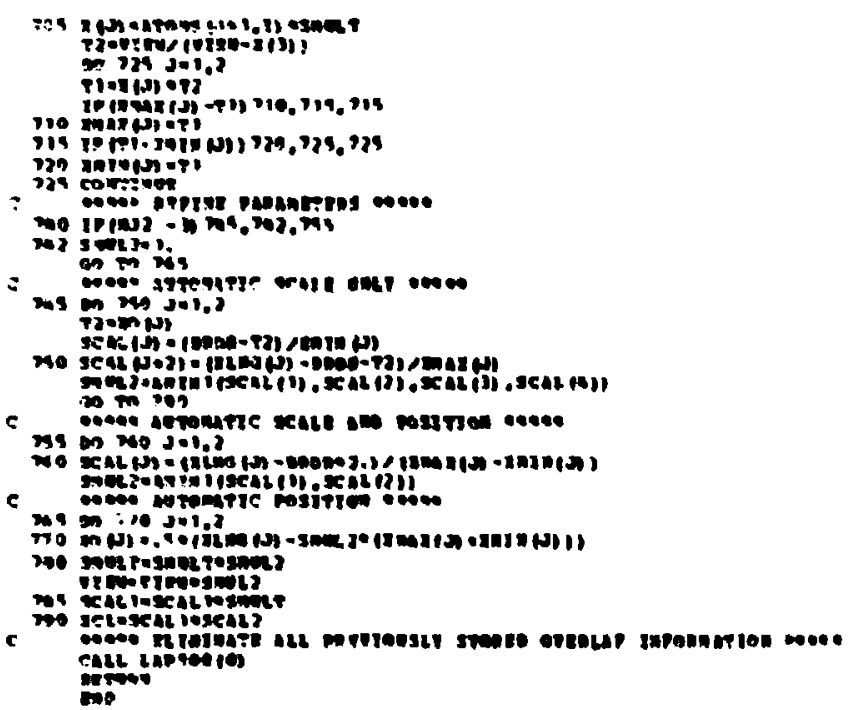

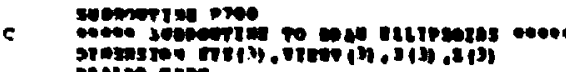

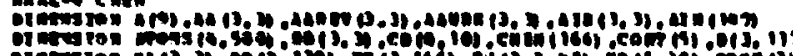

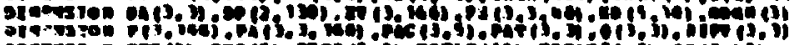

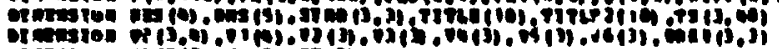

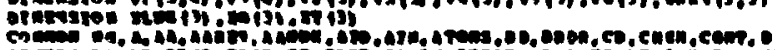

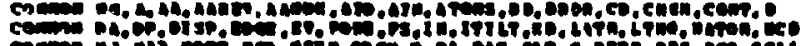

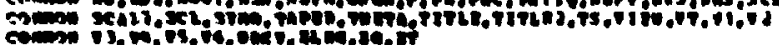

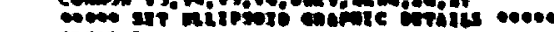
nitumis

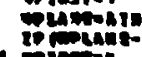

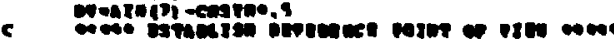
Plet.10

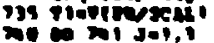

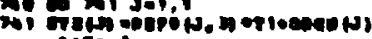

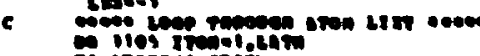

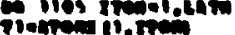

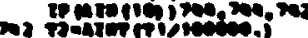

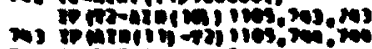

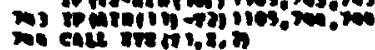

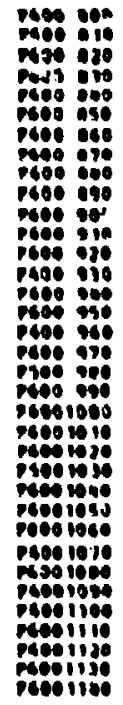

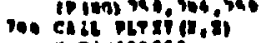

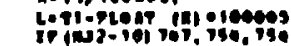

Pol inginge

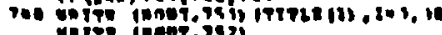

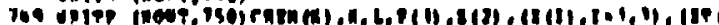

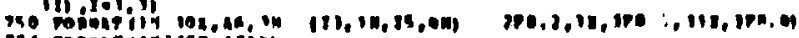

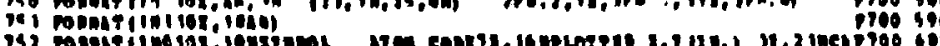

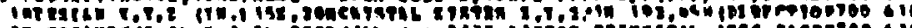

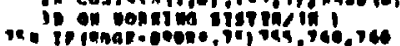

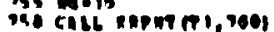

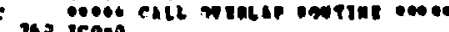

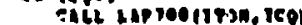

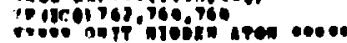

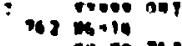

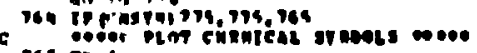

Yos 90.1 .

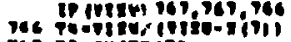

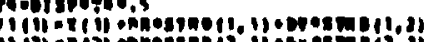

iinesin

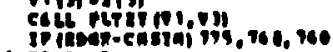

(3)

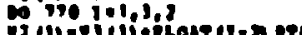

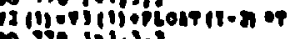

Min-nivioniont tu+n oro

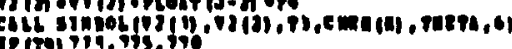

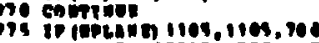

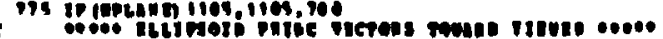

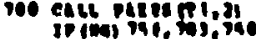

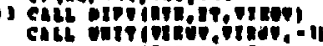

cati m(nithr, (i., th)

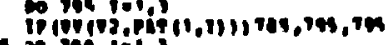

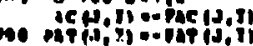

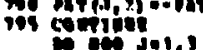

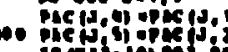

$10(4)=101 m, 61,001$

HI "

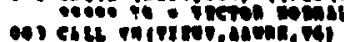

cite nirite.tion

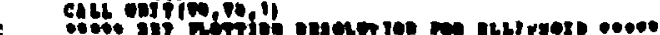
ilonesting

inecti

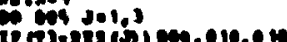

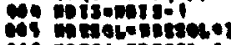

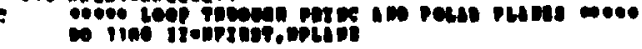




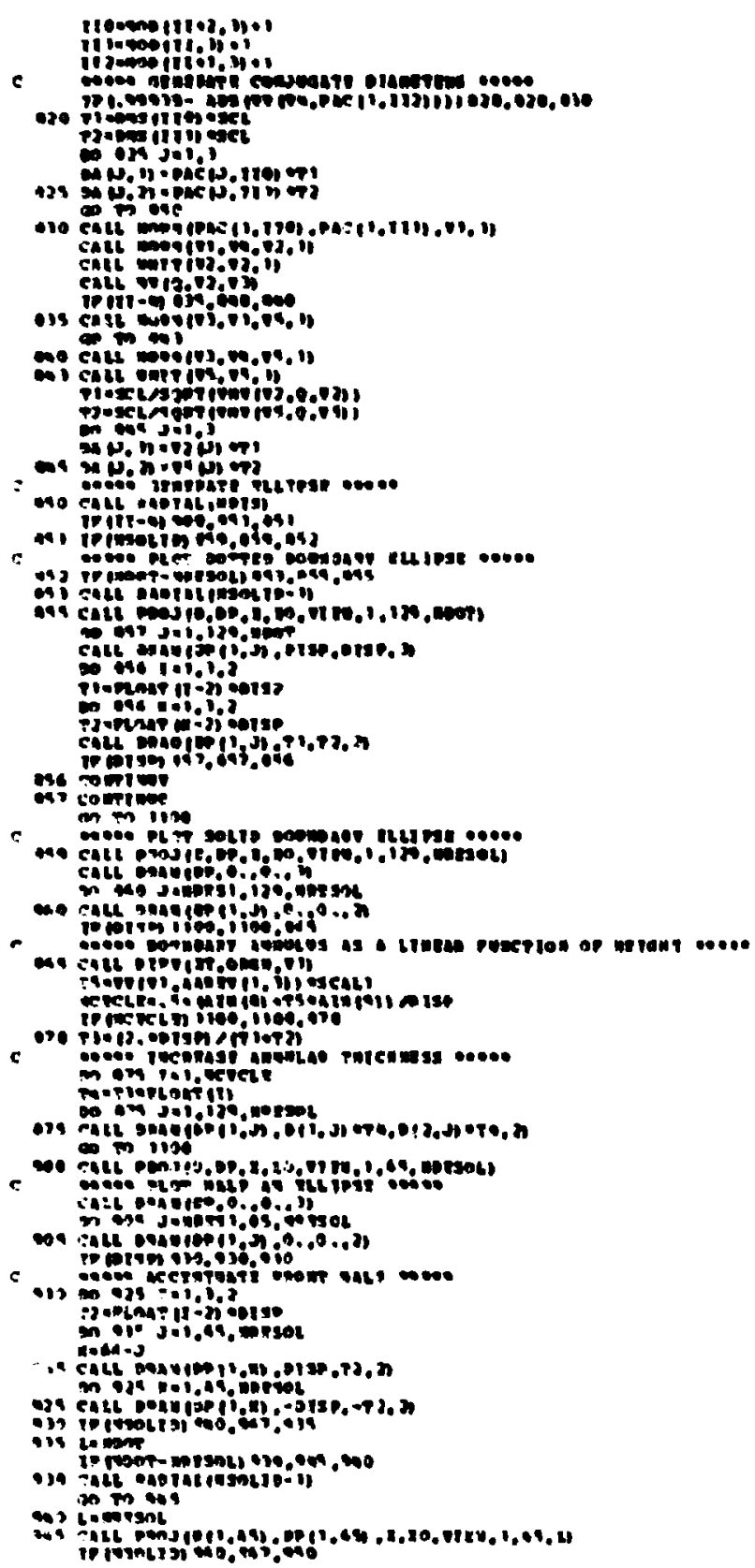

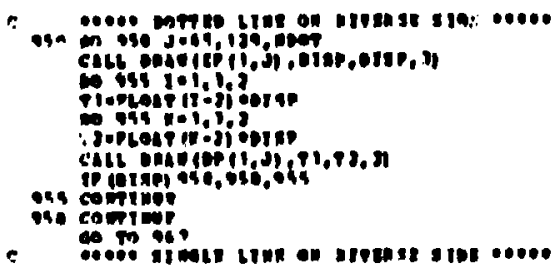

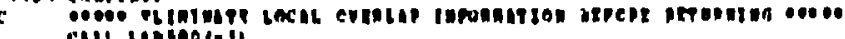

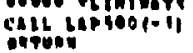
mition

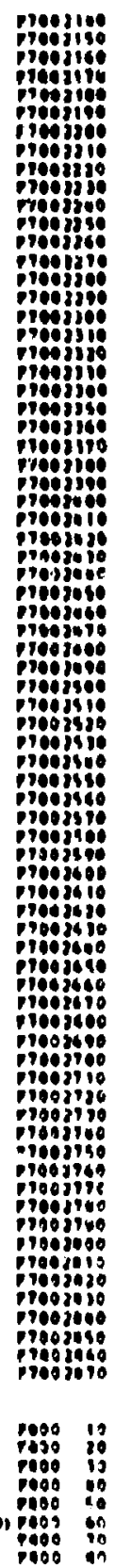

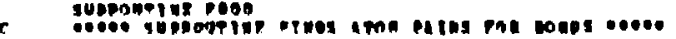

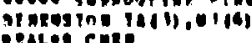

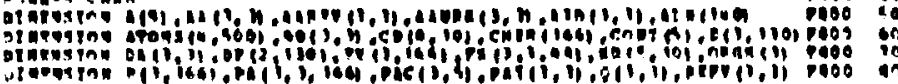




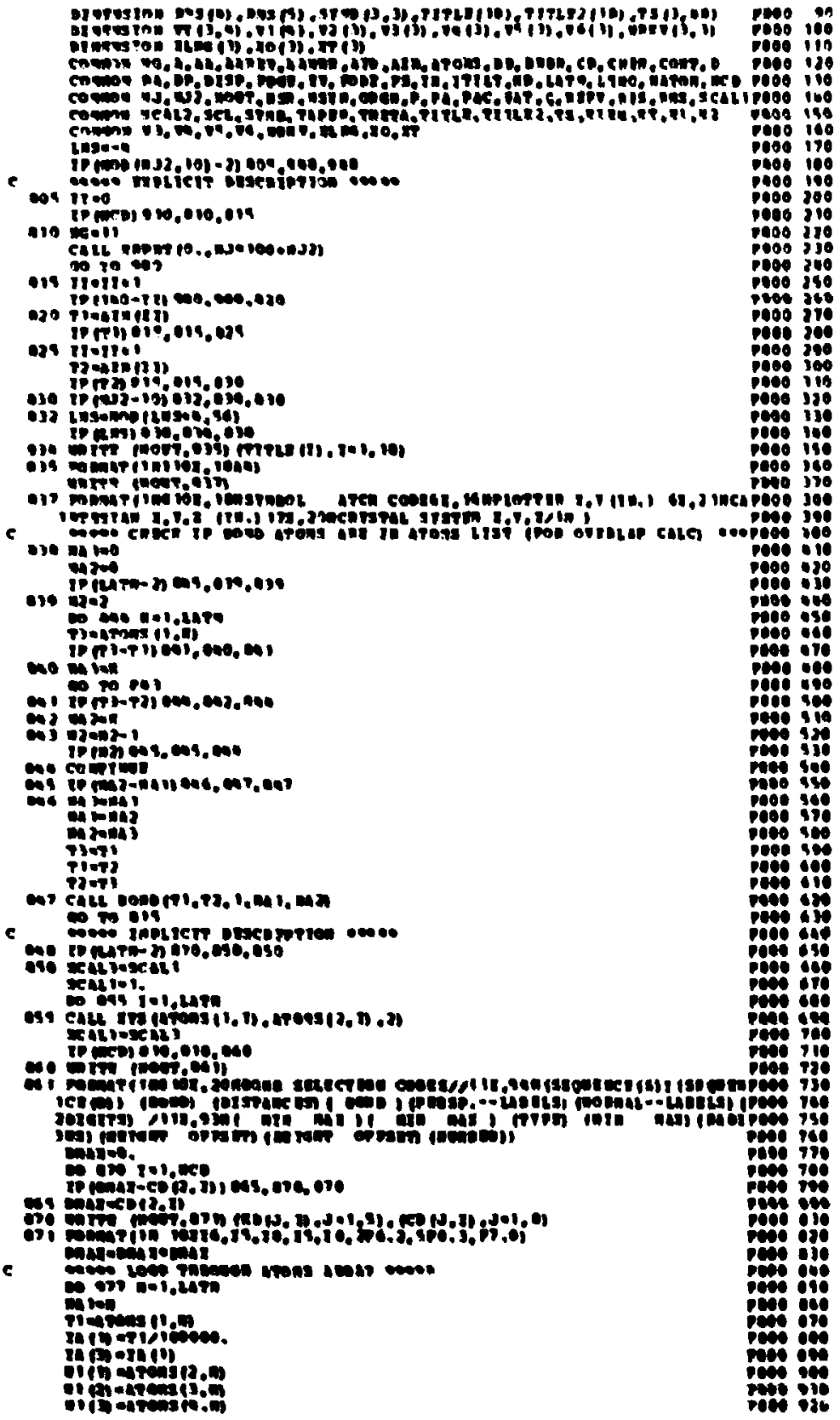



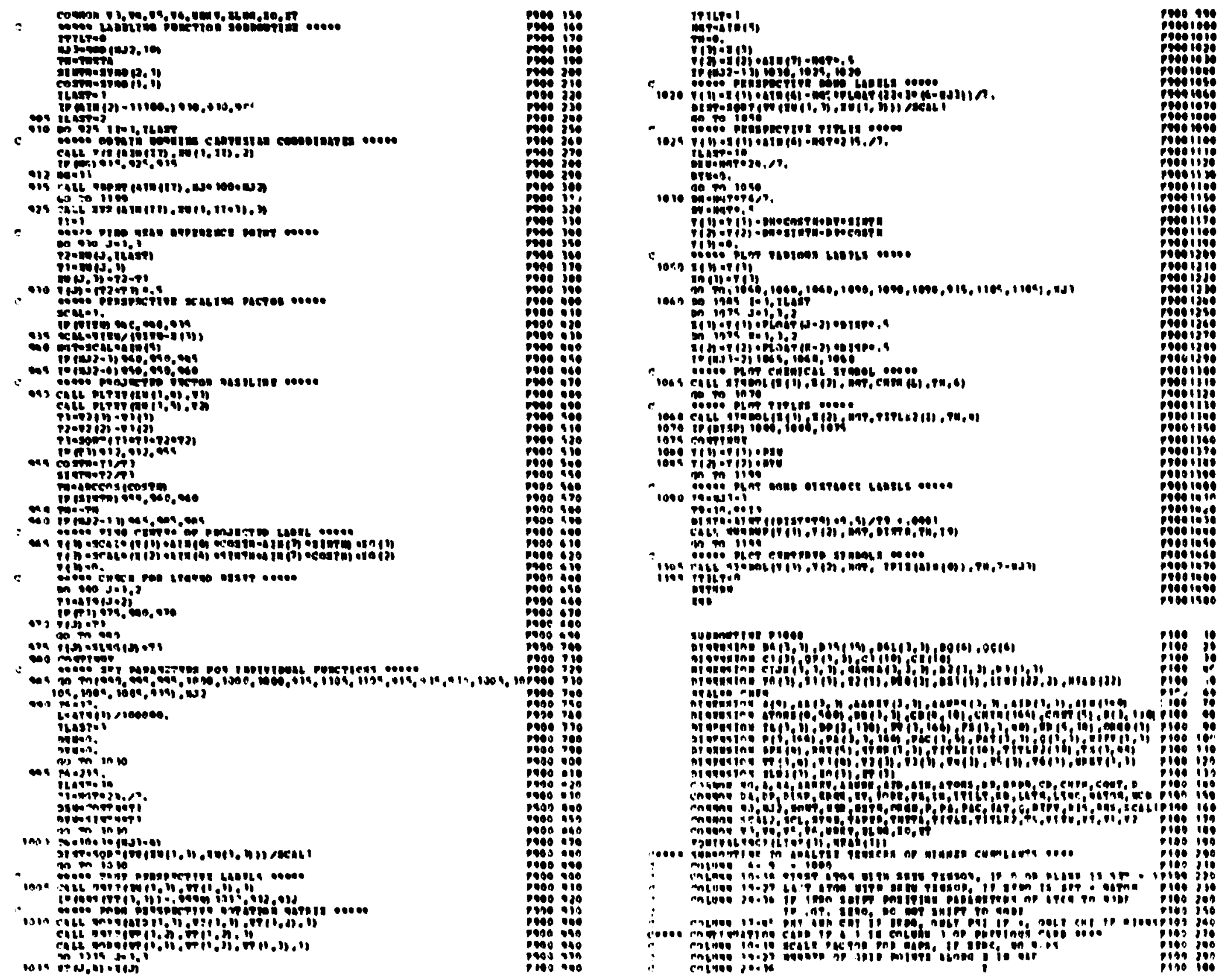


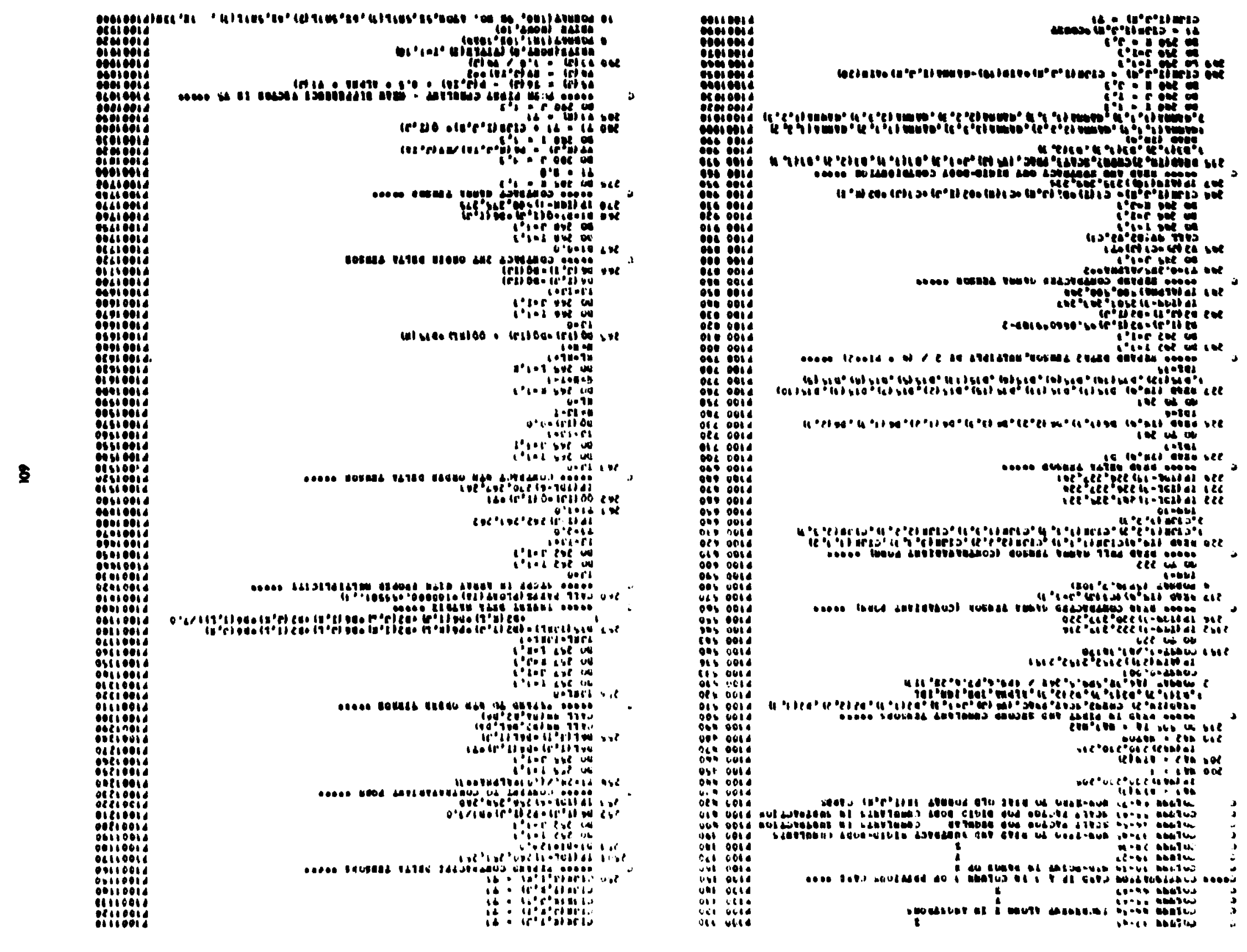




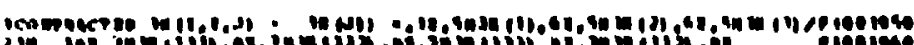

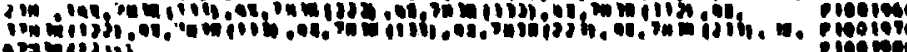

017 .

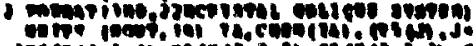

等

10

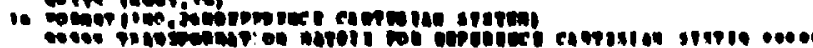

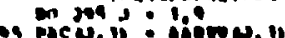

$117 m: 0$

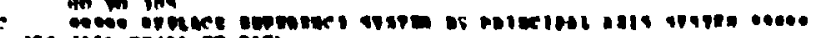

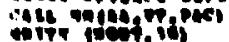

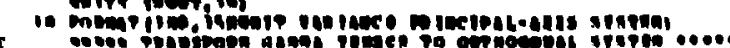

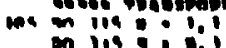

in

3 ins 30.4

in ing

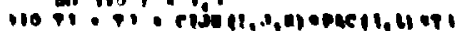

minnition: in

ancen:

W w whici, :

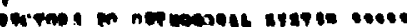

(Mi.

in :

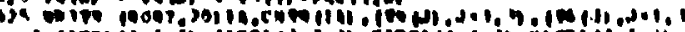

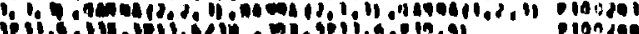

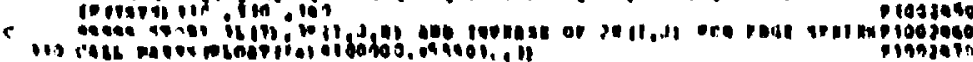

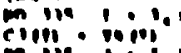

in.

anjo

$11,0,110+1,9$

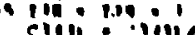

$\rightarrow$ ing

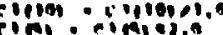

(che

lon 2 s.

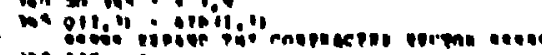

an ?"in's

mo m:

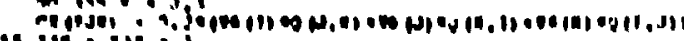

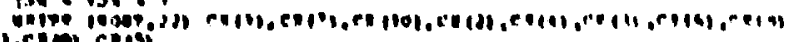

o chentiving

(1) $191,911,4,016,4$

1910 ?

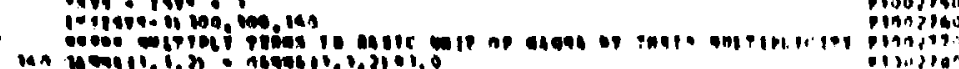

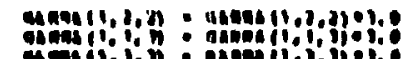

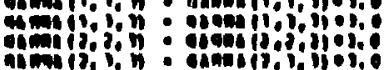

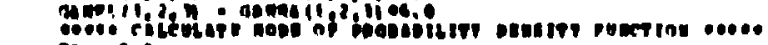
$\cos 2-1,0$

Le.

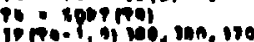

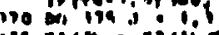

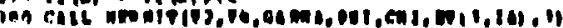

Tis ing

in (j)

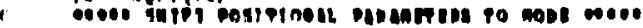

min" sis

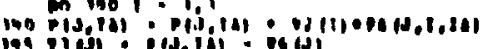

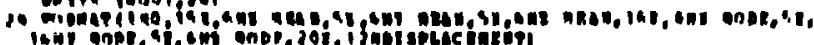

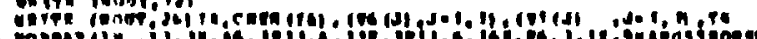

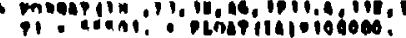

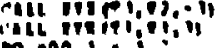

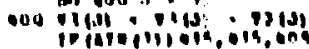

ina

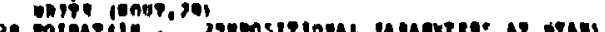

m in 23

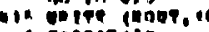

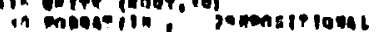

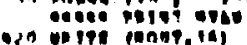

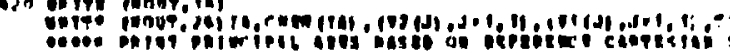

ublpo pact, lli

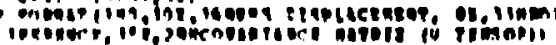

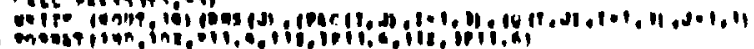

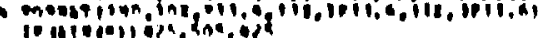

POMre

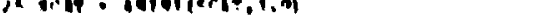

年,

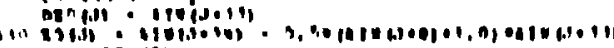

: : :

s.ere.....

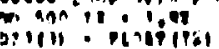

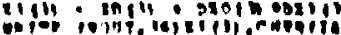

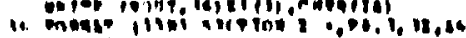

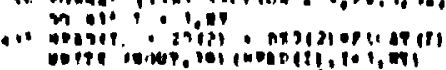

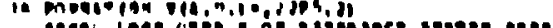

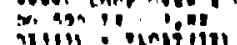

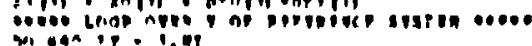




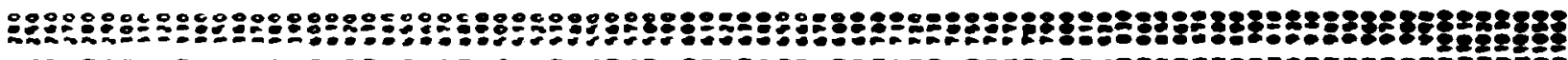

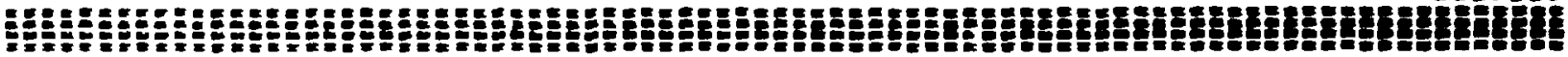

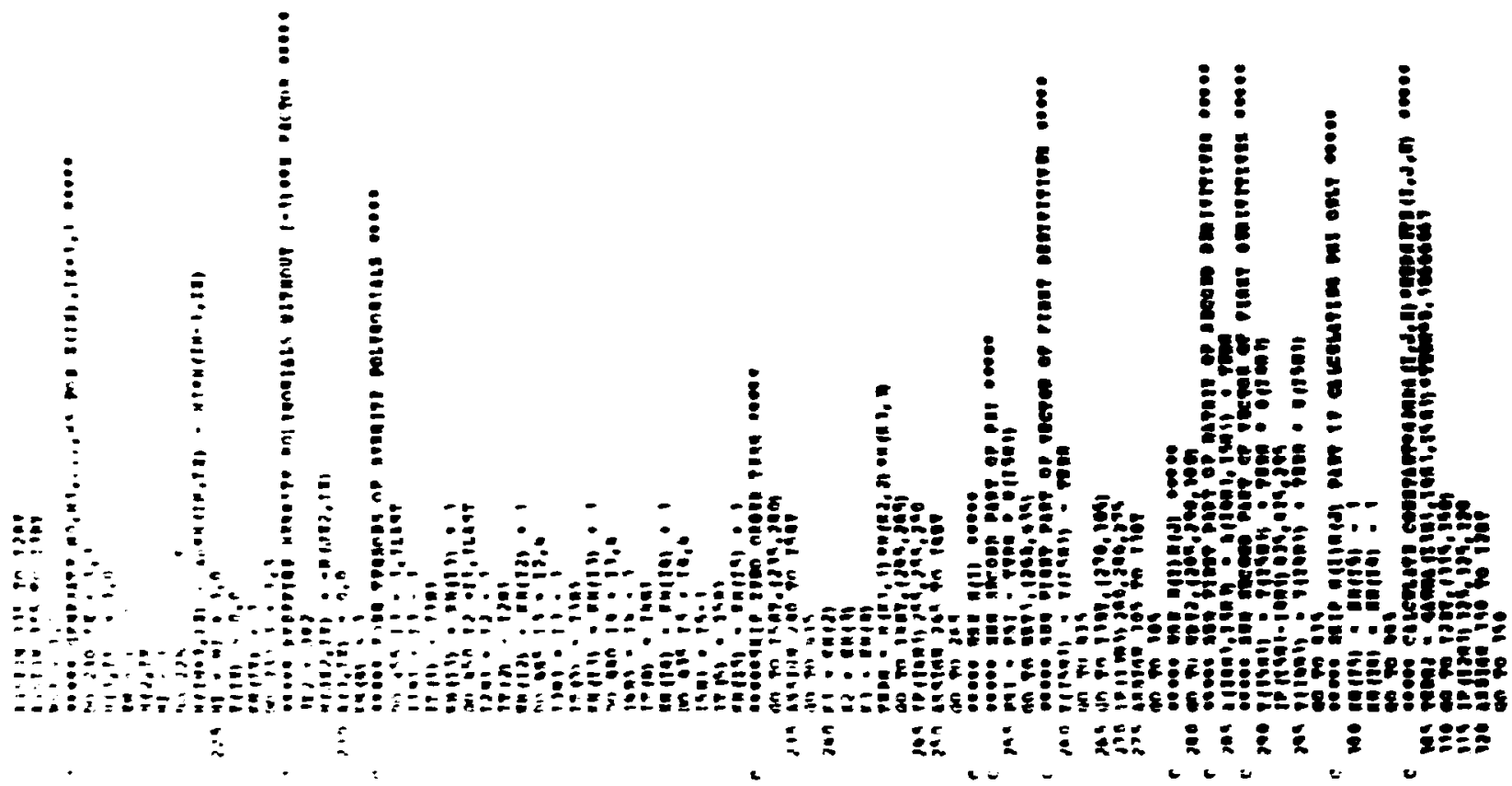

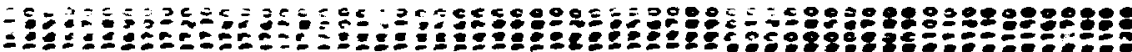

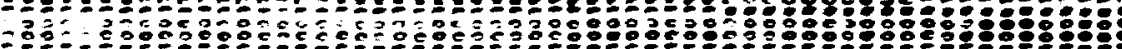

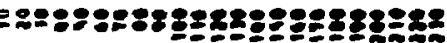

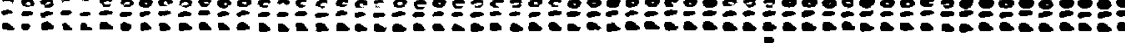

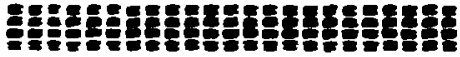
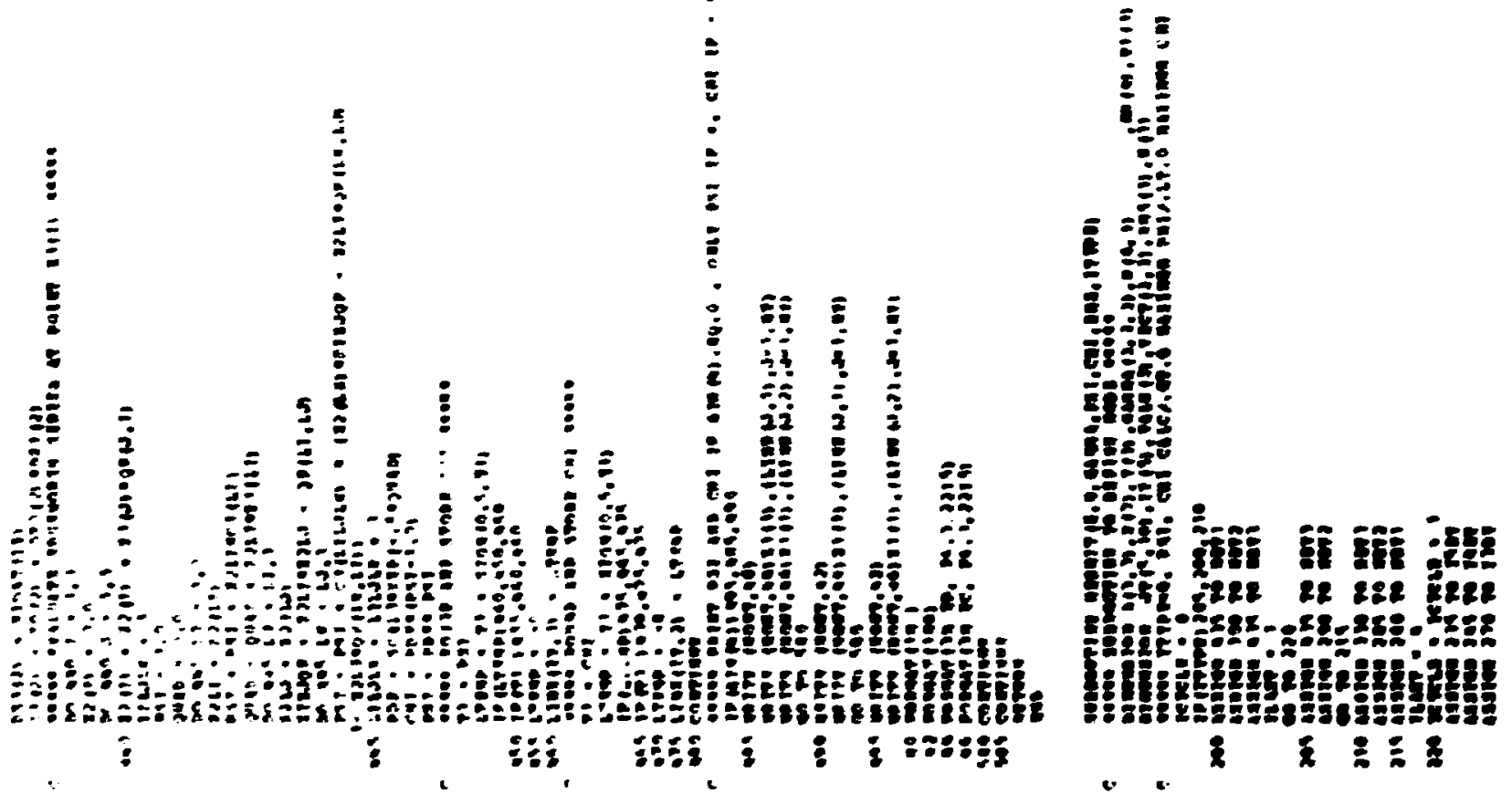


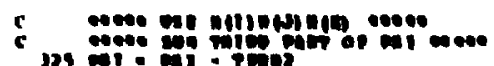

m

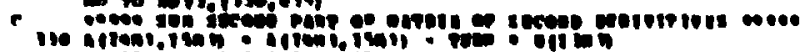

a

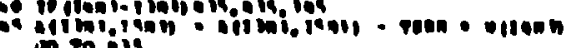

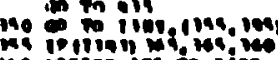

c

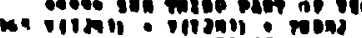

130 Pilquin

(1)

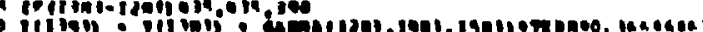

-

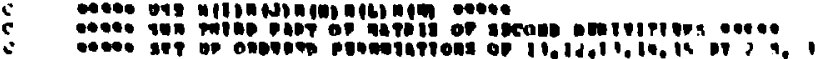

m. in

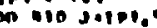

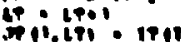

P1:17.0,

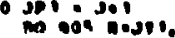

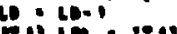

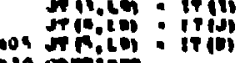

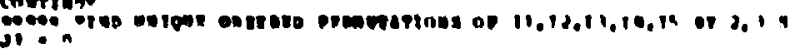
3⿻

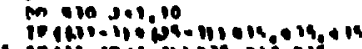

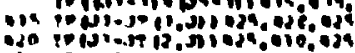

נi:

נ3:

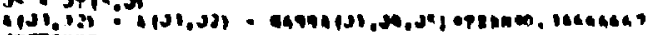

:

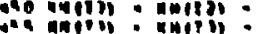

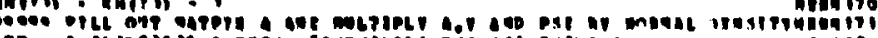

nil : : :

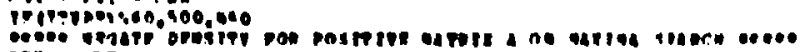

non

mon

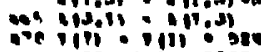

ce...

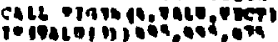

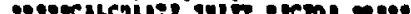

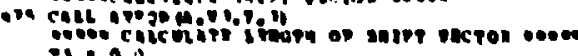

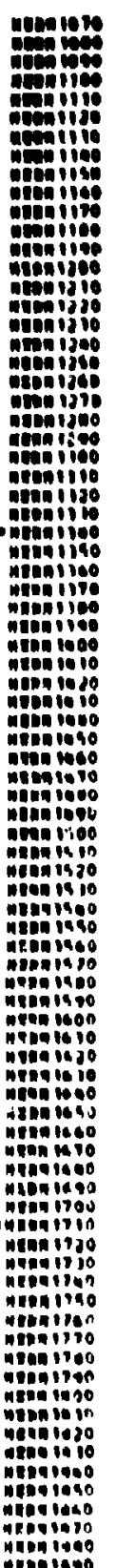

200

Het:1,

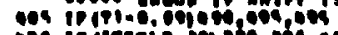

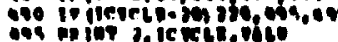

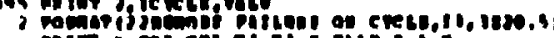

min

son

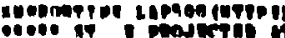

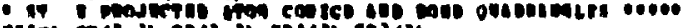

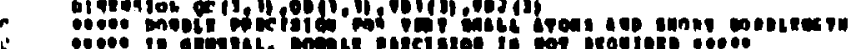

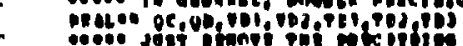

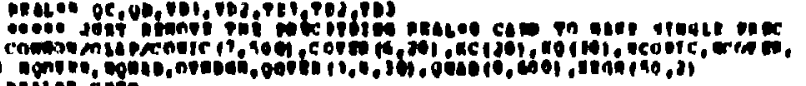

affeneng

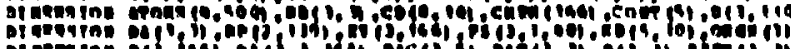

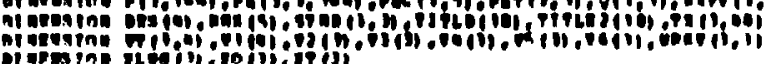

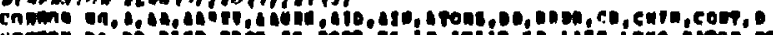

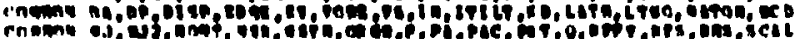

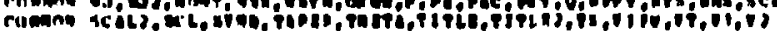

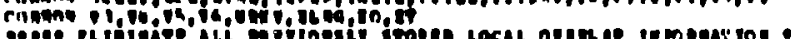
remengen

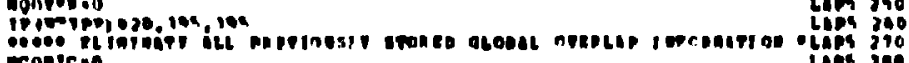

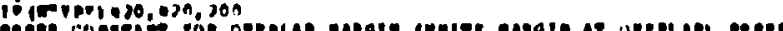

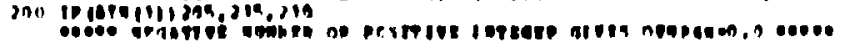
an in 19

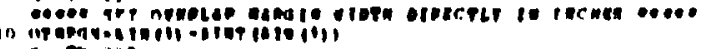

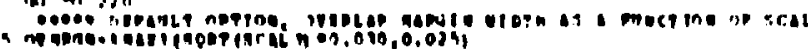
3a no

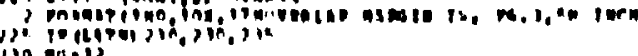

$$
\text { intinger }
$$

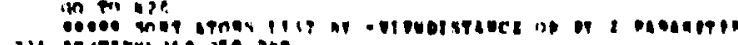

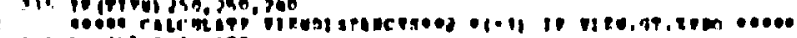

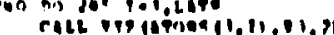

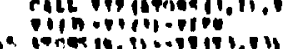

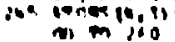

con

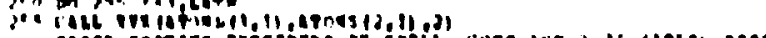
;it antiph

1. 10inimn, 109, 37n

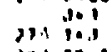

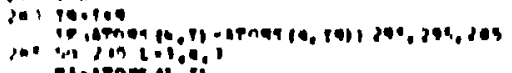

Lipg 190 


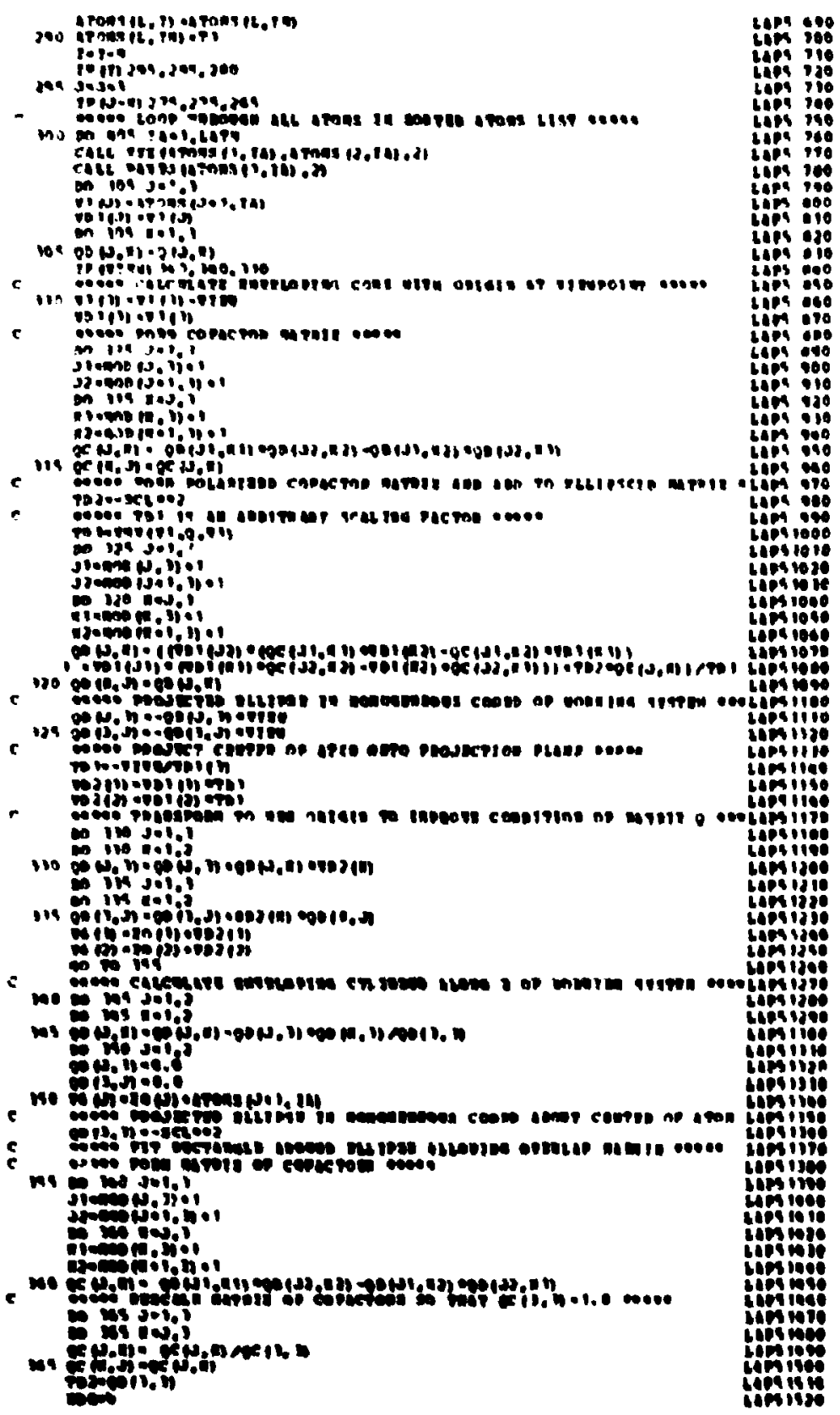

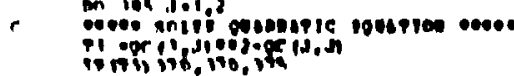

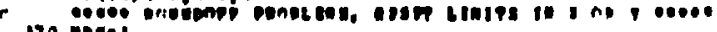
as al 0.000 comeneas

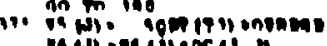
Tromentions
ine mere
ingen

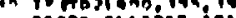

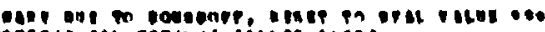

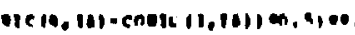

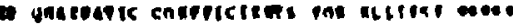

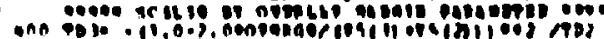

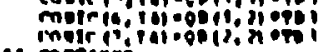
uns continger

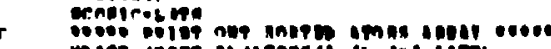

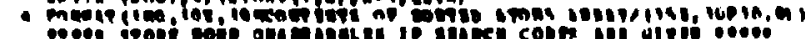
110 aide?, n1
c.

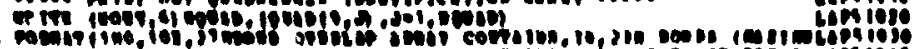 10. 190 agpons

en

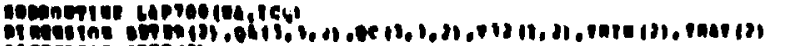

Iff

r.

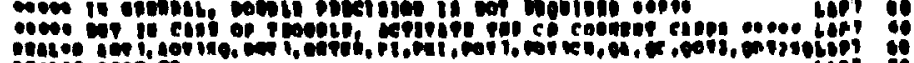

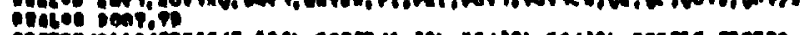

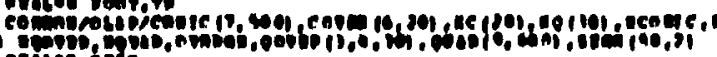

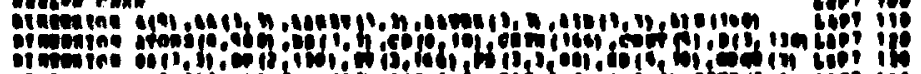

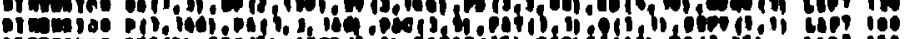

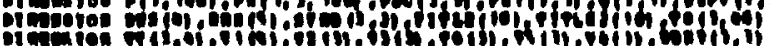

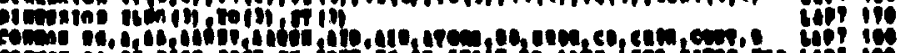

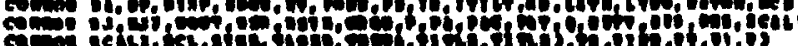

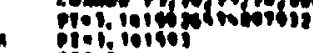

Extrition:e

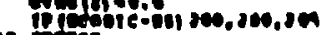

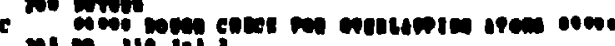

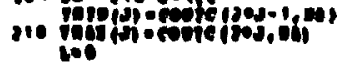

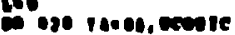




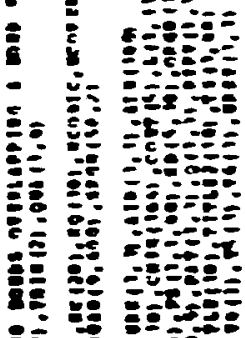

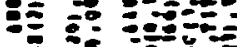
를

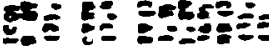
行 픙 E É

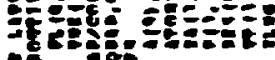

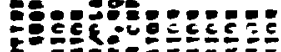
Un

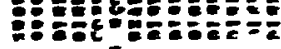

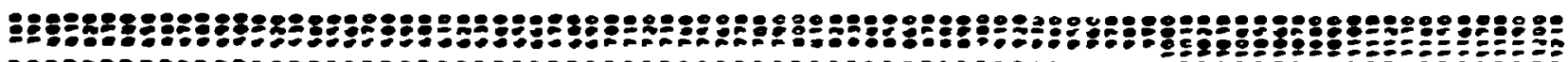

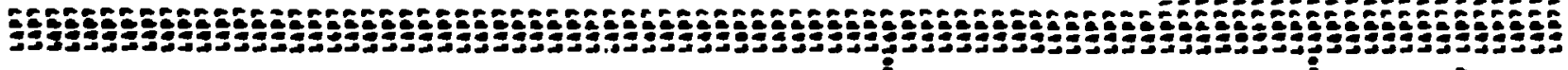
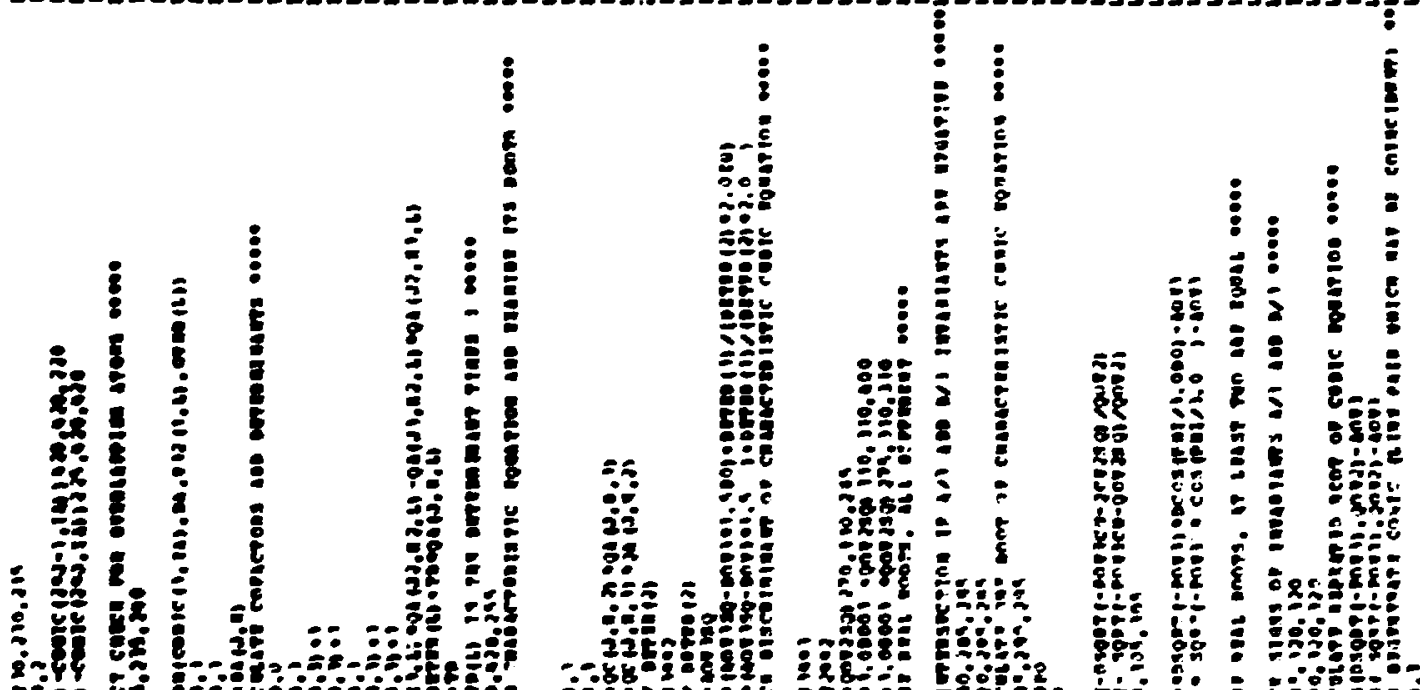

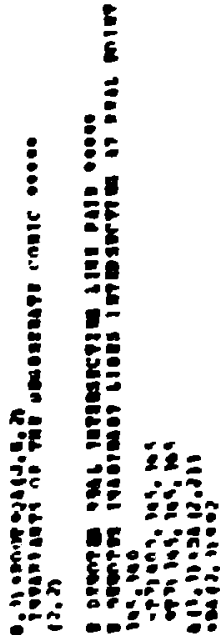

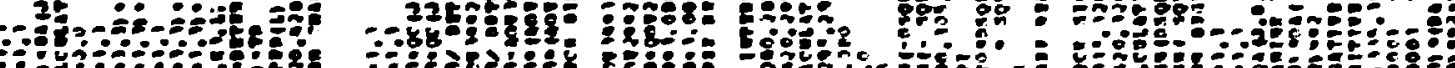

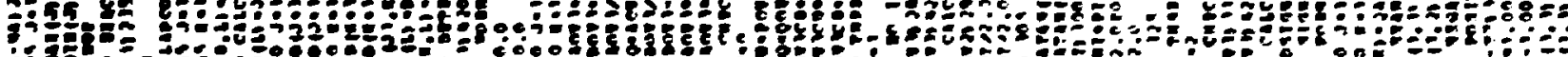

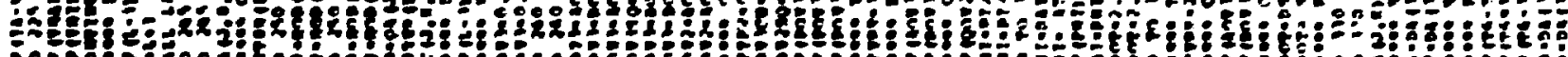
EREA $\therefore \%$ i. i i

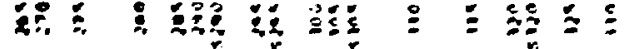




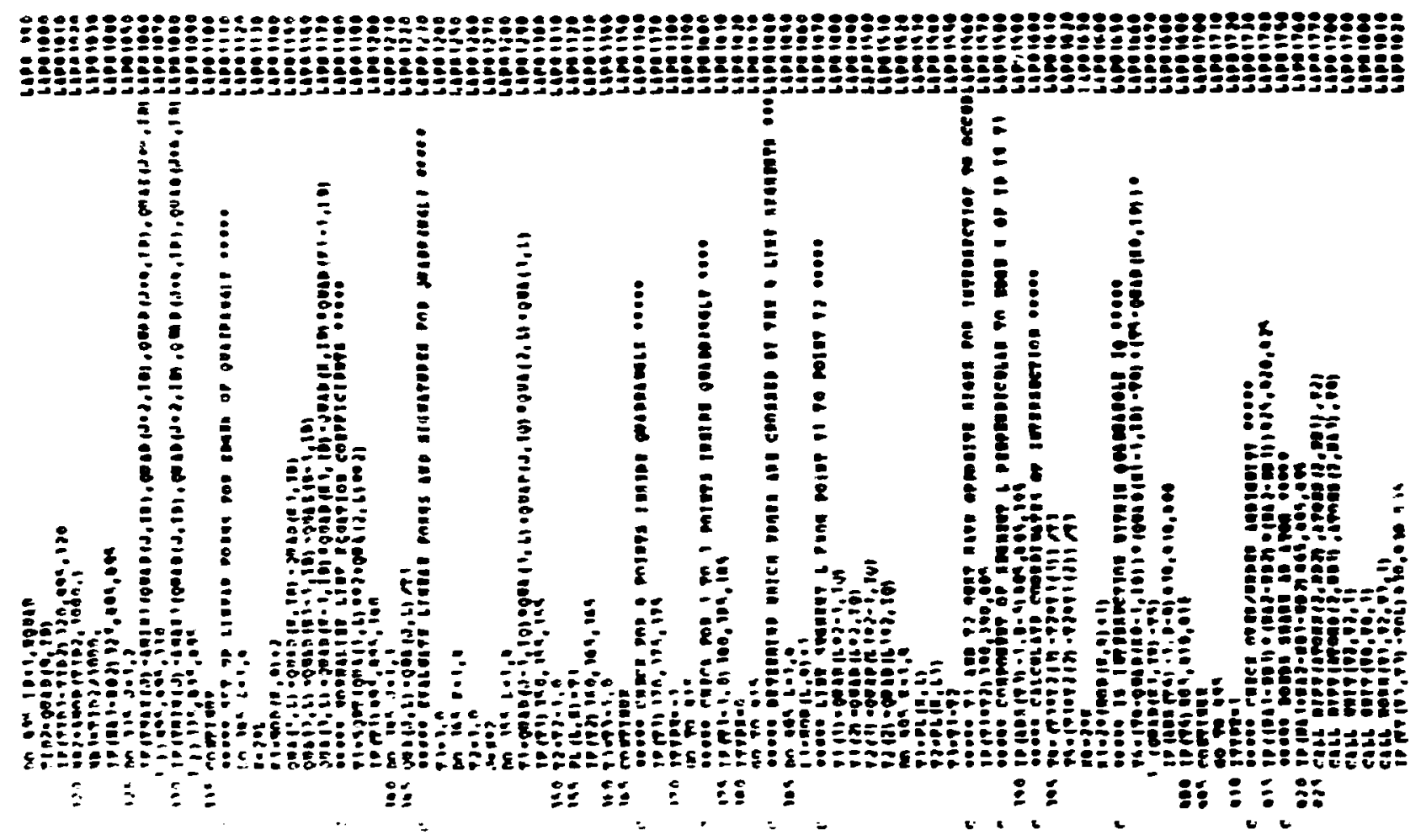

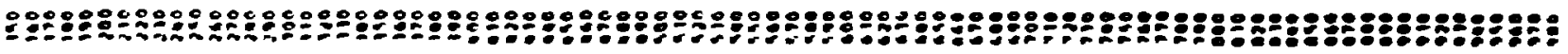

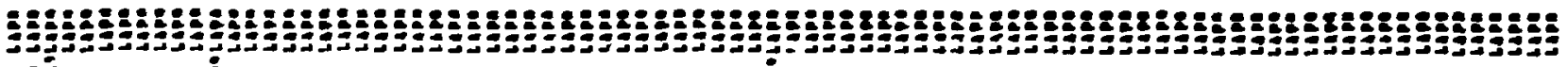
(1)
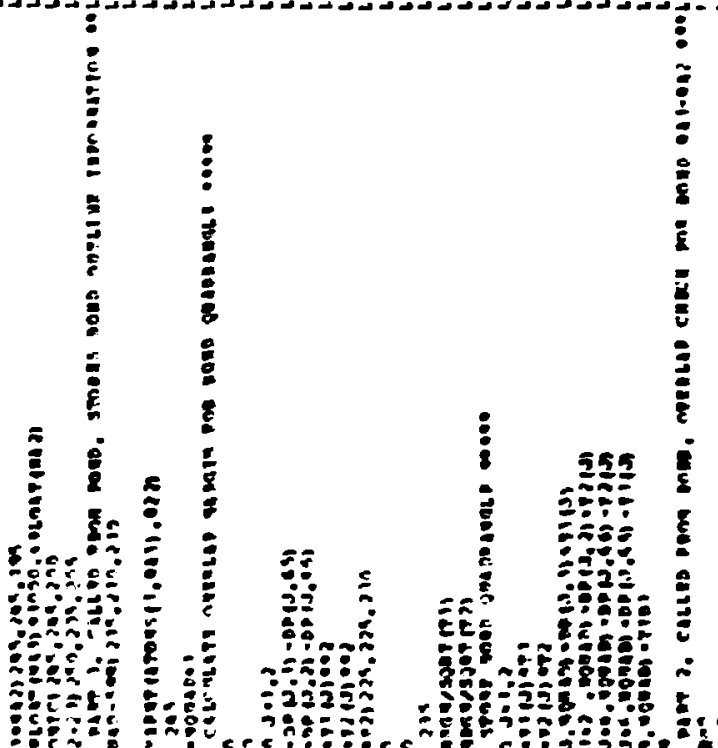

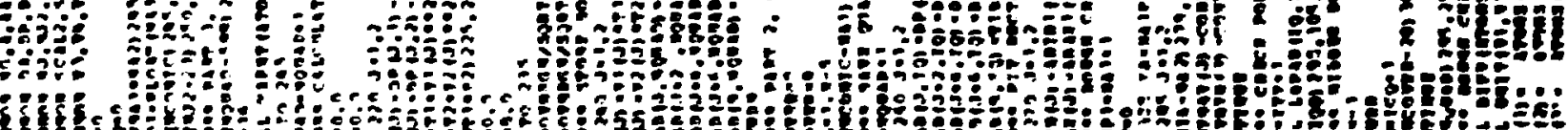

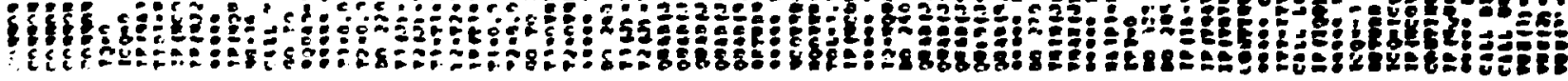

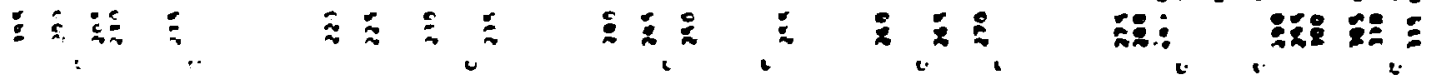




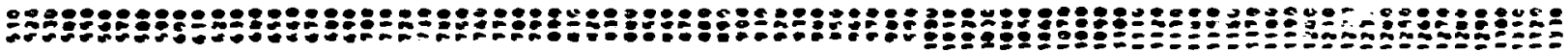

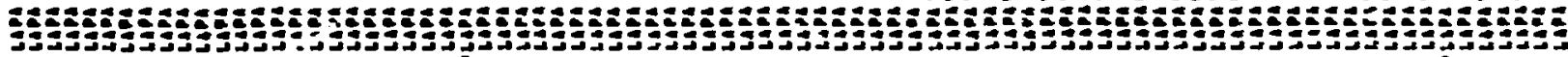

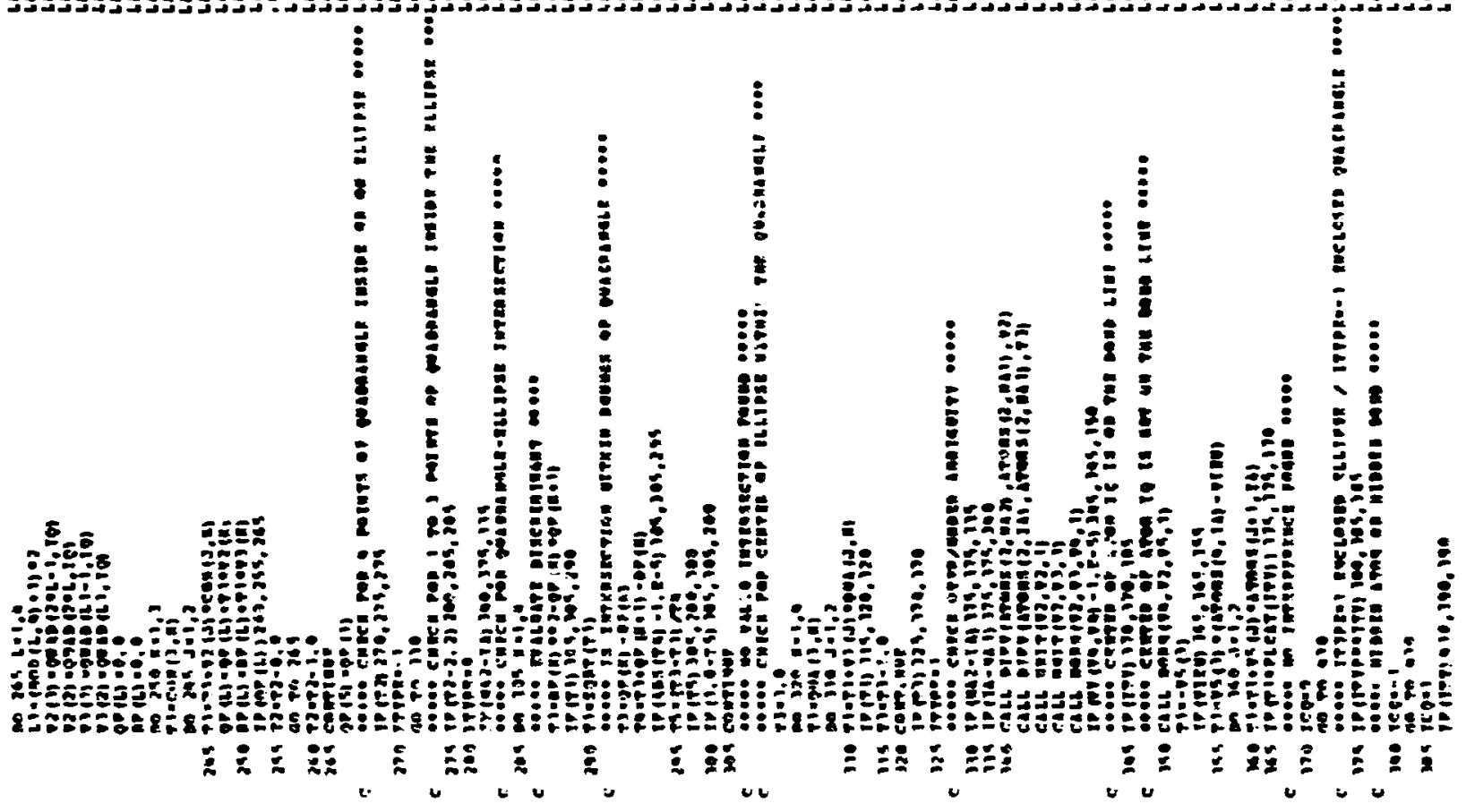

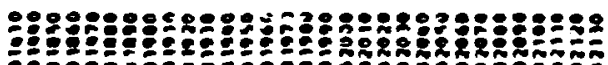

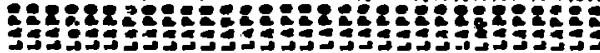

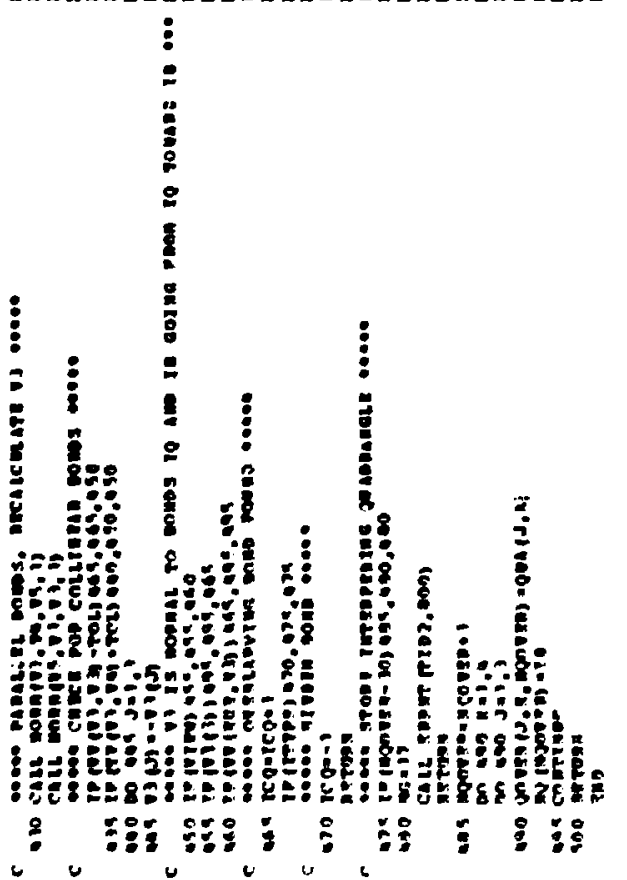

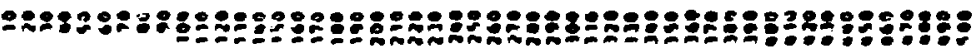

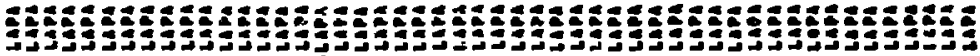

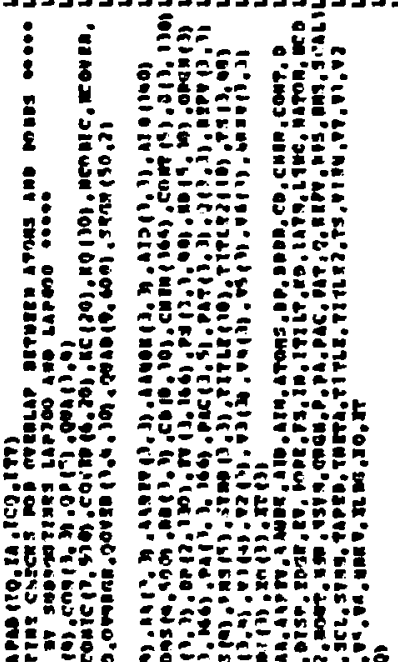

Jots.

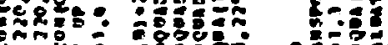
ons Guts: कo:

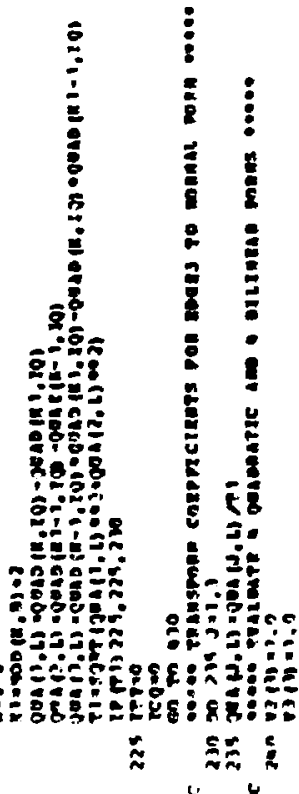



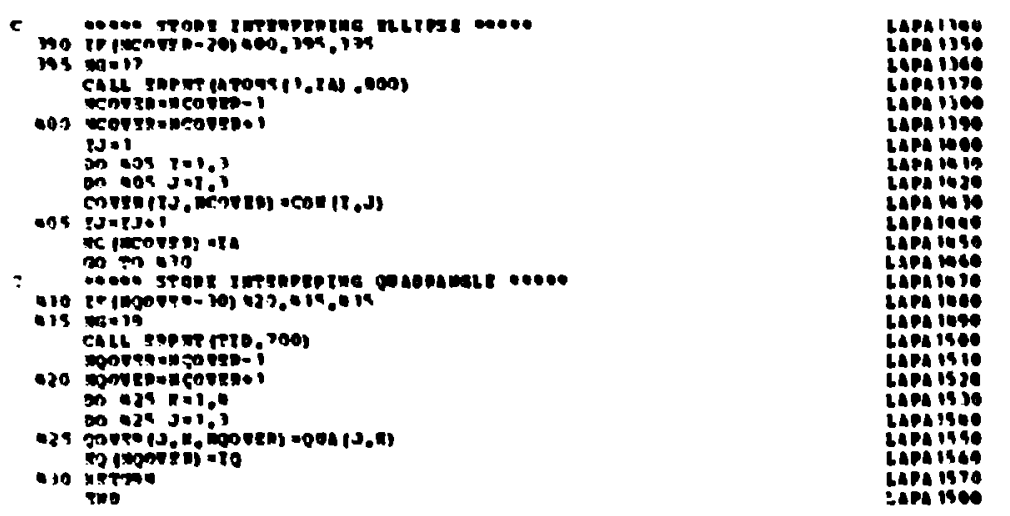

c

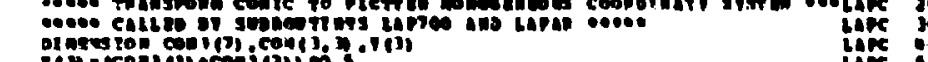

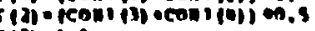
Iinmi:

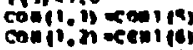
conis. $n \cos 160$

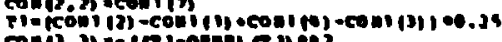
cong $\lim ^{\infty} \lim _{3=1,0}$

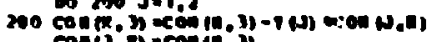

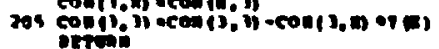
intim

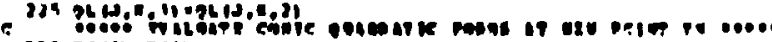

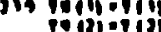

minge:

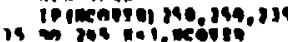

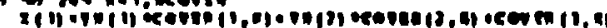

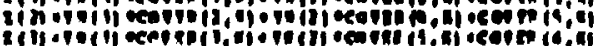

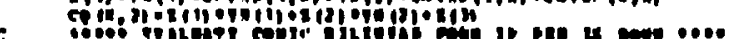

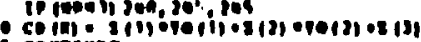

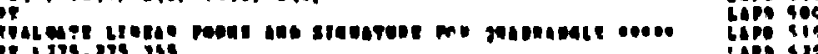

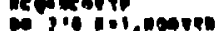

i.

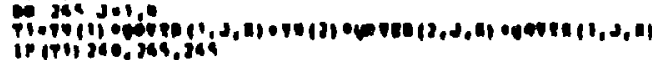

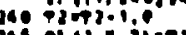
otw. $1,31=1$

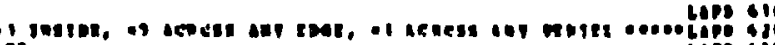

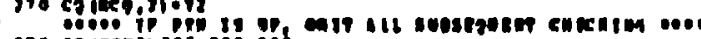

75 B.

Chlt gersilith, apt, tren

-

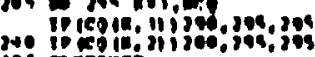

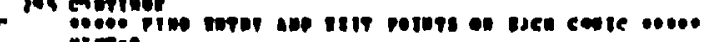

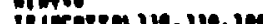

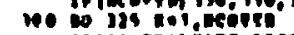

c nom

IP

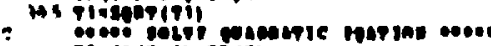

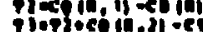

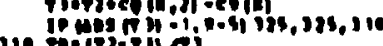

110 s.m.ting

e

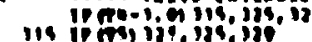

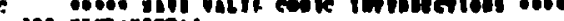

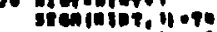

Brentiper, 1108

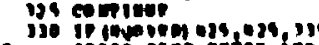

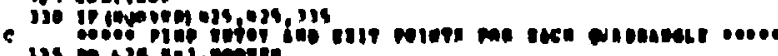

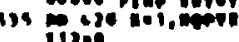

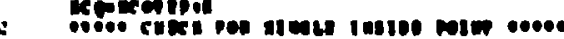

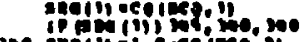

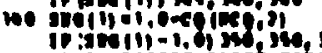

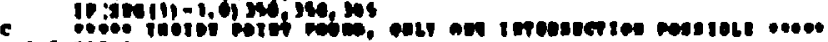

c nos

Tientu.h thontiditin

394

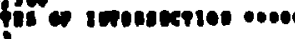

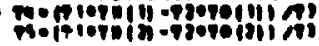

(O)

210

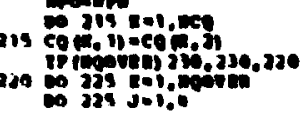

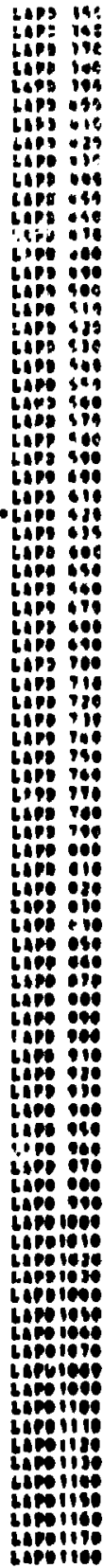




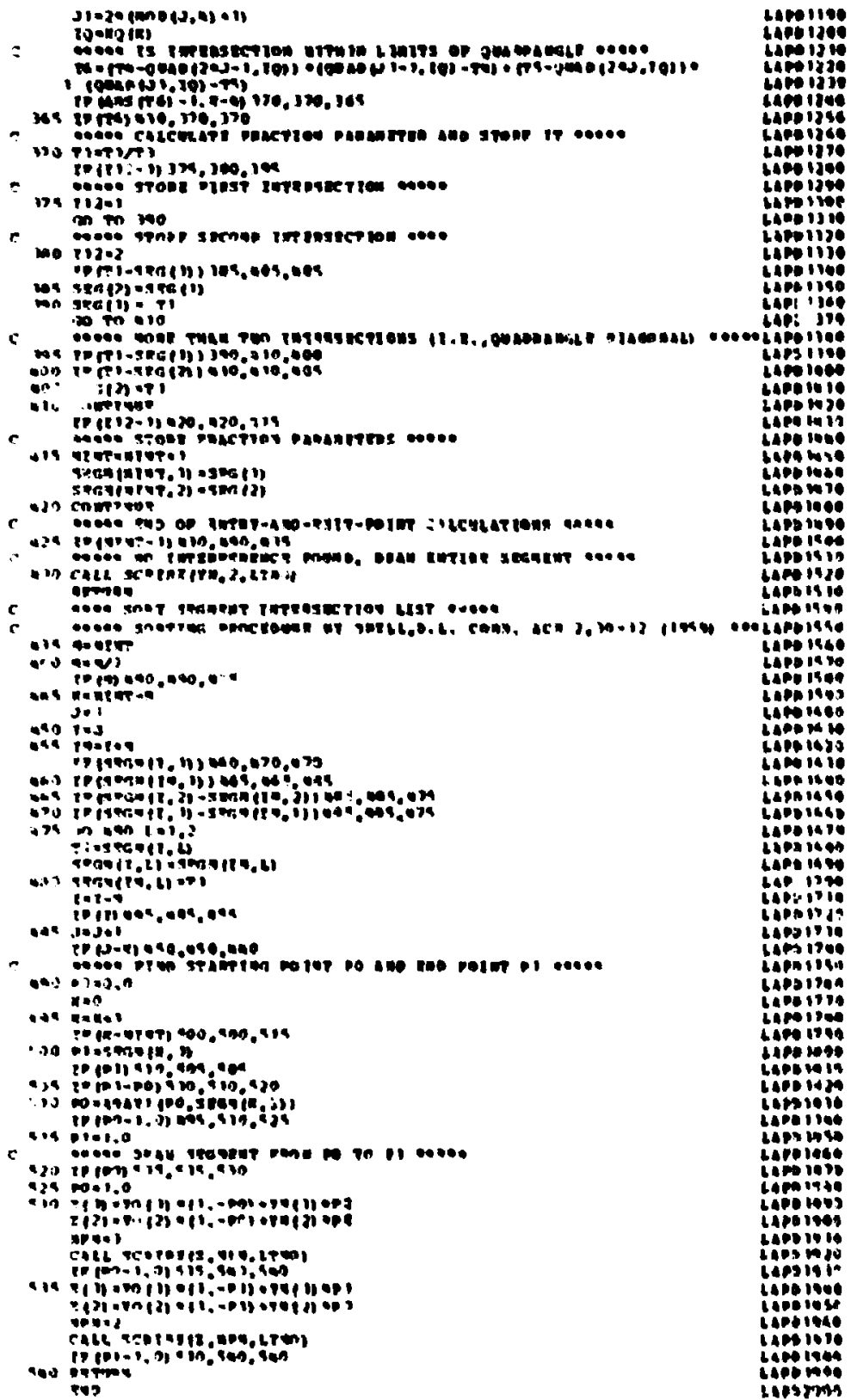

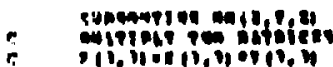

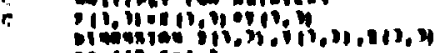

-

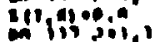

" ' :11,

:

-

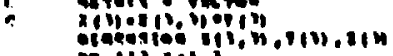

(2)

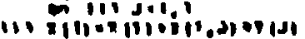

ind

:i:

-

(n)

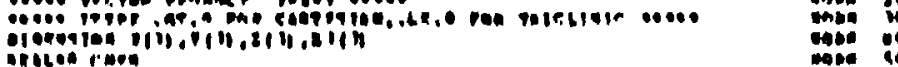

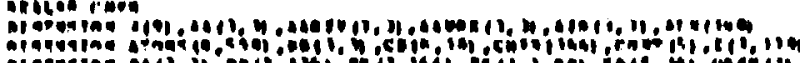

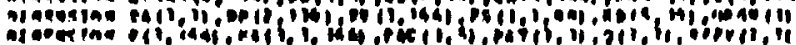

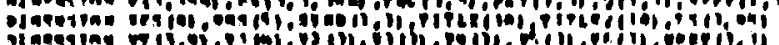

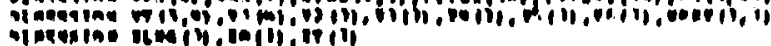

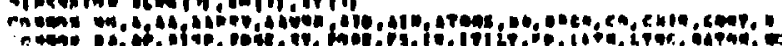

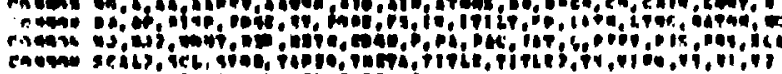

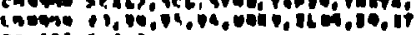

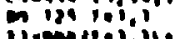

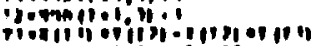

109 :

i.a ni.....?

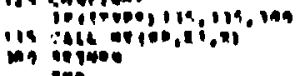

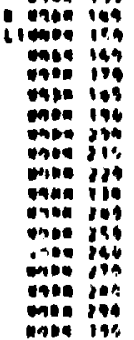

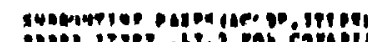

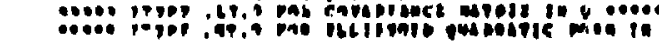
:...: ....1.

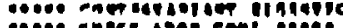

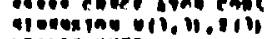

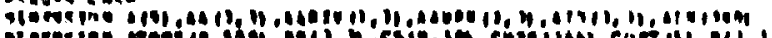

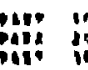

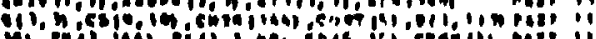

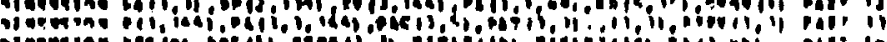

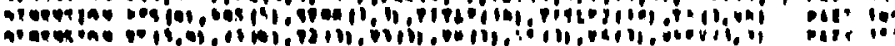

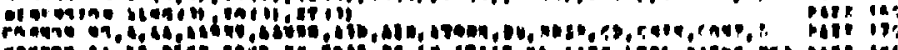

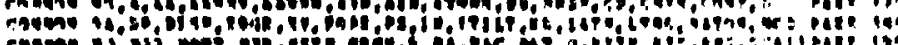

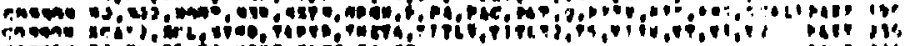

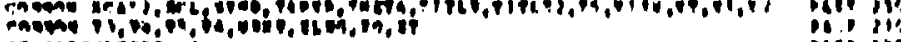

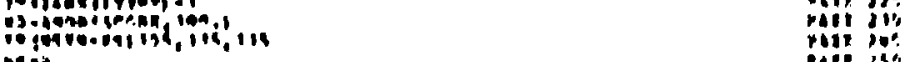

109 . 910 


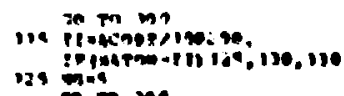

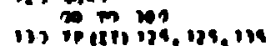

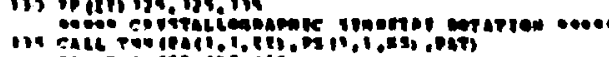

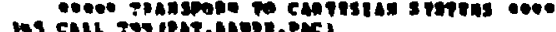

(3)

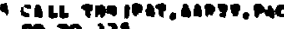

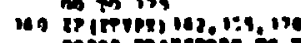

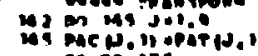

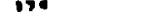

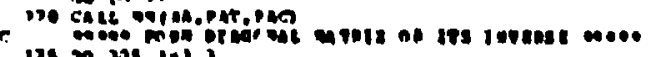

Tiping

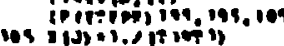

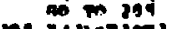

xos

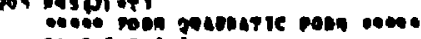

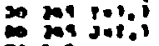

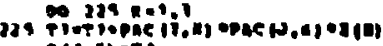

jas given

off -

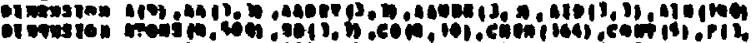

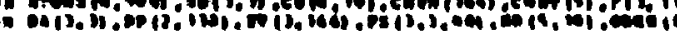
a

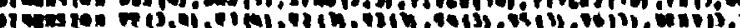
(1)

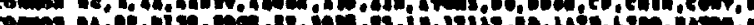

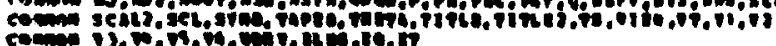

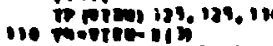

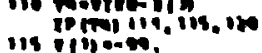

118 II)

ias 11.7row

(1) a11) Flope(1)

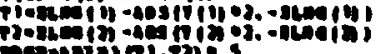

130

the

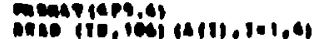

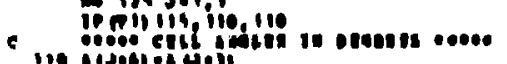

Ajofiliges

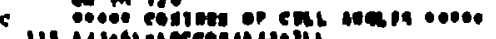

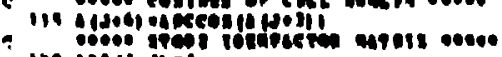

iso Alf

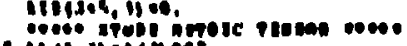

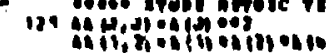

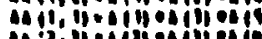

Af?ilinili,

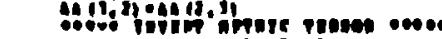

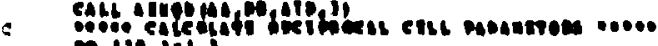

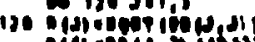

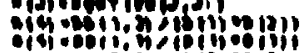

iins.

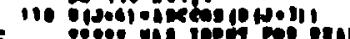

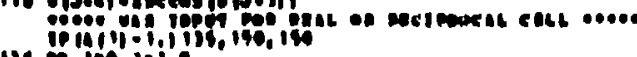

H.

ing

no

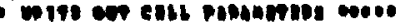

101 nomart

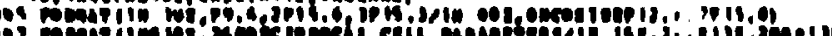
1,imet

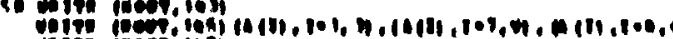

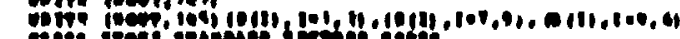

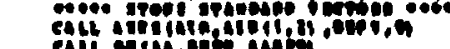

E 100 joi:?

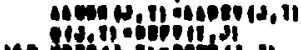

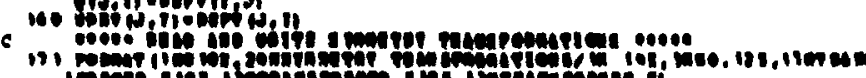

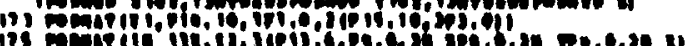

is antili

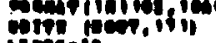

thine?

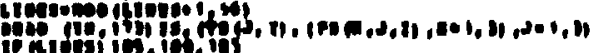

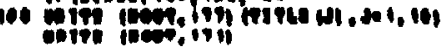




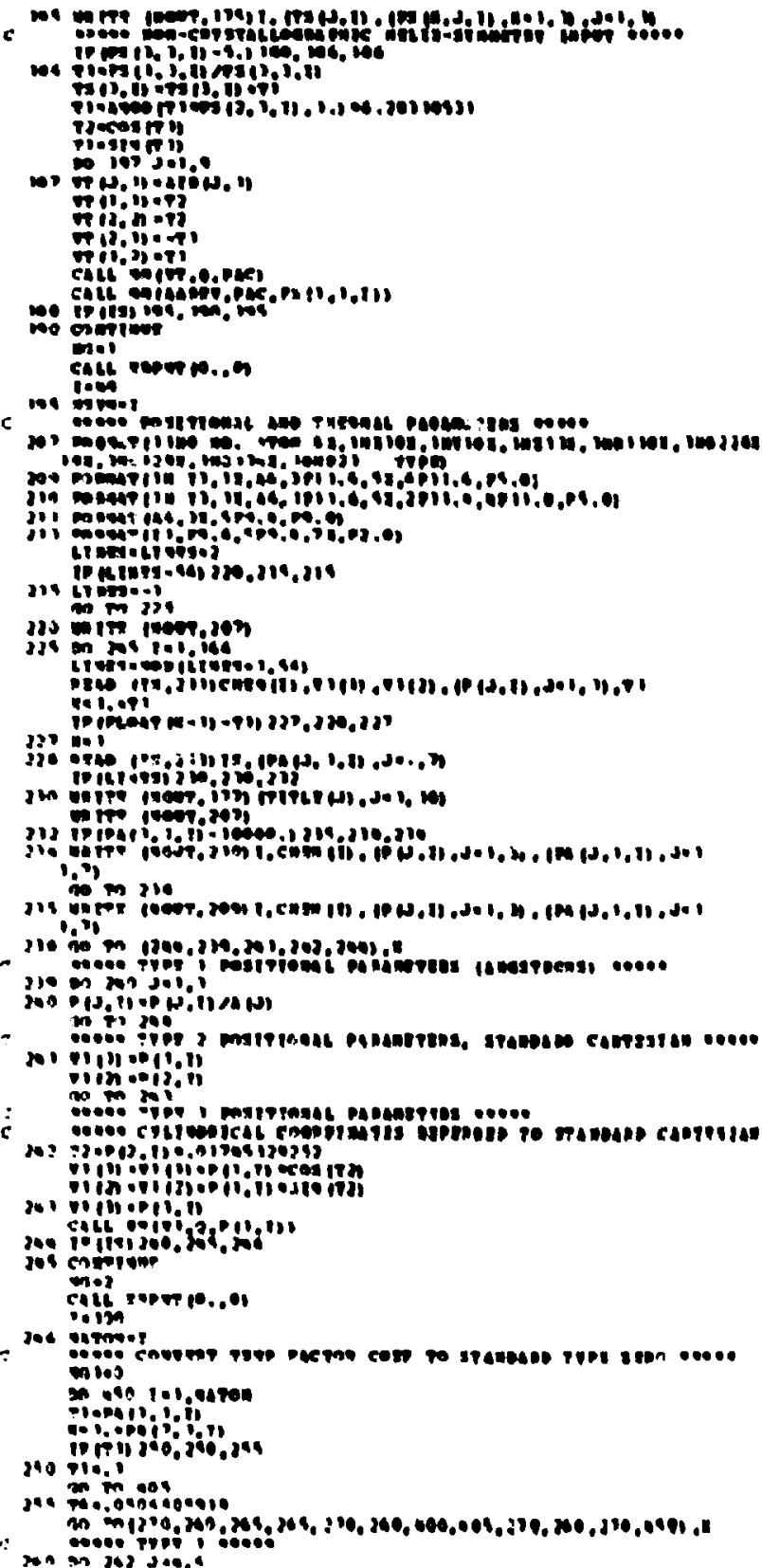

The

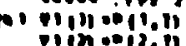

(0)

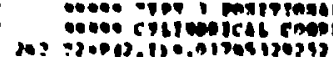

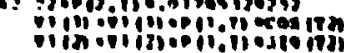

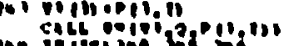

jo:

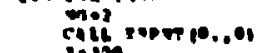

20,

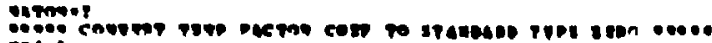
ming 101,01900

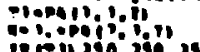

200717.11

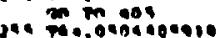

年,

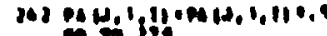

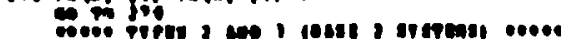

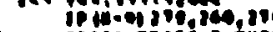

II)

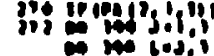

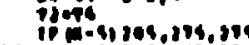

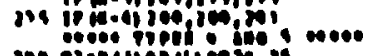

"

201 plogthog

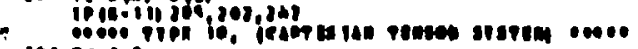

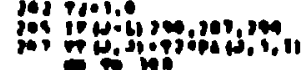

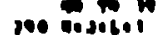

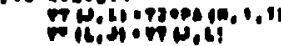

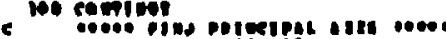

ar cou oniving

eits oniphisem

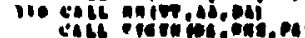

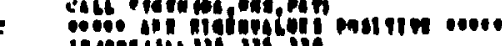

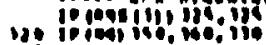

110 miet

" ins 30.9

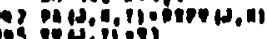

ing"ipl

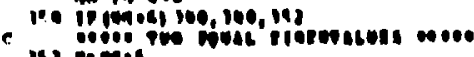

14)

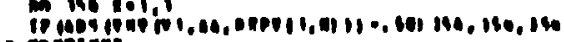

ias enit nit

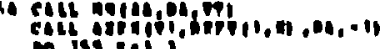

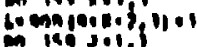

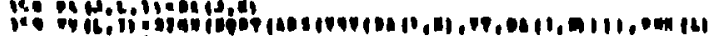

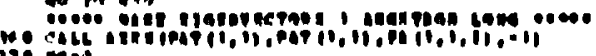

to $m$ ive $3.1,1$

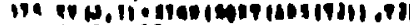

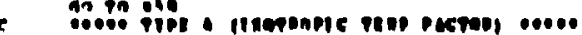

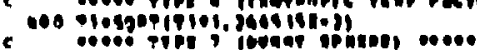

ons

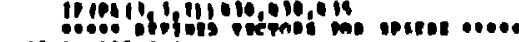

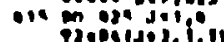

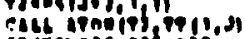

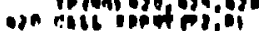

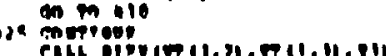

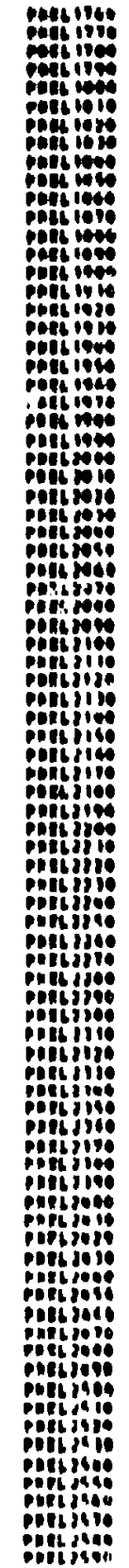



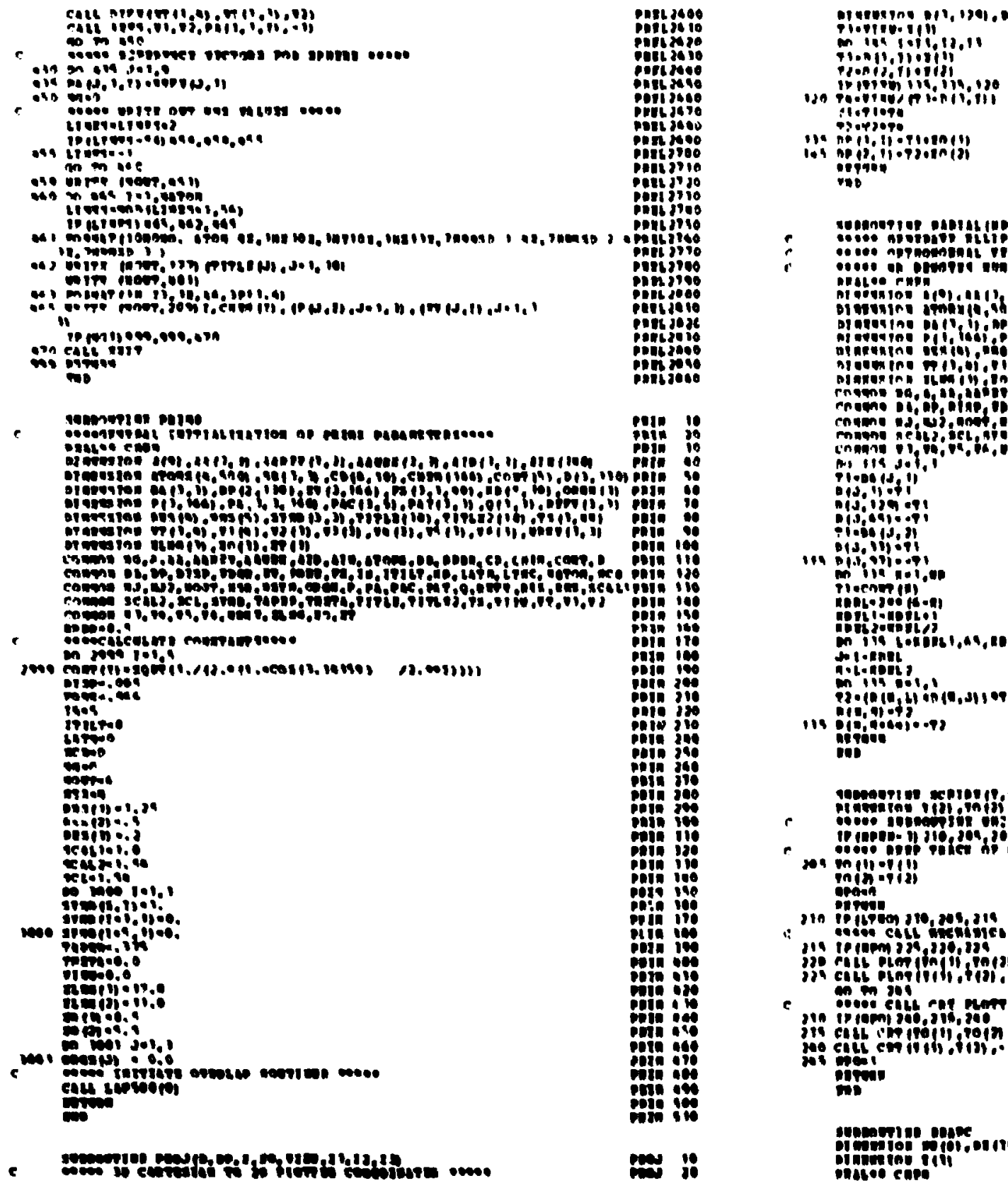

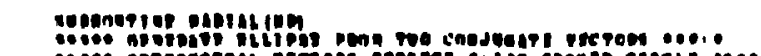

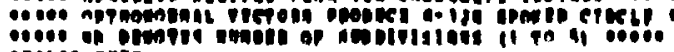

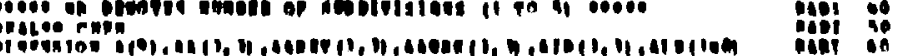

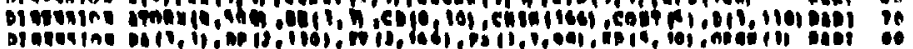

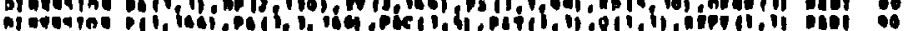

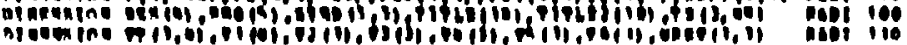

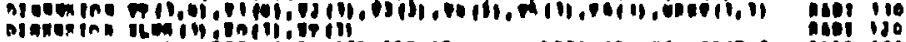

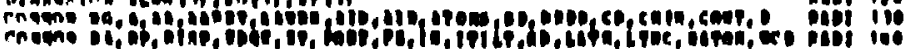
a manting mis ans

nis

ilinili,

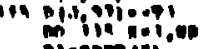

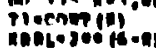

AH,ift;

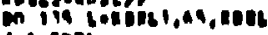

ni:ingt.

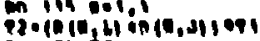

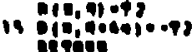

iiin

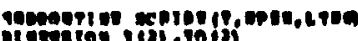

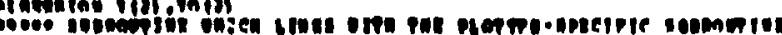

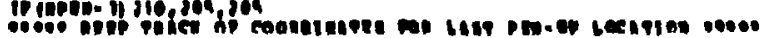
smin:

211 Pitton $310,204,319$

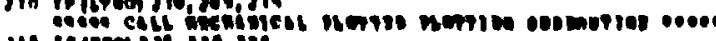

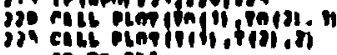

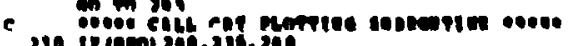

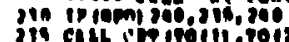

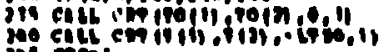

inim

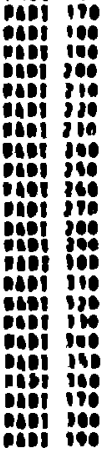

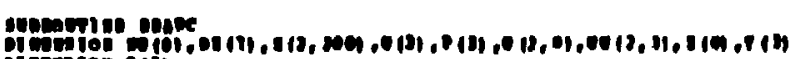

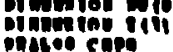

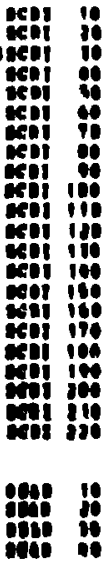




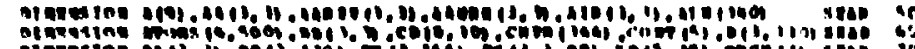

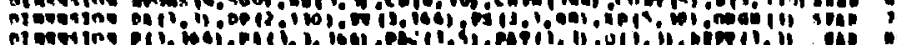

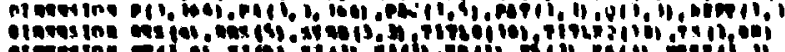
ination atwin

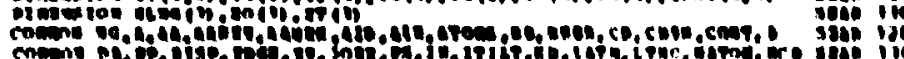

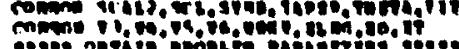

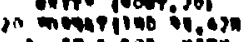

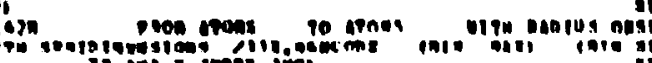

mn improslyy

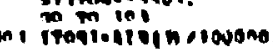

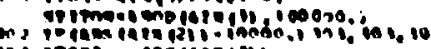

on

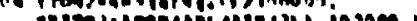

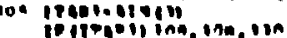

100 resil:

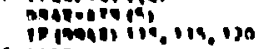

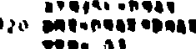

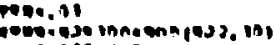

iavisiongs

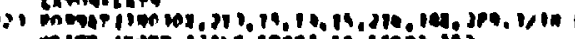

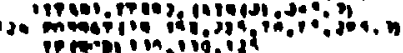

1,

in m miln.

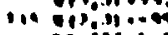

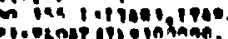

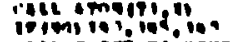

non

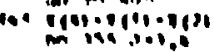

(om

ay

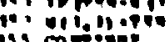

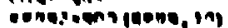

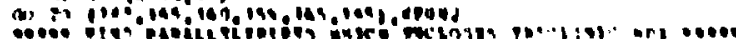
and an

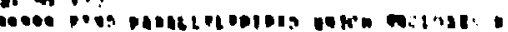

m $m ? 1,1$

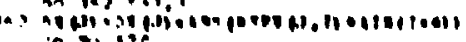

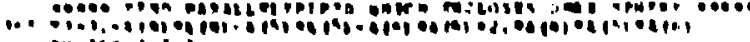

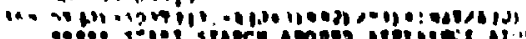

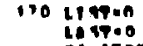

101 inom?

Moos

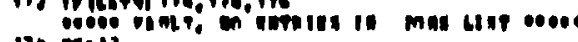

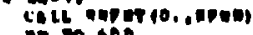

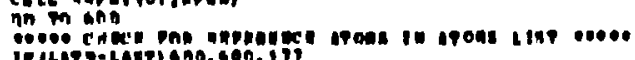

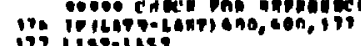

inthen.

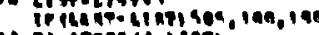

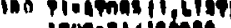

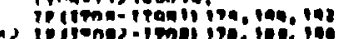

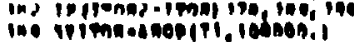

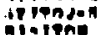

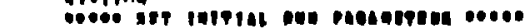

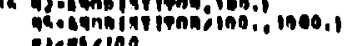

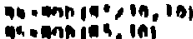

Ghempings, inf

are

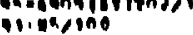

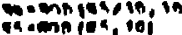

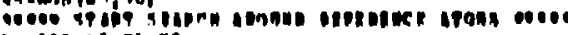

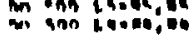

mon toralieg

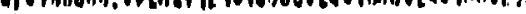

reil iprate?

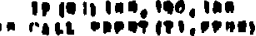

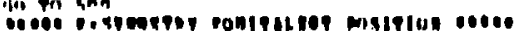

(20) weon

Con

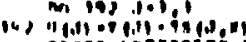

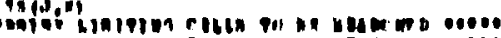

ming ing

ond 14,0

Mencinges

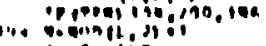

lase $\rightarrow 10$.

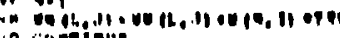

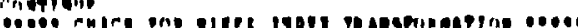

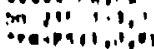

ner.e.

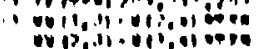

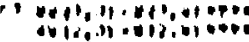

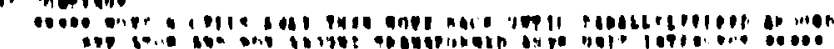

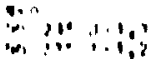

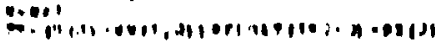

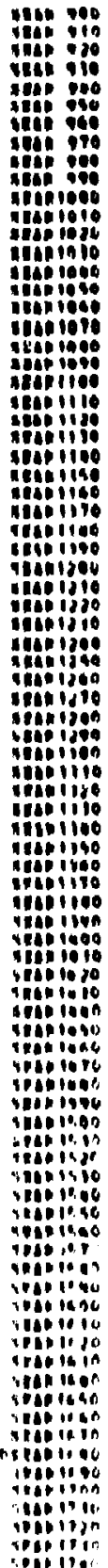




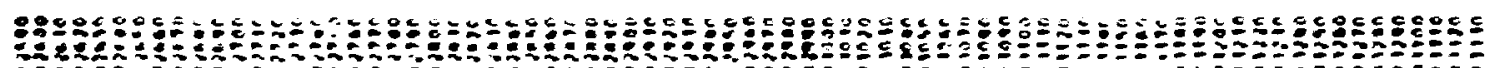

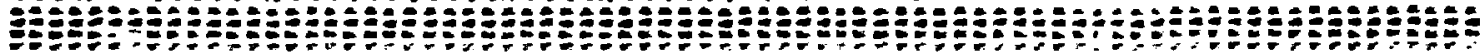

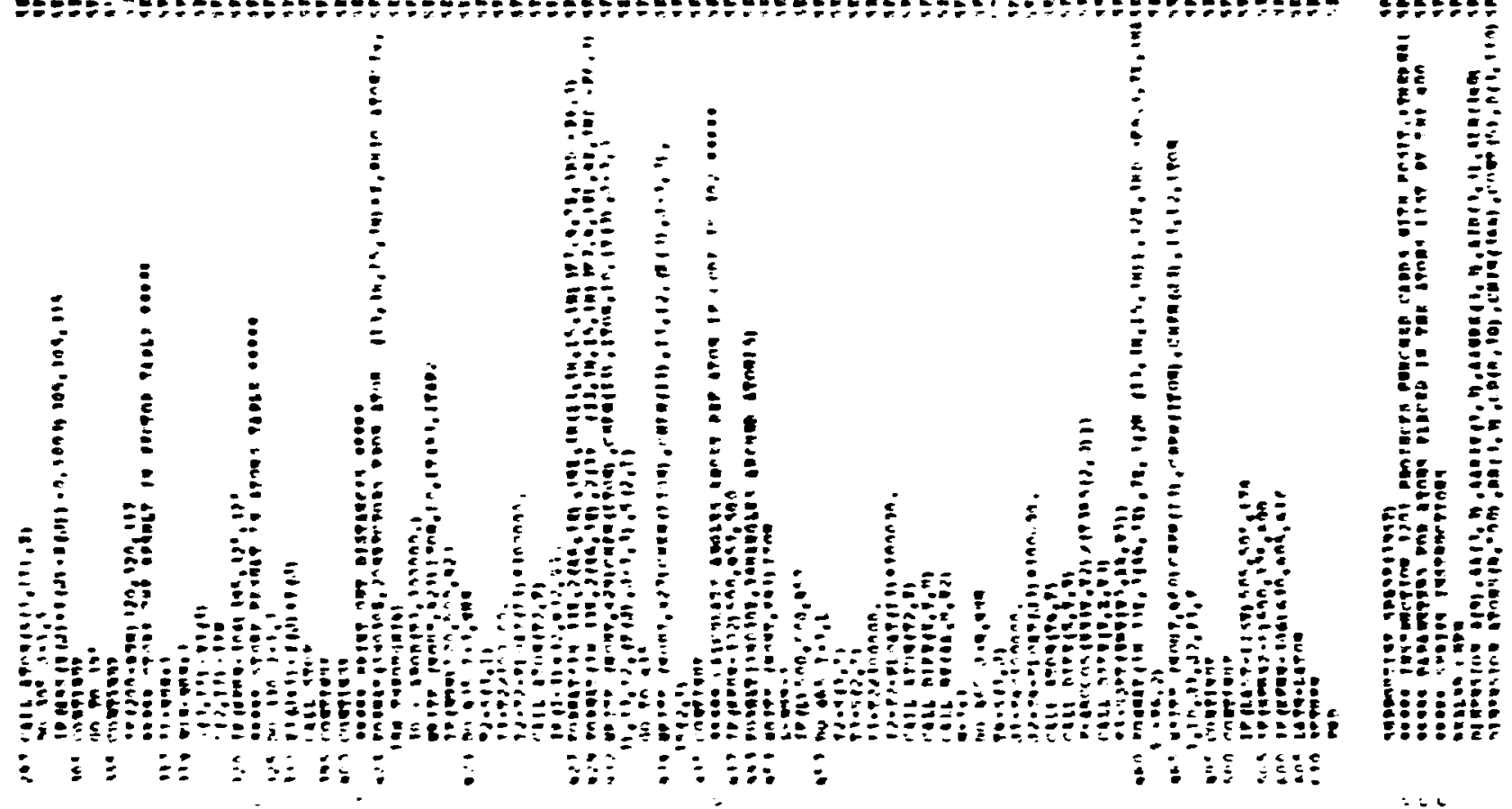

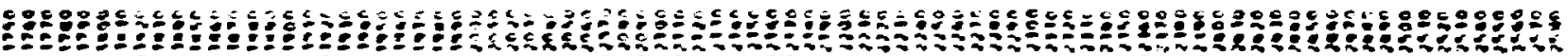

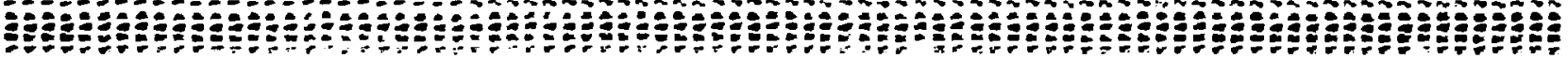

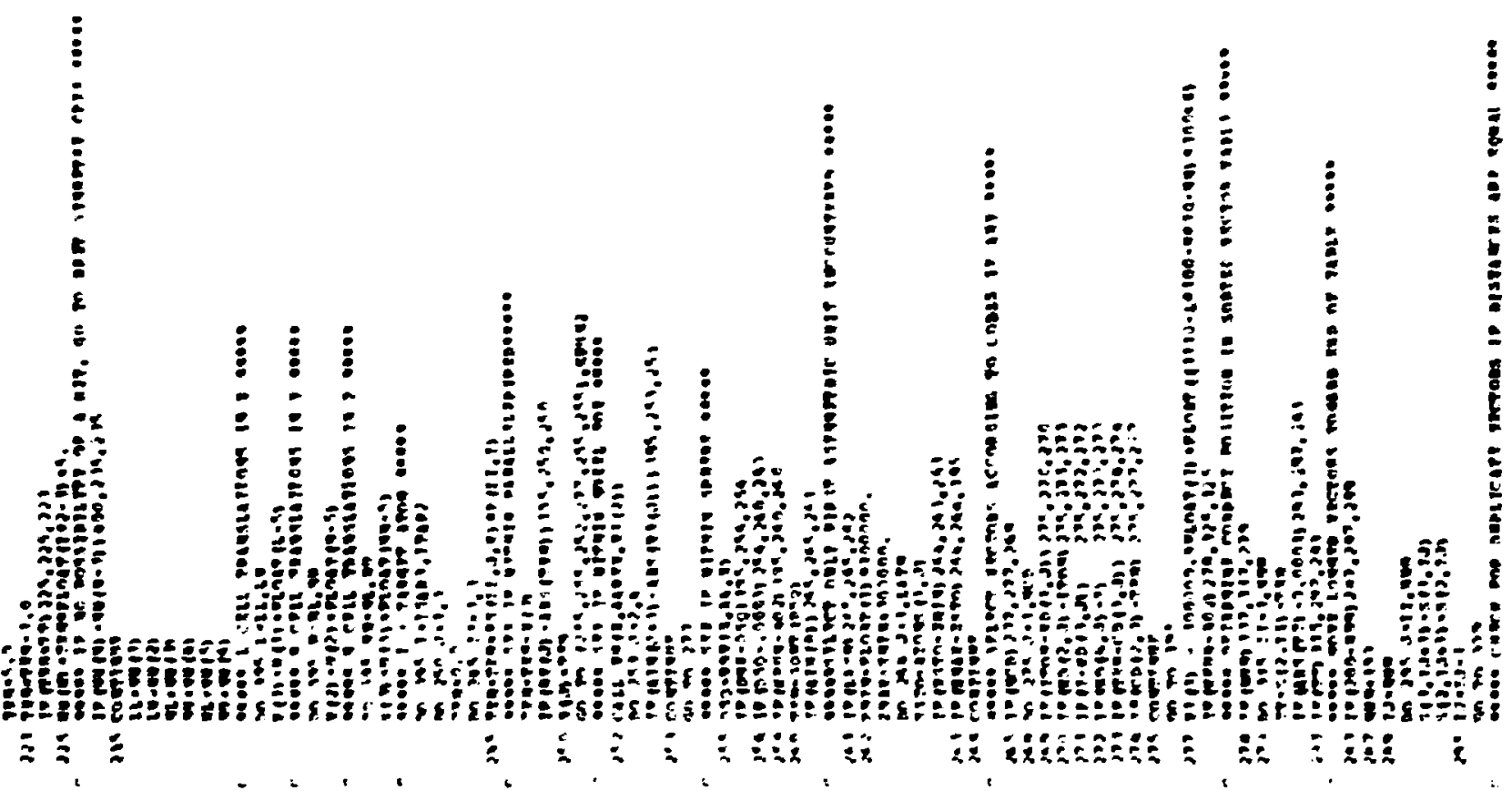




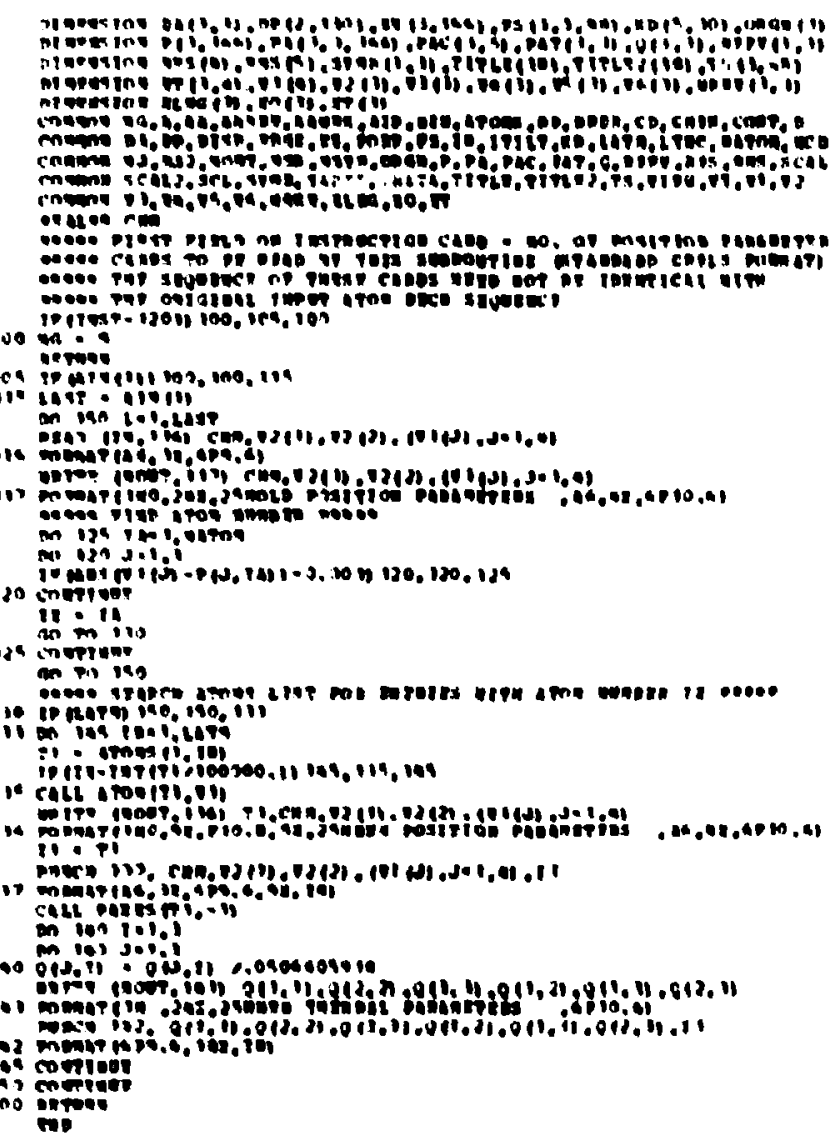

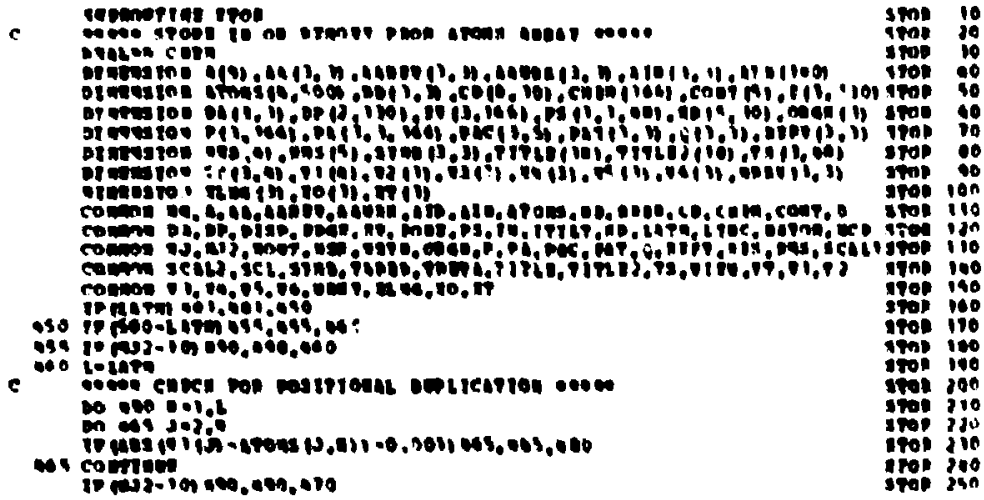

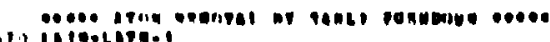

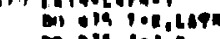

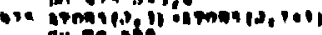

ant

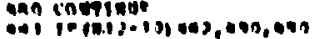

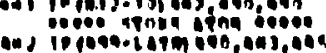

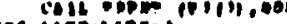

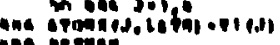
ingen

\section{.0000".}

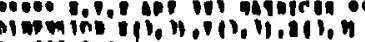

min enis

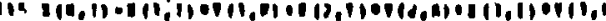

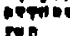

itt? in

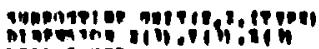

Pitoon ring

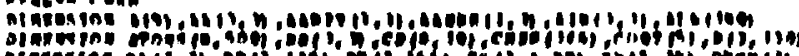

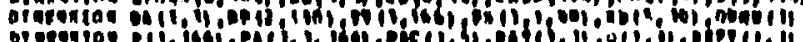

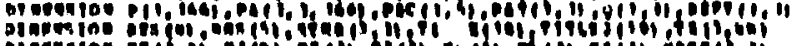

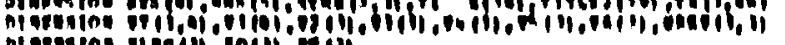

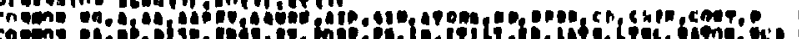

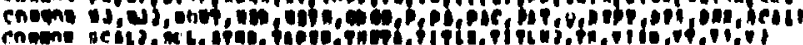
in-1111 !'in:I!I!

mo

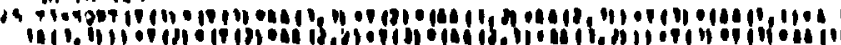

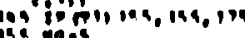

19. In in ino

ilingerion

in :19.1'1119

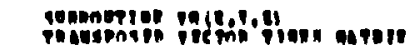

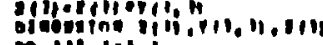

in

ila tinot(s)

inip 


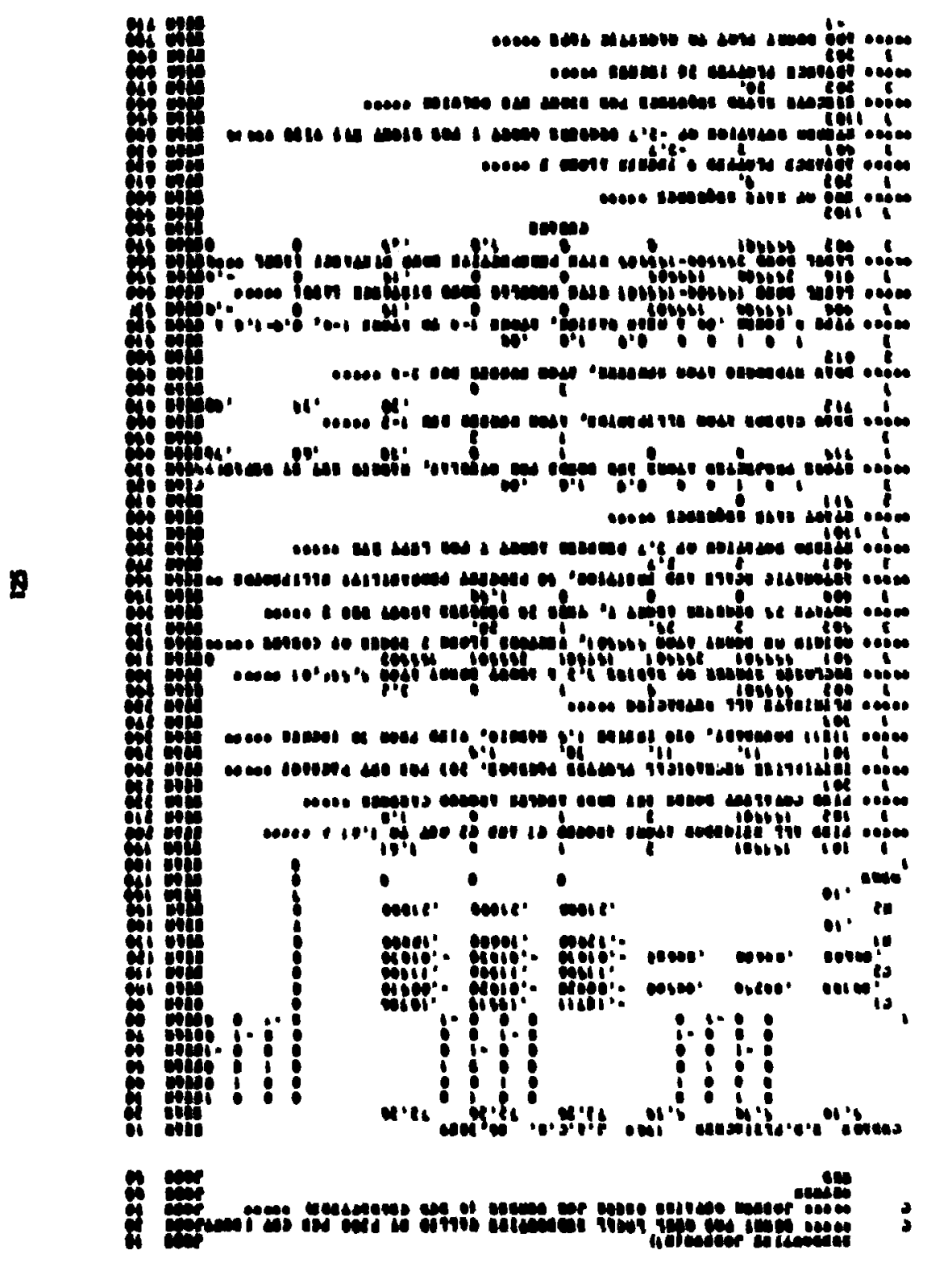

童

כ

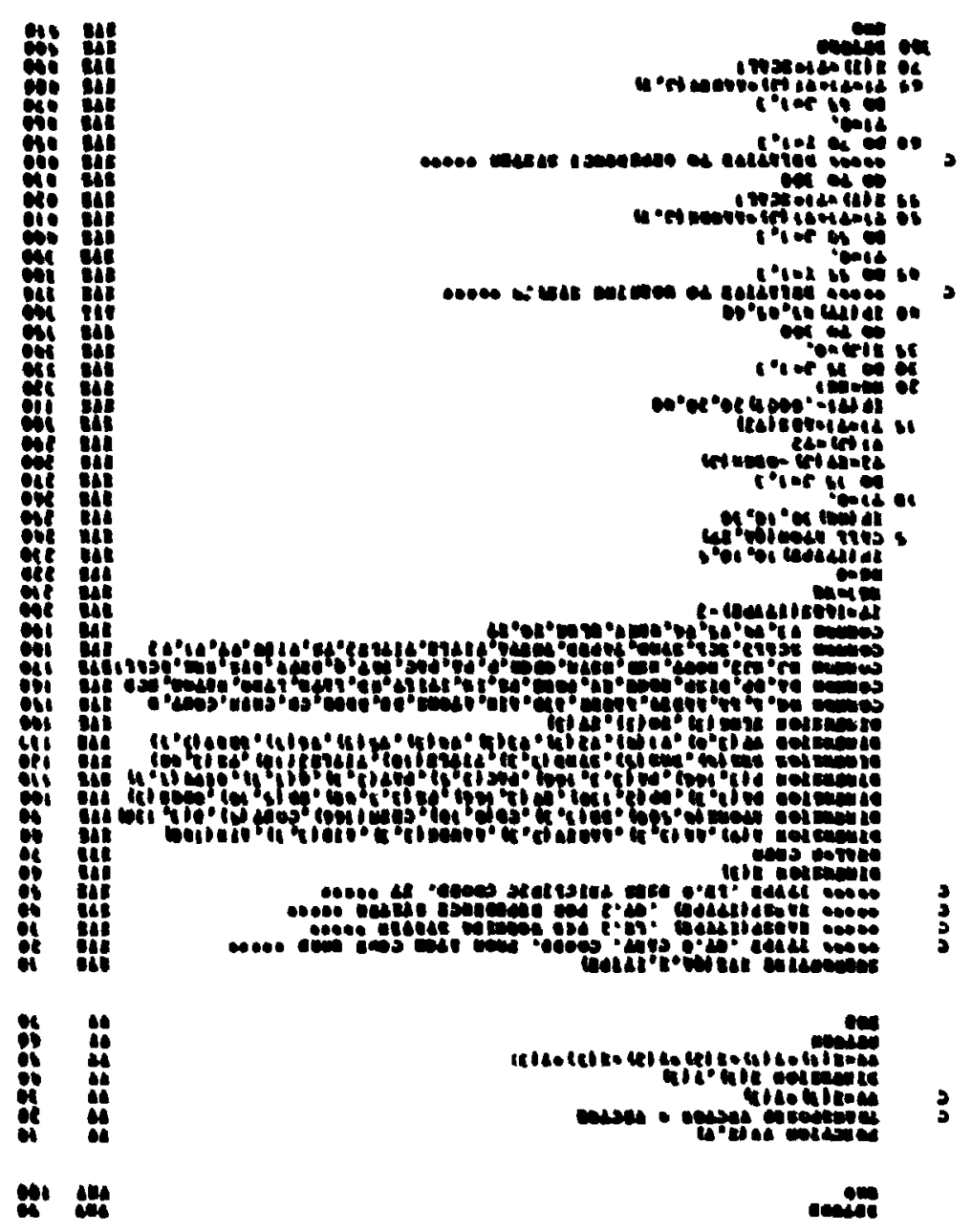

